\title{
A SEMI-ANALYTICAL MODEL \\ FOR FORM DRAG OF RIVER BEDFORMS
}

C.F. van der Mark 
Promotion Committee:

prof. dr. F. Eising

prof. dr. S.J.M.H. Hulscher

prof. dr. ir. H.W.M. Hoeijmakers

dr. ir. A. Blom

prof. dr. J. Fredsøe

prof. dr. ir. A. Hirschberg

dr. ir. E. Mosselman

dr. ir. J.S. Ribberink

dr. ir. C.J. Sloff

prof. dr. ir. W.S.J. Uijttewaal
University of Twente, chairman and secretary

University of Twente, promotor

University of Twente, promotor

Delft University of Technology, assistant promotor

Technical University of Denmark

University of Twente

Delft University of Technology, Deltares

University of Twente

Delft University of Technology, Deltares

Delft University of Technology

This research has been supported by the Dutch Technology Foundation STW, applied science division of the Netherlands Organization for Scientific Research (NWO) and the Technology Programme of the Ministry of Economic Affairs.

The KNAW-DJA supported a one-month visit to Hokkaido University, Sapporo, Japan.

Their support is gratefully acknowledged.

Cover: bedforms in the Hierdense or Leuvenumse beek.

Photographer / copyright holder of the cover photograph: Ruud Lardinois

ISBN 978-90-365-2866-5

Copyright (c) 2009 by C.F. van der Mark

Printed by Gildeprint Drukkerijen, the Netherlands

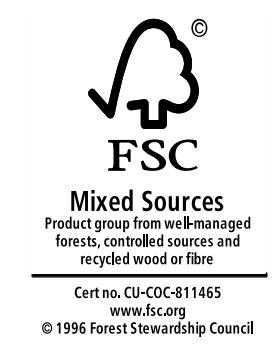




\title{
A SEMI-ANALYTICAL MODEL FOR FORM DRAG OF RIVER BEDFORMS
}

\author{
PROEFSCHRIFT
}

ter verkrijging van

de graad van doctor aan de Universiteit Twente,

op gezag van de rector magnificus,

prof. dr. H. Brinksma,

volgens besluit van het College voor Promoties

in het openbaar te verdedigen

op vrijdag 28 augustus 2009 om 15.00 uur

door

Caroline Francisca van der Mark

civiel ingenieur

geboren op 20 maart 1978

te Sassenheim 
This thesis has been approved by:

prof. dr. S.J.M.H. Hulscher promotor prof. dr. ir. H.W.M. Hoeijmakers promotor dr. ir. A. Blom

assistant promotor 
Voor mijn maatje 



\section{Contents}

$\begin{array}{ll}\text { Summary } & 11\end{array}$

$\begin{array}{ll}\text { Samenvatting } & 15\end{array}$

1 Introduction 19

1.1 Context . . . . . . . . . . . . . . . . . . . . . . . . . 19

1.2 Problem description $\ldots \ldots \ldots \ldots \ldots \ldots$

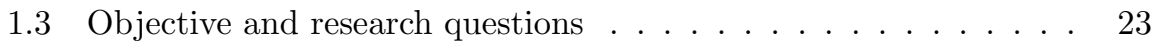

1.4 Methodology and thesis outline . . . . . . . . . . . . . . 23

2 Quantification of variability in bedform geometry 27

2.1 Introduction . . . . . . . . . . . . . . . . . . . . . . 27

2.2 Data . . . . . . . . . . . . . . . . . . 30

2.2 .1 Flume data . . . . . . . . . . . . . . . . . . . 30

2.2 .2 Field data . . . . . . . . . . . . . . . . . . 30

2.3 Data processing . . . . . . . . . . . . . . . . . . . . . 30

2.3.1 Grouping of streamwise bed elevation profiles . . . . . . 30

2.3.2 Bedform geometry from bed elevation profiles . . . . . . . 34

2.4 Probability density functions . . . . . . . . . . . . . . . . 35

2.4 .1 Results . . . . . . . . . . . . . . . . . . . . 35

2.4 .2 Discussion . . . . . . . . . . . . . . . . . . . . . 36

2.5 Coefficient of variation . . . . . . . . . . . . . . . . 38

2.5 .1 Results . . . . . . . . . . . . . . . . 38

2.5.2 Discussion . . . . . . . . . . . . . . . . . . . . . . . 41

2.6 Extreme values . . . . . . . . . . . . . . . . . . . . . 43

2.6 .1 Results . . . . . . . . . . . . . . . . . . . . 43

2.6 .2 Discussion . . . . . . . . . . . . . . . . . . . . . . . 44

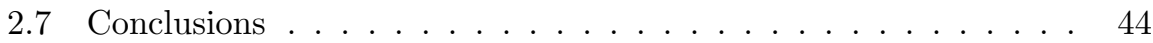

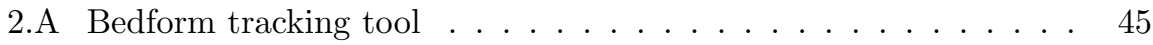

2.B Notation . . . . . . . . . . . . . . . . . . . . . . 46

3 A semi-analytical form drag model: application to uniform bedforms 49

3.1 Introduction . . . . . . . . . . . . . . . . . . . . . . . . 49

3.2 Basic Model for Form Drag . . . . . . . . . . . . . . . . . 51

3.3 Reference Form Drag Model . . . . . . . . . . . . . . . . . . . 52

3.3.1 Reference Situation . . . . . . . . . . . . . . . . . 52 
3.3.2 One-Dimensional Momentum Conservation Equation Applied to Reference Situation . . . . . . . . . . . . 52

3.3.3 Reference Energy Loss . . . . . . . . . . . . . 56

3.3.4 Reference Form Drag. . . . . . . . . . . . . . . 58

3.3.5 Mean Water Depth Equation . . . . . . . . . . . . 59

3.3.6 Solution to Reference Form Drag . . . . . . . . . . . . . 59

3.4 Correction Factors . . . . . . . . . . . . . . . 60

3.4 .1 Introduction . . . . . . . . . . . . . . 60

3.4.2 Lee Face Steepness . . . . . . . . . . . . . . . . . . . . . . 62

3.4 .3 Bedform Interaction . . . . . . . . . . . . . . . . . . . 65

3.4.4 Flow Separation Zone Height . . . . . . . . . . . . . . 68

3.5 Validation of Form Drag Model . . . . . . . . . . . . . . . . 70

3.6 Discussion . . . . . . . . . . . . . . . . . . 73

3.7 Conclusions . . . . . . . . . . . . . . . . . . 74

3.A Derivation of Bed Resistance from Measured Data . . . . . . . . 76

3.B Solution to Cubic Equation . . . . . . . . . . . . . . . . 77

3.C Validation of Numerical Model . . . . . . . . . . . . . . . . 79

3.D Notation . . . . . . . . . . . . . . . . . . . . . 81

4 A semi-analytical form drag model: application to alluvial and $\begin{array}{lr}\text { compound bedforms } & 85\end{array}$

4.1 Introduction . . . . . . . . . . . . . . . . . . . . 85

4.2 Semi-Analytical Form Drag Model . . . . . . . . . . . . . . 87

4.3 Correction Factor for Variability in Bedform Geometry . . . . . . 89

4.4 Application to Alluvial Bedforms . . . . . . . . . . . . . . . . 93

4.4.1 Measured Bed Resistance . . . . . . . . . . . . . . . 93

4.4.2 (Semi-)Analytical Bed Resistance Models . . . . . . . . . 95

4.4.3 Empirical Bed Resistance Models . . . . . . . . . . . . . . 97

4.4.4 Results of the (Semi-)Analytical Models . . . . . . . . . . 98

4.4.5 Results of the Empirical Models . . . . . . . . . . . 100

4.5 Application to Lee Face Angles Representative for the Field . . . 102

4.6 Application to Compound Bedforms . . . . . . . . . . . . . . 103

4.6.1 Compound Form Drag Model . . . . . . . . . . . . . . 103

4.6.2 Calibration of Compound Form Drag Model . . . . . . . . 105

4.7 Discussion . . . . . . . . . . . . . . . . 108

4.7.1 Alluvial Bedforms .................. . 108

4.7.2 Water Depth Prediction . . . . . . . . . . . . 110

4.8 Conclusions . . . . . . . . . . . . . . . . . . . 111

4.A Bed Resistance Models . . . . . . . . . . . . . . . . . . 112

4.B Notation ...................... 115

5 Discussion $\mathbf{1 1 9}$

5.1 Assumptions and neglected aspects . . . . . . . . . . . . . . 119

5.1.1 Independency of correction factors . . . . . . . . . . 119

5.1 .2 Hydrostatic pressure distribution . . . . . . . . . . . 120

5.1.3 Grain size distribution . . . . . . . . . . . . 120 
5.1.4 Boundary shear stress ................. . 121

5.1.5 Water temperature, viscosity, and Reynolds number . . . 121

5.1.6 Summary of neglected effects . . . . . . . . . . . . . 121

5.2 Fields of application of the form drag model . . . . . . . . . . . . 122

5.2.1 Bedforms under unidirectional flow . . . . . . . . . . . 122

5.2.2 Bedforms under bi- or multidirectional flow . . . . . . . . 122

5.2 .3 Groynes . . . . . . . . . . . . . . . . . 124

5.3 How to apply the form drag model in a morphodynamic model

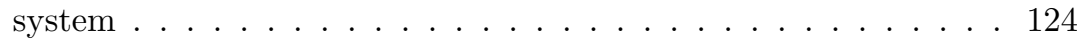

6 Conclusions and recommendations $\quad 127$

6.1 Conclusions . . . . . . . . . . . . . . . . . . 127

6.2 Recommendations ................... 131

A The effect of postprocessing multibeam echosounding data on bedform geometry

A.1 Multibeam echosounding measurements . . . . . . . . . . . . . 145

A.2 Postprocessing of MBES data . . . . . . . . . . . . . . . . . . . 148

A.2.1 Projection of bed elevations on a regular grid . . . . . . . 148

A.2.2 Effect of grid projection on bedform geometry . . . . . . . 149

B A new and widely applicable tool for determining bedform geometry

B.1 Introduction . . . . . . . . . . . . . . . . . . . . 151

B.2 Method for determining bedform geometry . . . . . . . . . . . 151

B.2.1 Procedure of the bedform tracking tool . . . . . . . . . 151

B.2.2 Evaluation of the procedure . . . . . . . . . . . 157

B.3 Conclusions . . . . . . . . . . . . . . . . . 163

C Variability in bedform geometry of sand waves in the North Sea

C.1 Introduction . . . . . . . . . . . . . . . . . . 165

C.2 Data processing . . . . . . . . . . . . . 166

C.3 Probability density functions . . . . . . . . . . . . . . 167

C.4 Coefficients of variation . . . . . . . . . . . . . . . . . 168

C.5 Extreme values . . . . . . . . . . . . . . . . . . . 168

C.6 Planning pipelines . . . . . . . . . . . . . . . . . . . . 169

D Derivation of mass, momentum, and energy conservation equations from integral formulations

D.1 Continuity equation or the law of conservation of mass . . . . . . 173

D.2 Newton's second law of motion or law of conservation of momentum174

D.3 First law of thermodynamics or the law of conservation of energy 176 
About the author

List of publications 183 


\section{Summary}

Bed resistance, i.e., the resistance to flow of the main channel bed of the river, may consist of two components (e.g. Rouse, 1965; Yen, 2002): (1) grain friction, and (2) form drag due to bedforms. The objective of the present study is to develop a form drag model applicable to bedform-dominated rivers under subcritical flow conditions.

It is expected that variability in bedform geometry affects form drag. Therefore, in order to incorporate variability in bedform geometry in a form drag model, we need to quantify this variability. Variability in bedform geometry has been studied using flume and field data of bedforms. It is found that the geometric variables under consideration, i.e., bedform height, bedform length, crest elevation, trough elevation, and lee face slope are best described by a positively skewed probability density function, such as the Weibull distribution.

Variability in bedform geometry can be characterized using simple generic relations. It appears that linear relations exist between standard deviation and mean value for bedform height, bedform length, crest elevation, and trough elevation if the ratio of width to hydraulic radius is larger than about ten. A constant coefficient of variation can then be applied to quantify variability in bedform geometry. For field data, the mean lee face slope is found to be significantly smaller than for alluvial flume data.

The semi-analytical form drag model, which is developed in the present study, consists of two components, i.e., (1) an analytically-based reference form drag model, accounting for the energy loss associated with a deceleration of the flow due to a sudden expansion of a free surface flow (i.e., the reference situation), and (2) an empirical coefficient taking into account effects due to deviations from the reference situation. The analytically-based reference form drag model is an extension of the models proposed by Yalin (1964a), Engelund (1966), and Karim (1999). The effect of nonuniformity of the velocity distribution over a cross-section is accounted for via a calibration coefficient.

The empirical coefficient, which is called the total correction factor, is constructed as the product of four correction factors, each of these factors accounting for an effect relevant to form drag due to bedforms. By doing so, it is assumed that the four effects are independent. The following four effects relevant to form drag that are not incorporated in the reference form drag are recognized:

1. the flow downstream of a bedform crest expands gradually rather than abruptly (correction factor for lee face steepness),

2. the flow pattern over closely spaced bedforms differs from the pattern over 
a solitary bedform (correction factor for bedform interaction),

3. the height of the flow separation zone may deviate from the bedform height (correction factor for flow separation zone height),

4. bedform geometry is irregular rather than regular (correction factor for variability in bedform geometry).

For each of these effects an expression for a correction factor has been developed.

To analyze the effect of lee face steepness and bedform spacing on form drag, the computational fluid dynamics software package Ansys CFX has been used. A validation of the numerical model using laboratory data of flow over fixed bedforms shows that Ansys CFX is well capable of predicting flow velocities, form drag, and the free surface elevation.

Using numerical simulations in Ansys CFX an expression for the effect of lee face steepness on form drag has been developed. The correction factor for lee face steepness increases with increasing lee face angle and equals more or less unity for lee face angles larger than about $50^{\circ}$.

An expression for the effect of bedform interaction on form drag is found to be a function of the ratio of bedform length to bedform height. The correction factor for bedform interaction describes that for increasing values of this ratio, the flow pattern over a bedform is less influenced by the flow pattern over the upstream bedform.

The height of the flow separation zone, and thus form drag, decreases if the flow separates at a brink point rather than at the highest point of the bedform. The correction factor for flow separation zone height is found to be a function of the ratio of flow separation zone height to bedform height, and describes that the larger the flow separation zone height, the larger is the form drag.

Provided that the mean bedform height is the same, the energy loss due to expansion is larger for the case of a series of irregular bedforms than for a series of regular bedforms, as the relation between energy loss and bedform height is a nonlinear one. The correction factor for variability in bedform geometry accounts for the effect that form drag increases for increasing variability in bedform geometry.

In the semi-analytical form drag model the four above-mentioned effects and the effect of nonuniformity of the flow velocity profile are included. In the so-called analytical form drag model these effects are not included. Both models are applied to laboratory measurements of flow over uniform fixed and alluvial bedforms. The results of the models are compared to those of existing bed resistance models to analyze the performance of the analytical and semianalytical models.

For the uniform fixed bedform data, it is found that the present semianalytical model yields better results than the analytical and empirical models considered. The empirical bed resistance models under consideration do not well predict bed resistance of uniform fixed bedforms.

The form drag model of Yalin (1964a) and Engelund (1966) yields the best results for the alluvial flume data. However, from data of flow over bedforms 
with small lee faces it appears that the semi-analytical form drag model yields better predictions of form drag than the Yalin (1964a) - Engelund (1966) form drag model. Therefore, for bedforms in the field, which are usually gentler than in the laboratory, the semi-analytical model is expected to yield better predictions of bed resistance than the Yalin (1964a) - Engelund (1966) model.

It is found that for the alluvial flume data the semi-analytical model, in which the four mentioned effects and the effect of nonuniformity of the flow velocity profile are included, does not yield better predictions of bed resistance than the analytical model and the model of Yalin (1964a) and Engelund (1966), in which these effects are not included. In the analytical model and the model of Yalin (1964a) and Engelund (1966) the neglected effects appear to cancel out. The assumption in the Yalin (1964a) - Engelund (1966) bed resistance model that flow expansion downstream of the bedform crest can be represented by expansion of a pipe flow rather than a free surface flow appears to be justified, as the differences between the Yalin (1964a) - Engelund (1966) model and the analytical model are small.

Based on the analysis performed in this thesis the author advises to apply the semi-analytical form drag model, as (a) the model is expected to yield the best results in field situations, and (b) an analytically-based model is preferred over an empirical model. The author advises to apply the analytical Yalin (1964a) - Engelund (1966) form drag model if a model is preferred that is more easy to apply than the semi-analytical model.

For the case of compound bedforms, it is shown that summation of the energy loss due to individual small-scale and large-scale bedforms yields a reasonably good prediction of form drag. 


\section{Samenvatting}

Bodemweerstand, i.e., de weerstand die de stroming ondervindt van de rivierbodem, bestaat uit de volgende twee componenten (e.g. Rouse, 1965; Yen, 2002): (1) korrelwrijving, en (2) vormweerstand als gevolg van bodemvormen. Het doel van dit onderzoek is het ontwikkelen van een vormweerstandsmodel dat toepasbaar is op bodemvorm-gedomineerde rivieren onder subkritische stromingscondities.

Verwacht wordt dat variabiliteit in bodemvormgeometrie de vormweerstand beïnvloedt. Om variabiliteit in bodemvormgeometrie mee te kunnen nemen in een vormweerstandsmodel, is het eerst nodig om deze variabiliteit te kwantificeren. Variabiliteit in bodemvormgeometrie is bestudeerd met behulp van gooten velddata van bodemvormen. De beschouwde geometrische variabelen, i.e., bodemvormhoogte, bodemvormlengte, topniveau, trogniveau en helling van de lijzijde blijken het beste te kunnen worden beschreven door een kansdichtheidsfunctie met positieve scheefheid zoals de Weibull verdeling.

Variabiliteit in bodemvormgeometrie kan worden gekarakteriseerd met behulp van eenvoudige generieke relaties. Het blijkt dat voor bodemvormhoogte, bodemvormlengte, topniveau en trogniveau lineaire relaties bestaan tussen de standaardafwijking en gemiddelde waarde als de verhouding tussen de rivierof gootbreedte en de hydraulische straal groter is dan ongeveer tien. Een constante variatiecoëfficiënt kan in dat geval worden toegepast om variabiliteit in bodemvormgeometrie te kwantificeren. De gemiddelde helling van de lijzijde blijkt aanzienlijk kleiner te zijn voor velddata dan voor gootdata.

In dit onderzoek is een semi-analytisch vormweerstandsmodel ontwikkeld. Dit model bestaat uit twee componenten, te weten (1) een referentie-vormweerstandsmodel met analytische basis dat het energieverlies in rekening brengt door vertraging van de stroming als gevolg van een abrupte expansie van een vrij-oppervlak stroming (de referentiesituatie), en (2) een empirische coëfficiënt die effecten door afwijkingen ten opzichte van de referentiesituatie in rekening brengt. Het referentie-vormweerstandsmodel is een uitbreiding van de modellen van Yalin (1964a), Engelund (1966) en Karim (1999). Een calibratiecoëfficiënt brengt het effect van niet-uniformiteit van het stroomsnelheidsprofiel over een dwarsdoorsnede in rekening.

De empirische coëfficiënt, die in dit onderzoek de totale correctiefactor wordt genoemd, is opgebouwd als het product van vier correctiefactoren. Elk van de vier correctiefactoren brengt een effect in rekening dat relevant is voor vormweerstand als gevolg van bodemvormen. Aangenomen wordt dat de vier effecten onafhankelijk van elkaar zijn. Voor elk van deze effecten is een uitdrukking voor 
de correctiefactor ontwikkeld. De vier effecten zijn:

1. de stroming benedenstrooms van een bodemvorm expandeert geleidelijk in plaats van abrupt (correctiefactor voor steilheid van de lijzijde),

2. het stromingspatroon over een reeks bodemvormen verschilt van het stromingspatroon over een solitaire bodemvorm (correctiefactor voor bodemvorm-interactie),

3. de hoogte van de loslaatzone kan afwijken van de bodemvormhoogte (correctiefactor voor hoogte van de loslaatzone),

4. bodemvormgeometrie is onregelmatig in plaats van regelmatig (correctiefactor voor bodemvormgeometrie).

Om het effect van de steilheid van de lijzijde en de afstand tussen bodemvormen te analyseren, is het softwarepakket Ansys CFX ingezet. Een validatie van het numerieke model met gebruikmaking van laboratoriummetingen van stroming over uniforme vaste bodemvormen laat zien dat Ansys CFX goed in staat is om stroomsnelheden, vormweerstand en het niveau van het vrije wateroppervlak te voorspellen.

Een uitdrukking voor het effect van de steilheid van de lijzijde op vormweerstand is ontwikkeld met behulp van numerieke simulaties in Ansys CFX. De correctiefactor voor steilheid van de lijzijde neemt toe met toenemende lijzijdehoek en is gelijk aan één voor lijzijdehoeken groter dan grofweg $50^{\circ}$.

De correctiefactor voor bodemvorm-interactie blijkt een functie te zijn van de verhouding tussen bodemvormlengte en bodemvormhoogte. De correctiefactor beschrijft dat voor toenemende waarden van deze verhouding, het stromingspatroon over een bodemvorm minder wordt beïnvloed door het stromingspatroon over de bovenstroomse bodemvorm.

De hoogte van de loslaatzone, en dus de vormweerstand, neemt af wanneer de stroming loslaat bij een brinkpunt in plaats van bij het hoogste punt van de bodemvorm. De correctiefactor voor hoogte van de loslaatzone is een functie van de verhouding tussen hoogte van de loslaatzone en bodemvormhoogte, en beschrijft dat hoe groter de hoogte van de loslaatzone, hoe groter de vormweerstand is.

Voor gelijkblijvende gemiddelde bodemvormhoogte is het energieverlies door expansie groter in geval van een reeks onregelmatige bodemvormen dan in geval van een reeks regelmatige bodemvormen, omdat de relatie tussen energieverlies en bodemvormhoogte een niet-lineaire relatie is. De correctiefactor voor variabiliteit in bodemvormgeometrie brengt het effect in rekening dat vormweerstand toeneemt voor toenemende variabiliteit in bodemvormgeometrie.

In het semi-analytische vormweerstandsmodel zijn de vier bovengenoemde effecten en het effect van niet-uniformiteit van het stroomsnelheidsprofiel meegenomen. In het zogenaamde analytische vormweerstandsmodel zijn deze effecten niet meegenomen. Beide modellen zijn toegepast op laboratoriummetingen van stroming over uniforme vaste en alluviale bodemvormen. De resultaten van de 
modellen zijn vergeleken met die van bestaande bodemweerstandsmodellen om de prestaties van het analytische en semi-analytische model te analyseren.

Het semi-analytische vormweerstandsmodel levert betere resultaten dan de beschouwde analytische en empirische modellen voor de uniforme vaste bodemvorm data. De beschouwde empirische bodemweerstandsmodellen geven geen goede voorspelling van de bodemweerstand bij uniforme vaste bodemvormen.

Het vormweerstandsmodel van Yalin (1964a) en Engelund (1966) levert de beste resultaten voor de alluviale gootdata. Echter, voor stroming over bodemvormen met kleine lijzijdehoeken is gebleken dat het semi-analytische vormweerstandsmodel betere voorspellingen van vormweerstand levert dan het Yalin (1964a) - Engelund (1966) vormweerstandsmodel. Voor veldsituaties waarin bodemvormen meestal flauwer zijn dan in het laboratorium is het daarom te verwachten dat het semi-analytische model betere voorspellingen van bodemweerstand geeft dan het Yalin (1964a) - Engelund (1966) model.

Voor de alluviale gootdata is gebleken dat het semi-analytische model waarin de vier genoemde effecten en het effect van niet-uniformiteit van het stroomsnelheidsprofiel zijn meegenomen geen betere voorspelling van de bodemweerstand levert dan het analytische model en het model van Yalin (1964a) en Engelund (1966), waarin deze effecten niet zijn meegenomen. In het analytische model en het model van Yalin (1964a) en Engelund (1966) vallen de verwaarloosde effecten klaarblijkelijk tegen elkaar weg. De aanname in het Yalin (1964a) - Engelund (1966) model dat stromingsexpansie benedenstrooms van de top van de bodemvorm kan worden voorgesteld als expansie van een pijpstroming in plaats van expansie van een vrij-oppervlak stroming blijkt gerechtvaardigd, omdat de verschillen tussen het Yalin (1964a) - Engelund (1966) model en het analytische model klein zijn.

Op basis van de analyse in dit proefschrift adviseert de auteur om ofwel het semi-analytische vormweerstandsmodel toe te passen, omdat (a) van dit model wordt verwacht dat het de beste resultaten geeft in veldsituaties, en (b) een model met analytische basis wordt verkozen boven een empirisch model, ofwel het analytische Yalin (1964a) - Engelund (1966) vormweerstandsmodel toe te passen wanneer een model wordt geprefereerd dat eenvoudig toepasbaar is.

Voor een situatie met samengestelde bodemvormen is aangetoond dat sommatie van het energieverlies als gevolg van individuele kleinschalige en grootschalige bodemvormen een redelijk goede voorspelling van vormweerstand levert. 


\section{Chapter 1}

\section{Introduction}

\subsection{Context}

\section{River management and model systems}

Rivers, flowing downhill from their sources to their mouths at the sea, ocean, or lake, transport water, sediments, and sometimes ice. For thousands of years, rivers and their fertile floodplains are used for agriculture, drinking water supply, and transport. Hence, since ages the surroundings of rivers are popular settling areas for, for instance, farms and factories. River basins now have become densely populated areas.

Nowadays, the main task of the river manager is to take care that water and sediments in a river system are transported in such a way that, at the same time, people are protected against flooding, and attention is paid to the provision of navigation, floodplain agriculture, ecology, and recreation. The river system needs to be developed, maintained, and cultivated so, that the (sometimes conflicting) functions in the area are accommodated. In order to do so, accurate predictions of water levels and bed levels in rivers are indispensable. Reliable design of dikes that are high enough to protect surrounding areas from flooding is essential during periods of high water levels (Figure 1.1a). During periods of low water levels on the other hand, for navigation purposes a certain channel width and water depth needs to be guaranteed (Figure 1.1b). It must be prevented that navigation is hindered by local sedimentation or bedforms.

Hydraulic and morphodynamic model systems are important tools in the prediction of water levels and bed levels. A morphodynamic model system describes the movement of water and sediment, as well as morphological changes through a set of mathematical equations. Examples of numerical model systems are the one-dimensional model system SOBEK, the two-dimensional and threedimensional model system Delft3D of Deltares, and the MIKE model system of the Danish Hydraulic Institute DHI.

The mathematical equations that are solved in a morphodynamic model system describe the relevant physical processes in a river system. For instance, water movement is described using (a simplified version of) the Navier-Stokes equations, and the sediment mass balance using a form of the Exner equation. Also flow resistance, acting in the opposite direction of the flow, needs to be described in a model system. Here, flow resistance comprises all sources of resistance to flow, such as vegetation resistance in the floodplains, resistance due 


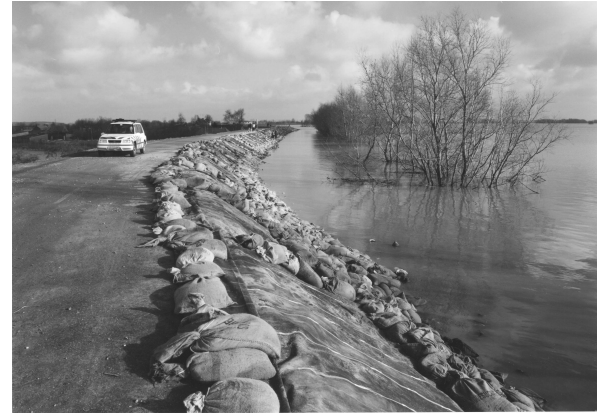

(a)

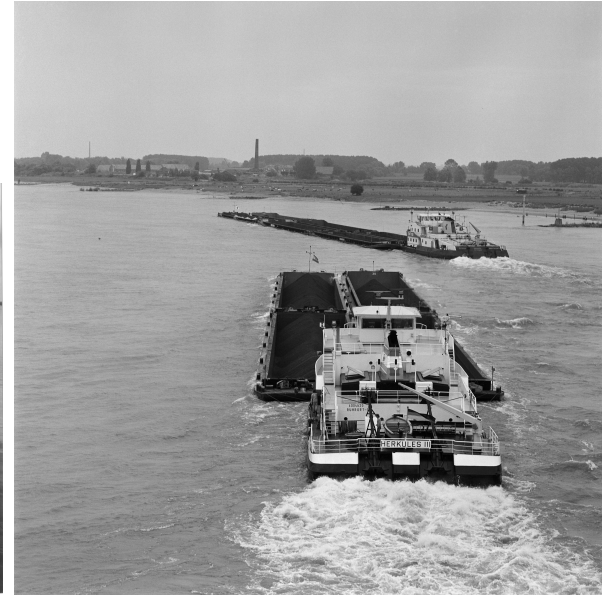

(b)

Figure 1.1: River management. (a) Protection against flooding during an extreme high water period in the Netherlands. (b) Navigation needs to be guaranteed, also during a low water period. Source: www.BeeldbankVenW.nl, Rijkswaterstaat.

to obstacles like groynes and bridge piers, resistance due to channel shape, meanders, or bends, and bed resistance (e.g. Knighton, 1998). In modeling river flow and predicting water levels, it is of particular importance to understand the processes that determine flow resistance, as the output of river-reach models has appeared sensitive to flow resistance of the main channel and the floodplains (e.g. Casas et al., 2006; Morvan et al., 2008). The accuracy of the output of a model system (e.g. water levels) may increase if the descriptors of relevant processes in the model system are improved. This thesis contributes to a better understanding of the processes determining bed resistance and thus to the prediction of water levels.

\section{Bed resistance}

Bed resistance, i.e., the resistance to flow of the main channel bed of the river, may consist of two components (e.g. Rouse, 1965; Yen, 2002): (1) grain friction due to individual grains protruding into the flow, (2) form resistance or form drag due to bedforms.

The bed resistance of a plane bed consists of the grain friction component only. When sediment transport starts, the bed may become unstable and bedforms (ripples or dunes) start to develop (e.g. Engelund and Hansen, 1967). The bed resistance of a bed covered with bedforms consists of both the components grain friction and form drag. In case bedforms are present, the contribution of form drag is usually dominant over grain friction (e.g. Knighton, 1998; McLean et al., 1999; Julien et al., 2002). Hence, an accurate estimate of form drag is important for predicting bed resistance. 
For predicting bed resistance, distinction needs to be made between form drag and grain friction. Einstein and Barbarossa (1952) distinguish between bed shear stress due to grains and bed shear stress due to bedforms such that the summation of both stresses equals the bed shear stress. It is usually assumed that (i) the bed shear stress, (ii) the bed shear stress due to grains, and (iii) the bed shear stress due to bedforms are caused by the same flow velocity, so that it is found that the bed resistance coefficient equals the summation of the resistance coefficient due to grain friction and that due to form drag (e.g. Alam and Kennedy, 1969).

\section{Form drag}

For unidirectional subcritical flow (i.e., the Froude number is smaller than unity) the shape of a bedform is characterized by a gentle stoss face, and a steeper lee face (e.g. Nelson et al., 1993). On the stoss face the rising bed elevation causes an acceleration of the flow, and a decrease in pressure; downstream of the bedform crest, the flow decelerates, and the pressure increases (e.g. Vanoni and Hwang, 1967) (Figure 1.2). The integration of the longitudinal component of the pressure along the bedform results in a drag force, which is called form drag (e.g. McLean et al., 1999).

The increasing pressure in the direction of the flow downstream of the bedform crest is called an adverse pressure gradient. If the adverse pressure gradient is sufficiently large, i.e., if a bedform lee face becomes so steep that the flow cannot follow the bed surface anymore, flow separation occurs resulting in a region with recirculating flow (e.g. Hoerner, 1965) (Figure 1.2). An adverse pressure gradient does not necessarily lead to flow separation (e.g. Fox and McDonald, 1994). For a very gentle lee face or a bedform having a streamlined shape, the adverse pressure gradient may be too small for the flow to separate, whereas it may lead to a form drag component.

The size of the flow separation zone is a measure for the rate of energy loss and of form drag. In general, the higher and steeper the bedform, the larger are the flow separation zone and the form drag. It is known that form drag is not only a function of bedform height and bedform steepness (defined as the ratio of mean bedform height to mean bedform length), but is also a function of the Froude number (Alam and Kennedy, 1969). Furthermore, the shape of the bedform may affect the size of the flow separation zone (e.g. Parteli et al., 2006) and thus the form drag. For instance, the angle of the bedform lee face (e.g. Best, 2005), or the precise location at which the flow separates from the bed surface (e.g. Schatz and Herrmann, 2006) affects the size of the flow separation zone. The size of the flow separation zone is also affected by the spacing between subsequent bedforms (e.g. Davies, 1980; Coleman et al., 2005). Alluvial bedforms are highly irregular in size, shape, and spacing (e.g. Nordin, 1971), and it may be expected that this variability in bedform geometry also affects form drag. We ground this hypothesis by drawing an analogy between grain friction and form drag. Often the $65 \%, 84 \%$, or $90 \%$ grain size is used as a representative diameter of the grains in predicting the grain friction, as this 
(a)
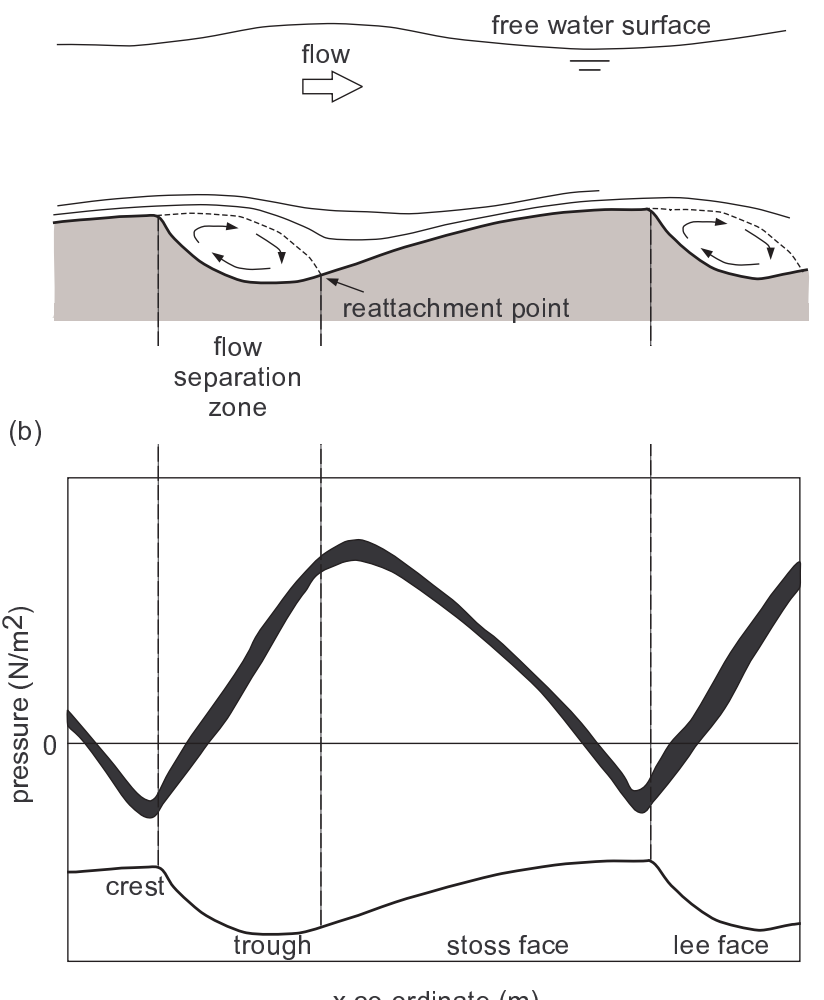

Figure 1.2: (a) Flow separation zone downstream of a bedform and (b) pressure distribution along the bedform (from Langhorne, 1978).

diameter is representative when determining its effect on the flow (Van Rijn, 1982). Analogously, a bedform that is higher, longer, or steeper than the median or mean bedform height, bedform length, or bedform steepness, respectively, may be representative with respect to its effect on form drag.

\section{Prediction of form drag}

Several physical and empirical models exist for predicting bedform geometry, i.e., bedform length, and bedform height, under steady flow conditions (e.g. Allen, 1978; Kennedy and Odgaard, 1991; Yalin, 1964b; Fredsøe, 1982; Van Rijn, 1984; Julien and Klaassen, 1995). Such models, which are commonly an explicit function of flow and sediment properties, usually predict the mean values of bedform geometry. Models for predicting form drag (e.g. Engelund, 1966; Vanoni and Hwang, 1967; Van Rijn, 1984; Karim, 1999) usually require mean bedform height, bedform steepness, and mean water depth as model input. 


\subsection{Problem description}

For situations in which the flow is steady and uniform, and bedform geometry and flow conditions are known, existing bed resistance models do not yield accurate predictions of bed resistance, i.e., the scatter is large (e.g. Wilbers, 2004; Jansen et al., 1979). The error between measured and computed bed resistance may be larger than $\pm 50 \%$, and, as a result, the error between measured and computed water depth may be larger than about $\pm 20 \%$ (e.g. Karim, 1995; Yang and Tan, 2008). As an example, Figure 1.3 illustrates the large scatter for the bed resistance model of Van Rijn (1984), for the alluvial data of Guy et al. (1966). The large scatter may indicate that the model does not capture all relevant processes that determine bed resistance.

A form drag model that captures the relevant processes is required, as such a model is expected to be widely applicable. For instance, a model in which the relevant processes are captured may be applicable to an extreme flood situation for which the model was not validated. De Vriend (2006) states that river flow modeling still lacks generally applicable descriptions of bed resistance.

None of the existing form drag models consider the Froude number, angle of the bedform lee face, size of the flow separation zone, or variability in bedform geometry. We expect that incorporating these relevant quantities in a form drag model leads to more accurate predictions of form drag, and thus of water depth.

\subsection{Objective and research questions}

The objective of the present study is to develop a form drag model applicable to bedform-dominated rivers under subcritical flow conditions. In combination with a grain friction model, the model provides a reach-averaged bed resistance coefficient.

The focus will be on the following research questions:

Q1. How can variability in bedform geometry be quantified?

Q2. Which physical mechanisms are relevant to form drag?

Q3. Which physical quantities are relevant to form drag?

Q4. How do the relevant quantities affect form drag?

Q5. How can the relevant quantities be incorporated in a form drag model?

Q6. How does the new form drag model perform compared to (a) laboratory data and (b) existing form drag models?

\subsection{Methodology and thesis outline}

Chapter 2: As described in Section 1.1, it is expected that variability in bedform geometry affects form drag. In order to incorporate variability in bedform geometry in a form drag model, there is a need to quantify the variability. This 


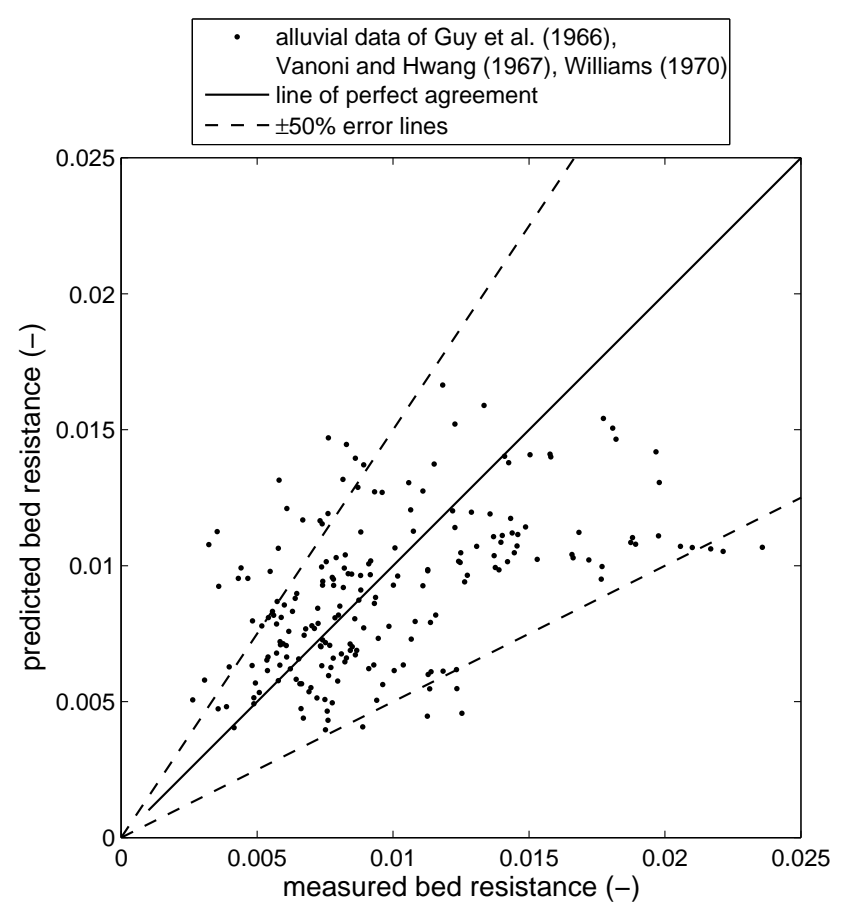

Figure 1.3: Predicted bed resistance against measured bed resistance using the bed resistance model of Van Rijn (1984), for the alluvial data of Guy et al. (1966).

chapter describes the results of a data analysis of variability in bedform geometry using laboratory and field data of bedforms (research question Q1).

Chapter 3: Literature on form drag is reviewed (research question Q2). Existing form drag models teach us which quantities are relevant (research question Q3) and how these quantities affect the form drag (research question Q4).

An analytically-based form drag model is developed, which is based on the analytical form drag models of Yalin (1964a), Engelund (1966), and Karim (1999). An analytically-based form drag model is preferable above an empirical model, as it is likely that an analytically-based model in which the dominant processes are captured is more widely applicable than an empirical model. Relevant quantities are incorporated in the form drag model (research question Q5).

In this chapter the new form drag model is validated against laboratory data of flow over uniform bedforms (research question Q6).

Chapter 4: The form drag model is extended to situations with variability in bedform geometry and so made applicable to alluvial bedforms. The model is applied to laboratory data of flow over alluvial bedforms, and the model results are compared to results of existing models (research question Q6). 
Chapter 5: This chapter discusses (as far as not already discussed in the derivation of the model) assumptions made in the development of the form drag model, and aspects that are not taken into account in the form drag model. The chapter describes the fields of application of the form drag model, and how the form drag model can be incorporated in a large-scale morphodynamic model system.

Chapter 6: This chapter reflects on the research questions by presenting the main conclusions of this thesis and providing recommendations for future research. 


\title{
Chapter 2
}

\section{Quantification of variability in bedform geometry $^{\star}$}

\begin{abstract}
We analyze the variability in bedform geometry in laboratory and field studies. Even under controlled steady flow conditions in laboratory flumes, bedforms are irregular in size, shape, and spacing, also in case of well-sorted sediment. Our purpose is to quantify the variability in bedform geometry. We use a bedform tracking tool to determine the geometric variables of the bedforms from measured bed elevation profiles. For each flume and field data set, we analyze variability in (1) bedform height, (2) bedform length, (3) crest elevation, (4) trough elevation, and (5) slope of the bedform lee face. Each of these stochastic variables is best described by a positively skewed probability density function such as the Weibull distribution. We find that, except for the lee face slope, the standard deviation of the geometric variable scales with its mean value as long as the ratio of width to hydraulic radius is sufficiently large. If the ratio of width to hydraulic radius is smaller than about ten, variability in bedform geometry is reduced. An exponential function is then proposed for the coefficients of variation of the five variables to get an estimate of variability in bedform geometry. We show that mean lee face slopes in flumes are significantly steeper than those in the field. The $95 \%$ and $98 \%$ values of the geometric variables appear to scale with their standard deviation. The above described simple relationships enable us to integrate variability in bedform geometry into engineering studies and models in a convenient way.
\end{abstract}

\section{$2.1 \quad$ Introduction}

Bedforms such as river dunes or marine sand waves are rhythmic bed features which develop because of the interaction between water flow and sediment transport. Often bedforms are schematized as a train of regular features (e.g., a sinusoidal wave, a train of identical triangles or smoothly shaped asymmetric forms). The purpose of such a simplification is, for instance, to explain the generation of sand waves through stability analysis (e.g., Hulscher, 1996), or to numerically (e.g., Yoon and Patel, 1996) or experimentally (e.g., Nelson et al., 1993; Lyn, 1993; McLean et al., 1999) analyze the turbulent flow structures over bedforms.

${ }^{\star}$ This chapter has been published as: Van der Mark, C.F., A. Blom, and S.J.M.H. Hulscher (2008), Quantification of variability in bedform geometry, J. Geophys. Res., 113, F03020, doi:10.1029/2007JF000940. 
Bed elevation profiles from a laboratory flume or the field show that bedforms are not regular (Figure 2.1), even under steady conditions and for well-sorted sediment (e.g., Nordin, 1971; Paola and Borgman, 1991).

Previous studies have shown that variability in bedform geometry, i.e., size, shape and spacing, is not the exception, but is the character of natural bedforms developing under and interacting with unidirectional flows (Jerolmack and Mohrig, 2005a). Natural bedform topography continuously evolves, i.e., bedforms merge and split (Gabel, 1993), even under steady flow conditions (Leclair, 2002). Bedform geometry under given flow conditions is modified by variations in the sediment flux (Jerolmack and Mohrig, 2005a). A modification in bedform geometry induces modification in flow acceleration, which in turn induces modification in the sediment flux (Nelson et al., 1993). Jerolmack and Mohrig (2005a) hold the nonlinear feedback between topography and sediment transport responsible for the variability in bedform geometry. Jerolmack and Mohrig (2005b) develop a surface evolution model for the topography of bed load dominated sandy rivers. They add a noise term to the sediment flux to account for local fluctuations in the sediment flux. Deterministic model simulations in which the noise term is zero evolve toward a static steady pattern of bedforms, i.e., uniform periodic bedforms. Model simulations in which the noise term has a mean value of zero and is Gaussian distributed evolve toward a bed topography that is continuously varying but in statistical sense homogeneous.

In several studies, we need information not only on the average geometric variables of bedforms, but also on their stochastics. For example, dredging, which is necessary to keep a navigational channel sufficiently deep, requires information on the highest crest elevations. On the other hand, construction of pipelines and cables buried in the sea bed, which may not be exposed to the flow, demands information on the deepest trough elevations. Similarly, safety against uplifting of a tunnel underneath a river bed needs to be guaranteed when a deep trough migrates over the tunnel (Amsler and García, 1997).

Furthermore, variability in bedform geometry needs to be taken into account when modeling (1) the thickness of cross-strata sets, (2) vertical sorting, or (3) bed roughness. The first example is illustrated by the fact that the variability in trough elevations is relevant in the reconstruction of the original heights of bedforms from the thickness of cross-strata in preserved deposits as it mainly determines the probability density function of cross-set thickness of preserved bedforms (e.g., Paola and Borgman, 1991; Leclair, 2002). Second, the variability in trough elevations affects the morphodynamic changes of the river bed when vertical sorting within bedforms plays a role. A model predicting the variability in trough elevations is required as a sub-model for a stochastic model for mass conservation of sediment mixtures (Blom et al., 2008). The third example concerns the effect of variability in bedform geometry upon form roughness. Form drag due to the presence of bedforms results in a component of flow resistance that is often called form roughness. As form roughness depends on the size, shape, and spacing of the bedforms (e.g., Allen, 1983; Nelson et al., 1993), we hypothesize that the variability in geometric variables of individual bedforms within a reach affects the reach-averaged form roughness. We ground this hy- 


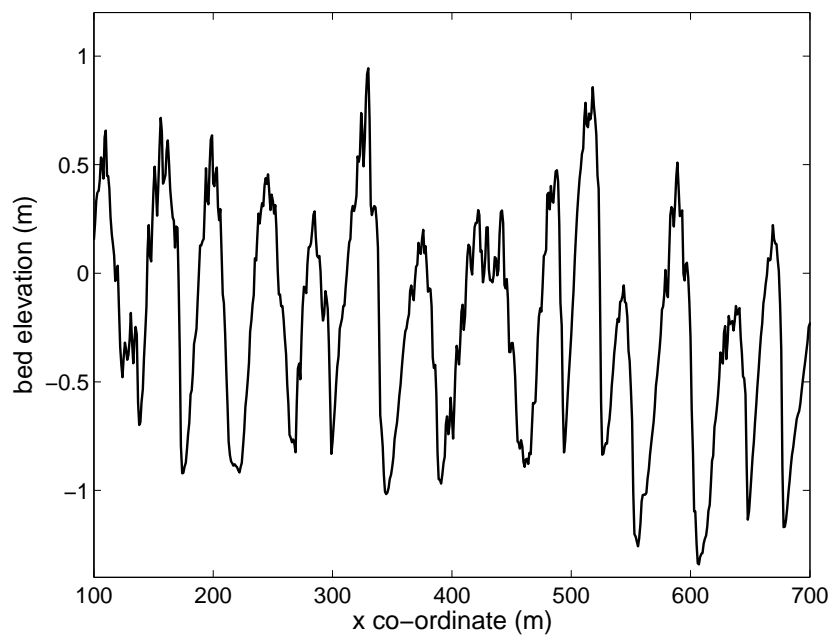

Figure 2.1: Bed elevation profile of the Waal branch of the Rhine River in the Netherlands. Measurements taken on December 11, 2006. Flow is from left to right.

pothesis by making an analogy between grain roughness and form roughness. Often the $65 \%, 84 \%$, or $90 \%$ grain size $\left(D_{65}, D_{84}\right.$, or $D_{90}$, respectively) is used as a representative diameter of the grains in predicting the grain roughness, as this diameter is representative in its effect on the flow (Van Rijn, 1982). Analogously, form roughness may also be determined by bedforms that are higher, longer, or steeper than the median or mean bedform height, bedform length, or bedform steepness, respectively.

The aim of this paper is to characterize variability in bedform geometry by analyzing flume and field data. In earlier work, researchers have reported mean values, standard deviations, and histograms of bedform height, bedform length, and bedform steepness (defined as bedform height divided by bedform length) for their own flume or field data set (e.g., Gabel, 1993; Wang and Shen, 1980). In the present paper we analyze a number of data sets of both flume and field experiments with a wide range of bedform heights and lengths and focus on finding generic relations describing variability in five geometric variables: (1) bedform height, (2) bedform length, (3) crest elevation, (4) trough elevation, and (5) lee face slope. For each of these stochastic variables, we consider (a) its probability density function, (b) its ratio of standard deviation to mean value (coefficient of variation), and (c) its extreme values (95\% and 98\%). In our data analysis, we process each data set in the same way using a new generally applicable bedform tracking tool. 


\section{$2.2 \quad$ Data}

\subsubsection{Flume data}

We use laboratory flume data (Table 2.1) of Driegen (1986), Klaassen (1990), Leclair (2002), and Blom et al. (2003). The experiments of Driegen (1986), Klaassen (1990), and Blom et al. (2003) were conducted in the Sand Flume of Delft Hydraulics in the Netherlands. Leclair (2002) performed a series of runs under varying flow conditions at Binghamton University (BU), New York, USA. We use the data from the BU runs in which no net aggradation occurs. We consider measured data from the flume region unaffected by the entrance and exit of the flume only. All measurements were taken under equilibrium (i.e., steady and uniform) conditions, which means that bedform geometry, flow, and sediment transport rate varied around steady mean values. We refer to Table 2.1 for details on the experiments.

\subsubsection{Field data}

We consider field data from the Waal branch of the Rhine River in the Netherlands, as well as field data from the North Loup River, Nebraska, USA (Table 2.1). The reaches are not influenced by river bends.

Multi-beam echo sounder measurements were made at two locations within the main channel of the Rhine River branch by the Dutch Ministry of Transport, Public Works and Water Management (Rijkswaterstaat). The first reach, measured on December 11, 2006, is $6 \mathrm{~km}$ long and $250 \mathrm{~m}$ wide, the second reach, measured in March 2007, is $200 \mathrm{~m}$ long and $60 \mathrm{~m}$ wide. Both reaches have a sandy bed: $D_{10} \approx 0.4 \mathrm{~mm}, D_{50} \approx 0.8 \mathrm{~mm}, D_{90} \approx 3 \mathrm{~mm}$ (Ten Brinke, 1997).

The measured bed elevations are projected on a regular grid of $1 \times 1 \mathrm{~m}^{2}$ by averaging the available bed elevation measurements (at least 10) within each grid cell. The effect of the averaging procedure on bedform geometry is negligible as the grid size is small with respect to bedform height and length (Appendix A).

The topographic data of the braided North Loup River (Figure 2.2) are derived from low-altitude aerial photography (Mohrig, 1994; Mohrig and Smith, 1996). The river bed consists of sand with median grain diameter $D_{50}=0.31 \mathrm{~mm}$ (Mohrig and Smith, 1996). We consider observations taken on two days (July 13 and 22, 1990), taken with an interval of 2 minutes and 1 minute, respectively, for a period of 2 hours and 40 minutes, respectively. The considered river reach is $30 \mathrm{~m}$ long and $15 \mathrm{~m}$ wide. Approximately constant river stage ensured that flow was essentially steady over the observation period (Jerolmack and Mohrig, $2005 b)$.

\subsection{Data processing}

\subsubsection{Grouping of streamwise bed elevation profiles}

In the assessment of the variability in bedform geometry we analyze the original bed elevation profiles (BEPs). We only use series of bed elevations measured along a transect, and no time series. In the flume experiments BEPs were measured in streamwise direction. For the field measurements we convert the 


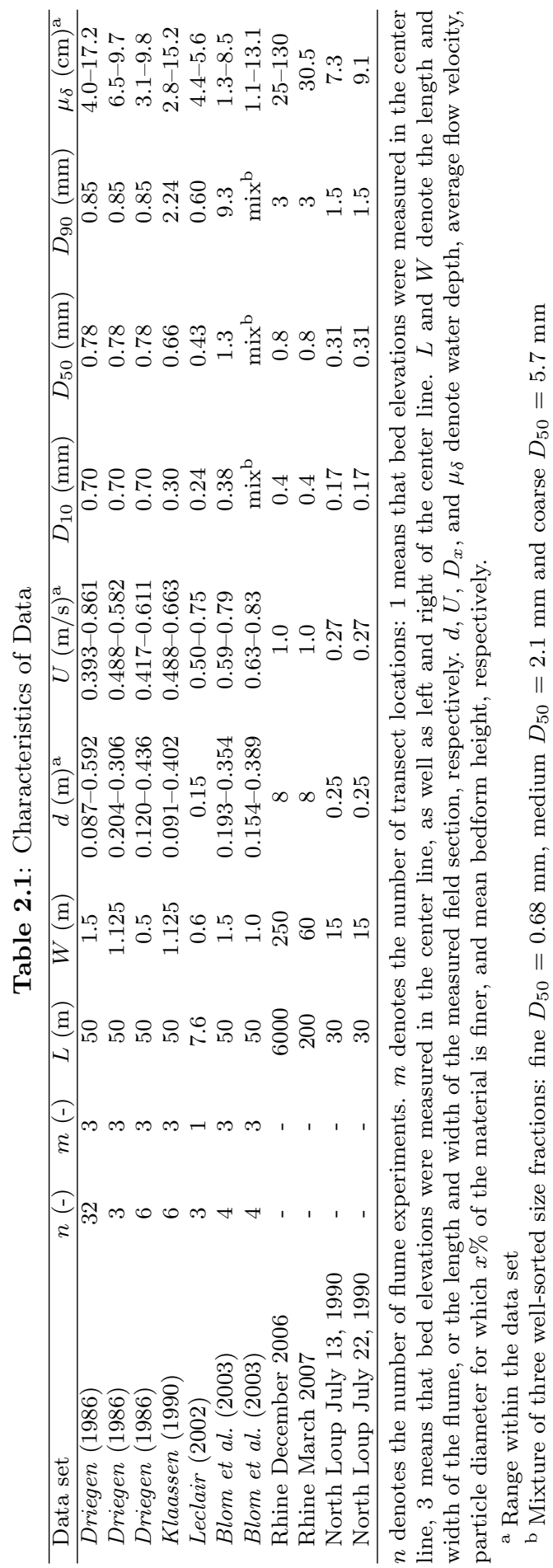




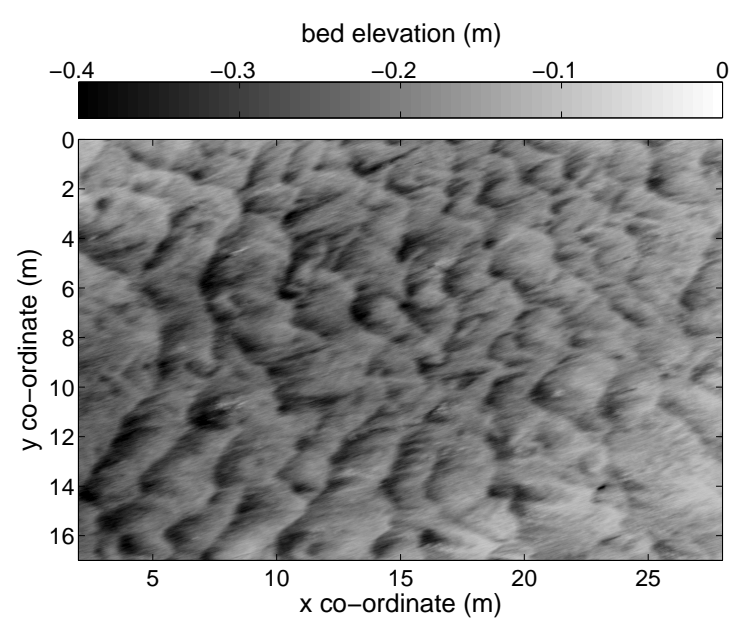

Figure 2.2: Bed elevation measurements of a part of the North Loup River taken on July 22, 1990 (Mohrig, 1994; Mohrig and Smith, 1996; Jerolmack and Mohrig, 2005b). Flow is from left to right.

original bed elevation profiles in $X$ and $Y$ co-ordinates to bed elevation profiles in the streamwise direction.

Within a data set we can distinguish two types of sets of BEPs (Figure 2.3): (1) a set of BEPs measured at the same transect (e.g., in the center of a flume) at various moments in time, and (2) a set of BEPs measured at the same time, but at different transects (e.g., one BEP measured in the center, one BEP left from the center, and one BEP right from the center of a flume). All BEPs from the flume experiments of Leclair (2002) are of type 1. The BEPs from the Waal branch data measured in December 2006 belong to type 2. All other flume and field BEPs are of both type 1 and type 2 .

It is allowed to group together bedform geometry derived from BEPs that are statistically homogeneous in both space and time (Paola and Borgman, 1991). In that case, the statistics of the BEPs as a whole are equal, although individual migrating bedforms continuously merge, split, and thus change in shape and size. We use a spatial scaling technique (Nikora and Hicks, 1997; Jerolmack and Mohrig, 2005b) to verify which BEPs within a data set are statistically homogeneous in space and/or time. The spatial scaling technique treats a series of bed elevations in a profile as a random function (see Nikora et al., 1997) instead of identifying individual bedforms in a profile. A measure of the variability in bed elevations is the standard deviation of bed elevations, sometimes referred to as the interface width (Barabási and Stanley, 1995; Jerolmack and Mohrig, 2005b). For a dune-covered bed, interface width grows as a power law with increasing domain length or window size. This power law growth holds for small window sizes. The power exponent characterizes the scaling of elevation fluctuations (Barabási and Stanley, 1995; Dodds and Rothman, 2000). There is a 
type 1

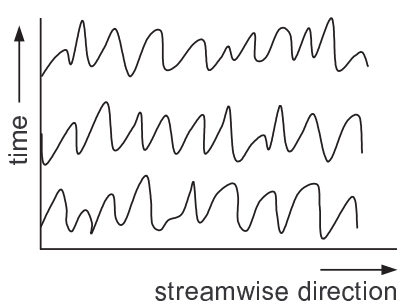

type 2

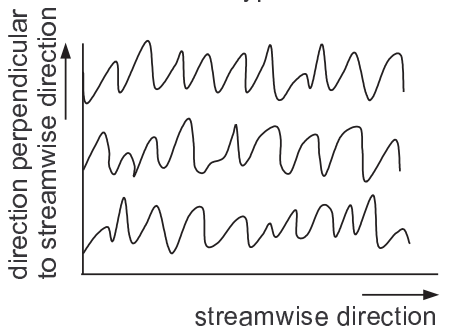

Figure 2.3: Two types of sets of bed elevation profiles are available: (1) timedependent bed elevation profiles, and (2) space-dependent bed elevation profiles.

gradual rollover of the interface width as the window size increases. We may characterize the location of rollover, i.e., the window size at which the rollover occurs, as a characteristic bedform length (Jerolmack and Mohrig, 2005b). The interface width associated with the location of rollover provides a characteristic bedform height. We consider a set of BEPs within a data set as statistically homogeneous if the characteristic bedform length, characteristic bedform height and the power exponent of the BEPs are equal.

Within each flume and field data set, we group together BEPs of type 1 as, according to the spatial scaling technique, these BEPs are statistically homogeneous.

In the flume experiments of Driegen (1986), Klaassen (1990), and Blom et al. (2003), BEPs were measured in the center of the flume, as well as left and right from the center. The spatial scaling technique shows that BEPs measured in the center deviate statistically from BEPs measured left and right from the center, which can be explained by sidewall influences. Therefore, for these experiments, we did not group together BEPs measured in the center with BEPs measured left and right from the center. Table 2.1 illustrates how for each experiment we have $m \times n$ sub data sets of statistically homogeneous flume BEPs. As a result, we obtain 168 flume sub data sets.

Within the Waal branch reach measured in December 2006 the flow conditions and thus bedform geometry varies in space. For instance, near the banks the flow velocity and bedform geometry deviate from those in the center. Figure 2.4 shows interface width against window size for 3 transects along the Waal branch of the Rhine River. The location of gradual rollover of the 3 BEPs is different, indicating that these BEPs are not statistically homogeneous. The spatial scaling technique enables us to divide the reach into smaller reaches in which the BEPs are statistically homogeneous. This procedure results in 15 homogeneous sub data sets for the Waal data of December 2006, one homogeneous sub data set for the Waal data of March 2007, and two homogeneous sub data sets for the North Loup River data. 


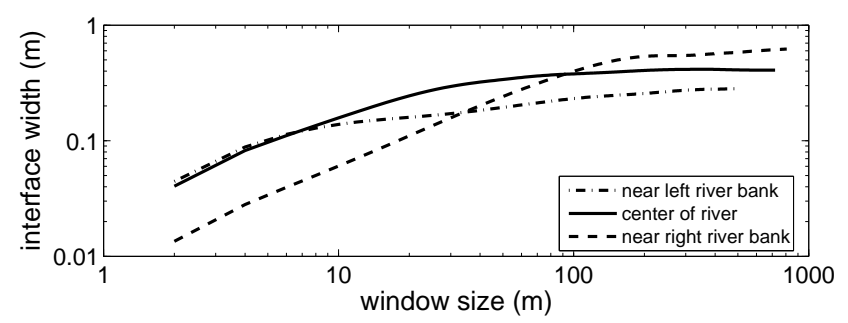

Figure 2.4: Interface width against window size for bed elevation profiles at 3 transects along the Waal branch of the Rhine River.

\subsubsection{Bedform geometry from bed elevation profiles}

There exist several methods to find crest and trough locations and determine the geometric characteristics of individual bedforms. Examples of methods are (1) the manual selection of crests and troughs, (2) the selection of local maxima and minima and next the use of threshold values for bedform height and/or bedform length for selecting which of the maxima and minima are considered as crests and troughs, respectively, and (3) the selection of crests and troughs between zero upcrossings and zero downcrossings. Other matters that require consideration in the analysis of bedform geometry are how to detrend the BEPs (e.g., by fitting a linear line or by applying a moving average), and how to define the geometric variables. For instance, some authors define bedform length as the distance between two successive bedform troughs (e.g., Wang and Shen, 1980), others use the distance between two successive zero upcrossings (e.g., Annambhotla et al., 1972), or the distance between two crests (Crickmore, 1970).

The method to find crest and trough locations and the above considerations may influence the resulting bedform geometry (Prent, 1998). Choices are usually made subjectively on the basis of the whole bed configuration (Crickmore, 1970). In order to compare various sets of measurements, we need to use the same method to find crests and troughs and to use the same definitions of geometric variables for each data set. Therefore it is generally not desirable to compare bedform data of different researchers if the original BEPs are lacking (Crickmore, 1970).

Van der Mark and Blom (2007) have developed a bedform tracking tool which determines the geometry of the individual bedforms from original BEPs (Appendix B). The code has been applied to marine sand wave data (Van der Mark et al., 2008a, Appendix C), flume data, and river data. Appendix 2.A shortly describes the details of the bedform tracking tool. Figure 2.5 illustrates the definitions of geometric variables in the detrended BEP. In developing the bedform tracking tool, subjective decisions have been avoided as much as possible. The numerical code can easily be applied to various data sets, without the necessity to 'tune' the code to a data set or to define threshold values.

We now have 186 sub data sets containing bedform geometry taken from the BEPs. The number of bedform heights, bedform lengths, crest elevations, and trough elevations in one sub data set equals at least 50, and on average, about 


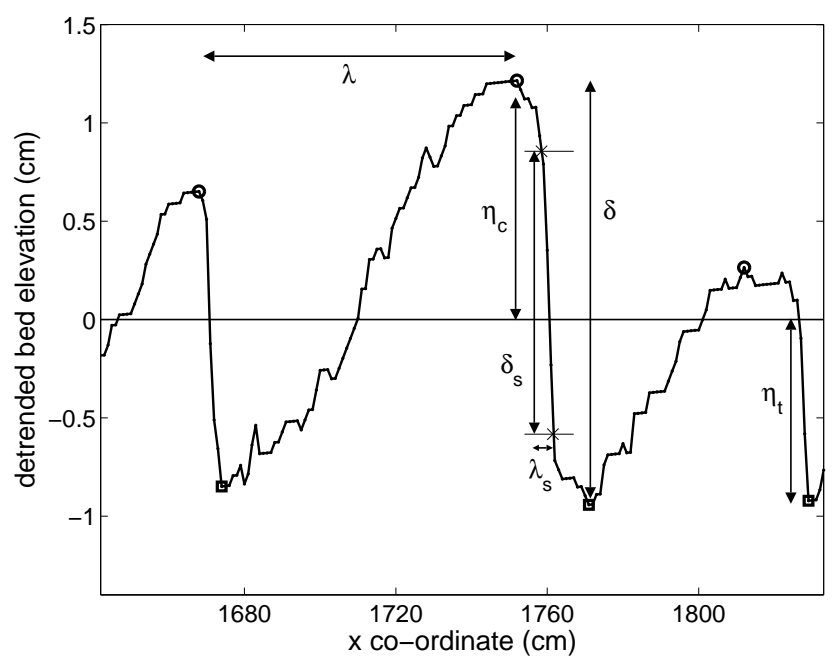

Figure 2.5: Definitions of the geometric variables in a detrended BEP: $\lambda$ denotes bedform length, $\delta$ denotes bedform height, $\eta_{c}$ and $\eta_{t}$ denote crest elevation and trough elevation, respectively. The lee face slope $S_{l}$ is defined as $\delta_{s} / \lambda_{s}$. Crests and troughs are indicated with circles and squares, respectively. Flow is from left to right.

900.

\subsection{Probability density functions}

\subsubsection{Results}

We analyze whether the five geometric variables are distributed according to a known probability density function. For each sub data set we determine the Exponential, Gamma, Gaussian, Gumbel, Log-normal, Rayleigh, Weibull, and Uniform distributions for each geometric variable. The distributions are determined using the mean and standard deviation of the geometric variable for each sub data set.

Figure 2.6 shows an example of imposed probability density functions (PDFs) for dimensionless bedform heights and lengths measured in one of the flume experiments. Dimensionless bedform height is defined as the bedform height divided by the mean bedform height of the sub data set. For each sub data set we determine the goodness of the PDFs using an expression for the relative error $E_{X^{*}}$, which is equal to the integral of the absolute value of the difference between the measured and imposed PDF:

$$
E_{X^{*}}=\int_{0}^{\infty}\left|\left[p_{m}\left(X^{*}\right)-p_{i}\left(X^{*}\right)\right]\right| d X^{*}
$$

where $X^{*}$ denotes the dimensionless geometric variable, $p_{m}\left(X^{*}\right)$ denotes the measured PDF, and $p_{i}\left(X^{*}\right)$ denotes the imposed PDF. By definition, the integrals of the imposed PDF and measured PDF are equal to 1 . If the measured 
Table 2.2: Average error values $\overline{E_{X^{*}}}$ for the goodness of the imposed PDF for the following dimensionless geometric variables $\left(X^{*}\right)$ : bedform height $\delta^{*}$, bedform length $\lambda^{*}$, crest elevation $\eta_{c}^{*}$, trough elevation $\eta_{t}^{*}$, and lee face slope $S_{l}^{*}$.

\begin{tabular}{ccccccccc}
\hline & $\begin{array}{c}\text { Gauss- } \\
\text { ian }\end{array}$ & $\begin{array}{c}\text { Gam- } \\
\text { ma }\end{array}$ & $\begin{array}{c}\text { Ray- } \\
\text { leigh }\end{array}$ & $\begin{array}{c}\text { Wei- } \\
\text { bull }\end{array}$ & $\begin{array}{c}\text { Expo- } \\
\text { nential }\end{array}$ & $\begin{array}{c}\text { Log- } \\
\text { normal }\end{array}$ & $\begin{array}{c}\text { Gum- } \\
\text { bel }\end{array}$ & $\begin{array}{c}\text { Uni- } \\
\text { form }\end{array}$ \\
\hline$\delta^{*}$ & 0.28 & $\mathbf{0 . 2 8}$ & 0.39 & $\mathbf{0 . 2 9}$ & 0.87 & 0.32 & 0.42 & 0.74 \\
$\lambda^{*}$ & 0.41 & $\mathbf{0 . 3 2}$ & 0.41 & $\mathbf{0 . 3 4}$ & 0.82 & $\mathbf{0 . 3 2}$ & 0.61 & 0.95 \\
$\eta_{c}^{*}$ & 0.33 & 0.36 & 0.32 & $\mathbf{0 . 2 8}$ & 0.59 & 0.48 & 0.47 & 0.55 \\
$\eta_{t}^{*}$ & 0.35 & 0.32 & 0.37 & $\mathbf{0 . 2 8}$ & 0.55 & 0.44 & 0.51 & 0.70 \\
$S_{l}^{*}$ & 0.47 & 0.53 & 0.52 & 0.43 & 0.73 & 0.63 & 0.50 & 0.52 \\
\hline
\end{tabular}

$\mathrm{PDF}$ and imposed PDF are equal, the error is 0 , whereas if the measured PDF and imposed PDF do not overlap at all, the error is 2. For each of the imposed PDFs we determine the average error $\overline{E_{X^{*}}}$ by averaging over all sub data sets. The imposed PDF with the smallest average error corresponds to the best approximation of the data. Table 2.2 presents the average error values for each imposed PDF for each geometric variable. In finding the best approximation, we have not fitted the PDFs to the data. We have imposed the mean value and the standard deviation of the specific geometric variable from the specific sub data set to the distribution.

We find that for bedform height the Gaussian, Gamma, and Weibull distributions provide the best approximations. The Gamma, Log-normal, and Weibull distributions provide the best approximations for bedform length. For crest elevation, trough elevation, and lee face slope we find that the Weibull distribution yields the best approximation. It appears that for all five geometric variables, the Weibull distribution performs well. Depending on its shape parameter, $k$, the Weibull distribution can be both positively skewed $(k<2.6)$, negatively skewed $(k>3.7)$, or not/hardly skewed $(2.6<k<3.7)$. All sub data sets appear to have shape parameters in the range 1.8-2.7, which means that the imposed Weibull distributions are positively skewed.

Many phenomena can be approximated well by the Gaussian distribution (e.g., Jenkins and Watts, 1968). It appears that, except for the Gaussian distribution, the distributions yielding the best approximations are positively skewed. The reason we find positively skewed distributions to be good approximations of the data, may be that, by definition, in our analysis the five geometric variables are positive values (Figure 2.5). We recommend the Weibull, Gamma, or Log-normal distributions rather than the Gaussian, Gumbel, or Uniform distributions, as the latter distributions admit negative values.

\subsubsection{Discussion}

Previous researchers have assigned several types of probability density functions to bedform heights and bedform lengths as found from BEPs of flume and field experiments. For instance, bedform height is identified as following the Rayleigh distribution (Ashida and Tanaka, 1967; Nordin, 1971), the Weibull 


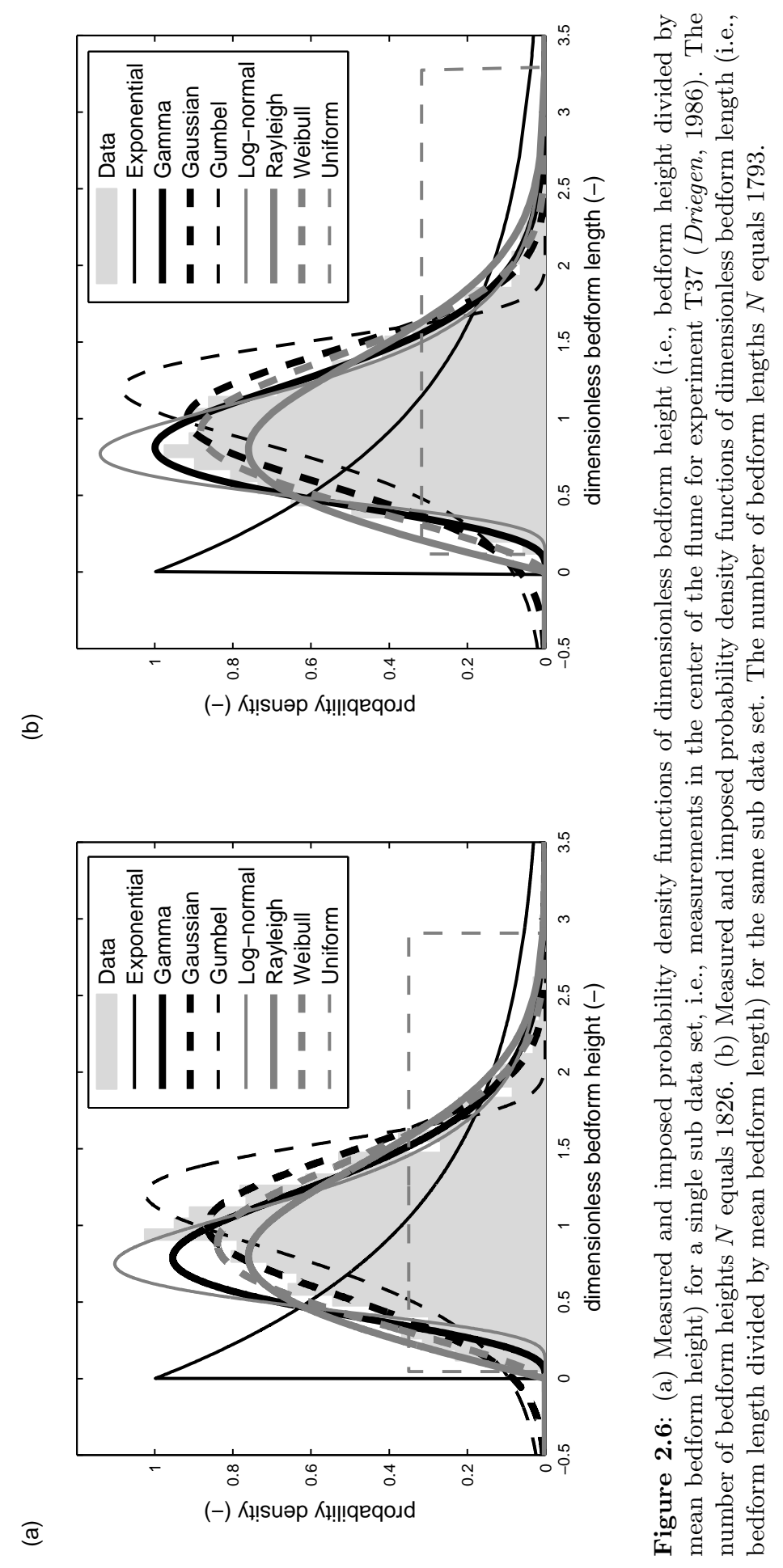


distribution (Wang and Shen, 1980), the Exponential distribution (Annambhotla et al., 1972), the Gamma distribution (Leclair et al., 1997), the Gaussian distribution (Mahmood and Ahmadi-Karvigh, 1976), and the Beta distribution (Prent and Hickin, 2001). We mention four reasons why different types of optimal PDFs have been found: (1) differences in the preprocessing of the measured bed elevation profiles (e.g., different methods to remove outliers, to detrend the BEPs, or to filter the BEPs), (2) differences in the methods to determine the locations of crests and troughs, (3) differences in the definition of geometric variables, and (4) differences with respect to the types of imposed PDFs used in the analysis. For instance, Mahmood and Ahmadi-Karvigh (1976) compare their bedform length data to Gaussian, Exponential, Cauchy, Uniform, and Rayleigh distributions and not to, for example, the Weibull distribution.

\subsection{Coefficient of variation}

\subsubsection{Results}

In the present study we focus on finding generic relations describing variability in the five geometric stochastic variables. We study the variability in each geometric variable $X$ by determining for each sub data set the mean value $\mu_{X}$, the standard deviation $\sigma_{X}$, and the coefficient of variation $C_{X}$, which is defined as the ratio of the standard deviation to the mean value:

$$
C_{X}=\frac{\sigma_{X}}{\mu_{X}}
$$

in which $X$ denotes the geometric stochastic variable (i.e., bedform height, bedform length, crest elevation, trough elevation, or lee face slope).

For bedform height, Figure 2.7a shows the standard deviation as a function of the mean value. Figure 2.7a shows that a more or less linear relation exists between the standard deviation of bedform height and the mean bedform height. Figures $2.7 \mathrm{~b}, 2.7 \mathrm{c}$, and $2.7 \mathrm{~d}$ show that such linear relations also exist for bedform length, crest elevation, and trough elevation, respectively.

Figure 2.7e shows the standard deviation against the mean value for the lee face slope. The scatter is large and no linear relation exists between the standard deviation and the mean value for the lee face slope, especially for mean lee face slopes larger than 0.2. Roughly, we may see a linear trend in the field data. The standard deviation of the flume data roughly varies between 0.13 and 0.22 , which appears to be independent of the mean lee face slope. The fact that lee face slopes cannot become much steeper than the natural angle of repose of the sediment may explain why the linear trend disappears for increasing lee face slope. It appears that lee faces in the flume are significantly steeper than those in the field, which is also found by Best and Kostaschuk (2002).

We have seen that a more or less linear relation exists between standard deviation and mean geometric variable, which means that the coefficient of variation is a more or less constant value. We now analyze the effects of the ratio of flume or river width to hydraulic radius on the coefficient of variation in Figure 2.8. The hydraulic radius of the flume experiments is corrected for sidewall 
(a)

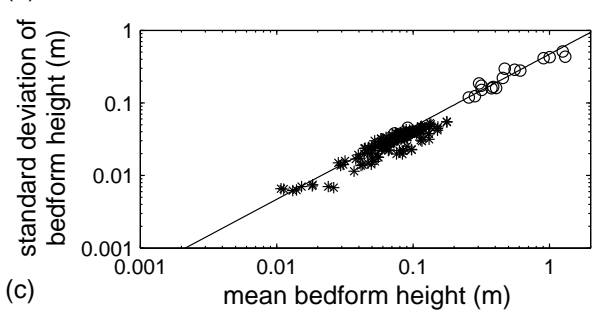

(c)

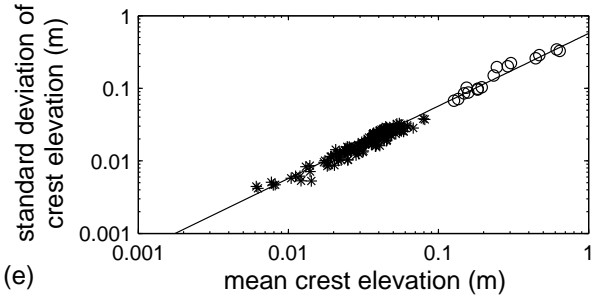

(e)

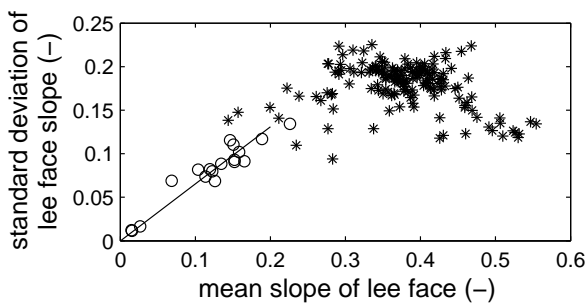

(b)
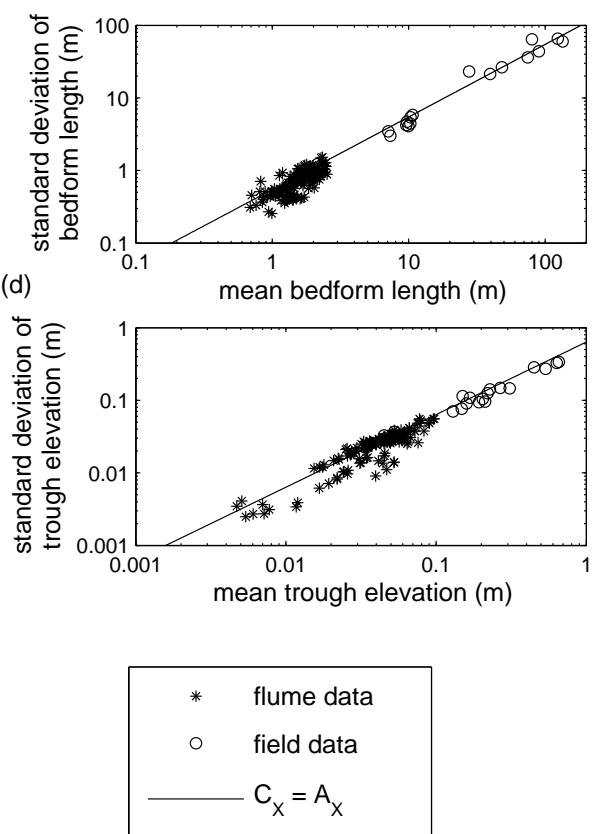

Figure 2.7: Standard deviation against mean value for (a) bedform height, (b) bedform length, (c) crest elevation, (d) trough elevation, and (e) lee face slope. The solid lines represent Eq. (2.4).

roughness using the method of Vanoni and Brooks (1957). For the five geometric variables, Figure 2.8 shows that their coefficients of variation decrease with decreasing ratio of flume width to hydraulic radius for ratios smaller than about ten. For each geometric variable we fit the following exponential function through the data points:

$$
C_{X}=A_{X}\left[1-\exp \left(\frac{-W / R}{B_{X}}\right)\right]
$$

in which $C_{X}$ denotes the coefficient of variation of geometric variable $X, W$ denotes the flume or river width, $R$ denotes the hydraulic radius, and $A_{X}$ and $B_{X}$ denote constants. Table 2.3 presents the constants $A_{X}$ and $B_{X}$ for each geometric variable $X$. The exponential function simply expresses that for relatively narrow flume widths the variability in bedform geometry is restricted. For ratios of width to hydraulic radius larger than about ten, the coefficient of variation of stochastic variable $X$ becomes:

$$
C_{X}=A_{X}
$$


(a)

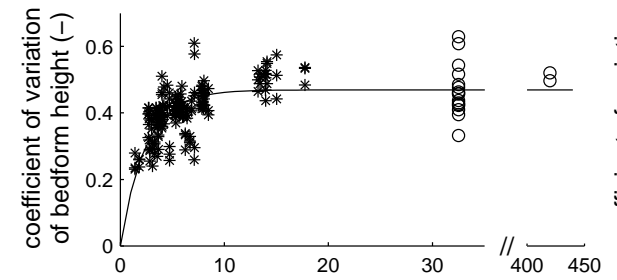

(c)

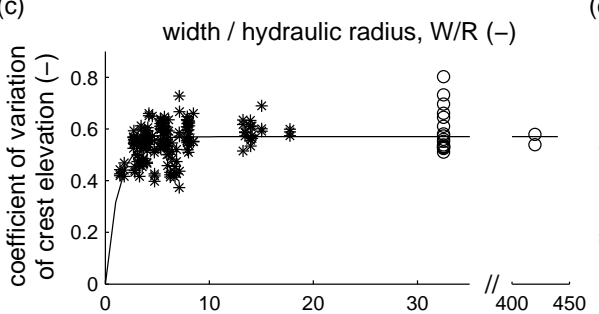

(e)

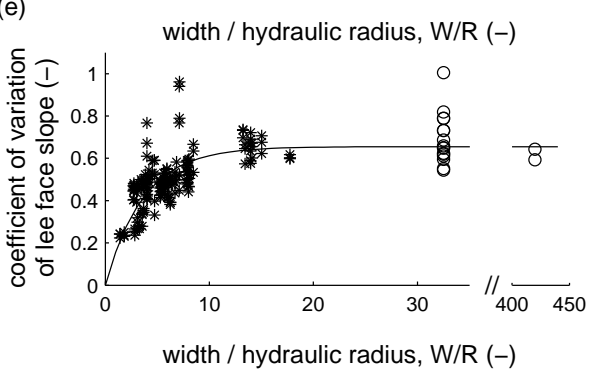

(b)

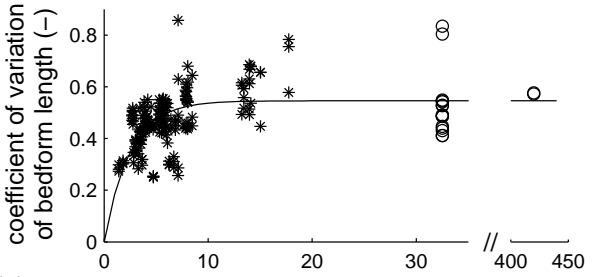

(d)
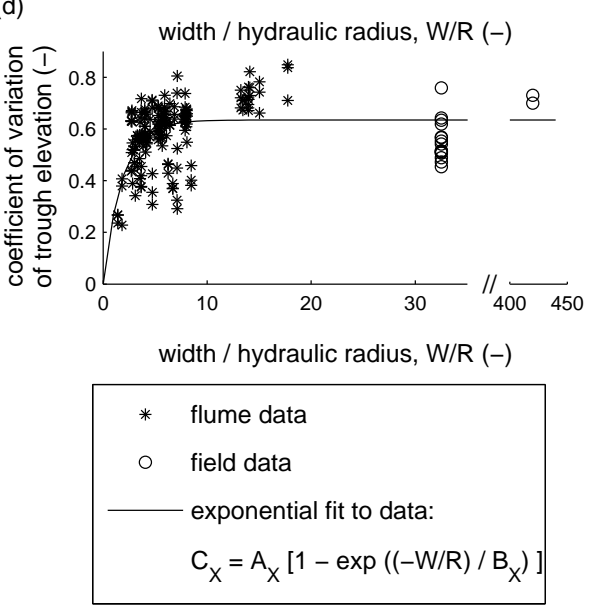

Figure 2.8: Coefficient of variation against the flume or river width divided by hydraulic radius for (a) bedform height, (b) bedform length, (c) crest elevation, (d) trough elevation, and (e) lee face slope. The solid lines represent Eq. (2.3).

In Figure 2.7, the solid lines represent Eq. (2.4). We can see that for field conditions, where ratios of width to water depth are usually larger than ten, Eq. (2.4) can be used to get an estimate of the variability in bedform geometry. Figure 2.8 shows that variability in bedform geometry in flume experiments is comparable to variability in field measurements if the ratio of width to hydraulic radius is larger than ten.

Williams (1970) has shown that the flume width influences the mean geometric bedform variables. Also Crickmore (1970) reports an increase of both mean bedform length and bedform height for increasing values of the ratio of width to water depth for the same specific discharge. We have shown that bedform variability decreases with decreasing ratio of width to water depth. These results are confirmed with respect to bedform length by the findings of Van Rijn and Klaassen (1981). For a relatively narrow flume, the flow separation behind a dune will be more or less uniform over the width of the flume and the recirculation will be stable. A relatively wider flume may result in a recirculation 
Table 2.3: Constants $A_{X}$ and $B_{X}$ in Eq. (2.3) and coefficients relating the $95 \%$ and $98 \%$ values of geometric bedform variables to their standard deviations.

\begin{tabular}{ccccc}
\hline$X$ & $A_{X}$ & $B_{X}$ & $C_{X 95}$ & $C_{X 98}$ \\
\hline$\delta$ & 0.47 & 2.4 & 1.7 & 2.2 \\
$\lambda$ & 0.55 & 2.5 & 1.9 & 2.6 \\
$\eta_{c}$ & 0.57 & 1.2 & 1.7 & 2.0 \\
$\eta_{t}$ & 0.63 & 1.8 & 1.8 & 2.3 \\
$S_{l}$ & 0.66 & 3.7 & - & - \\
\hline
\end{tabular}

pattern that is unstable in lateral direction, which may restrict the width of a bedform. As a result, more than one bedform may occur over the width of a flume, which may result in more variability.

Figure 2.8 shows that some sub data sets have more regular bedform geometry (i.e., a relatively small coefficient of variation) than other sub data sets having similar ratios of width to hydraulic radius. Sediment sorting processes may explain differences in bedform variability between sub data sets. For instance, the presence of a coarse layer underneath migrating bedforms reduces the variability in trough elevations (Wilcock and Southard, 1989; Blom et al., 2003; Leclair and Blom, 2005). Figure 2.9 shows the coefficient of variation of trough elevation against the flume or river width divided by hydraulic radius, and we distinguish between sub data sets with uniform sediment and sub data sets with nonuniform sediment. A nonuniform sediment mixture is here defined as a mixture with a geometric standard deviation $\left(\sigma_{g}=\sqrt{D_{84} / D_{16}}\right)$ larger than 1.6 (Diplas and Sutherland, 1988). From Figure 2.9, it appears that roughly the coefficient of variation for uniform sediment experiments is larger than for nonuniform sediment experiments in which a coarse layer underneath the bedforms may develop.

However, it may be better to have a criterion based on partial transport rather than the above criterion in order to distinguish between experiments with and without the formation of a coarse layer. Partial transport is here defined as the condition in which the coarsest grain sizes in the mixture are not (significantly) entrained or transported by the flow (Blom et al., 2003). For many of the flume and field experiments studied here data on partial transport is unavailable. We therefore recommend further research on this topic.

\subsubsection{Discussion}

We have seen that, for sufficiently large ratios of width to hydraulic radius, the standard deviation of bedform height increases linearly with the mean bedform height. Often a relationship exists between the standard deviation and the mean of a sample, such that the larger the mean, the larger the standard deviation (Sincich, 1985). For instance, daily maximum wind speed analyzed at several locations in several months satisfies this condition (Yan et al., 2002).

For the Calamus River, Nebraska, USA, Gabel (1993) finds values for the coefficient of variation of bedform height $C_{\delta}$ varying between 0.34 and 0.53 , 


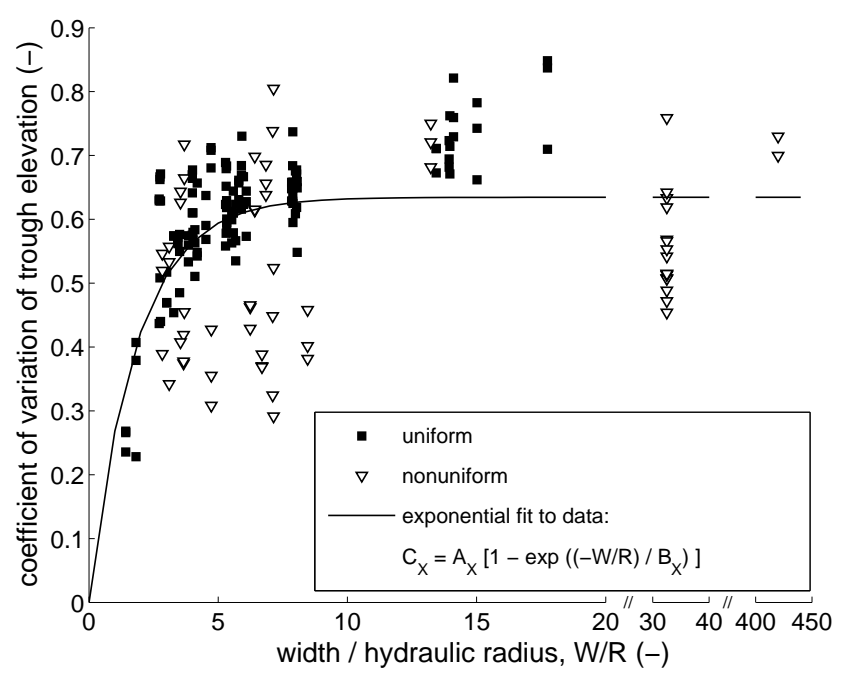

Figure 2.9: Coefficient of variation of trough elevation against the flume or river width divided by hydraulic radius. Distinction is made between uniform and nonuniform sediment experiments.

with a mean coefficient of variation of 0.44 , which is close to the proposed value $\left(C_{\delta}=A_{\delta}=0.47\right)$. Also the flume data by Wang and Shen $(1980)(W / h \approx 8$, $C_{\delta}$ ranges between 0.41 and 0.50$)$ and Leclair et al. (1997) $\left(W / h \approx 5, C_{\delta}\right.$ ranges between 0.39 and 0.48 ) agree to the proposed coefficient of variation of bedform height.

The proposed value of the coefficient of variation of bedform length, $C_{\lambda}=$ $A_{\lambda}=0.55$, appears to be somewhat larger than the one found by Gabel (1993) for the Calamus River. Smaller coefficients of variation of bedform length are also found by Wang and Shen (1980) and Leclair et al. (1997), also when taken into account the reduction in variability due to the flume width effect. This is probably due to the fact that they remove small scale bedforms from their analysis, which results in a larger mean bedform length and a smaller standard deviation of bedform length.

Some of the considered reaches of the Waal branch consist of (secondary) bedforms superimposed on larger (primary) bedforms. We have analyzed the coefficients of variation of geometric variables for the primary and the secondary bedforms separately. There appear to be no significant differences between the coefficients of variation for primary and secondary bedform geometry.

Figure 2.8 shows that, although the coefficients of variation of bedform geometry are more or less constant for ratios of width to hydraulic radius larger than about ten, there is quite some scatter. Some sub data sets have somewhat more regular bedform geometry than other sub data sets. It appears that if bedform heights are relatively regular, bedform lengths, crest elevations, and trough elevations are relatively regular, as well. 


\subsection{Extreme values}

\subsubsection{Results}

We analyze the $95 \%$ and $98 \%$ values for bedform height, bedform length, crest elevation, and trough elevation, in order to get insight in the extreme values of the distribution. We only consider the sub data sets in which the sample size is larger than 100 in order to have a sufficiently accurate estimate of the $95 \%$ and $98 \%$ values.

Figure $2.10 \mathrm{a}$ shows the relative $95 \%$ bedform height, i.e., the $95 \%$ bedform height minus the mean bedform height $\left(\delta_{95}-\mu_{\delta}\right)$, as a function of the standard deviation of bedform height. For bedform height we find that

$$
C_{\delta 95}=\frac{\delta_{95}-\mu_{\delta}}{\sigma_{\delta}}=1.7
$$

where the coefficient $C_{\delta 95}$ is a constant relating the $95 \%$ bedform height to the standard deviation of bedform height. This means that we can predict the $95 \%$ bedform height from the mean bedform height and the measured or predicted standard deviation:

$$
\delta_{95}=C_{\delta 95} \sigma_{\delta}+\mu_{\delta}
$$

With Eq. (2.2) this becomes

$$
\delta_{95}=\mu_{\delta}\left(C_{\delta 95} C_{\delta}+1\right)
$$

or, in generic form

$$
X_{95}=\mu_{X}\left(C_{X 95} C_{X}+1\right)
$$

This means that we can determine the $95 \%$ value if the mean value is predicted using some submodel for mean bedform height and using the proposed coefficients in Table 2.3. Similar to Eq. (2.5), for bedform length $C_{\lambda 95}$ equals 1.9, for crest elevation $C_{\eta c 95}$ equals 1.7 , and for trough elevation $C_{\eta t 95}$ equals 1.8 (Table 2.3).

Figure $2.10 \mathrm{~b}$ shows the relative $98 \%$ bedform height, i.e., the $98 \%$ bedform height minus the mean bedform height $\left(\delta_{98}-\mu_{\delta}\right)$, as a function of the standard deviation of bedform height. Table 2.3 shows the coefficients $C_{\delta 98}, C_{\lambda 98}, C_{\eta c 98}$, $C_{\eta t 98}$, relating the $98 \%$ values for bedform height, bedform length, crest elevation, and trough elevation to their respective standard deviations. Given these coefficients, we are able to predict the $98 \%$ value of the geometric variable, $X$, from the mean value, $\mu_{X}$, and the measured or predicted standard deviation of the geometric variable, $\sigma_{X}$ :

$$
X_{98}=C_{X 98} \sigma_{X}+\mu_{X}
$$

Or, with Eq. (2.2) this becomes

$$
X_{98}=\mu_{X}\left(C_{X 98} C_{X}+1\right)
$$


(a)

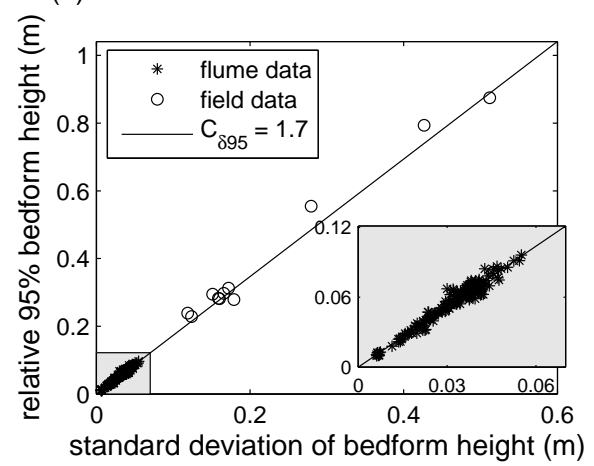

(b)

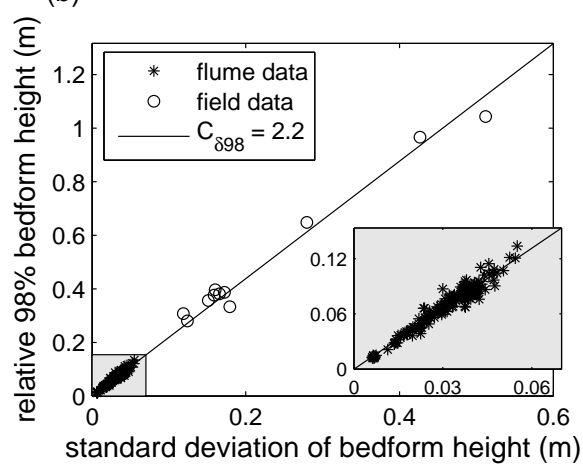

Figure 2.10: (a) Relative $95 \%$ bedform height, $\delta_{95}-\mu_{\delta}$, against standard deviation of bedform height, $\sigma_{\delta}$. (b) Relative $98 \%$ bedform height, $\delta_{98}-\mu_{\delta}$, against standard deviation of bedform height, $\sigma_{\delta}$.

\subsubsection{Discussion}

Theoretically it can be shown that $C_{X 95}$ equals 1.64 and $C_{X 98}$ equals 2.05 if the stochastic variable $X$ follows a Gaussian distribution, independent of the values of $\mu_{X}$ and $\sigma_{X}$. A value of $C_{X 95}$ or $C_{X 98}$ that is larger than the value of 1.64 or 2.05 indicates that the extreme value is more remote from the mean value than in the case of a Gaussian distribution. This confirms the finding in Section 2.4 that geometric bedform variables are distributed according to a type of distribution that has a longer tail for the higher values.

\subsection{Conclusions}

We have studied the stochastics of bedform geometry for both flume and field data. The five geometric variables bedform height, bedform length, crest elevation, trough elevation, and lee face slope are best described using a positively skewed probability density function. The Weibull distribution performs well for the considered geometric variables.

The stochastics of bedform geometry can be characterized using simple generic relations. Linear relations exist between standard deviation and mean value for bedform height, bedform length, crest elevation, and trough elevation if the ratio of width to hydraulic radius is larger than about ten. As such, a constant coefficient of variation can be applied to quantify variability in bedform geometry. For field conditions, a constant coefficient of variation is a good approximation. If the ratio of width to hydraulic radius is smaller than about ten, variability in bedform height, bedform length, crest elevation, and trough elevation is restricted, which may be represented by an exponential function for the coefficient of variation.

For field data, the mean lee face slope is significantly smaller than for flume data, and the standard deviation scales with the mean lee face slope. For flume 
data the standard deviation does not scale with the mean lee face slope, as the slope cannot become much steeper than the natural angle of repose.

The $95 \%$ and $98 \%$ values of the geometric variables scale with their standard deviation, so that we are able to predict the extremes using the proposed relations and given the mean values for the geometric variables.

The proposed relations between mean geometric variables and their standard deviations, and $95 \%$ and $98 \%$ values are useful for, for instance, engineering studies. The relations can be applied to determine an estimate of the extremes in crest elevation in a navigational channel, or to determine the optimal depth of a tunnel or trench to place a pipeline in.

\section{A Bedform tracking tool}

Van der Mark and Blom (2007) have developed a bedform tracking tool which determines the geometric variables of individual bedforms from the original bed elevation profiles (BEPs). In short, the procedure of the bedform tracking tool is as follows:

1. For each BEP we find and replace outliers.

2. For each BEP we determine the trend line. We choose either a linear trend line or a weighted moving average trend line. As all flume experiments were conducted under steady and uniform conditions (i.e., no spatial variations), the trend line is best described by a linear fit to the measured bed elevations. For the field measurements, the trend line is rather represented by a moving average.

3. We detrend the BEP using the trend line so that the detrended BEP fluctuates around the zero line.

4. We apply a weighted moving average filter which yields a filtered BEP. The filtered BEP is only used to avoid the effect of small fluctuations in the BEP around the zero line on the resulting zero up- and downcrossings.

5. We determine zero upcrossings and zero downcrossings in the filtered BEP.

6. We determine crests and troughs in the original BEP. A crest is located at the maximum value between a zero up- and zero downcrossing. A trough is located at the minimum value between a zero down- and zero upcrossing.

7. We determine the geometry of individual bedforms in the detrended BEP (bedform height, $\delta$, bedform length, $\lambda$, crest elevation, $\eta_{c}$, trough elevation, $\eta_{t}$, and lee face slope, $S_{l}$, see Figure 2.5). We define crest elevation as the vertical distance from crest to zero line, and trough elevation as the vertical distance from trough to zero line. Bedform height is defined as the vertical distance between crest and downstream trough. Bedform length is defined as the horizontal distance between two consecutive crests. The lee face slope is defined as the vertical distance divided by the horizontal distance 
of a distinct part of the lee face. To determine the lee face slope we exclude a distance of one sixth of the bedform height below the crest and a distance of one sixth of the bedform height above the trough as these regions are usually transitional areas.

\section{B Notation}

$A_{X} \quad$ constant, dimensionless.

$B_{X} \quad$ constant, dimensionless.

$C_{X} \quad$ coefficient of variation of stochastic variable $X$, dimensionless.

$C_{X 95} \quad$ coefficient relating the $95 \%$ value of stochastic variable $X$ minus the mean of $X$ to the standard deviation of $X$, dimensionless.

$C_{X 98} \quad$ coefficient relating the $98 \%$ value of stochastic variable $X$ minus the mean of $X$ to the standard deviation of $X$, dimensionless.

$D_{x} \quad$ particle diameter for which $x \%$ of the material is finer, $\mathrm{mm}$.

$E_{X^{*}} \quad$ error value for the goodness of an imposed PDF relative to the measured PDF of dimensionless stochastic variable $X^{*}$, dimensionless.

$\overline{E_{X^{*}}}$ error value for the goodness of an imposed PDF relative to the measured PDF of dimensionless stochastic variable $X^{*}$, averaged over all considered experiments, dimensionless.

$d \quad$ water depth, m.

$k \quad$ shape parameter of Weibull distribution, dimensionless.

$L \quad$ flume length, m.

$m \quad$ number of transect locations, dimensionless.

$n \quad$ number of flume experiments, dimensionless.

$N \quad$ sample size, dimensionless.

$p_{i}(X) \quad$ imposed probability density function of stochastic variable $X$, unity as for $X^{-1}$.

$p_{m}(X) \quad$ measured probability density function of stochastic variable $X$, unity as for $X^{-1}$.

$R \quad$ hydraulic radius, $\mathrm{m}$.

$S_{l} \quad$ slope of the lee face of a bedform $\left(S_{l}=\delta_{s} / \lambda_{s}\right)$, dimensionless.

$U \quad$ average flow velocity, $\mathrm{m} / \mathrm{s}$.

$W \quad$ flume or river width, $\mathrm{m}$.

$X \quad$ stochastic variable, unity as for the variable. In this study: bedform height, bedform length, crest elevation, trough elevation, lee face slope.

$X^{*} \quad$ dimensionless stochastic variable.

$X_{95} \quad 95 \%$ value of stochastic variable $X$, unity as for $X$.

$X_{98} \quad 98 \%$ value of stochastic variable $X$, unity as for $X$.

$\delta \quad$ bedform height, $\mathrm{m}$.

$\delta_{s} \quad$ part of bedform height that is used to determine lee face slope, $\mathrm{m}$.

$\eta_{c} \quad$ crest elevation, $\mathrm{m}$.

$\eta_{t} \quad$ trough elevation, $\mathrm{m}$.

$\lambda \quad$ bedform length, $m$. 
$\lambda_{s} \quad$ part of bedform length that is used to determine lee face slope, $\mathrm{m}$.

$\mu_{X} \quad$ mean value of stochastic variable $X$, unity as for $X$.

$\sigma_{g} \quad$ geometric standard deviation of sediment mixture, dimensionless.

$\sigma_{X} \quad$ standard deviation of stochastic variable $X$, unity as for $X$.

Acknowledgments The authors would like to acknowledge the Institute for Inland Water Management and Waste Water Treatment (J. Sieben and A.J.A. Wagener) for providing the Waal branch data, S.F. Leclair for providing flume data, D. Mohrig and D.J. Jerolmack for providing the North Loup data, and S.F. Leclair and S.R. McLean for their useful review comments. An earlier and less extended version of this work was published in "River, Coastal and Estuarine Morphodynamics: RCEM 2007: Proceedings of the Fifth IAHR Symposium on River, Coastal and Estuarine Morphodynamics", held in Enschede, the Netherlands, 1721 September 2007, edited by C.M. Dohmen-Janssen and S.J.M.H. Hulscher, and published by Taylor \& Francis, Leiden/ London, 2007. The results in the present paper supersede those in the prior RCEM paper. This research project, which is part of the VICI project ROUGH WATER (project number TCB6231), is supported by the Technology Foundation STW, applied science division of the Netherlands Organization for Scientific Research (NWO) and the technology programme of the Ministry of Economic Affairs. 


\title{
Chapter 3
}

\section{A semi-analytical form drag model: application to uniform bedforms ${ }^{\star}$}

\begin{abstract}
A new semi-analytical form drag model is presented. The basis of the model is an analytically-based submodel that describes form drag due to an abrupt expansion of a free surface flow. We combine this analytically-based submodel with correction factors in order to account for (1) a non-abrupt expansion, (2) bedform interaction, and (3) deviation of the flow separation zone height from the bedform height. The analytically-based submodel is an extension of the form drag model of Yalin (1964a) and Engelund (1966), in which it is assumed that the effects of a bedform on the flow are described by an abrupt expansion of a pipe flow. The results of the new semi-analytical form drag model are compared to laboratory data of flow over uniform bedforms. The predicted form drag agrees well to the measured one. In Chapter 4, the model is extended to the case of nonuniform bedforms and is applied to alluvial and compound bedforms.
\end{abstract}

\subsection{Introduction}

Bed resistance is the total bed drag force exerted on the flow by the bed (e.g. Vanoni and Hwang, 1967). Bed resistance can be divided into two components (Einstein and Barbarossa, 1952; Julien et al., 2002): (a) grain friction, resulting from resistance to flow due to the shear stress applied on individual grains on the river bed, and (b) form drag, resulting from resistance to flow due to the pressure gradient and energy loss in the flow separation zone located on the lee side of bedforms.

Bed resistance is a key factor in predicting the water level as a function of discharge (e.g. Alam and Kennedy, 1969; Van Rijn, 1984). An accurate prediction of water levels, especially during floods, is essential for preventing rivers from flooding or dikes from breaching. Form drag often accounts for the majority of the bed resistance (e.g. Julien and Klaassen, 1995; McLean et al., 1999). Hence, an accurate estimate of form drag is important.

There exist both empirical and (semi-)analytical models to calculate form drag. The empirical models can be divided into implicit and explicit methods.

*This chapter has been submitted to J. Geophys. Res. as: Van der Mark, C.F., A. Blom, W.S.J. Uijttewaal, S.J.M.H. Hulscher, and H.W.M. Hoeijmakers, A semi-analytical form drag model: application to uniform bedforms. 
Implicit models (Engelund and Hansen, 1967; Wright and Parker, 2004) are form drag models in which the grain friction and bed resistance are related empirically, so that form drag is not explicitly solved using the bedform geometry. Examples of explicit empirical models include the models of Van Rijn (1982, 1984) and Vanoni and Hwang (1967). These models determine form drag based on predicted or measured water depth and bedform geometry, i.e., bedform height and length.

An example of an analytical model is the form drag model developed by Yalin (1964a) and Engelund (1966). Both authors independently developed the same model (Yalin and Da Silva, 2001). In the analytical form drag model of Yalin (1964a) and Engelund (1966) it is assumed that the effects of a bedform on the flow are described by a sudden expansion of a pipe flow. Energy loss due to a sudden pipe flow expansion is determined applying the one-dimensional momentum and energy conservation equations over the expansion region, i.e., the Borda-Carnot equation (e.g. Borda, 1766; Daugherty and Franzini, 1965). In the semi-analytical form drag model of Karim (1999), which is an extension of the Yalin (1964a) and Engelund (1966) model, the effect of a bedform on the flow is assumed to be represented by a sudden expansion of a free surface flow rather than a pipe flow.

An analytically-based form drag model is preferable above an empirical form drag model as we expect that an analytically-based model in which the relevant processes are captured is more widely applicable than an empirical model. An empirical model is only applicable within the ranges of flow conditions and bedform geometry for which the empirical coefficients in the model are derived.

Form drag is known to be a function of (1) the Froude number (Alam and Kennedy, 1969), (2) the steepness of the bedform lee face (e.g. Best, 2005), (3) the spacing between bedforms (e.g. Davies, 1980; Coleman et al., 2005), and (4) the size of the flow separation zone (e.g. Schatz and Herrmann, 2006; Parsons et al., 2004). As far as known to the authors, none of the existing form drag models are a function of the Froude number, steepness of the lee face, or the size of the flow separation zone. The objective of this chapter is to present a new semi-analytical form drag model applicable to subcritical flows. The model is an extension of the form drag models of Yalin (1964a) - Engelund (1966) and Karim (1999). We apply the model to laboratory data of flow over uniform fixed bedforms. In Chapter 4 we apply the model to more realistic bedforms.

In Section 3.2 we will introduce the basic model which consists of two components, and in the Sections 3.3 and 3.4 we will elaborate on each of these two components. In the derivation of the present model we will indicate the differences between the present model and the form drag model of Yalin (1964a) and Engelund (1966), and the one of Karim (1999). Section 3.5 presents a validation of the new form drag model using laboratory data of flow over uniform bedforms. 


\subsection{Basic Model for Form Drag}

For steady and uniform flow, the total boundary shear stress, $\tau_{T}$, balances with the component of the gravitational force per unit area in the flow direction (e.g. Einstein, 1950):

$$
\tau_{T}=\rho g R S
$$

in which $\rho$ denotes the water density, $g$ the gravitational acceleration, $R$ the hydraulic radius, and $S$ the energy slope. We apply the following relation between the total boundary shear stress and the mean flow velocity, $U$ (e.g. Henderson, 1966):

$$
\tau_{T} \equiv c_{f, T} \rho U^{2}
$$

in which $c_{f, T}$ denotes a dimensionless resistance coefficient expressing the total resistance, and the mean flow velocity, $U$, equals the flow velocity averaged over a cross-sectional area. Combination of equations (3.1) and (3.2) yields (e.g. Henderson, 1966)

$$
c_{f, T}=\frac{g R S}{U^{2}}
$$

The energy slope, $S$, over a channel section of length $L$ is equal to the total energy loss, $\Delta H_{T}$, i.e., $\Delta H_{T}=S L$ (e.g. Daugherty and Franzini, 1965; Fox and McDonald, 1994), so that equation (3.3) becomes

$$
c_{f, T}=\frac{g R \Delta H_{T}}{L U^{2}}
$$

The total resistance in a straight bedform-dominated channel consists of three sources of resistance, namely grain friction, form drag due to bedforms, and sidewall friction. In this study the bed shear stress, $\tau_{b}$, is determined from the total boundary shear stress, $\tau_{T}$, using the sidewall correction procedure of Vanoni and Brooks (1957). We follow the decomposition proposed by Einstein and Barbarossa (1952), in which the bed shear stress is divided into a contribution due to grain friction, $\tau^{\prime}$, and a contribution due to form $\operatorname{drag}, \tau^{\prime \prime}$ :

$$
\tau_{b}=\tau^{\prime}+\tau^{\prime \prime}
$$

If it is assumed that the bed shear stress, $\tau_{b}$, the bed shear stress due to grain friction, $\tau^{\prime}$, and the bed shear stress due to form drag, $\tau^{\prime \prime}$, are caused by the same mean flow velocity, it is found that the resistance coefficient related to the bed, $c_{f, b}$, equals the summation of the resistance coefficient due to grain friction and the one due to form drag:

$$
c_{f, b}=c_{f}^{\prime}+c_{f}^{\prime \prime}
$$

in which $c_{f}^{\prime}$ denotes the grain friction coefficient and $c_{f}^{\prime \prime}$ the form drag coefficient.

The proposed semi-analytical form drag model describes the drag of the flow over bedforms by providing an expression for the form drag coefficient, $c_{f}^{\prime \prime}$. The energy slope, $S$, is partitioned into an energy slope due to grain friction, $S^{\prime}$, and 
an energy slope due to form drag, $S^{\prime \prime}$ (Meyer-Peter and Müller, 1948), which yields for the form drag coefficient

$$
c_{f}^{\prime \prime} \equiv \frac{\tau^{\prime \prime}}{\rho U^{2}}=\frac{g d S^{\prime \prime}}{U^{2}}=\frac{g d \Delta H^{\prime \prime}}{L U^{2}}
$$

in which $d$ denotes the mean water depth and $\Delta H^{\prime \prime}$ the energy loss due to form drag (compare with equations (3.3) and (3.4), and also see Appendix 3.A).

The basic model for form drag consists of two components, i.e., (1) an analytically-based expression for the form drag coefficient in a reference situation, $c_{f, \text { ref }}^{\prime \prime}$, and (2) an expression taking into account effects due to deviations from the reference situation, i.e., the total correction factor, $\gamma_{T}$ :

$$
c_{f}^{\prime \prime}=\gamma_{T} c_{f, \text { ref }}^{\prime \prime}
$$

In Section 3.3 we will describe the reference situation and will derive an expression for the reference form drag coefficient, $c_{f, \text { ref }}^{\prime \prime}$, which is based on the analytical expression for the energy loss due to a sudden expansion of a free surface flow using the one-dimensional momentum and energy conservation equations in the expansion region (also see Appendix D). In Section 3.4 we will elaborate on the total correction factor, $\gamma_{T}$.

\subsection{Reference Form Drag Model}

\subsubsection{Reference Situation}

Figure 3.1 shows the reference situation for the analytically-based reference form drag model: (a) the flow is steady; (b) the bed is horizontal; (c) the lee face angle of the bedform, $\theta$, equals $90^{\circ}$, i.e., downstream of the crest the flow expands abruptly; (d) the flow pattern over a bedform is not affected by upstream and downstream bedforms; (e) the bedform crest is horizontal and extends over such a reach that streamlines above the crest are parallel to the bed; (f) the height of the flow separation zone downstream of the bedform, $\delta_{f}$, is equal to the bedform height, $\delta ;(\mathrm{g})$ grain friction is absent in the expansion region. The latter is allowed as energy loss due to a change in cross-sectional area predominates over a short region (e.g. Fox and McDonald, 1994; Chaudhry, 2008). Please note that we do not neglect grain friction, $c_{f}^{\prime}$, as grain friction is accounted for using a grain friction model. A horizontal bed may be assumed, as the effect of the bed slope on the flow expansion downstream of the bedform is negligible (e.g. Henderson, 1966).

\subsubsection{One-Dimensional Momentum Conservation Equation Applied to Reference Situation}

We consider the flow expansion occurring downstream of the bedform crest to be the dominant process for predicting form drag. In order to derive an analytical expression for the energy loss due to sudden expansion of a free surface flow, we apply the one-dimensional momentum and energy conservation equations in the expansion region. 


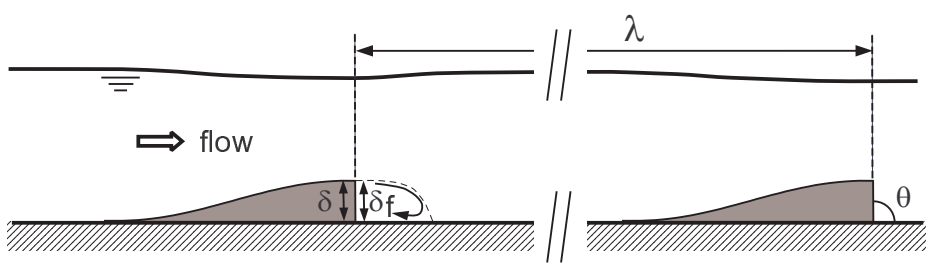

Figure 3.1: Reference situation for the reference form drag model.

We consider a free surface flow as sketched in the reference situation. Two cross-sections are defined (Figure 3.2); cross-section 1 is located immediately downstream of the bedform, and cross-section 2 is located at such a distance downstream of the flow separation zone that the flow is fully recovered from the expansion, which means that the streamlines are parallel to the bed. Energy is dissipated in the wake downstream of the bedform, i.e., between cross-sections 1 and 2. Here we apply the conservation equation for the component of the momentum in $x$-direction (e.g. Fox and McDonald, 1994):

$$
\begin{gathered}
\frac{\partial}{\partial t} \iiint_{V} \rho u d V+\iint_{A=\partial V} \rho u \vec{u} \cdot \vec{n} d A= \\
{\left[\iiint_{V} \rho \vec{f} d V\right] \cdot \vec{e}_{x}-\left[\iint_{A=\partial V}\left(p-p_{a}\right) \vec{n} d A\right] \cdot \vec{e}_{x}}
\end{gathered}
$$

in which $\vec{u}=[u v w]^{T}$ denotes the velocity vector and $u$ denotes the $x$-component of the velocity. $V$ and $A=\partial V$ denote the fixed control volume and its bounding surface, respectively, $\vec{n}$ denotes the outward pointing unit normal vector, $\vec{f}$ the external volume force, $\vec{e}_{x}$ the unit vector in $x$-direction, $p$ the pressure, $p_{a}$ the atmospheric pressure, and $t$ time. The first term on the left-hand side represents the change in momentum within the control volume per unit time and the second term on the left-hand side represents the net outgoing momentum flux at the boundary of the control volume. The terms on the right-hand side represent the acting forces. The first term represents the external volume forces or body forces acting on the control volume and the second term represents the pressure forces acting on the boundary of the control surface. The surface forces due to viscous stresses are left out here as we neglect grain friction in the control volume.

In the reference situation the external volume force, i.e., gravitation, equals zero in $x$-direction, since the channel is horizontal. Flow conditions are steady, so that the first term on the left-hand side of equation (3.9) equals zero. Equation (3.9) now reduces to

$$
\iint_{\partial V} \rho u \vec{u} \cdot \vec{n} d A=-\left[\iint_{\partial V}\left(p-p_{a}\right) \vec{n} d A\right] \cdot \vec{e}_{x}
$$

Pressure forces act at the inlet (cross-section 1) and outlet (cross-section 2). As streamlines are parallel at cross-sections 1 and 2 and the velocity in the flow 


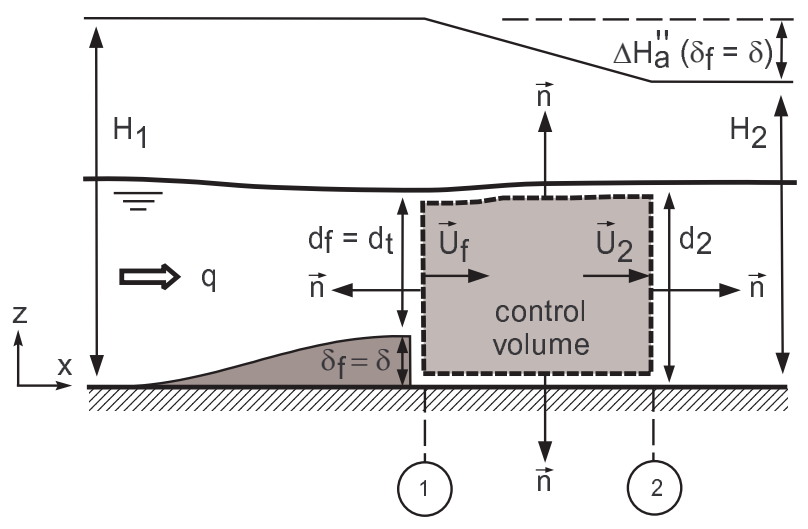

Figure 3.2: Definition sketch of free surface flow over the reference bedform.

separation zone is small, the pressure can be assumed to be hydrostatic both at cross-sections 1 and 2:

$$
\frac{d p}{d z}=-\rho g
$$

in which $z$ denotes the upward normal coordinate from the bed. By integrating and evaluating the constant of integration using the condition of atmospheric pressure at the water surface, it follows from equation (3.11) that

$$
p(x, z)=p_{a}+\rho g[d(x)-z]
$$

in which $d(x)$ denotes the local water depth. By integrating the right-hand side of equation (3.10) over the water depth and channel width, $W$, at cross-sections 1 and 2 , equation (3.10) now becomes

$$
\begin{aligned}
\iint_{\partial V} \rho u \vec{u} \cdot \vec{n} d A & =\frac{1}{2} \rho g W\left[d_{1}^{2}-d_{2}^{2}\right] \\
& =\frac{1}{2} \rho g W\left[\left(d_{f}+\delta_{f}\right)^{2}-d_{2}^{2}\right]
\end{aligned}
$$

in which the subscripts 1 and 2 refer to cross-sections 1 and 2, respectively. In equation (3.13) we apply that the water depth at cross-section $1, d_{1}$, is equal to the water depth at the location where the flow separates, $d_{f}$, plus the flow separation zone height, $\delta_{f}$. In the reference situation, the water depth at the location where the flow separates equals the water depth at the bedform crest, $d_{t}$ (Figure 3.2).

The left-hand side of equation (3.13) represents the momentum flux across the boundary of the control volume. As the streamlines are parallel to the bed at cross-sections 1 and 2 , the flow field is directed in $x$-direction only, so that $|\vec{u}|=u$. Elaborating the left-hand side term for both cross-sections 1 and 2 in 
equation (3.13) results in

$$
-\iint_{A_{1}} u_{1}^{2} \rho d A+\iint_{A_{2}} u_{2}^{2} \rho d A=\frac{1}{2} \rho g W\left[\left(d_{f}+\delta_{f}\right)^{2}-d_{2}^{2}\right]
$$

The momentum flux through cross-section 1 occurs over the distance $d_{f}$ (Figure 3.2). As such, for cross-section 1 we integrate over the domain from $z=\delta_{f}$ to $z=\delta_{f}+d_{f}$, so that equation (3.14) becomes

$$
\begin{gathered}
\rho\left[-\int_{0}^{W} d y \int_{\delta_{f}}^{d_{f}+\delta_{f}} u_{f}^{2} d z+\int_{0}^{W} d y \int_{0}^{d_{2}} u_{2}^{2} d z\right]= \\
\frac{1}{2} \rho g W\left[\left(d_{f}+\delta_{f}\right)^{2}-d_{2}^{2}\right]
\end{gathered}
$$

in which $u_{f}$ denotes the velocity in $x$-direction at the crest of the bedform.

We express the velocity in terms of the average velocity $U=\frac{1}{A} \iint_{A} u d A$, i.e., averaged over the cross-sectional area. As such, the momentum flux terms in equation (3.15) are expressed as

$$
\iint_{A} \rho u^{2} d A \equiv \beta \rho U^{2} A
$$

in which $\beta=\overline{u^{2}} / U^{2}$ denotes the momentum coefficient which corrects for the fact that $\overline{u^{2}}$ is not equal to $U^{2}$ if the velocity distribution is not uniform over the crosssection (e.g. Chow, 1959). For natural channels, $\beta$ has a value within the range 1.05-1.17 (Chow, 1959). Incorporation of equation (3.16) in equation (3.15) yields

$$
\rho W\left(-\beta_{1} U_{f}^{2} d_{f}+\beta_{2} U_{2}^{2} d_{2}\right)=\frac{1}{2} \rho g W\left[\left(d_{f}+\delta_{f}\right)^{2}-d_{2}^{2}\right]
$$

By dividing by the channel width, $W$, expressing the velocity in terms of the specific discharge, $q=U_{f} d_{f}=U_{2} d_{2}$, and rearranging, equation (3.17) now becomes (e.g. Chanson, 2004)

$$
\frac{1}{2} \rho g\left(d_{f}+\delta_{f}\right)^{2}+\beta_{1} \rho \frac{q^{2}}{d_{f}}=\frac{1}{2} \rho g d_{2}^{2}+\beta_{2} \rho \frac{q^{2}}{d_{2}}
$$

Equation (3.18), with $d_{f}=d_{t}$ and $\delta_{f}=\delta$, is the one-dimensional momentum conservation equation applied to the reference situation.

Also Yalin (1964a) and Engelund (1966) apply the momentum conservation equation in developing their form drag model, but assume a pipe flow rather than a free surface flow. As such, the pressure is assumed to be constant over a cross-section rather than hydrostatically distributed. The one-dimensional momentum conservation equation applied by Yalin (1964a) and Engelund (1966) then becomes

$$
p_{1}\left(d_{f}+\delta\right)+\beta_{1} \rho \frac{q^{2}}{d_{t}}=p_{2} d_{2}+\left.\beta_{2} \rho \frac{q^{2}}{d_{2}}\right|_{\mathrm{YE}}
$$

in which YE denotes that the equation was derived by Yalin (1964a) and Engelund (1966). 


\subsubsection{Reference Energy Loss}

Next, we derive an expression for the energy loss due to the sudden expansion in the reference situation (i.e., the reference energy loss). Energy loss due to the expansion results from energy dissipation between cross-sections 1 and 2, which can then be expressed as the difference in energy head between cross-sections 1 and $2\left(\Delta H_{a}^{\prime \prime}\right)$ :

$$
\Delta H_{a}^{\prime \prime}=H_{1}-H_{2}
$$

in which the subscript 'a' refers to the analytically derived energy loss due to expansion based on the one-dimensional energy conservation equation. We call $\Delta H_{a}^{\prime \prime}$ the analytical energy loss. $H$ denotes the energy head averaged over the cross-section. For a free surface flow with a hydrostatic pressure distribution and a horizontal bed, energy head is defined as (e.g. Henderson, 1966; Fox and McDonald, 1994)

$$
H=z_{b}+d+\alpha \frac{U^{2}}{2 g}
$$

in which $z_{b}$ denotes the bed elevation above datum. The first term on the right-hand side is known as the datum head, the second term as the pressure head, and the third term as the velocity head. Datum head plus pressure head are called the piezometric head. The piezometric head represents the potential energy, whereas the velocity head represents the kinetic energy (e.g. Chaudhry, 2008). The kinetic energy coefficient, $\alpha$, is introduced so that in equation (3.21) the section-averaged velocity can be applied. $\alpha=\overline{u^{3}} / U^{3}$ takes into account the effect on the velocity head of the nonuniformity of the velocity distribution. For natural channels, the kinetic energy coefficient is of the order of 1.15-1.50 (Chow, 1959). Combining equations (3.20) and (3.21) and expressing the velocity in terms of the specific discharge, equation (3.20) becomes

$$
\Delta H_{a}^{\prime \prime}=\delta_{f}+d_{f}-d_{2}+\frac{q^{2}}{2 g}\left(\frac{\alpha_{1}}{d_{f}^{2}}-\frac{\alpha_{2}}{d_{2}^{2}}\right)
$$

where we apply that the depth at cross-section $1, d_{1}$, equals $d_{1}=\delta_{f}+d_{f}$ and bed elevations at cross-sections 1 and 2 are equal $\left(z_{b, 1}=z_{b, 2}\right)$ since the bed is horizontal.

For simplicity, from now on we apply

$$
\alpha_{1}=1, \alpha_{2}=1, \beta_{1}=1, \beta_{2}=1
$$

We now suppose that the reference energy loss, $\Delta H_{\text {ref }}^{\prime \prime}$, i.e., the energy loss due to the expansion in a free surface flow in the reference situation, equals the measured energy loss due to expansion in a free surface flow in the reference situation, $\Delta H_{\text {meas }}^{\prime \prime}$. Laboratory experiments of an abrupt expansion in a free surface flow conducted by Bloemberg (2001) show that the analytical energy loss, $\Delta H_{a}^{\prime \prime}$, deviates from the measured energy loss due to expansion, $\Delta H_{\text {ref }}^{\prime \prime}$. Therefore, we introduce a calibration coefficient, $c_{1}$, which relates the reference energy loss, $\Delta H_{\text {ref }}^{\prime \prime}$, to the analytical energy loss, $\Delta H_{a}^{\prime \prime}$ :

$$
\Delta H_{\text {ref }}^{\prime \prime}=\Delta H_{\text {meas }}^{\prime \prime}=c_{1} \Delta H_{a}^{\prime \prime}
$$




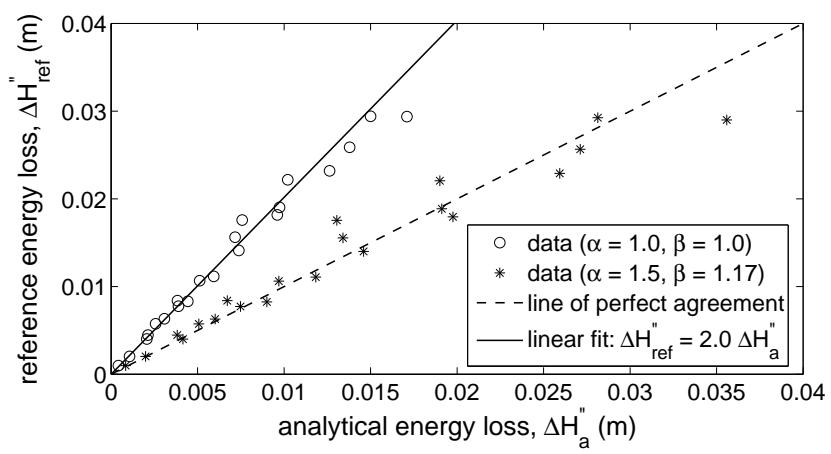

Figure 3.3: Reference energy loss, $\Delta H_{\text {ref }}^{\prime \prime}$, against analytical energy loss, $\Delta H_{a}^{\prime \prime}$. Data are from Bloemberg (2001).

The value of the calibration coefficient, $c_{1}$, is determined using laboratory experiments of flow over a single bedform with a lee face angle of $90^{\circ}$ performed by Bloemberg (2001). Figure 3.3 shows the energy loss due to expansion computed using the analytical one-dimensional approach $\left(\Delta H_{a}^{\prime \prime}\right)$ against the measured energy loss due to expansion $\left(\Delta H_{\text {ref }}^{\prime \prime}\right)$. The analytical energy loss is computed from the measured specific discharge, $q$, the measured water depth downstream of the influence zone of the bedform, $d_{2}$, and by applying equations (3.18), (3.22), and (3.23). We corrected the measured energy loss for sidewall effects and for grain friction (see Appendix 3.A). Figure 3.3 shows that $c_{1}$ is equal to 2.0. If we would have applied $\alpha_{1}=1.5, \alpha_{2}=1.5, \beta_{1}=1.17$, and $\beta_{2}=1.17$ (Chow, 1959) rather than equation (3.23), Figure 3.3 shows that the calibration coefficient is equal to about unity. From Figure 3.3 we conclude that the calibration coefficient accounts for the effect that the flow velocity distribution is not uniform over the cross-section at the cross-sections 1 and 2, i.e., the coefficient corrects for the fact that we apply the four equations provided by (3.23) (also see Section 3.6).

For a pipe flow expansion, as considered by Yalin (1964a) and Engelund (1966), the analytical energy loss due to expansion becomes (e.g. Henderson, 1966)

$$
\left.\Delta H_{a}^{\prime \prime}\right|_{\mathrm{YE}}=\frac{q^{2}}{2 g}\left(\frac{1}{d_{f}}-\frac{1}{d_{2}}\right)^{2}
$$

This equation is known as the Borda-Carnot equation (Borda, 1766). Also here $\alpha_{1}, \alpha_{2}, \beta_{1}$, and $\beta_{2}$ equal unity.

Yalin (1964a) and Engelund (1966) do not distinguish between the analytical energy loss and reference energy loss, so that

$$
\left.\Delta H_{\mathrm{ref}}^{\prime \prime}\right|_{\mathrm{YE}}=\left.\Delta H_{a}^{\prime \prime}\right|_{\mathrm{YE}}
$$

where $\left.\Delta H_{a}^{\prime \prime}\right|_{\mathrm{YE}}$ is given by equation (3.25). 


\subsubsection{Reference Form Drag}

We now rewrite the reference energy loss in terms of the reference form drag coefficient. We assume that the energy loss of a series of $N$ subsequent identical bedforms equals $N$ times the loss of a single bedform. This assumption is allowed, as in the reference situation we define the distance between two bedforms to be so large that the flow patterns over subsequent bedforms do not interact. The total energy loss of a series of $N$ reference bedforms, $\Delta H_{\mathrm{ref}, T}^{\prime \prime}$, becomes:

$$
\Delta H_{\mathrm{ref}, T}^{\prime \prime}=N \Delta H_{\mathrm{ref}}^{\prime \prime}
$$

in which $N$ denotes the number of bedforms. We refer to section 3.4.3 for the description of the method of including the effects of bedform interaction on form drag.

The energy slope due to form drag, $S^{\prime \prime}$, equals the total energy loss due to expansion over a series of bedforms divided by the length of the reach under consideration, $L$ :

$$
S^{\prime \prime}=\frac{\Delta H_{\mathrm{ref}, T}^{\prime \prime}}{L}
$$

For a series of bedforms, the length of the reach under consideration, $L$, is equal to the number of flow expansions times the distance between two flow expansions, i.e., the distance between two subsequent bedform crests, $\lambda(L=N \lambda)$, so that equations (3.28) and (3.27) result in

$$
S^{\prime \prime}=\frac{\Delta H_{\mathrm{ref}}^{\prime \prime}}{\lambda}
$$

By combining equations (3.7) and (3.29) we obtain the following formulation for the reference form drag coefficient:

$$
c_{f, \text { ref }}^{\prime \prime}=\frac{g d \Delta H_{\mathrm{ref}}^{\prime \prime}}{U^{2} \lambda}
$$

Then, by combining equations (3.22), (3.23), (3.24), and (3.30), and applying $q=U d$, we find the following expression for the reference form drag coefficient:

$$
c_{f, \text { ref }}^{\prime \prime}=\frac{c_{1} g d^{3}}{q^{2} \lambda}\left[\delta_{f}+d_{f}-d_{2}+\frac{q^{2}}{2 g}\left(\frac{1}{d_{f}^{2}}-\frac{1}{d_{2}^{2}}\right)\right]
$$

Equation (3.31) describes the form drag in the reference situation, i.e., a situation of abrupt expansion of a free surface flow. Grain friction and sidewall friction are accounted for separately (also see Appendix 3.A).

By combining equations (3.25), (3.26), and (3.30), and applying $q=U d$, the form drag model developed by Yalin (1964a) and Engelund (1966) becomes

$$
\left.c_{f, \text { ref }}^{\prime \prime}\right|_{\mathrm{YE}}=\frac{d^{3}}{2 \lambda}\left(\frac{1}{d_{f}}-\frac{1}{d_{2}}\right)^{2}
$$




\subsubsection{Mean Water Depth Equation}

The reference form drag model, equation (3.31), is a function of the water depth at the bedform crest, $d_{t}=d_{f}$, the water depth downstream of the influence zone of the bedform, $d_{2}$, and the mean water depth, $d$. The one-dimensional momentum conservation equation for the reference situation, equation (3.18), relates the water depths $d_{f}$ and $d_{2}$. In this section we provide an additional equation relating the mean water depth, $d$, to $d_{t}$ in order to be able to compute the reference form drag, $c_{f, \text { ref }}^{\prime \prime}$, in equation (3.31) as a function of the mean water depth.

By definition, the mean water depth, $d$, equals

$$
d=\frac{1}{L} \int_{L} d(x) d x
$$

For a bedform-dominated river reach we now assume that the following approximation of equation (3.33) provides a suitable relation for the mean water depth:

$$
d=d_{t}+\frac{1}{2} \delta
$$

Yalin (1964a) and Engelund (1966) also apply equation (3.34)

$$
\left.d\right|_{\mathrm{YE}}=d_{t}+\frac{1}{2} \delta
$$

and use the following additional relation:

$$
\left.d\right|_{\mathrm{YE}}=d_{2}-\frac{1}{2} \delta
$$

\subsubsection{Solution to Reference Form Drag}

We are able to determine the reference form drag, $c_{f, \text { ref }}^{\prime \prime}$, if the specific discharge, $q$, the bedform height, $\delta=\delta_{f}$, and one of the water depths $\left(d, d_{f}=d_{t}\right.$, or $d_{2}$ ) are known. First, the two unknown water depths are solved using equations (3.18), (3.23) and (3.34) (i.e., two equations and two unknowns). To this end, we rewrite this set of two equations into a cubic equation. Using Cardano (1545)'s classical solution (e.g. Korn and Korn, 1968), we solve this cubic equation (see Appendix 3.B). Finally, the reference form drag is determined from equation (3.31).

The form drag model developed by Yalin (1964a) and Engelund (1966) becomes, by combining equations (3.32), (3.35), and (3.36)

$$
\left.c_{f, \mathrm{ref}}^{\prime \prime}\right|_{\mathrm{YE}}=\frac{d^{3}}{2 \lambda}\left(\frac{\delta}{d^{2}-\frac{1}{4} \delta^{2}}\right)^{2}
$$

Finally, Yalin (1964a) and Engelund (1966) neglect the term $\frac{1}{4} \delta^{2}$ in equation (3.37) as they assume that $\frac{1}{4} \delta^{2} \ll d^{2}$, so that equation (3.37) reduces to

$$
\left.c_{f, \mathrm{ref}}^{\prime \prime}\right|_{\mathrm{YE}}=\frac{\delta^{2}}{2 \lambda d}
$$


Equation (3.38) is the form drag model as proposed by Yalin (1964a) and Engelund (1966). The model describes the form drag in a situation of abrupt expansion of a pipe flow, and is derived from the one-dimensional momentum and energy conservation equations for pipe flow expansion.

Karim (1999) applies the same assumptions as Yalin (1964a) and Engelund (1966) in deriving his form drag model, but applies the expression for the energy loss due to expansion of a free surface flow. As such, Karim (1999)'s derivation starts with the same form drag coefficient as we do (equations (3.31) and (3.23)):

$$
\left.c_{f, \mathrm{ref}}^{\prime \prime}\right|_{\mathrm{K}}=\frac{C_{1} g d^{3}}{q^{2} \lambda}\left[\delta+d_{f}-d_{2}+\frac{q^{2}}{2 g}\left(\frac{1}{d_{f}^{2}}-\frac{1}{d_{2}^{2}}\right)\right]
$$

in which $C_{1}$ denotes a dimensionless parameter equal to 0.85 , and $\mathrm{K}$ refers to Karim's model. It is assumed that the depth at the crest, $d_{t}=d_{f}$, is equal to the mean depth, $d$, minus half a bedform height, $\delta$, i.e., equation (3.35), and that the water depth downstream of the influence zone of the bedform, $d_{2}$, is equal to the mean depth plus half a bedform height, i.e., equation (3.36). Equation (3.39) now becomes

$$
\left.c_{f, \text { ref }}^{\prime \prime}\right|_{\mathrm{K}}=\frac{C_{1} g d^{3}}{q^{2} \lambda}\left[\frac{q^{2} \delta d}{g\left(d^{2}-\frac{1}{4} \delta^{2}\right)^{2}}\right]
$$

By neglecting the term $\frac{1}{4} \delta^{2}$ in equation (3.40), the following reference form drag model is obtained:

$$
\left.c_{f, \mathrm{ref}}^{\prime \prime}\right|_{\mathrm{K}}=C_{1} \frac{\delta}{\lambda}
$$

Please note that by applying both equations (3.35) and (3.36) to a free surface flow, the momentum conservation equation over the flow expansion region in a free surface flow (i.e., equation (3.18)) does not hold anymore.

\subsection{Correction Factors}

\subsubsection{Introduction}

As (fixed) bedforms in a laboratory flume and especially alluvial bedforms in the field deviate from the reference situation, we introduce a total correction factor, $\gamma_{T}$, which takes into account the effects on the form drag of deviations from the reference situation (see equation (3.8)). Alluvial bedforms are different from the reference situation with respect to the fact that

(a) the flow expansion is gradual rather than abrupt,

(b) the flow pattern over a bedform is affected by upstream and downstream bedforms,

(c) the flow separation zone height may deviate from the bedform height, and

(d) bedform geometry is variable rather than regular. 
We now assume that the total correction factor, $\gamma_{T}$, is the following function of four independent correction factors each representing one of the abovementioned four effects on the form drag:

$$
\gamma_{T}=\gamma_{s} \gamma_{i} \gamma_{f} \gamma_{v}
$$

where $\gamma_{s}, \gamma_{i}, \gamma_{f}$, and $\gamma_{v}$ denote the correction factors for the four abovementioned respective effects. If an effect does not affect the form drag, its correction factor equals 1 . Please note that we assume that the four effects do not interact with each other.

With equation (3.42), the new semi-analytical form drag model in equation (3.8) becomes

$$
c_{f}^{\prime \prime}=\gamma_{s} \gamma_{i} \gamma_{f} \gamma_{v} c_{f, \text { ref }}^{\prime \prime}
$$

In this chapter we derive formulations for the effect on form drag of a gradual flow expansion $\left(\gamma_{s}\right)$, of bedform interaction $\left(\gamma_{i}\right)$, and of the flow separation zone height deviating from the bedform height $\left(\gamma_{f}\right)$. In Chapter 4 we study the effect of variability in bedform geometry on form drag $\left(\gamma_{v}\right)$.

Yalin (1964a) and Engelund (1966) do not incorporate the above-mentioned effects in their form drag model, so that

$$
\left.c_{f}^{\prime \prime}\right|_{\mathrm{YE}}=\left.c_{f, \mathrm{ref}}^{\prime \prime}\right|_{\mathrm{YE}}
$$

Comparing equation (3.38) to the measured form drag for laboratory data of Guy et al. (1966), Engelund (1977) introduces the calibration coefficient, $c_{E}$, into equation (3.38):

$$
\left.c_{f}^{\prime \prime}\right|_{\mathrm{E}}=c_{E} \frac{\delta^{2}}{2 \lambda d}
$$

in which

$$
c_{E}=2.5 \exp \left(\frac{-2.5 \delta}{d}\right)
$$

and subscript $E$ refers to the form drag model of Engelund (1977). Please note that the calibration coefficient, $c_{E}$, represents a combination of effects on the form drag due to: (a) simplifications leading to the model proposed by Yalin (1964a) and Engelund (1966), i.e., equation (3.38), for instance the assumption of pipe flow rather than a free surface flow, (b) the difference between the measured energy loss and the analytical energy loss (compare equations (3.24) and (3.26)), and (c) the four effects represented by equations (3.8) and (3.42).

Karim (1999) introduces the loss coefficient, $K_{1}$, which is a function of the dimensionless bedform height and length. The form drag model proposed by Karim (1999) becomes

$$
\left.c_{f}^{\prime \prime}\right|_{\mathrm{K}}=\left.K_{1} c_{f, \mathrm{ref}}^{\prime \prime}\right|_{\mathrm{K}}
$$

in which $K_{1}=0.55\left(\frac{\delta}{d}\right)^{0.375}\left(\frac{\lambda}{d}\right)^{-0.2}$ for the dune, ripple, and transitional (washed out dune) regime. 


\subsubsection{Lee Face Steepness}

The reference form drag describes the form drag due to an abrupt expansion of the free surface flow downstream of the bedform crest. In other words, the angle of the lee face is $90^{\circ}$ in the reference situation. As such, the correction factor for lee face steepness, $\gamma_{s}$, by definition equals 1 if the lee face angle is $90^{\circ}$. Alluvial bedforms in a laboratory flume or the field typically have lee face angles in the order of $5^{\circ}$ to $30^{\circ}$ (e.g. Best and Kostaschuk, 2002). We expect that the smaller the lee face angle, the smaller is the amount of energy that is dissipated (e.g. Gibson, 1912; Henderson, 1966).

We analyze the correction factor for lee face steepness, $\gamma_{s}$, by performing numerical simulations in which we vary the angle of the lee face. These numerical simulations have been performed using the commercial computational fluid dynamics (CFD) software package Ansys CFX (release 11.0). The set of equations solved by Ansys CFX are the Navier-Stokes equations for three-dimensional unsteady flow. The equations that are solved are the Reynolds-averaged equations using an element-based finite-volume method (Ansys CFX, 2006). Ansys CFX offers various turbulence models.

In Appendix 3.C we validate models set up in Ansys CFX of free surface flow over a series of bedforms by comparison of predicted results with measured data. The agreement between simulations and experiments is good.

In the numerical simulations there is a single bedform in the computational domain having a horizontal crest and a varying lee face angle (Figure 3.4). The bedform height, $\delta$, in all simulations is $0.04 \mathrm{~m}$, and the length of the bedform stoss face, $\lambda_{s}$, is $1 \mathrm{~m}$. The length of the computational domain equals $5 \mathrm{~m}$, and the height $0.7 \mathrm{~m}$. We apply an unstructured hexahedral mesh with grid cell size of $2 \mathrm{~mm}$. At the upstream inflow boundary we impose a logarithmic velocity distribution. At the downstream boundary we impose the water depth, $d_{2}$. The bed is defined as a rough wall having a Nikuradse roughness height of $0.5 \mathrm{~mm}$. We perform free surface simulations using the homogeneous multiphase model,

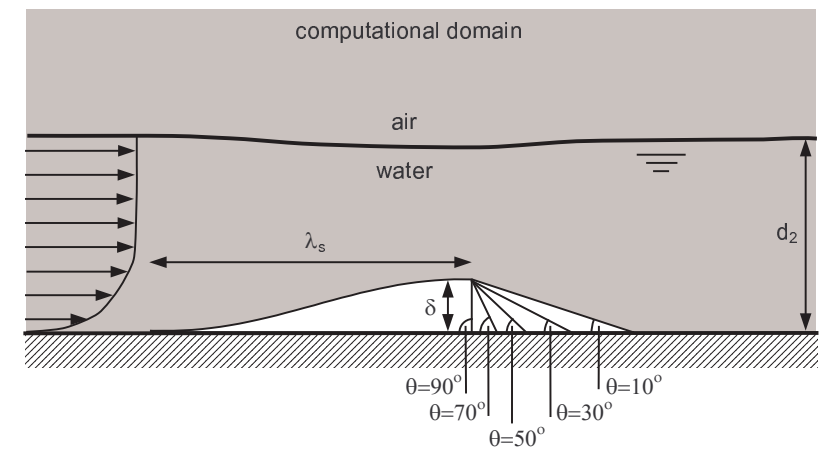

Figure 3.4: Set-up of the numerical simulations for deriving an expression for the correction factor for lee face steepness, $\gamma_{s}$. 


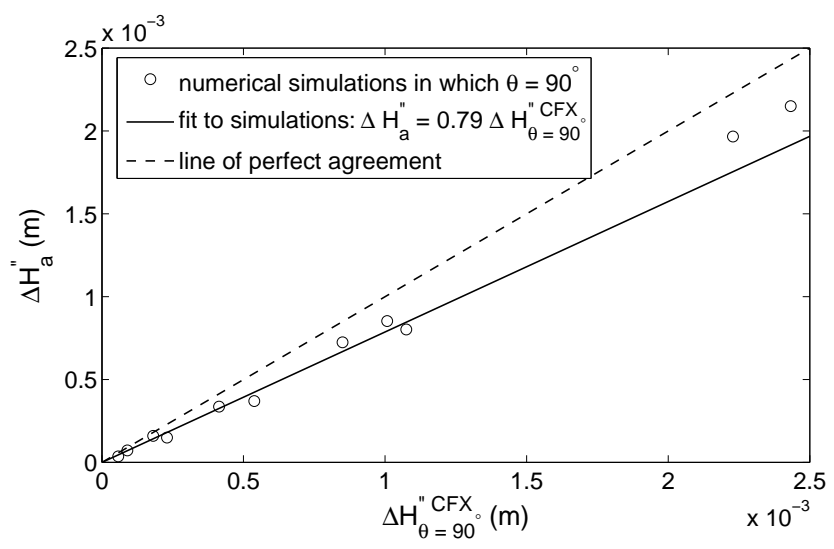

Figure 3.5: Analytical energy loss, $\Delta H_{a}^{\prime \prime}$, against simulated energy loss with lee face angle equal to $90^{\circ}, \Delta H_{\theta=90^{\circ}}^{\prime \prime}$.

which is an option within Ansys CFX to simulate both water and air. The $k-\epsilon$ turbulence model is applied in all simulations, as this model yields good results for our case (Appendix 3.C).

We perform simulations in which $\theta=10^{\circ}, \theta=30^{\circ}, \theta=50^{\circ}, \theta=70^{\circ}$, and $\theta=90^{\circ}$ (Figure 3.4). Besides the lee face angle, we vary the ratio of bedform height to water depth downstream of the influence zone of the bedform $\left(\delta / d_{2}=\right.$ $\left.0.13, \delta / d_{2}=0.22, \delta / d_{2}=0.33\right)$, and the Froude number at the downstream boundary $\left(F r_{2}=0.1, F r_{2}=0.2, F r_{2}=0.3, F r_{2}=0.4\right)$. In total, we perform 55 simulations. Simulations in which the flow is critical at the crest are excluded from the analysis, as application of the present form drag model is limited to subcritical flows. This limitation to subcritical flow is applied, as flow expansion may not be the relevant mechanism for form drag in the situation of supercritical flow (also see Chapter 5).

All correction factors except the one for lee face steepness, $\gamma_{s}$, are equal to 1 in the simulations: $\gamma_{i}=\gamma_{f}=\gamma_{v}=1$. The form drag coefficient in equation (3.43) now reduces to

$$
c_{f}^{\prime \prime}=\gamma_{s} c_{f, \text { ref }}^{\prime \prime}
$$

Expressing the correction factor for lee face steepness in terms of the energy loss, equation (3.48) with equations (3.7), (3.24) and (3.30) becomes

$$
\gamma_{s}=\frac{c_{f}^{\prime \prime}}{c_{f, \text { ref }}^{\prime \prime}}=\frac{\Delta H^{\prime \prime}}{\Delta H_{\text {ref }}^{\prime \prime}}=\frac{\Delta H^{\prime \prime}}{c_{1} \Delta H_{a}^{\prime \prime}}
$$

Figure 3.5 shows the analytical energy loss due to an abrupt expansion, $\Delta H_{a}^{\prime \prime}$, against the predicted energy loss due to an abrupt expansion in the numerical simulations in which the lee face angle equals $90^{\circ}$. We introduce a calibration coefficient, $c_{2}$, which relates the numerically derived energy loss to the analytical energy loss:

$$
\Delta H_{a}^{\prime \prime}=c_{2} \Delta H_{\theta=90^{\circ}}^{\prime \prime C \mathrm{CFX}}
$$




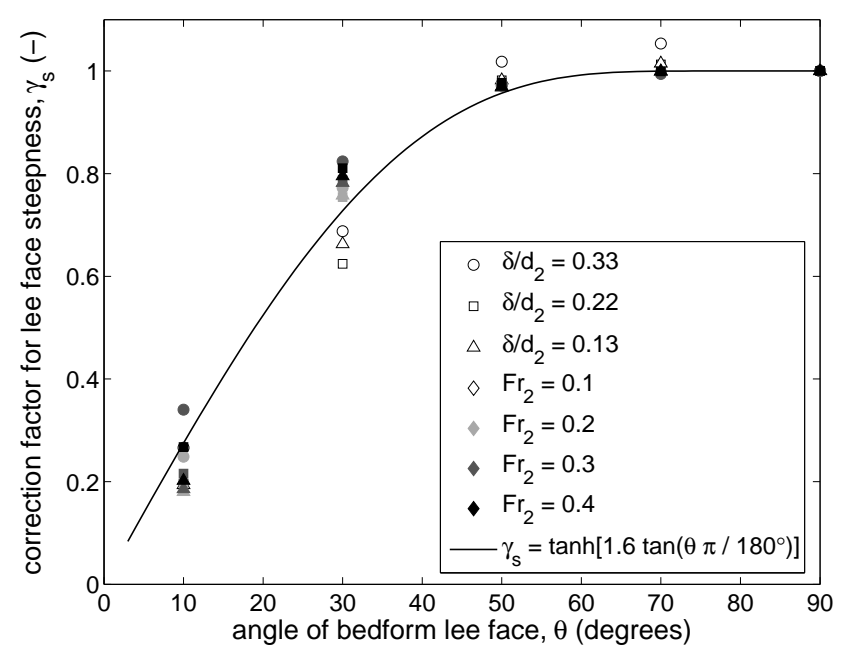

Figure 3.6: Correction factor for lee face steepness, $\gamma_{s}$, against lee face angle, $\theta$, obtained from the numerical simulations. The different symbols indicate the ratio of bedform height to water depth downstream of the influence zone of the bedform, $\delta / d_{2}$. The greyscale of the symbols indicates the Froude number downstream of the influence zone of the bedform, $\mathrm{Fr}_{2}$.

where $c_{2}=0.79$ (Figure 3.5) and the superscript CFX indicates that this energy loss is computed numerically. Using equation (3.50), equation (3.49) now becomes

$$
\gamma_{s}=\frac{\Delta H^{\prime \prime}}{\Delta H_{\mathrm{ref}}^{\prime \prime}}=\frac{\Delta H^{\prime \prime}}{c_{1} c_{2} \Delta H_{\theta=90^{\circ}}^{\prime \prime C F X}}
$$

The reference energy loss and the numerically derived energy loss are related through the coefficients $c_{1}$ and $c_{2}$. We now assume that the energy loss due to gradual expansion, $\Delta H^{\prime \prime}$ in equation (3.51), and the numerically derived energy loss due to gradual expansion, $\Delta H^{\prime \prime} \mathrm{CFX}$, are equally related through the coefficients $c_{1}$ and $c_{2}$. As such, equation (3.51) becomes

$$
\gamma_{s}=\frac{c_{1} c_{2} \Delta H^{\prime \prime} \mathrm{CFX}}{c_{1} c_{2} \Delta H_{\theta=90^{\circ}}^{\prime \prime C F X}}=\frac{\Delta H^{\prime \prime C F X}}{\Delta H_{\theta=90^{\circ}}^{\prime \prime C F X}}
$$

The numerical simulations now enable us to analyze the correction factor for lee face steepness using equation (3.52).

Figure 3.6 shows the correction factor for lee face steepness, $\gamma_{s}$, against the lee face angle, $\theta$, for all simulations. For lee face angles smaller than about $50^{\circ}$ the correction factor decreases for decreasing lee face angle, which indicates that the form drag decreases compared to the reference situation. The number of data points is small, so we are only able to give the following first approximation for the expression of the correction factor for lee face steepness (Figure 3.6):

$$
\gamma_{s}=\tanh \left[1.6 \tan \left(\frac{\theta \pi}{180^{\circ}}\right)\right]
$$




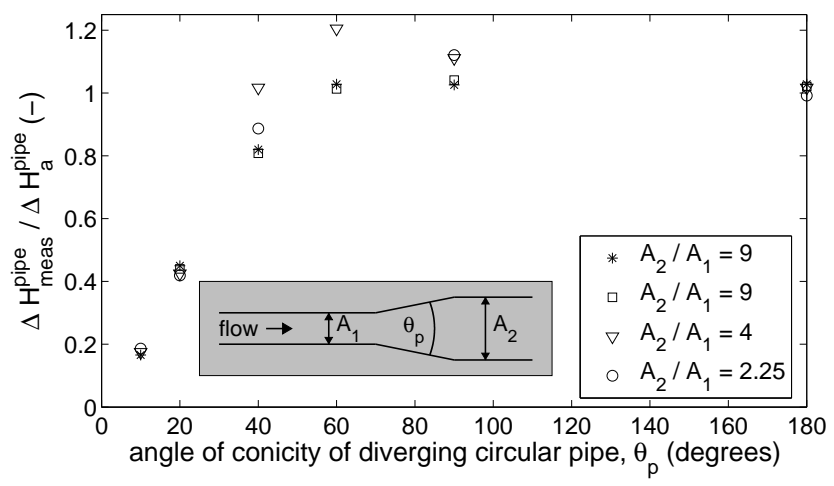

Figure 3.7: Measured energy loss for pipe flow expansion, $\Delta H_{\text {meas }}^{\text {pipe }}$, divided by analytical energy loss for a pipe flow expansion, $\Delta H_{a}^{\text {pipe }}=\left(U_{1}-U_{2}\right)^{2} / 2 g$, against the angle of conicity of a diverging circular pipe, $\theta_{p}$. A denotes the cross-sectional area of the pipe. Data are from Gibson $(1911,1912)$.

where the lee face angle, $\theta$, is in degrees.

The correction factor for lee face steepness increases with increasing lee face angle and is even somewhat larger than unity for lee face angles larger than about $50^{\circ}$. The experiments of Gibson $(1911,1912)$ support the results of our numerical simulations, as for flow expansion in pipe flows the same behavior is observed (see Figure 3.7).

\subsubsection{Bedform Interaction}

In the reference situation (Section 3.3.1), the flow pattern over a bedform is not affected by upstream and downstream bedforms, and so the effect of bedform interaction on form drag is not incorporated. This means that individual losses of bedforms are simply added to obtain the total energy loss of bedforms (see equation (3.27)). We need to incorporate the effect of bedform interaction on form drag, as numerical simulations of Schatz and Herrmann (2006) have shown that the effect of bedform interaction on form drag is significant. The correction factor for bedform interaction, $\gamma_{i}$, equals 1 if there is no bedform interaction, and is expected to be smaller than 1 in cases where bedform interaction becomes relevant.

Schatz and Herrmann (2006) show that a bedform that is part of a series of bedforms behaves differently from a solitary bedform with respect to flow separation and thus energy loss. They perform simulations of airflow over both solitary bedforms and a series of nine bedforms using the CFD software package Fluent. The simulation of flow over a series of nine bedforms shows that the length of the flow separation zone on the lee side of the bedforms decreases and converges towards the downwind end of the computational domain. The separation zone length of the most upstream bedform in the series appeared to be comparable to the one of a solitary bedform under the same flow conditions. Schatz and Herrmann (2006) conclude that the separation zone length of a 


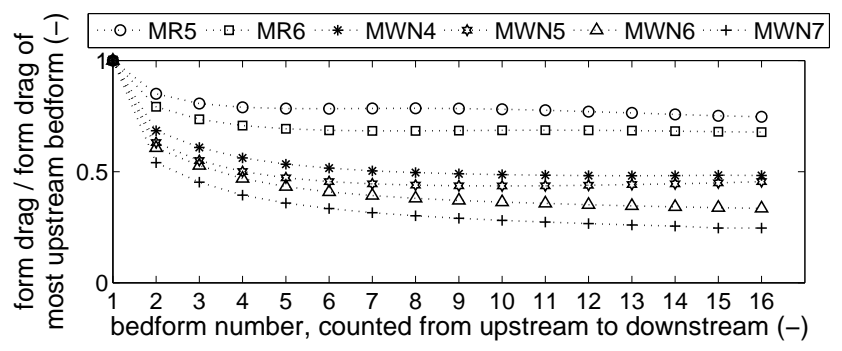

Figure 3.8: Form drag divided by form drag of the most upstream bedform for a series of 16 bedforms. The form drag results from numerical simulations, in which the imposed boundary conditions are equal to the ones in laboratory experiments. MR denotes an experiment of Van Mierlo and De Ruiter (1988), MWN denotes an experiment of McLean et al. (1999).

bedform in a series is about $25 \%$ smaller than the separation zone length of a solitary bedform. A bedform as part of a series of bedforms causes less form drag than a solitary bedform, as a bedform being in the lee of an upstream bedform is exposed to lower velocities than a solitary bedform.

We develop an expression for the correction factor for bedform interaction, $\gamma_{i}$, using numerical simulations of water flow. The software package Ansys CFX allows us to determine form drag of individual bedforms in a series of bedforms by integrating the bed pressure over the length of the bedform:

$$
F^{\prime \prime}=\int_{0}^{\lambda} p \frac{d \eta}{d x} d x
$$

in which $F^{\prime \prime}$ denotes form drag and $\eta$ the bed elevation.

First, we simulate flow over uniform bedforms in the flume experiments of Van Mierlo and De Ruiter (1988) and McLean et al. (1999) (also see Appendix 3.C). The flow conditions and bedforms imposed in the numerical simulations are equal to the ones imposed in the laboratory experiments. Figure 3.8 shows the form drag for a series of 16 bedforms divided by the form drag experienced by the most upstream bedform. We find that form drag decreases and converges towards the form drag of the downstream bedforms, like Schatz and Herrmann (2006) find for the separation zone length in case of airflow.

Next, we perform simulations of both solitary bedforms and series of bedforms in which the bedform geometry and flow conditions are equal. We find that, under the same flow conditions, form drag of a solitary bedform is equal to the form drag of the most upstream bedform in a series of bedforms. We consider the form drag of the most downstream bedform in the series to be the form drag of a bedform experiencing bedform interaction. As such, the correction factor for bedform interaction, $\gamma_{i}$, equals the form drag of the most downstream bedform divided by the form drag of the most upstream bedform. 


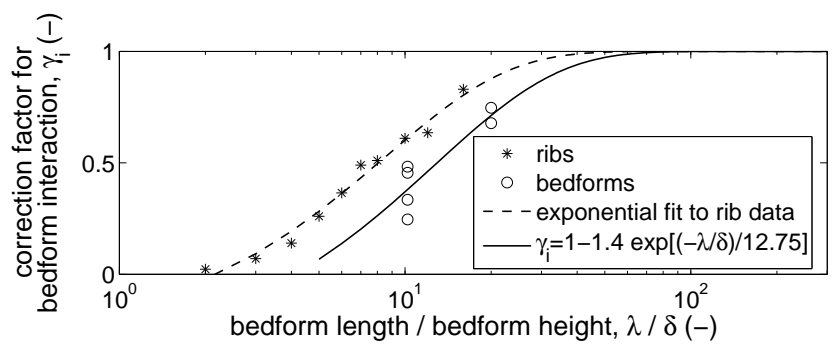

Figure 3.9: Correction factor for bedform interaction, $\gamma_{i}$, against the ratio of bedform length to bedform height, $\lambda / \delta$. The data on ribs are from laboratory experiments of Coleman et al. (2005). The bedform data are numerical simulations.

For the numerical simulations, equation (3.43) reduces to

$$
\gamma_{i}=\frac{c_{f}^{\prime \prime}}{\gamma_{s} c_{f, \text { ref }}^{\prime \prime}}
$$

as $\gamma_{f}=1$ and $\gamma_{v}=1$ in all simulations. In equation (3.55) $c_{f}^{\prime \prime}=\left.c_{f}^{\prime \prime}\right|_{\text {int }, \theta}$ denotes the form drag of a bedform in a series with a lee face angle, $\theta$, and the subscript 'int' denotes 'interaction'. We combine equations (3.52) and (3.55), as well as the equations $\Delta H_{\text {ref }}^{\prime \prime}=c_{1} c_{2} \Delta H_{\theta=90^{\circ}}^{\prime \prime}$ (see equation (3.51)) and $\Delta H^{\prime \prime} / \Delta H_{\text {ref }}^{\prime \prime}=c_{f}^{\prime \prime} / c_{f, \text { ref }}^{\prime \prime}$ (see equation (3.49)), and apply the same assumption as used for the correction factor for lee face steepness, i.e., $\Delta H^{\prime \prime}=c_{1} c_{2} \Delta H^{\prime \prime}$ CFX , so that we obtain

$$
\gamma_{i}=\frac{c_{f, \text { int }, \theta}^{\prime \prime}}{\gamma_{s} c_{f, \text { ref }}^{\prime \prime}}=\frac{c_{f, \text { int }, \theta}^{\prime \prime} \mathrm{CFX}}{c_{f, \text { sol }, \theta}^{\prime \prime} \operatorname{CFX}}=\frac{c_{f}^{\prime \prime} \mathrm{CFX} \mid}{c_{f}^{\text {th }} \text { bedform }}
$$

in which 'sol' denotes 'solitary bedform' or 'no interaction'.

Figure 3.9 shows the correction factor plotted against the ratio of bedform length, $\lambda$, to bedform height, $\delta$, both for the square ribs in experiments of Coleman et al. (2005) and for the numerical simulations of the series of bedforms. The correction factor for bedform interaction, $\gamma_{i}$, appears to be a function of the ratio of bedform length to bedform height, like the laboratory data on square ribs by Coleman et al. (2005). We suggest to describe the correction factor for bedform interaction as an exponential function having asymptote 1, as the ribs of Coleman et al. (2005) support an exponential behavior. Based on the numerical simulations, we suggest the following expression for the correction factor for bedform interaction:

$$
\gamma_{i}=1-1.4 \exp \left[\frac{-\lambda / \delta}{12.75}\right]
$$

We suppose that the shift between the results for the ribs and those for the bedforms in Figure 3.9 is due to the large difference in shape between ribs and bedforms and its effect on the resulting flow pattern. 


\subsubsection{Flow Separation Zone Height}

The size of the flow separation zone affects the energy loss and so the form drag (e.g. Best, 2005). The correction factor for flow separation zone height, $\gamma_{f}$, accounts for the effect on form drag in the case that the height of the flow separation zone deviates from the one in the reference situation, i.e., the bedform height (see Section 3.3.1).

Realistic bedforms in the field may have a brink point, defined as the location where the flow separates, and which is located downstream of and lower than the highest point of a bedform, i.e., the bedform crest (e.g. Wilbers, 2004). According to this definition, a brink point does not always have to be present, and, if present, is located between a crest and the downstream trough. Most bedforms in the study reach in the Paraná River, Argentina, have a brink point downstream of and lower than the bedform crest (Parsons et al., 2005). The height of the flow separation zone (FSZ height) is smaller than the bedform height if a brink point is present. As such, form drag is affected by the presence and height of the brink point (e.g. Wilbers, 2004).

For uniform triangular-shaped laboratory bedforms, the FSZ height is larger than the bedform height (e.g. Parsons et al., 2004; Schatz and Herrmann, 2006; Dong et al., 2007). The numerical simulations of flow over triangular-shaped bedforms by Parsons et al. (2004) show that the flow separation zone becomes larger for larger stoss face angles as the stream lines at the stoss have a larger upward vertical component. Numerical simulations by Schatz and Herrmann (2006) indicate that the ratio of FSZ height to bedform height may be as large as 1.2. Wind tunnel experiments by Dong et al. (2007) in which the stoss face angle is varied illustrate that the ratio of FSZ height to bedform height increases for increasing stoss angle until a maximum of 1.5 for a stoss face angle of $15^{\circ}$.

In order to derive an expression for the correction factor for FSZ height, we perform analytical computations in which effects of lee face steepness, bedform interaction and variability in bedform geometry are absent $\left(\gamma_{i}=1, \gamma_{s}=1\right.$, $\gamma_{v}=1$ ), so that the form drag coefficient in equation (3.43) reduces to

$$
c_{f}^{\prime \prime}=\gamma_{f} c_{f, \text { ref }}^{\prime \prime}
$$

In the analytical computations we determine the analytical energy loss due to expansion for a situation in which the FSZ height, $\delta_{f}$, deviates from the bedform height. Expressing the form drag in terms of the analytical energy loss using equations (3.24) and (3.30), equation (3.58) becomes

$$
\gamma_{f}=\frac{c_{f}^{\prime \prime}}{c_{f, \text { ref }}^{\prime \prime}}=\frac{\Delta H_{a}^{\prime \prime}\left(\delta_{f}\right)}{\Delta H_{a}^{\prime \prime}\left(\delta_{f}=\delta\right)}
$$

For a given Froude number, $\mathrm{Fr}$, and ratio of bedform height to mean water depth, $\delta / d$, the analytical energy loss for the situation that the FSZ height equals the bedform height, $\Delta H_{a}^{\prime \prime}\left(\delta_{f}=\delta\right)$, is computed using equations (3.18), (3.22), (3.34), (3.23), and $d_{f}=d_{t}$.

We determine the analytical energy loss due to expansion for the situation that the FSZ height is not equal to the bedform height (Figure 3.10) by assuming 


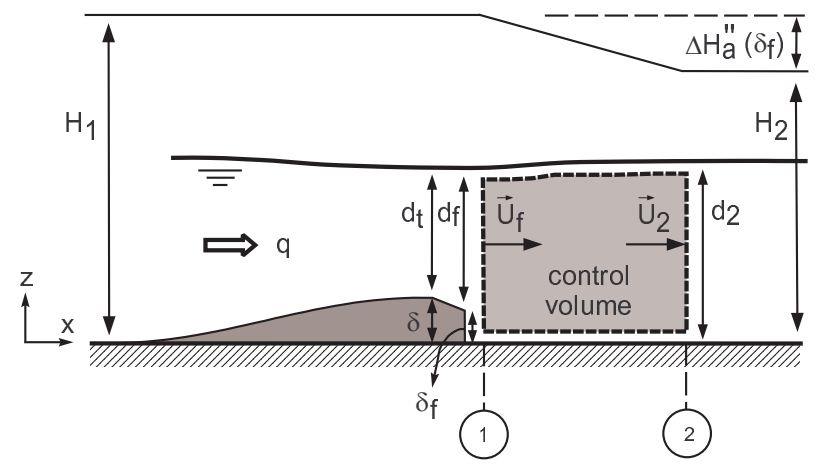

Figure 3.10: Definition sketch of free surface flow over a bedform having a brink point height at which the flow separates.

that (1) energy loss due to expansion results from energy dissipation between cross-sections 1 and 2 only, just as we did for the reference energy loss, and that (2) energy is conserved between the bedform crest and the location where the flow separates, i.e., the energy head at the bedform crest, $H_{t}$, equals the energy head at cross-section $1, H_{1}$, or

$$
\delta+d_{t}+\frac{q^{2}}{2 g d_{t}^{2}}=\delta_{f}+d_{f}+\frac{q^{2}}{2 g d_{f}^{2}}
$$

For given Froude number, $\mathrm{Fr}$, and ratio of bedform height to mean water depth, $\delta / d$, the analytical energy loss for the situation that the FSZ height may deviate from the bedform height, $\Delta H_{a}^{\prime \prime}\left(\delta_{f}\right)$ in equation (3.59), is now computed using equations (3.18), (3.22), (3.34), (3.23), and equation (3.60).

In the analytical computations, we vary the ratio of FSZ height to bedform height, the Froude number, and the ratio of bedform height to mean water depth. We determine the correction factor using equation (3.59). Figure 3.11 shows for a selection of results of analytical computations the correction factor for FSZ height, $\gamma_{f}$, plotted against the ratio of FSZ height to bedform height, $\delta_{f} / \delta$. The ratio of bedform height to mean water depth and the Froude number appear not to significantly affect the correction factor for FSZ height. Based on the results of the analytical computations, we propose the following expression for the correction factor for FSZ height (Figure 3.11):

$$
\gamma_{f}=0.2\left(\frac{\delta_{f}}{\delta}\right)^{2}\left[4+\left(\frac{\delta_{f}}{\delta}\right)^{2}\right]
$$

According to Wilbers (2004), the ratio of brink point height, $\delta_{b}=\delta_{f}$, to bedform height, $\delta$, is about 0.8 for alluvial bedforms. In that case, the correction factor for FSZ height, $\gamma_{f}$, equals 0.6.

Laboratory experiments of flow over a series of uniform bedforms by Kornman (1995), in which the brink point height is varied, confirm that a smaller 


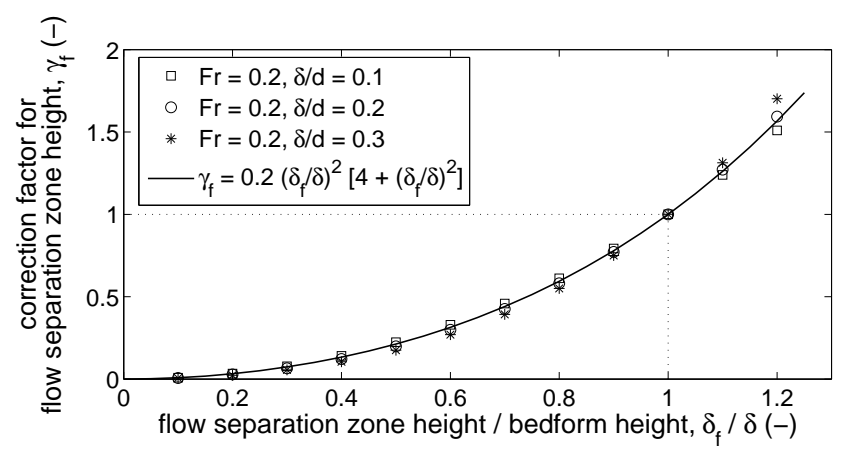

Figure 3.11: Correction factor for flow separation zone (FSZ) height, $\gamma_{f}$, against the ratio of FSZ height to bedform height. $\delta_{f} / \delta$.

ratio of brink point height to bedform height yields a smaller form drag. A quantitative comparison between these experiments and our expression for the correction factor for FSZ height is not performed, as the flow in the Kornman (1995) experiments was not uniform over the length of the flume.

\subsection{Validation of Form Drag Model}

In this chapter we consider flume data of flow over uniform fixed bedforms to analyze the performance of the new semi-analytical form drag model. Flume size, flow conditions, and bedform shape differ between the experiments. Aalberts (2007) studies flow over sawtooth-shaped concrete bedforms. Shen et al. (1990) analyze flow over triangular bedforms made of plastic, aluminium, or plastered with sand. Venditti and Bennett (2000) analyze flow over triangular bedforms made of steel. Van Mierlo and De Ruiter (1988), McLean et al. (1999), and Coleman et al. (2007) consider dune-shaped bedforms with a cosine-shaped stoss face. Ogink (1989) studies flow over rounded triangular-shaped bedforms plastered with sand. In total, we consider 157 laboratory experiments. The data on flume width, bedform geometry, flow conditions and energy slope as presented in the references enable us to determine the measured bed resistance, $c_{f, b}^{\text {meas }}$ (see Appendix 3.A). We apply the procedure of Vanoni and Brooks (1957) to correct for sidewall friction (Appendix 3.A).

We compare predicted to measured bed resistance instead of form drag as (a) the "measured" bed resistance is closer to the measured total resistance (only sidewall friction is corrected for) than the "measured" form drag (sidewall friction and grain friction need to be corrected for), and (b) empirical coefficients in the form drag models of Engelund (1977) and Karim (1999) depend on the applied grain friction model.

We obtain the predicted bed resistance, $c_{f, b}^{\text {model }}$, by summation of the predicted form drag coefficient, $c_{f}^{\prime \prime}$, and predicted grain friction coefficient, $c_{f}^{\prime}$. Form drag and grain friction are predicted using the measured flow conditions (mean 
water depth and specific discharge), measured bedform geometry, and grain diameter. We apply the following form drag and grain friction models:

a. the Yalin (1964a) - Engelund (1966) form drag model (equations (3.38) and (3.44)) and the grain friction model of Yalin (1964a),

b. the Yalin (1964a) - Engelund (1966) form drag model (equations (3.38) and (3.44)) and the grain friction model of Engelund (1966),

c. the form drag model of Engelund (1977) (equations (3.45) and (3.46)) and the grain friction model of Engelund (1966),

d. the form drag model of Karim (1999) (equations (3.41) and (3.47)) and the grain friction model of Karim (1999),

e. the present analytical form drag model (equations (3.8), (3.18), (3.23), (3.31), and (3.34) with $\gamma_{T}=1$ and $c_{1}=1$ ) and the grain friction model of Engelund (1966),

f. the present semi-analytical form drag model (equations (3.8), (3.18), (3.23), (3.31), (3.34), (3.42), and $\left.c_{1}=2.0\right)$ and the grain friction model of Engelund (1966). We apply equations (3.53), (3.57), and (3.61) to determine $\gamma_{s}, \gamma_{i}$, and $\gamma_{f}$, respectively. Note that $\gamma_{v}=1$ in all considered experiments, as the bedform geometry is regular. For the triangular bedforms we apply a ratio of flow separation zone height to bedform height of 1.2 (Schatz and Herrmann, 2006) (Section 3.4.4).

In this chapter we only consider (semi-)analytical form drag models. As purely empirical models are usually calibrated using alluvial data, we apply the empirical models in Chapter 4.

Figure 3.12 shows the predicted bed resistance coefficient against the measured one for the 157 laboratory experiments. For each model we determine the mean relative error as follows:

$$
E=\left[\sqrt{\frac{1}{n} \sum_{i=1}^{n}\left(\frac{c_{f, b}^{\text {model }}-c_{f, b}^{\text {meas }}}{c_{f, b}^{\text {meas }}}\right)^{2}}\right] \times 100 \%
$$

in which 'model' refers to the predicted bed resistance and 'meas' to the measured bed resistance. Table 3.1 presents the mean relative error for each of the six models under consideration. Table 3.1 illustrates that assuming a free surface flow expansion (model e in Table 3.1) does not yield an improvement compared to the model in which a pipe flow expansion is assumed (model b).

The introduction of the calibration coefficient proposed by Engelund (1977) does not yield an improvement of the model results compared to the Engelund (1966) model (compare models b and c in Table 3.1). The Engelund (1977) calibration coefficient is calibrated on the alluvial bedform data set of Guy et al. (1966), and, appears not to perform well for uniform fixed bedforms. 
Table 3.1: Mean relative error, $E$, following from equation (3.62) for each bed resistance model under consideration.

\begin{tabular}{llc}
\hline \multicolumn{2}{c}{ Model } & $E(\%)$ \\
\hline a. & Yalin (1964a) model & 26 \\
b. & Engelund (1966) model & 21 \\
c. & Engelund (1977) model & 38 \\
d. & Karim (1999) model & 97 \\
e. & present analytical model & 22 \\
f. & present semi-analytical model & 17 \\
\hline
\end{tabular}
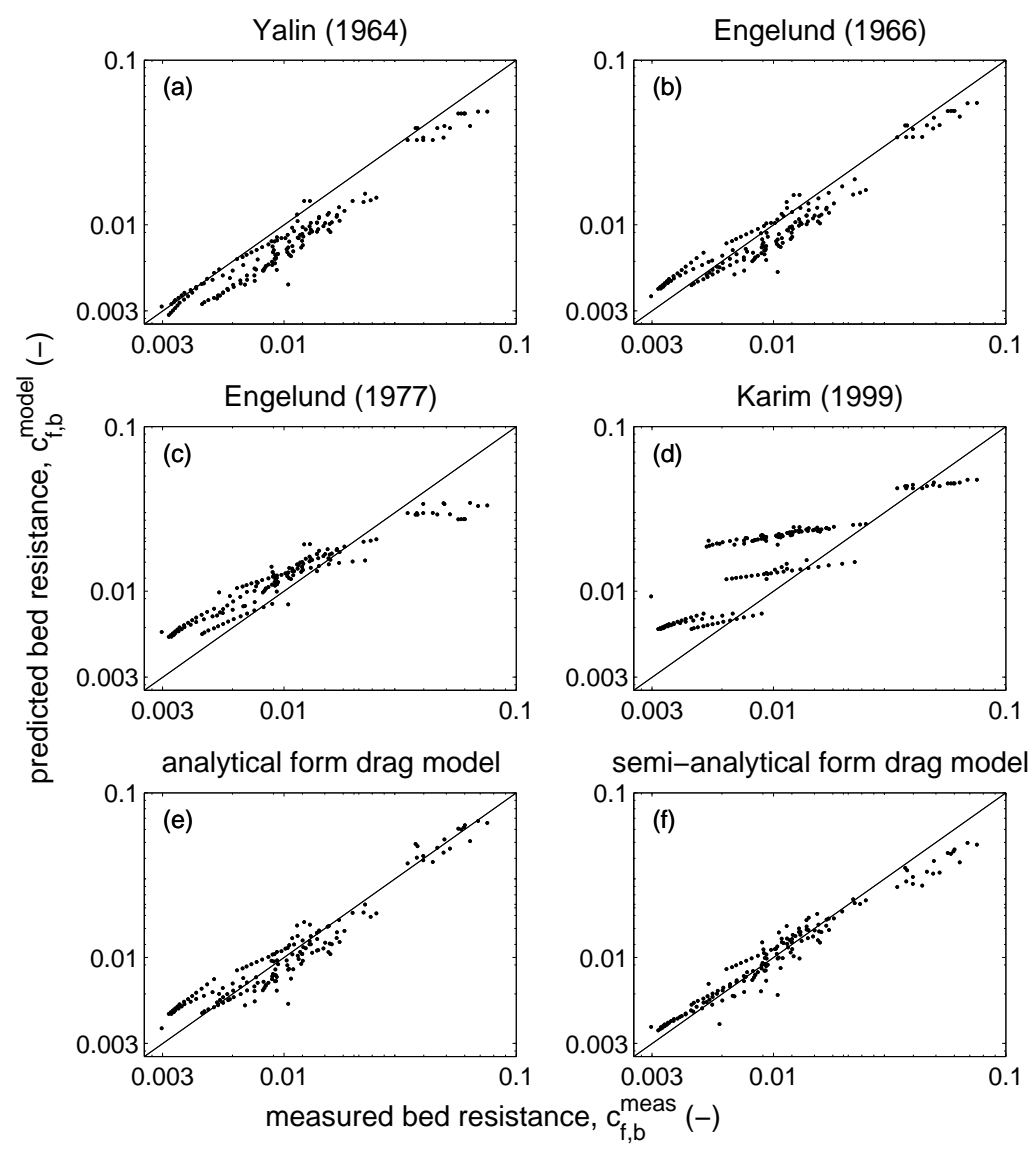

Figure 3.12: Predicted bed resistance using the models of (a) Yalin (1964a), (b) Engelund (1966), (c) Engelund (1977), (d) Karim (1999), (e) the present analytical model, and (f) the present semi-analytical model against measured bed resistance. The solid lines indicate the lines of perfect agreement. 
Table 3.1 shows that incorporation of the effects due to lee face steepness, bedform interaction, flow separation zone height, and nonuniformity of the flow velocity profile yields a small improvement (compare models e and f).

Table 3.1 illustrates that the Yalin (1964a) - Engelund (1966) form drag model in combination with the grain friction model of Engelund (1966) yields better results than the grain friction model of Yalin (1964a) (compare models a and b). The Yalin (1964a) model predicts smaller values of the bed resistance, which is due to the fact that the grain friction model of Yalin (1964a) only accounts for energy loss due to grain friction over the stoss face of the bedform.

The bed resistance model of Karim (1999) yields the least accurate results of the models considered. This may be due to the momentum not being conserved over the region of the flow expansion (see Section 3.3.6).

\subsection{Discussion}

In the derivation of the present semi-analytical form drag model we apply a calibration coefficient, $c_{1}=2.0$, relating the reference energy loss to the analytical energy loss. The calibration coefficient accounts for the effect that the velocity distributions at cross-sections 1 and 2 are not uniform. If we would have applied values for the kinetic energy and momentum coefficient somewhat larger than unity rather than values equal to unity (equation (3.23)), the value of the calibration coefficient would be between 1 and 2 (see Figure 3.3). For simplicity, we have chosen here to apply equation (3.23) (and thus $c_{1}=2.0$ ), as (a) the values of the kinetic energy and momentum coefficient are not known well (e.g. Chaudhry, 2008) for a bedform-dominated channel or for a situation as defined by the reference situation, and (b) it is unclear if and how $\alpha_{1}$ (at the bedform crest) deviates from $\alpha_{2}$ (downstream of the influence zone of the bedform) and likewise if and how $\beta_{1}$ deviates from $\beta_{2}$.

We have assumed that the four effects that are represented by the correction factors are independent. We expect that the effects on form drag described by the values of the correction factors are more significant than potential effects on form drag due to dependency between the correction factors (also see Chapter 5).

We have assumed that the total correction factor, $\gamma_{T}$, is equal to multiplicating the correction factors of the four effects that affect the reference form drag (equation (3.42)), such that a factor equals unity if its effect is absent. However, this is just one possible method to incorporate the four effects. For instance, we could also have chosen for a model in which the effects are summed rather than multiplied, e.g. $\gamma_{T}=1+\hat{\gamma}_{s}+\hat{\gamma}_{i}+\hat{\gamma}_{f}+\hat{\gamma}_{v}$.

The expressions for the correction factors for lee face steepness, bedform interaction, and flow separation zone height represent first onsets for the incorporation of the effects on form drag, as at this point we have only few data available to analyze each of the effects.

As can be seen from Figures 3.6 and 3.11, the correction factors $\gamma_{s}$ and $\gamma_{f}$ may not only be a function of the bedform geometry, but also of the flow conditions, characterized by the Froude number and ratio of bedform height to 
mean water depth. At the moment, the dependency of flow conditions is not incorporated in the expressions for the correction factors.

The derived correction factor for flow separation zone height is a function of the height of the flow separation zone. However, the correction factor may also be a function of the length of the flow separation zone. If a brink point is present, the streamlines at the brink point have a vertical component in downward direction. The larger the vertical component in downward direction, the smaller is the length of the flow separation zone (e.g. Schatz and Herrmann, 2006), and the smaller the form drag. Further research is required to analyze whether the correction factor can be improved by incorporating (a model for) the length of the flow separation zone.

We include four relevant effects affecting form drag in the semi-analytical form drag model. Effects on form drag of suspended sediment, three-dimensionality of bedforms, and bedform migration are not incorporated in the form drag model:

- Suspended sediment load tends to dampen turbulence (Vanoni and Nomi$\cos , 1960$ ), and thereby reduces resistance to flow (e.g. Richards, 1982; Khullar et al., 2007).

- Bedforms in the field are often three-dimensional (e.g. Nordin, 1971). Maddux et al. (2003a,b) and Venditti (2007) show that the bed resistance of three-dimensional bedforms may differ from the bed resistance of twodimensional bedforms.

- The effect of bedform migration on form drag is expected to be negligible, as the migration rate is relatively small and not expected to affect the flow expansion.

Presently we are not able to evaluate to what extent these effects contribute to the form drag, and for now we do not incorporate these effects in our form drag model. In Chapter 4 the effect of variability in bedform geometry in streamwise direction is included in the model, and the effect of three-dimensionality is discussed.

River flood plains can contain obstacles, e.g. levees, spillways, groynes, or spur dikes, which affect the flow and its conveyance capacity. Training works such as groynes or spur dikes are constructed to prevent erosion of the banks and to keep the main channel navigable. If the discharge is high enough these obstacles are submerged. We expect that the approach followed in the development of the semi-analytical form drag model, i.e., a reference form drag times correction factors accounting for deviations from the reference situation, may be useful for determining the resistance to flow due to groynes or other obstacles (also see Chapter 5).

\subsection{Conclusions}

We present a new semi-analytical form drag model predicting form drag due to bedforms in rivers under subcritical flow conditions. The new form drag model 
consists of two components, i.e., (1) an analytically-based reference form drag model, accounting for energy loss associated with the deceleration of the flow due to a sudden expansion of a free surface flow, and (2) an empirical coefficient taking into account effects due to deviations from the reference situation. The analytically-based reference form drag model is an extension of the model proposed by Yalin (1964a) and Engelund (1966). The empirical coefficient takes into account that (a) the flow expansion downstream of the bedform crest is gradual rather than sudden, (b) the flow pattern over closely spaced bedforms differs from the pattern over a solitary bedform, (c) the flow separation zone height may deviate from the bedform height, and (d) bedforms are irregular in height and length. In this chapter, we propose expressions for the first three effects. The fourth effect is elaborated on in Chapter 4. We assume that the four effects do not interact with each other.

To analyze the effect of lee face steepness and bedform interaction on form drag, we use the CFD software package Ansys CFX. A validation study of the numerical model to laboratory data of flow over uniform bedforms shows that Ansys CFX is well capable of predicting flow velocities, form drag, and the free surface elevation.

Using numerical simulations we develop an expression for the effect of lee face steepness on form drag. The correction factor for lee face steepness increases with increasing lee face angle and equals approximately unity for lee face angles larger than about $50^{\circ}$.

The flow pattern over closely spaced bedforms differs from the pattern over a solitary bedform. A bedform as part of a series of bedforms causes less form drag than a solitary bedform. An expression for the effect of bedform interaction on form drag is found to be a function of the ratio of bedform length to bedform height. The expression describes that for increasing values of this ratio, the flow pattern over a bedform is less influenced by the flow patterns over the surrounding bedforms.

The height of the flow separation zone may deviate from the bedform height, which affects the form drag. An expression taking into account this effect is found to be a function of the ratio of the flow separation zone height to the bedform height. The expression describes that the larger the flow separation zone height, the larger is the form drag.

The expressions accounting for the effects of lee face steepness, bedform interaction, and flow separation zone height are first onsets, as at this point only few data are available for their derivation.

In this chapter the semi-analytical form drag model is applied to laboratory experiments of flow over uniform fixed bedforms. We find that the model yields better results than the Yalin (1964a) - Engelund (1966) model, as the present model is able to take into account that (1) a gentler lee face angle, (2) the interaction between flow patterns over subsequent bedforms, and (3) a smaller flow separation zone height yield a smaller form drag. 


\section{A Derivation of Bed Resistance from Measured Data}

In this appendix we explain how we derive bed resistance from measured flume data. The measured total resistance in a straight flume consists of three sources of resistance: grain friction, form drag due to bedforms, and sidewall friction. We correct the measured total resistance for sidewall friction to find an estimate of the bed resistance from the measured data.

The total energy loss, $\Delta H_{T}$, over a channel section of length $L$ is equal to

$$
\Delta H_{T}=S L
$$

The energy loss in a straight flume under bedform-dominated conditions can be divided into energy loss due to grain friction, $\Delta H^{\prime}$, due to form drag, $\Delta H^{\prime \prime}$, and due to sidewall friction, $\Delta H^{\prime \prime \prime}$, as the total energy loss of a flow system is the direct summation of the component energy losses (e.g. Daugherty and Franzini, 1965)

$$
\Delta H_{T}=\Delta H^{\prime}+\Delta H^{\prime \prime}+\Delta H^{\prime \prime \prime}
$$

We now consider the force balance of a channel with width $W$ and a small bed slope, so that $S=\tan \varphi \approx \sin \varphi$, in which $\varphi$ denotes the bed slope angle:

$$
-F^{\prime}-F^{\prime \prime}-F^{\prime \prime \prime}+L d W \rho g S=0
$$

in which $F^{\prime}$ denotes the force due to grain friction, $F^{\prime \prime}$ denotes the force due to form drag and $F^{\prime \prime \prime}$ the force due to sidewall friction. Equation (3.65) expresses that all resistance forces balance the component of the gravitational force in the flow direction. If we combine equations (3.63), (3.64), and (3.65) by eliminating the term $S L$, we obtain

$$
\Delta H^{\prime}+\Delta H^{\prime \prime}+\Delta H^{\prime \prime \prime}=\frac{F^{\prime}}{\rho g d W}+\frac{F^{\prime \prime}}{\rho g d W}+\frac{F^{\prime \prime \prime}}{\rho g d W}
$$

We divide equation (3.66) into three parts, as we assume that individual energy losses are due to their corresponding friction force terms only. The forces in equation (3.66) are rewritten into shear stresses times the wetted area at which these forces work $\left(F^{\prime}=\tau^{\prime} W L, F^{\prime \prime}=\tau^{\prime \prime} W L, F^{\prime \prime \prime}=\tau^{\prime \prime \prime} 2 d L\right)$, and shear stresses are rewritten in resistance coefficients $\left(\tau^{\prime}=c_{f}^{\prime} \rho U^{2}, \tau^{\prime \prime}=c_{f}^{\prime \prime} \rho U^{2}, \tau^{\prime \prime \prime}=c_{f}^{\prime \prime \prime} \rho U^{2}\right)$. We obtain

$$
\begin{aligned}
\Delta H^{\prime} & =\frac{F^{\prime}}{\rho g d W}=\frac{\tau^{\prime} W L}{\rho g d W}=c_{f}^{\prime} \frac{L U^{2}}{g d} \\
\Delta H^{\prime \prime} & =\frac{F^{\prime \prime}}{\rho g d W}=\frac{\tau^{\prime \prime} W L}{\rho g d W}=c_{f}^{\prime \prime} \frac{L U^{2}}{g d} \\
\Delta H^{\prime \prime \prime} & =\frac{F^{\prime \prime \prime}}{\rho g d W}=\frac{\tau^{\prime \prime \prime} 2 d L}{\rho g d W}=c_{f}^{\prime \prime \prime} \frac{2 L U^{2}}{g W}
\end{aligned}
$$

in which $c_{f}^{\prime \prime \prime}$ denotes the sidewall friction coefficient and $\tau^{\prime \prime \prime}$ the boundary shear stress due to sidewall friction. 
By substituting the equations (3.4) and (3.67) into (3.64), we obtain

$$
c_{f, T} \frac{L U^{2}}{g R}=c_{f}^{\prime} \frac{L U^{2}}{g d}+c_{f}^{\prime \prime} \frac{L U^{2}}{g d}+c_{f}^{\prime \prime \prime} \frac{2 L U^{2}}{g W}
$$

Dividing by $L U^{2} / g d W$, substituting the hydraulic radius $R$ by $R=W d /(W+$ $2 d$ ), replacing $c_{f}^{\prime}+c_{f}^{\prime \prime}$ by the bed resistance $c_{f, b}$ yields

$$
c_{f, b}=c_{f, T}+\frac{2 d}{W}\left(c_{f, T}-c_{f}^{\prime \prime \prime}\right)
$$

Equation (3.69) is the method for sidewall correction proposed by Vanoni and Brooks (1957).

The resistance coefficient due to sidewall friction, $c_{f}^{\prime \prime \prime}$, is estimated as (Cheng and Chua, 2005)

$$
c_{f}^{\prime \prime \prime}=\frac{1}{8}\left[20\left(R e / 8 c_{f, T}\right)^{0.1}-39\right]^{-1}
$$

in which $R e$ denotes the Reynolds number $(R e=4 U R / \nu$, where $\nu$ denotes the kinematic viscosity).

We are now able to determine the measured bed resistance, $c_{f, b}$, from equations (3.3), (3.69), and (3.70), if bed slope, $S$, channel width, $W$, mean water depth, $d$, and mean velocity, $U$, are measured.

\section{B Solution to Cubic Equation}

The reference form drag given by equation (3.31) is a function of (1) the mean water depth, (2) the water depth at the bedform crest, and (3) the water depth downstream of the influence zone of the bedform. If the water density, bedform height, specific discharge, momentum coefficients, and one of the three water depths are known, we are able to solve the remaining two water depths using equations (3.18) and (3.34). Namely, we have two equations to solve for two unknown variables.

By eliminating one of the two remaining unknown water depths from equations (3.18) and (3.34), we obtain a cubic equation. Cardano (1545)'s method provides an analytical solution to a cubic equation (e.g. Korn and Korn, 1968) of the general form

$$
x^{3}+a_{1} x^{2}+a_{2} x+a_{3}=0
$$

in which $a_{1}, a_{2}, a_{3}$ are real coefficients. The three solutions of the cubic equation are (e.g. Korn and Korn, 1968)

$$
x=-\frac{a_{1}}{3}+I^{k} \sqrt[3]{-\frac{q_{c}}{2}+\sqrt{D}}+I^{-k} \sqrt[3]{-\frac{q_{c}}{2}-\sqrt{D}}
$$

in which $k=[0,1,2]$, complex number $I=-\frac{1}{2}+\frac{1}{2} \sqrt{3} i$, discriminant $D=$ $\left(q_{c} / 2\right)^{2}+\left(p_{c} / 3\right)^{3}, p_{c}=a_{2}-\left(a_{1}^{2}\right) / 3$, and $q_{c}=2\left(a_{1} / 3\right)^{3}-\left(a_{1} a_{2}\right) / 3+a_{3}$.

Next, we will explain how equations (3.18) and (3.34) can be solved for the remaining unknown water depths, provided that (a) the mean water depth, $d$, is known, or (b) the water depth at the bedform crest, $d_{t}$, is known, or (c) the water depth downstream of the influence zone of the bedform, $d_{2}$, is known. 
(a) Solving for $d_{t}$ and $d_{2}$

Rewriting equation (3.18) yields

$$
d_{2}^{3}+a_{1} d_{2}^{2}+a_{2} d_{2}+a_{3}=0
$$

with

$$
\begin{aligned}
& a_{1}=0 \\
& a_{2}=-\left(\delta+d_{t}\right)^{2}-\frac{2 \beta_{1} q^{2}}{g d_{t}} \\
& a_{3}=\frac{2 \beta_{2} q^{2}}{g}
\end{aligned}
$$

We first solve $d_{t}$ using equation (3.34), and then $d_{2}$ in equation (3.73) using equations (3.72) and (3.74). Equation (3.73) has three solutions. We need to use $k=0$, as $k=1$ and $k=2$ yield a value of $d_{2}$ smaller than 0 and a Froude number downstream of the influence zone of the bedform, $F r_{2}=q /\left(d_{2} \sqrt{g d_{2}}\right)$, larger than 1 , respectively.

\section{(b) Solving for $d$ and $d_{2}$}

We solve $d_{2}$ in equation (3.73) using equations (3.72) and (3.74) and $d$ using equation (3.34). We need to use $k=0$, as $k=1$ and $k=2$ yield a value of $d_{2}$ smaller than 0 and a Froude number downstream of the influence zone of the bedform, $F r_{2}=q /\left(d_{2} \sqrt{g d_{2}}\right)$, larger than 1, respectively.

(c) Solving for $d$ and $d_{t}$

Rewriting equation (3.18) yields

$$
d_{t}^{3}+a_{1} d_{t}^{2}+a_{2} d_{t}+a_{3}=0
$$

with

$$
\begin{aligned}
& a_{1}=2 \delta \\
& a_{2}=\delta^{2}-d_{2}^{2}-\frac{2 \beta_{2} q^{2}}{g d_{2}} \\
& a_{3}=\frac{2 \beta_{1} q^{2}}{g}
\end{aligned}
$$

We first solve $d_{t}$ in equation (3.75) using equations (3.72) and (3.76) and then $d$ using equation (3.34). We need to use $k=0$, as $k=1$ and $k=2$ yield a value of $d_{t}$ smaller than 0 and a Froude number at the crest, $F r_{1}$, larger than 1 , respectively.

Please note that the three solutions of a cubic equation given by equation (3.72) may be (1) all real values, or (2) one real value and two complex values (conjugated). The type of solution depends on the value of the discriminant, $D$. For values of $D>0$, there exist one real and two complex roots. 
For values of $D \leq 0$, only real roots exist. The solutions represent water depth values that are not be complex. We find that for flow conditions within the range $F r<1$ and $\delta / d<0.8$, the discriminant, $D$, is always negative, and thus there is only one real-valued solution.

\section{C Validation of Numerical Model}

We use the CFD software package Ansys CFX to analyze the effects of lee face steepness and bedform interaction on form drag. In this appendix we validate the prediction that follows from Ansys CFX using laboratory data.

We have carried out numerical simulations of experiments 2-7 of McLean et al. (1999) and the experiments T5 and T6 of Van Mierlo and De Ruiter (1988). These experiments focused on flow over bedforms in a laboratory flume. In the numerical simulations, 16 bedforms in a series $(\lambda=1.6 \mathrm{~m})$ were considered. We have performed simulations in which we varied the mesh density, the Nikuradse grain roughness height, and the turbulence model. The $k-\epsilon$ turbulence model and shear stress transport (SST) turbulence model (Ansys CFX, 2006; Menter, 1994) were tested. The SST model was designed to give more

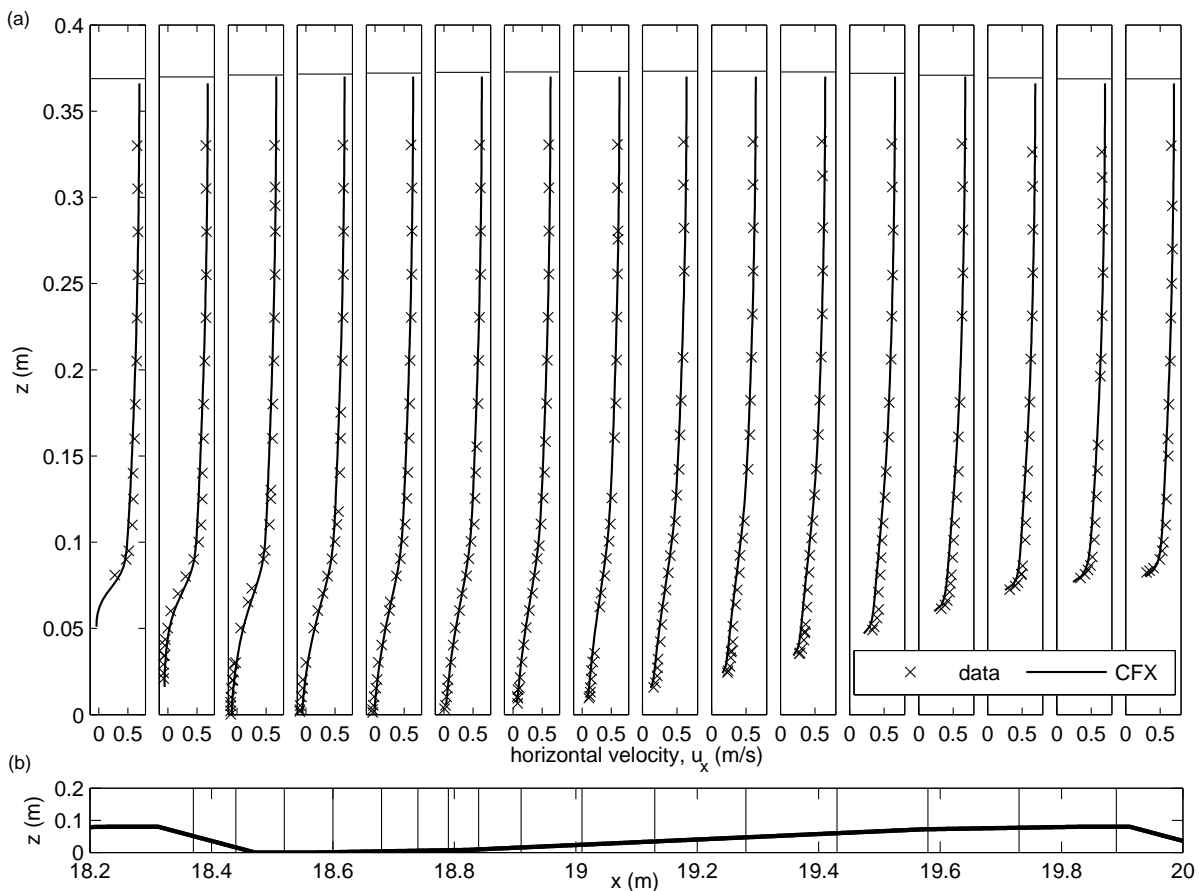

Figure 3.13: (a) Horizontal flow velocities as predicted by the numerical model and measured data of Van Mierlo and De Ruiter (1988), and (b) bedform shape and locations along the bedform where velocities were measured indicated by the vertical lines. 


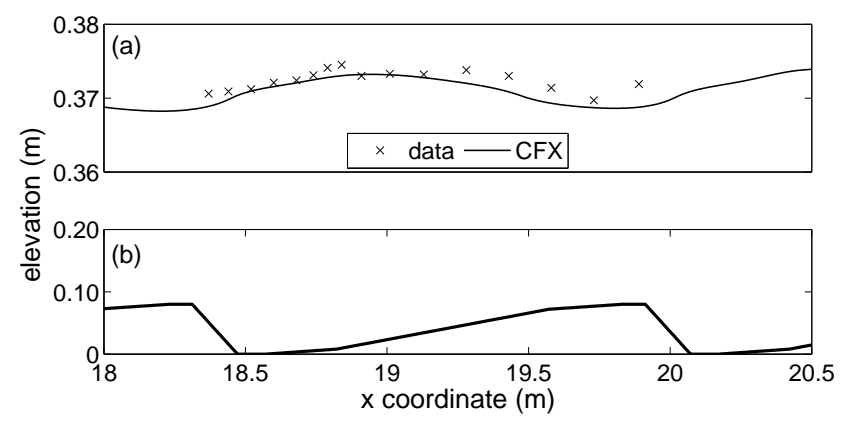

Figure 3.14: (a) Measured and predicted water level elevation over a bedform. Measured data are from Van Mierlo and De Ruiter (1988). (b) Bedform shape.

accurate predictions of the extent of flow separation due to adverse pressure gradients (Ansys CFX, 2006). It has been shown that the SST model may yield a major improvement in terms of flow separation predictions compared to the $k-\epsilon$ turbulence model (e.g. Bardina et al., 1997). In our simulations, however, the $k-\epsilon$ turbulence model showed the best results and is used in the simulations considered in this thesis. A reason that in the present application the SST model does not perform better than the $k-\epsilon$ model may be that the option of a rough bottom is not yet possible, so that simulations using the SST model are performed with a smooth bottom. Figure 3.13 shows horizontal flow velocities measured at 16 locations over a bedform in experiment T6 of Van Mierlo and De Ruiter (1988) together with horizontal flow velocities as predicted by the numerical model. The measured and predicted velocities agree well. Figure 3.14 shows the measured and predicted water level elevation over the bedform, and illustrates that the numerical model is able to reproduce the decrease in water level at the bedform crest.

In the flume experiments bed pressure along the bedform was measured, so

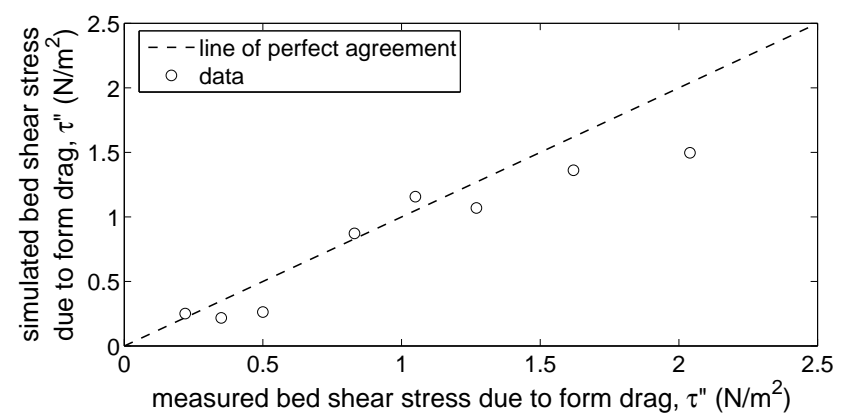

Figure 3.15: Predicted bed shear stress due to form drag against measured bed shear stress due to form drag. Measured data are from McLean et al. (1999). 
that the measured form drag is determined by integrating the bed pressure over one bedform length (Table 2 of McLean et al., 1999). Figure 3.15 compares the measured and predicted form drag per bedform length and per flume width. The agreement between predictions and experiments is satisfactory.

\section{D Notation}

A cross-sectional area, m.

$a_{1} \quad$ real coefficient in cubic equation, $m$.

$a_{2} \quad$ real coefficient in cubic equation, $\mathrm{m}^{2}$.

$a_{3} \quad$ real coefficient in cubic equation, $\mathrm{m}^{3}$.

$c_{E} \quad$ calibration coefficient in form drag model of Engelund (1977), dimensionless.

$c_{f}^{\prime} \quad$ grain friction coefficient, dimensionless.

$c_{f}^{\prime \prime} \quad$ form drag coefficient, dimensionless.

$c_{f}^{\prime \prime \prime} \quad$ sidewall friction coefficient, dimensionless.

$c_{f, b} \quad$ bed resistance coefficient, dimensionless.

$c_{f, \text { ref }}^{\prime \prime} \quad$ reference form drag coefficient, i.e., form drag for the reference situation, dimensionless.

$c_{f, T} \quad$ total resistance coefficient, dimensionless.

$C_{1} \quad$ parameter in form drag model of Karim (1999), dimensionless.

$c_{1} \quad$ calibration coefficient relating the reference energy loss to the analytical energy loss, dimensionless.

$c_{2} \quad$ calibration coefficient relating the numerically derived energy loss to the analytical energy loss, dimensionless.

$D \quad$ discriminant for solving cubic equation, $\mathrm{m}^{6}$.

d mean water depth, m.

$d_{f} \quad$ water depth at the location where the flow separates, $m$.

$d_{t} \quad$ water depth at the bedform crest, $\mathrm{m}$.

$d(x) \quad$ water depth as a function of $x$ coordinate, $\mathrm{m}$.

$d_{1} \quad$ water depth at cross-section 1, i.e., immediately downstream of the bedform, m.

$d_{2} \quad$ water depth at cross-section 2, i.e., downstream of the influence zone of the bedform, m.

E mean relative error between measured and predicted bed resistance, dimensionless.

$\vec{e}_{x} \quad$ unit vector in $x$-direction, dimensionless.

$\vec{f} \quad$ external volume force, $\mathrm{N} / \mathrm{kg}$.

$F^{\prime} \quad$ grain friction, N.

$F^{\prime \prime} \quad$ form drag, N.

$F^{\prime \prime \prime} \quad$ sidewall friction, N.

$\mathrm{Fr} \quad$ Froude number, dimensionless.

$g \quad$ gravitational acceleration, $\mathrm{m} / \mathrm{s}^{2}$.

$H \quad$ energy head averaged over a cross-section, $\mathrm{m}$.

I complex number for solving cubic equation, dimensionless. 
$K_{1} \quad$ parameter in form drag model of Karim (1999), dimensionless.

$k=[0,1,2]$, parameter for solving cubic equation, dimensionless.

$k \quad$ turbulence kinetic energy, defined as the variance of the fluctuations in velocity, $\mathrm{m}^{2} / \mathrm{s}^{2}$.

$L \quad$ flume length or length of channel section, $m$.

$N \quad$ number of bedforms, dimensionless.

$n \quad$ sample size, dimensionless.

$\vec{n} \quad$ outward pointing unit normal vector, dimensionless.

$p \quad$ pressure, $\mathrm{N} / \mathrm{m}^{2}$.

$p_{a} \quad$ atmospheric pressure, $\mathrm{N} / \mathrm{m}^{2}$.

$p_{c} \quad$ parameter for solving cubic equation, $\mathrm{m}^{2}$.

$q \quad$ specific discharge, $\mathrm{m}^{2} / \mathrm{s}$.

$q_{c} \quad$ parameter for solving cubic equation, $\mathrm{m}^{3}$.

$R \quad$ hydraulic radius, $m$.

Re Reynolds number, dimensionless.

$S \quad$ energy slope, equal to bed slope under uniform conditions, dimensionless.

$S^{\prime} \quad$ energy slope due to grain friction, dimensionless.

$S^{\prime \prime} \quad$ energy slope due to form drag, dimensionless.

$t \quad$ time, s.

$U \quad$ mean flow velocity, i.e., averaged over cross-sectional area, $\mathrm{m} / \mathrm{s}$.

$u \quad$ component of the flow velocity in $x$-direction, $\mathrm{m} / \mathrm{s}$.

$\vec{u} \quad$ flow field, $\mathrm{m} / \mathrm{s}$.

$V \quad$ volume, $\mathrm{m}^{3}$.

$v \quad$ component of the flow velocity in $y$-direction, $\mathrm{m} / \mathrm{s}$.

$W \quad$ channel width, m.

$w \quad$ component of the flow velocity in $z$-direction, $\mathrm{m} / \mathrm{s}$.

$x \quad$ horizontal coordinate in streamwise direction, $\mathrm{m}$.

$y$ horizontal coordinate in lateral direction, $\mathrm{m}$.

$z \quad$ vertical coordinate, $m$.

$z_{b} \quad$ bed elevation above datum, $\mathrm{m}$.

$\alpha \quad$ kinetic energy coefficient, dimensionless.

$\beta \quad$ momentum coefficient, dimensionless.

$\gamma_{f} \quad$ correction factor for flow separation zone (FSZ) height, dimensionless.

$\gamma_{i} \quad$ correction factor for bedform interaction, dimensionless.

$\gamma_{s} \quad$ correction factor for lee face steepness, dimensionless.

$\gamma_{T} \quad$ total correction factor taking into account effects due to deviations from the reference situation, dimensionless.

$\gamma_{v} \quad$ correction factor for variability in bedform geometry, dimensionless. energy loss due to grain friction, $\mathrm{m}$.

$\Delta H_{a}^{\prime \prime}$ energy loss due to form drag, $\mathrm{m}$. energy loss due to sidewall friction, $\mathrm{m}$. analytical energy loss, i.e., energy loss due to expansion based on the analytical one-dimensional approach, $\mathrm{m}$.

$\Delta H_{a}^{\text {pipe }} \quad$ analytical energy loss for pipe flow expansion, $\mathrm{m}$.

$\Delta H_{\text {meas }}^{\text {pipe }}$ measured energy loss for pipe flow expansion, $\mathrm{m}$. 
$\Delta H_{\text {meas }}^{\prime \prime} \quad$ measured energy loss, i.e., measured energy loss due to expansion in the reference situation, $\mathrm{m}$.

$\Delta H_{\text {ref }}^{\prime \prime} \quad$ reference energy loss, i.e., energy loss due to expansion in the reference situation, $\mathrm{m}$.

$\Delta H_{\mathrm{ref}, T}^{\prime \prime}$ total energy loss due to expansion of a series of reference bedforms, $\mathrm{m}$.

$\Delta H_{T} \quad$ total energy loss, $\mathrm{m}$.

$\delta \quad$ mean bedform height, $\mathrm{m}$.

$\delta_{b} \quad$ brink point height, $\mathrm{m}$.

$\delta_{f} \quad$ height of the flow separation zone, $\mathrm{m}$.

$\epsilon \quad$ turbulence eddy dissipation (the rate at which the velocity fluctuations dissipate), $\mathrm{m}^{2} / \mathrm{s}^{3}$.

$\eta \quad$ bed elevation, $\mathrm{m}$.

$\theta \quad$ mean angle of bedform lee face, ${ }^{\circ}$.

$\theta_{p} \quad$ angle of conicity of diverging circular pipe, ${ }^{\circ}$.

$\lambda$ mean bedform length, i.e., the distance between two subsequent bedform crests, $m$.

$\lambda_{s} \quad$ length of the bedform stoss face, $\mathrm{m}$.

$\nu \quad$ kinematic viscosity, $\mathrm{m}^{2} / \mathrm{s}$.

$\rho \quad$ water density, $\mathrm{kg} / \mathrm{m}^{3}$.

$\tau^{\prime} \quad$ bed shear stress due to grain friction, $\mathrm{N} / \mathrm{m}^{2}$.

$\tau^{\prime \prime} \quad$ bed shear stress due to form drag, $\mathrm{N} / \mathrm{m}^{2}$.

$\tau^{\prime \prime \prime} \quad$ boundary shear stress due to sidewall friction, $\mathrm{N} / \mathrm{m}^{2}$.

$\tau_{b} \quad$ bed shear stress, $\mathrm{N} / \mathrm{m}^{2}$.

$\tau_{T} \quad$ total boundary shear stress, $\mathrm{N} / \mathrm{m}^{2}$.

$\varphi \quad$ bed slope angle, ${ }^{\circ}$.

Acknowledgments The authors acknowledge Yasuyuki Shimizu and RobertJan Labeur for their contribution to the numerical analysis. KNAW-DJA is acknowledged for supporting a visit to Japan by the first author. Marinus Aalberts and Gijs Bloemberg are thanked for using the data of their flume experiments. We acknowledge Chris Boeije and Jim Kok for answering questions on the numerical model system Ansys CFX. Erik Horstman, Dirk Rijnsdorp, Sander de Vree, and Tom Wijdenes are thanked for their contribution to the bedform interaction analysis and experiments. We would like to thank Jan Ribberink, Arjan Sieben, Guus Stelling, and emeritus professor Battjes for fruitful discussions. This research project, which is part of the VICI project Rough Water, is supported by the Technology Foundation STW, applied science division of the Netherlands Organization for Scientific Research (NWO) and the technology programme of the Ministry of Economic Affairs. 


\title{
Chapter 4
}

\section{A semi-analytical form drag model: application to alluvial and compound bedforms ${ }^{\star}$}

\begin{abstract}
Following on the development of a semi-analytical form drag model by Van der Mark et al. (2009), we extend the model by developing an expression for a correction factor for variability in bedform geometry. The correction factor accounts for the effect that a larger variability in bedform height and length yields a larger form drag. The resulting semi-analytical model is validated against alluvial laboratory data and its predictions are compared to results of other (semi-)analytical and empirical bed resistance models. The analytical form drag model of Yalin (1964a) and Engelund (1966) appears to yield the best results of the considered models for the alluvial laboratory data. Although the semi-analytical form drag model does not show an improvement for the alluvial bedform data compared to the Yalin (1964a) Engelund (1966) form drag model, for lee face angles representative for the field the semi-analytical model shows promising results. We therefore advise to apply either the semi-analytical model or the Yalin (1964a) - Engelund (1966) form drag model. The authors would like to underline the large value of all analytical models tested in this research. In the case of compound bedforms summation of the energy loss due to individual small-scale and large-scale bedforms yields a reasonably good prediction of the form drag.
\end{abstract}

\subsection{Introduction}

Bed resistance is an important parameter in predicting water levels in rivers. It consists of two components, i.e., form drag, which is the resistance due to bedforms, and grain friction, which is the resistance due to grains (Einstein and Barbarossa, 1952).

An accurate estimate of form drag is important, as form drag often accounts for the majority of the bed resistance (e.g. Julien and Klaassen, 1995; McLean et al., 1999). To calculate form drag both empirical and (semi-)analytical models exist. Examples of explicit empirical models are the models of Van Rijn (1982,

^This chapter will be submitted to J. Geophys. Res. as: Van der Mark, C.F., A. Blom, S.J.M.H. Hulscher, and H.W.M. Hoeijmakers, A semi-analytical form drag model: application to alluvial and compound bedforms. 
1984) and Vanoni and Hwang (1967). These models determine form drag based on predicted or measured water depth and bedform geometry. Implicit empirical models (e.g. Engelund and Hansen, 1967; Wright and Parker, 2004) are form drag models that are not an explicit function of the bedform geometry. In the analytical form drag model of Yalin (1964a) and Engelund (1966) it is assumed that the energy loss due to form drag can be described by a sudden expansion of a pipe flow and as such can be determined using the Borda-Carnot equation (e.g. Borda, 1766; Daugherty and Franzini, 1965). The semi-analytical form drag model of Karim (1999) is an extension of the Yalin (1964a) and Engelund (1966) model; the effect of a bedform on the flow is assumed to be represented by a sudden expansion of a free surface flow rather than a pipe flow.

Besides bedform height and bedform steepness (defined as the ratio of mean bedform height to mean bedform length), form drag is known to be a function of the Froude number (Alam and Kennedy, 1969), the steepness of the bedform lee face (e.g. Best, 2005), the spacing between bedforms (e.g. Davies, 1980; Coleman et al., 2005), and the size of the flow separation zone (e.g. Schatz and Herrmann, 2006; Parsons et al., 2004). As none of the existing explicit form drag models are a function of the Froude number, steepness of the lee face, or the size of the flow separation zone, Van der Mark et al. (2009) have developed a semi-analytical form drag model in which these quantities are incorporated.

The semi-analytical form drag model developed by Van der Mark et al. (2009) consists of two components, i.e., (1) an analytically-based reference form drag model, accounting for the energy loss associated with the deceleration of the flow downstream of a sudden expansion in a free surface flow, and (2) an empirical coefficient taking into account effects due to deviations from the reference situation. The empirical coefficient takes into account that (a) the flow expansion downstream of the bedform crest is gradual rather than sudden, (b) the flow pattern over a bedform is influenced by the flow patterns over the surrounding bedforms, (c) the flow separation zone height may deviate from the bedform height, and (d) bedforms are irregular in height and length. Each of these four effects are accounted for through a correction factor.

In Chapter 3, the semi-analytical model is applied to fixed bedform data in which bedforms are identical in height and length. Hence, the correction factor for variability in bedform geometry equals unity for these uniform bedform data. Alluvial bedforms, however, are irregular in size, shape and spacing (e.g. Nordin, 1971), which is expected to affect the form drag. In this chapter we derive an expression for the correction factor for variability in bedform geometry to be applied to the semi-analytical form drag model by Van der Mark et al. (2009). The extended semi-analytical model is applicable to alluvial bedforms which show variability in height and length.

Field measurements have shown that smaller scale bedforms can be superimposed on larger scale bedforms (e.g. Julien et al., 2002; Parsons et al., 2005; Best, 2005). Knowledge on bed resistance in case of compound bedforms is important as in many rivers bedforms of different scales occur. In this chapter we analyze whether in case of compound bedforms form drag can be predicted by summation of the energy loss due to flow expansion downstream of both the 
small-scale and large-scale bedforms.

The objective of this chapter is (a) to extend the semi-analytical form drag model to situations with variability in bedform geometry and so make it applicable to alluvial bedforms, (b) to validate the resulting semi-analytical model using alluvial laboratory data, (c) to compare the model results to results of other (semi-)analytical and empirical models, and (d) to analyze whether the concept of summation of individual flow expansions is applicable to the case of compound bedforms.

In Section 4.2 we will briefly describe the semi-analytical form drag model developed by Van der Mark et al. (2009), and in Section 4.3 we will derive an expression for the correction factor for variability in bedform geometry. In Section 4.4 we will apply the model to alluvial laboratory data and compare the results to those of other models. Section 4.6 describes the analysis of compound bedforms.

\subsection{Semi-Analytical Form Drag Model}

In this section we summarize the form drag model presented by Van der Mark et al. (2009). Van der Mark et al. (2009) develop a semi-analytical form drag model and apply it to laboratory data of flow over uniform fixed bedforms. The form drag model consists of two components, i.e., (1) an expression for the form drag coefficient in a reference situation, $c_{f \text {, ref }}^{\prime \prime}$, and (2) an expression taking into account effects due to deviations from the reference situation, $\gamma_{T}$ :

$$
c_{f}^{\prime \prime}=\gamma_{T} c_{f, \text { ref }}^{\prime \prime}
$$

where $c_{f}^{\prime \prime}$ denotes the form drag coefficient, and $\gamma_{T}$ denotes the total correction factor, i.e., a dimensionless coefficient taking into account effects due to deviations from the reference situation. The reference situation is defined as a situation in which (a) the flow is steady, (b) the bed is horizontal, (c) the lee face angle of the bedforms, $\theta$, equals $90^{\circ}$, i.e., downstream of the crest the flow expands abruptly, (d) the flow pattern over a bedform is not affected by upstream and downstream bedforms, (e) the bedform crest is horizontal and extends over such a reach that streamlines above the crest are parallel to the bed, (f) the height of the flow separation zone downstream of the bedform, $\delta_{f}$, is equal to the bedform height, $\delta$, and $(\mathrm{g})$ grain friction is absent in the expansion region. The latter is allowed as energy loss due to a change in cross-sectional area dominates over a short region (e.g. Fox and McDonald, 1994; Chaudhry, 2008). Please note that grain friction is not neglected; we will describe how it is accounted for in Section 4.4.2. The reference form drag of a series of $N$ bedforms equals

$$
\begin{aligned}
c_{f, \text { ref }}^{\prime \prime} & =\frac{c_{1} g d^{3} \Delta H_{a, T}^{\prime \prime}}{q^{2} L} \\
& =\frac{c_{1} g d^{3} \Delta H_{a}^{\prime \prime}}{q^{2} \lambda}
\end{aligned}
$$


in which $\Delta H_{a}^{\prime \prime}$ denotes the analytical energy loss due to expansion of a free surface flow, $\Delta H_{a, T}^{\prime \prime}$ denotes the total analytical energy loss over the series of $N$ bedforms $\left(\Delta H_{a, T}^{\prime \prime}=N \Delta H_{a}^{\prime \prime}\right), c_{1}$ denotes a calibration coefficient relating the analytical energy loss to the real or measured energy loss in the reference situation $\left(c_{1}=2.0\right), d$ denotes the mean water depth, $g$ the gravitational acceleration, $q$ the specific discharge, $\lambda$ the bedform length, and $L$ the length of the considered reach $(L=N \lambda)$. The calibration coefficient accounts for the effect that the flow velocity distribution is not uniform over the cross-section.

The analytical energy loss, $\Delta H_{a}^{\prime \prime}$, is defined as the difference in energy head over the expansion region, i.e., the energy head immediately downstream of the bedform crest minus the energy head downstream of the influence zone of the bedform, and equals (e.g. Chanson, 2004)

$$
\Delta H_{a}^{\prime \prime}=\delta+d_{t}-d_{2}+\frac{q^{2}}{2 g}\left(\frac{1}{d_{t}^{2}}-\frac{1}{d_{2}^{2}}\right)
$$

in which $d_{t}$ and $d_{2}$ denote the water depth at the bedform crest and the water depth downstream of the influence zone of the bedform, respectively. If the mean water depth, $d$, or one of the water depths $d_{t}$ or $d_{2}$ are known, the remaining two unknown water depths can be determined using the one-dimensional momentum conservation equation over the expansion region downstream of the bedform (equation (4.5)) and a relation between the mean water depth and the water depth at the bedform crest (equation (4.6)):

$$
\begin{gathered}
\frac{1}{2} \rho g\left(d_{t}+\delta\right)^{2}+\rho \frac{q^{2}}{d_{t}}=\frac{1}{2} \rho g d_{2}^{2}+\rho \frac{q^{2}}{d_{2}} \\
d=d_{t}+\frac{1}{2} \delta
\end{gathered}
$$

Bedforms are different from the reference situation with respect to the fact that (a) the flow expansion is gradual rather than abrupt, (b) the flow pattern over a bedform is also affected by surrounding bedforms, (c) the flow separation zone height may deviate from the bedform height, and (d) bedform geometry is variable rather than regular. The total correction factor, $\gamma_{T}$, in equation (4.1) is the following function of four correction factors each representing the four above-mentioned effects on the form drag:

$$
\gamma_{T}=\gamma_{s} \gamma_{i} \gamma_{f} \gamma_{v}
$$

where $\gamma_{s}, \gamma_{i}, \gamma_{f}$, and $\gamma_{v}$ denote the correction factors for the four abovementioned respective effects. Van der Mark et al. (2009) derive the following expressions for the correction factors:

$$
\begin{aligned}
& \gamma_{s}=\tanh \left[1.6 \tan \left(\frac{\theta \pi}{180^{\circ}}\right)\right] \\
& \gamma_{i}=1-1.4 \exp \left[\frac{-\lambda / \delta}{12.75}\right] \\
& \gamma_{f}=0.2\left(\frac{\delta_{f}}{\delta}\right)^{2}\left[4+\left(\frac{\delta_{f}}{\delta}\right)^{2}\right]
\end{aligned}
$$


in which $\theta$ denotes the bedform lee face angle in degrees and $\delta_{f}$ the height of the flow separation zone.

The semi-analytical is given by equations (4.1) and (4.3). In the so-called analytical form drag model the four above-mentioned effects and the effect of nonuniformity of the flow velocity profile on form drag are not accounted for, i.e., the total correction factor, $\gamma_{T}$, and the calibration coefficient, $c_{1}$, both equal unity.

Van der Mark et al. (2009) apply the analytical and semi-analytical form drag models to series of fixed bedforms in which bedforms are identical. For such cases, the correction factor for variability in bedform geometry, $\gamma_{v}$, equals unity and does not play a role. In the next section we will derive a formulation for this correction factor for variability in bedform geometry.

\subsection{Correction Factor for Variability in Bedform Geome- try}

Alluvial (laboratory) bedforms are highly irregular in size, shape, and spacing (e.g. Nordin, 1971). Van der Mark et al. (2008b) show that bedform height can be described by a positively skewed Weibull distribution, and that the coefficient of variation of bedform height, $C_{\delta}$, which is defined as the ratio of the standard deviation to the mean value of the bedform height, equals about 0.47 .

Under the condition that the mean bedform height is the same, the total analytical energy loss due to expansion, $\Delta H_{a, T}^{\prime \prime}$, is larger for the case of irregular bedform geometry than for the case of regular geometry, as the relation between energy loss and bedform height (equation 4.4) is nonlinear. The correction factor for variability in bedform geometry that we will derive in this section accounts for this increase in total energy loss for irregular bedforms relative to regular bedforms.

To derive an expression for the correction factor for variability in bedform geometry, we perform analytical computations in which the correction factors for bedform interaction and flow separation zone height equal unity, i.e., the flow over a bedform is not affected by upstream and downstream bedforms and the flow separation zone height equals the bedform height (Figure 4.1). Equation (4.1), with Equation (4.7), can now be written as

$$
\gamma_{v}=\frac{c_{f}^{\prime \prime}}{\gamma_{s} c_{f, \mathrm{ref}}^{\prime \prime}}
$$

The form drag of a single bedform $\left(c_{f}^{\prime \prime}=\left.c_{f}^{\prime \prime}\right|_{\text {irreg }}\right)$ is determined using equation (4.2). The total analytical energy loss of a series of $N$ irregular bedforms is obtained by summation of the individual analytical energy losses of the $N$ bedforms:

$$
\Delta H_{a, T}^{\prime \prime}=\left.\Delta H_{a, T}^{\prime \prime}\right|_{\text {irreg }}=N \sum_{i=1}^{N} p\left(\delta_{i}\right) \gamma_{s} \Delta H_{a, i}^{\prime \prime}
$$




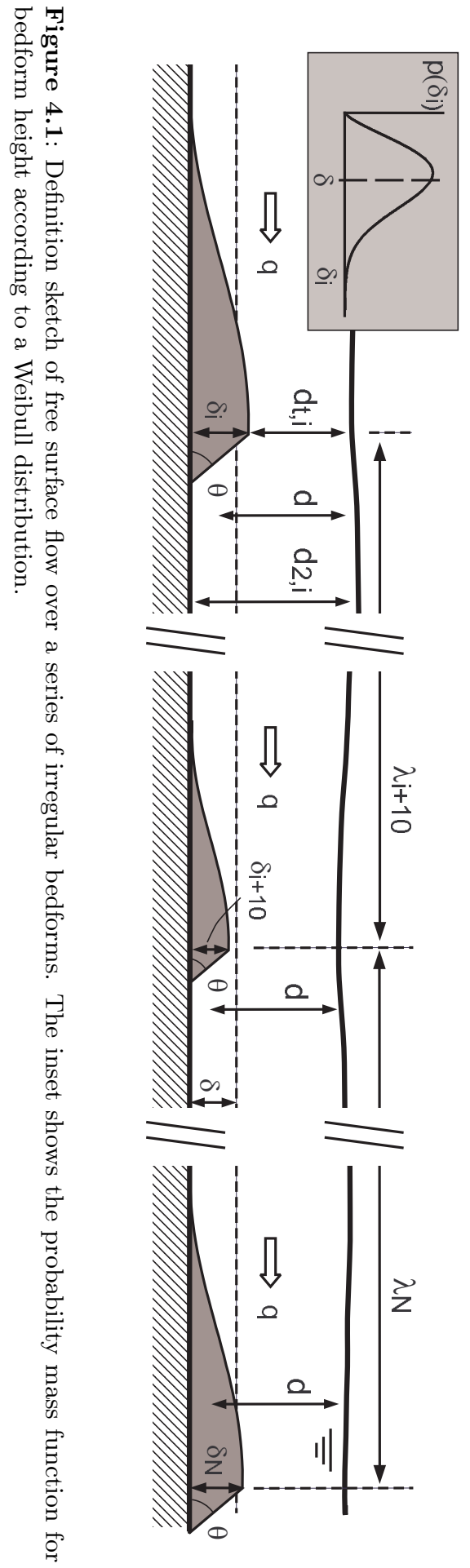


in which $p\left(\delta_{i}\right)$ denotes the probability mass function for (the discrete random variable) bedform height, which is distributed according to a Weibull distribution (inset in Figure 4.1), and $i$ is a subscript referring to the bedform number in the series. By definition, $\sum_{i=1}^{N} p\left(\delta_{i}\right)=1$. The analytical energy loss of the $i^{\text {th }}$ bedform is determined using

$$
\Delta H_{a, i}^{\prime \prime}=\delta_{i}+d_{t, i}-d_{2, i}+\frac{q^{2}}{2 g}\left(\frac{1}{d_{t, i}^{2}}-\frac{1}{d_{2, i}^{2}}\right)
$$

(compare with equation (4.4)) in which $d_{t, i}$ and $d_{2, i}$ denote the water depths at the crest and downstream of the influence zone of bedform $i$, respectively. The water depths, $d_{t, i}$ and $d_{2, i}$, are determined from the momentum conservation equation over the expansion region of a free surface flow, and a relation between the depth at the crest and the mean water depth (compare with equations (4.5) and (4.6)):

$$
\begin{gathered}
\frac{1}{2} \rho g\left(\delta_{i}+d_{t, i}\right)^{2}+\rho \frac{q^{2}}{d_{t, i}}=\frac{1}{2} \rho g d_{2, i}^{2}+\rho \frac{q^{2}}{d_{2, i}} \\
d=d_{t, i}+\frac{1}{2} \delta_{i}
\end{gathered}
$$

Under equilibrium conditions bedform length and bedform height of individual bedforms are positively correlated (e.g. Wang and Shen, 1980), and we apply the following linear relation between bedform length, $\lambda_{i}$, and bedform height, $\delta_{i}$ (Blom and Parker, 2004):

$$
\lambda_{i}=\frac{\lambda}{\delta} \delta_{i}
$$

where $\lambda$ and $\delta$ denote the mean bedform length and height, respectively. As such, the domain length, $L$, in equation (4.2) becomes

$$
L=\left.L\right|_{\text {irreg }}=N \sum_{i=1}^{N} p\left(\lambda_{i}\right) \lambda_{i}=\frac{\lambda}{\delta} N \sum_{i=1}^{N} p\left(\delta_{i}\right) \delta_{i}
$$

We are now able to determine the correction factor for variability in bedform geometry using equations (4.11)-(4.17) and equation (4.2) when the Froude number, $F r$, the ratio of mean bedform height to mean water depth, $\delta / d$, the mean bedform height, $\delta$, and a Weibull distribution of bedform heights characterized by the coefficient of variation, $C_{\delta}$, are known. For simplicity, we assume that the angle of the lee face, $\theta$, has the same value for each individual bedform (Figure 4.1). As such, the correction factor for lee face steepness disappears by division (equation (4.11)), and its value becomes irrelevant.

For a selection of analytical computations, Figure 4.2 shows the correction factor for variability in bedform geometry, $\gamma_{v}$, against the ratio of mean bedform height to mean water depth, $\delta / d$. As a fit to the analytical results, we propose the following exponential function for the correction factor for variability in 


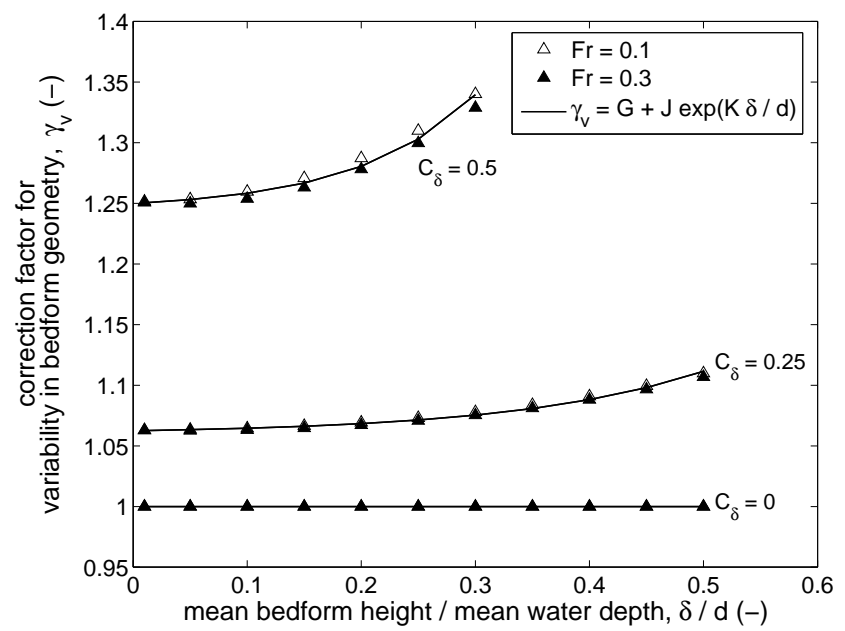

Figure 4.2: Correction factor for variability in bedform geometry, $\gamma_{v}$, against the ratio of mean bedform height to mean water depth, $\delta / d$, for analytical computations in which Froude number, $F r$, and coefficient of variation of bedform height, $C_{\delta}$, are varied. Solid lines represent equation (4.18). 
bedform geometry, as an exponential function appears to yield the best fit to the analytical results (Figure 4.2):

$$
\gamma_{v}=G+J \exp \left[K \frac{\delta}{d}\right]
$$

in which

$$
\begin{aligned}
G & =C_{\delta}^{2}-0.010 C_{\delta}+1.0 \\
J & =0.010 C_{\delta} \\
K & =15 C_{\delta}+2.3
\end{aligned}
$$

Please note that equation (4.18) is not dependent on the Froude number, as the Froude number was found to only slightly affect the correction factor for variability in bedform geometry (Figure 4.2 ).

For a coefficient of variation of $C_{\delta}=0.47$ (Van der Mark et al., 2008b), equation (4.18) reduces to

$$
\gamma_{v}=1.2+0.0047 \exp \left[9.4 \frac{\delta}{d}\right]
$$

For bedforms having a ratio of mean bedform height, $\delta$, to mean water depth, $d$, of 0.2 (e.g. Allen, 1984), the correction factor for bedform geometry equals

$$
\gamma_{v}=1.23
$$

Please note that the analysis presented in this section is necessary to derive the expression for the correction factor for variability in bedform geometry based on analytical calculations. In practice, only equation (4.18), (4.19), or (4.20) is necessary.

\subsection{Application to Alluvial Bedforms}

\subsubsection{Measured Bed Resistance}

We now consider laboratory data of the flow over alluvial bedforms to analyze the performance of both the analytical and semi-analytical form drag model. We also compare the results of the analytical and semi-analytical models to results of existing (semi-)analytical and empirical bed resistance models (Table 4.1 and Appendix 4.A).

We compare predicted to measured bed resistance rather than form drag as (1) some of the existing models do not distinguish between a grain friction and form drag coefficient explicitly, (2) a "measured" bed resistance is closer to the measured total resistance (only sidewall friction is corrected for) than a "measured" form drag (sidewall friction and grain friction needs to be corrected for), and (3) a form drag model needs to be applied with the grain friction model with which it was derived, as empirical coefficients in various form drag models depend on the applied grain friction model. 


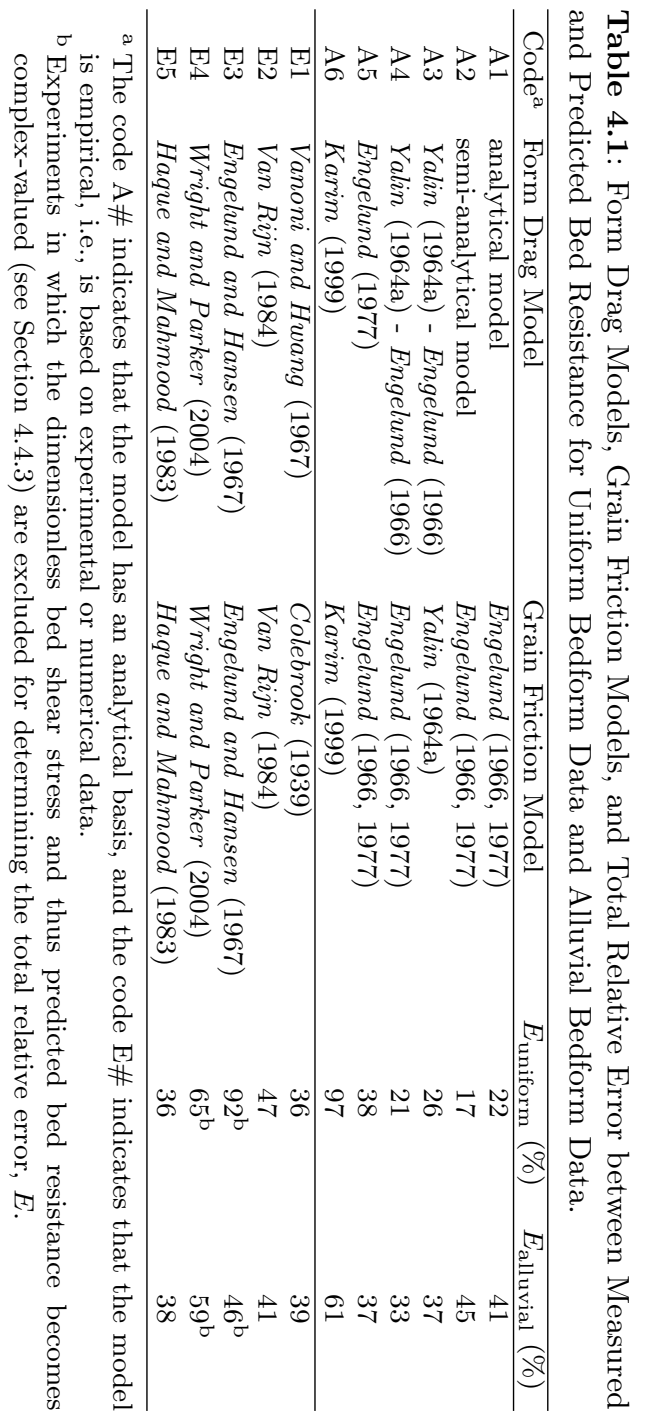


We consider the experimental data of Guy et al. (1966), Vanoni and Hwang (1967), Williams (1970), Wang and Shen (1980), Driegen (1986), Klaassen (1990), and Blom et al. (2003). All considered data belong to the lower flow regime (i.e., ripple or dune regime) according to the bedform classification diagram of Simons and Richardson (1966). Hence, none of the original data belongs to the upper flow regime (i.e., transition or antidune regime).

The original bed elevation profiles of the data of Driegen (1986), Klaassen (1990), and Blom et al. (2003) are used to determine mean bedform height, mean bedform length, mean angle of the bedform lee face, and variability in bedform height. Guy et al. (1966), Vanoni and Hwang (1967), Williams (1970), and Wang and Shen (1980) report measured mean bedform height and mean bedform length. Wang and Shen (1980) also report variability in bedform height.

Measured bed resistance, $c_{f, b}^{\text {meas }}$, is determined by correcting the measured total resistance, $c_{f, T}$, for sidewall friction, $c_{f}^{\prime \prime \prime}$, using the procedure of Vanoni and Brooks (1957):

$$
c_{f, b}^{\text {meas }}=c_{f, T}+\frac{2 d}{W}\left(c_{f, T}-c_{f}^{\prime \prime \prime}\right)
$$

in which $W$ denotes flume width. The sidewall friction coefficient, $c_{f}^{\prime \prime \prime}$, is estimated as (Cheng and Chua, 2005)

$$
c_{f}^{\prime \prime \prime}=\frac{1}{8}\left[20\left(\operatorname{Re} / 8 c_{f, T}\right)^{0.1}-39\right]^{-1}
$$

where $R e$ denotes the Reynolds number $(R e=4 U R / \nu$, with $U$ the mean flow velocity, $R$ the hydraulic radius, and $\nu$ the kinematic viscosity).

\subsection{2 (Semi-)Analytical Bed Resistance Models}

The predicted semi-analytical bed resistance, i.e., the bed resistance as predicted using the semi-analytical form drag model (indicated with model A2 in Table 4.1), is obtained by summation of the grain friction coefficient, $c_{f}^{\prime}$, and the semi-analytical form drag coefficient, $c_{f}^{\prime \prime}$ :

$$
c_{f, b}=c_{f}^{\prime}+c_{f}^{\prime \prime}
$$

where $c_{f}^{\prime \prime}$ is given by equations (4.1)-(4.7). The correction factor for variability in bedform geometry, $\gamma_{v}$, in equation (4.7) is determined using equation (4.18). We determine the correction factors for lee face steepness, $\gamma_{s}$, for bedform interaction, $\gamma_{i}$, and for flow separation zone height, $\gamma_{f}$, in equation (4.7) using equations (4.8), (4.9), and (4.10), respectively. To determine the four correction factors, we apply the measured mean bedform height, $\delta$, measured mean bedform length, $\lambda$, and, if available, the measured mean lee face angle, $\theta$, and measured variability in bedform height, $C_{\delta}$. If the lee face angle was not measured or reported, we apply a lee face angle, $\theta$, of $22^{\circ}$, which is about the average of the measured lee face angles in the data of Driegen (1986), Klaassen (1990), and Blom et al. (2003). If variability in bedform height cannot be determined 
from the data, we apply the model for variability in bedform height developed by Van der Mark et al. (2008b):

$$
C_{\delta}=0.47\left[1-\exp \left(\frac{-W / R}{2.4}\right)\right]
$$

The ratio of flow separation zone height to bedform height, $\delta_{f} / \delta$, is taken equal to unity in the alluvial experiments, as we assume that the bedform crest of alluvial bedforms is parallel to the mean bed elevation and extends over such a reach that streamlines above the crest are parallel.

The grain friction, $c_{f}^{\prime}$, is determined using the grain friction model of Engelund $(1966,1977)$ :

$$
c_{f}^{\prime}=\left[6+\frac{1}{\kappa} \ln \left(\frac{u_{f}^{\prime 2}}{g S k_{s}}\right)\right]^{-2}
$$

in which $\kappa$ denotes the Von Kármán constant $(\kappa=0.4), u_{f}^{\prime}$ the shear velocity due to grain friction, $S$ the energy slope, and $k_{s}$ the Nikuradse grain roughness height. The grain roughness height equals $k_{s}=2 D_{65}$, where $D_{65}$ denotes the grain diameter for which $65 \%$ of the sediment is finer. We apply $k_{s}=2 D_{50}$ if $D_{65}$ is unknown, where $D_{50}$ denotes the median diameter of the sediment. We apply this grain friction model, so that differences in predicted bed resistance using the models A1, A2, A4, and A5 (Table 4.1) can be attributed to the form drag models.

In Section 4.4.4 we will compare the results of the analytical and semianalytical bed resistance models to the analytical models of Yalin (1964a) and Engelund (1966) (models A3 and A4 in Table 4.1) and the semi-analytical models of Engelund (1977) (model A5) and Karim (1999) (model A6). Below we describe these models.

The form drag model of Yalin (1964a) and Engelund (1966) (YE form drag model) is based on the momentum and energy conservation equations applied to the expansion of a pipe flow, i.e., the Borda-Carnot equation (e.g. Borda, 1766; Daugherty and Franzini, 1965), rather than to the expansion of a free surface flow. It is assumed that (a) the depth at the crest is equal to the mean depth minus half a bedform height, and (b) the water depth downstream of the influence zone of the bedform is equal to the mean depth plus half a bedform height.

The form drag model of Engelund (1977) is equal to the YE form drag model except for an additional calibration coefficient, $c_{E}$, which was determined based on the alluvial laboratory data of Guy et al. (1966).

Karim (1999) applies the expression for the energy loss due to expansion of a free surface flow rather than a pipe flow, and applies the same water depth equations as in the YE form drag model. Please note that by applying two water depth equations, the momentum conservation equation over the flow expansion region does not hold anymore.

Bed resistance is obtained by summation of the form drag coefficients of Yalin (1964a) - Engelund (1966), Engelund (1977), and Karim (1999) and the 
grain friction coefficients using the grain friction models as proposed by Yalin (1964a), Engelund (1966), Engelund (1977), and Karim (1999), respectively (see Table 4.1 and Appendix 4.A). The grain friction model of Yalin (1964a) only accounts for energy loss due to grain friction along the stoss face of the bedform. As such, Yalin (1964a) uses a submodel to determine the length of the stoss face.

\subsubsection{Empirical Bed Resistance Models}

In Section 4.4.5 we will compare the results of the (semi-)analytical models to the ones of the empirical models. In this section, the empirical models of Vanoni and Hwang (1967), Van Rijn (1984), Engelund and Hansen (1967), Wright and Parker (2004), and Haque and Mahmood (1983) are described (see Table 4.1 and Appendix 4.A).

The models of Engelund and Hansen (1967) and Wright and Parker (2004) predict bed resistance based on an empirical relation between grain friction and bed resistance. As such, form drag is not predicted explicitly. The Engelund and Hansen (1967) model was calibrated using laboratory data and the Wright and Parker (2004) model was calibrated using field data only.

For predicting bed resistance using the models of Engelund and Hansen (1967) and Wright and Parker (2004), one needs to determine the dimensionless bed shear stress. For some experiments, however, the dimensionless bed shear stress becomes complex-valued, which is due to taking the square root of a negative value. This negative value occurs if the dimensionless grain shear stress is smaller than an empirical constant in these models (see Appendix 4.A). Apparently, these models are not suitable for circumstances in which the grain shear stress is small.

Although physically incorrect, the Van Rijn (1984) model sums Nikuradse grain roughness height and equivalent bedform roughness height (i.e., $k_{s, v R}=$ $\left.k_{s}^{\prime}+k_{s}^{\prime \prime}\right)$ rather than grain friction and form drag coefficients. The form drag model of Haque and Mahmood (1983) is based on numerical simulations in which bed pressure is integrated along a bedform.

Vanoni and Hwang (1967) determine the value of the grain friction, $c_{f}^{\prime}$, from a graph of the friction factor against Reynolds number for several values of the relative roughness (i.e., the Moody diagram). To obtain bed resistance, we apply the following expression for the grain friction (Colebrook, 1939), which yields the same values of the grain friction for their data as the Moody diagram:

$$
c_{f}^{\prime}=\frac{1}{8}\left[1.8 \log \left(\frac{R e}{7}\right)\right]^{-2}
$$

Haque and Mahmood (1983) apply the following grain friction model (K. Mahmood, pers. comm., 2009):

$$
c_{f}^{\prime}=\left[5.75 \log \left(\frac{12.27 R}{D_{65}}\right)\right]^{-2}
$$




\subsubsection{Results of the (Semi-)Analytical Models}

Figure 4.3 shows predicted bed resistance against measured bed resistance for the (semi-)analytical bed resistance models A1 through A6. Table 4.1 shows the total relative error between measured and predicted bed resistance, $E$ :

$$
E=\left[\sqrt{\frac{1}{n} \sum_{i=1}^{n} e^{2}}\right] \times 100 \%
$$

in which

$$
e=\frac{c_{f, b}^{\text {model }}-c_{f, b}^{\text {meas }}}{c_{f, b}^{\text {meas }}}
$$

The experiments in which the dimensionless bed shear stress becomes complexvalued are excluded from the analysis in order to be able to determine the total relative error for the models of Engelund and Hansen (1967) (12\% of the experiments excluded) and Wright and Parker (2004) (4\% of the experiments excluded). In this section we discuss Figure 4.3 and the results of the (semi-)analytical models in Table 4.1.

For the uniform fixed bedform data (Van der Mark et al., 2009) the analytical model (model A1), semi-analytical model (model A2), and the YE form drag model (models A3 and A4) yield comparable results. The results of the model of Engelund (1977) show that incorporation of the calibration coefficient, $c_{E}$, worsens the prediction of bed resistance for the uniform bedform data.

All (semi-)analytical models yield poor results for the alluvial bedform data compared to the uniform data, which is expressed by the scatter around the lines of perfect agreement in Figure 4.3.

The YE form drag model in combination with the grain friction model of Engelund (1966) (model A4) yields the best results for the alluvial flume data. It appears that, for the alluvial bedform data, the semi-analytical model yields slightly worse results than the analytical model (Figures $4.3 \mathrm{~g}$, h, and Table 4.1). The inclusion of additional physical effects, i.e., the effect of nonuniformity of the flow velocity profile, and the effects of lee face steepness, bedform interaction, deviation of flow separation zone height, and variability in bedform geometry on form drag, appears not to improve the model results. In the discussion section we will come back to this topic.

Figure 4.4 shows the relative error between measured and predicted bed resistance, $e$, of the analytical model (model A1) and the YE form drag model (model A4) against the ratio of bedform height to mean water depth, $\delta / d$, for the alluvial bedform data. The differences in model results between the YE form drag model and the analytical form drag model appear to be small (Table 4.1 and Figure 4.4), especially for ratios of the bedform height to the mean water depth, $\delta / d$, smaller than 0.33 , which are conditions realistic for the field (e.g. Knighton, 1998). Hence, the assumptions of Yalin (1964a) and Engelund (1966) that (a) flow expansion downstream of a bedform crest may be represented by expansion of a pipe flow rather than a free surface flow and that (b) the term $\frac{1}{4} \delta^{2}$ can be neglected appears to be justified. 

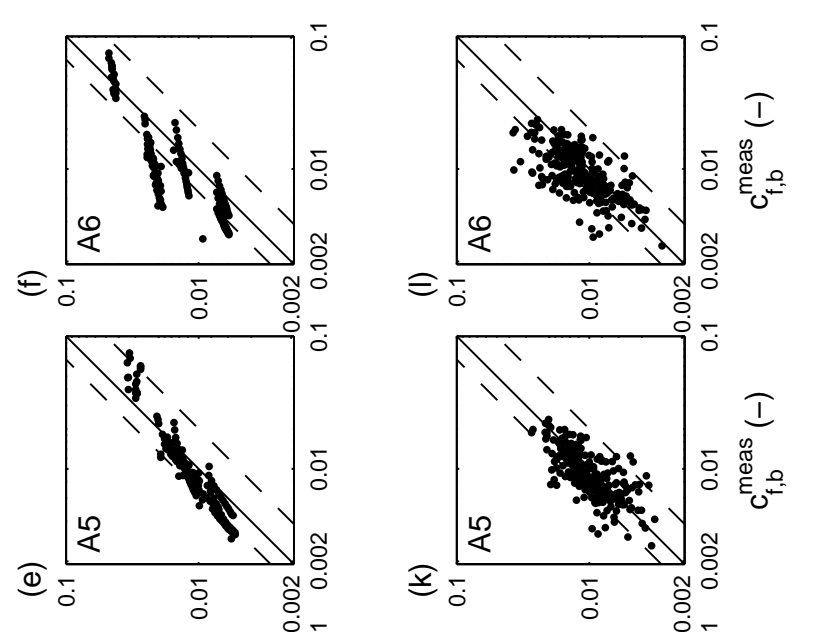

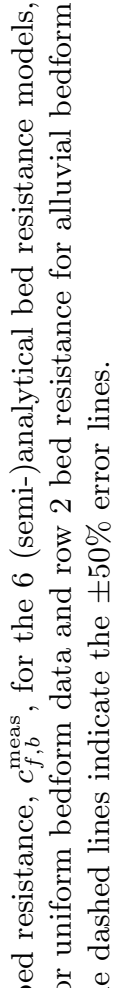
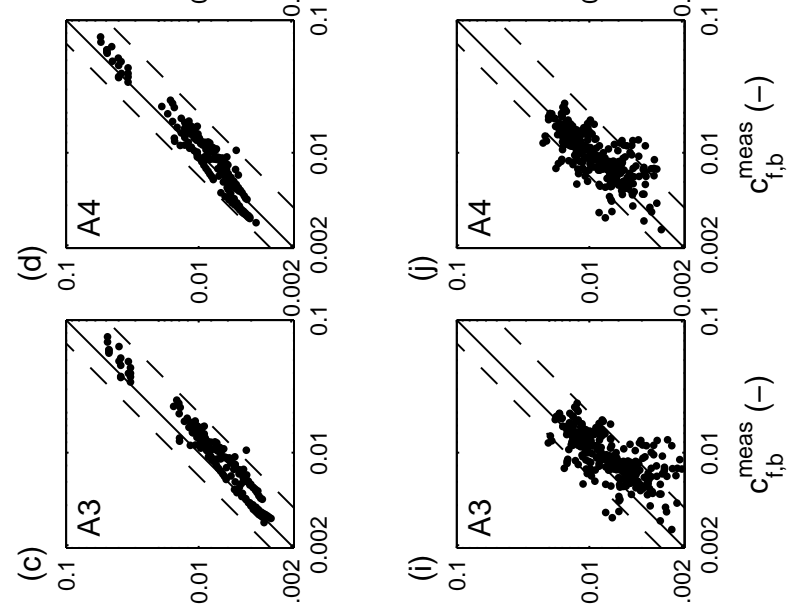

峞导

范 :

跣

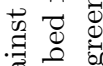
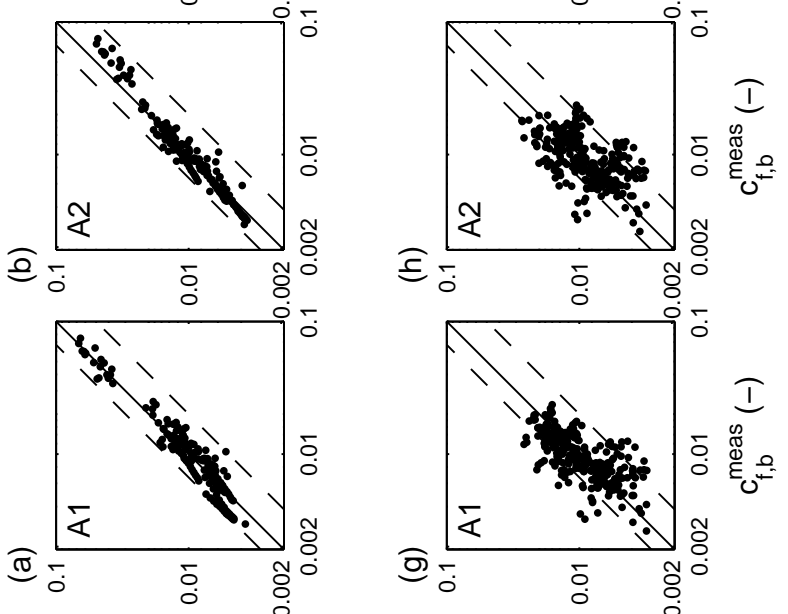

:

ब- $\frac{0}{0}$

हiv

8

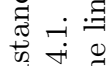

क

बृ

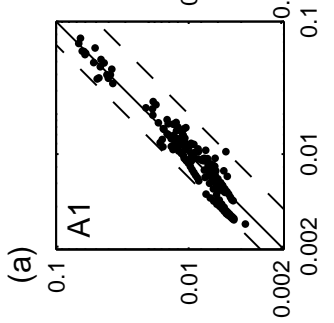

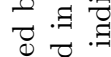

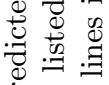

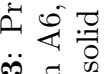

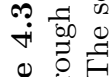

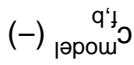

(-)

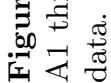




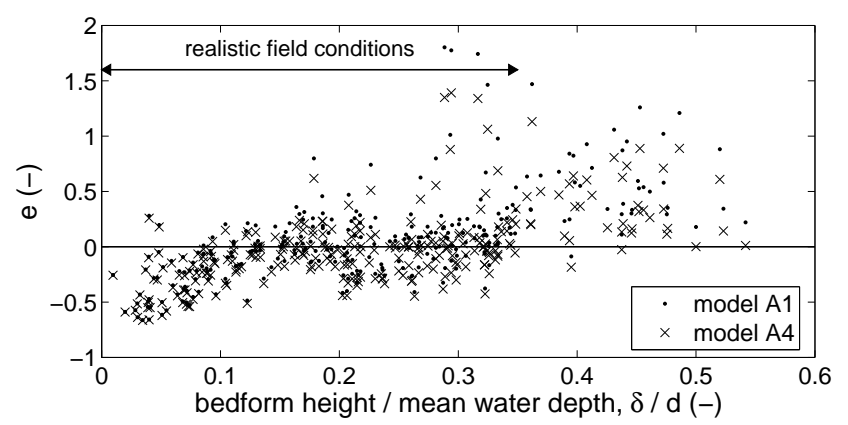

Figure 4.4: Relative error in predicted bed resistance, $e$ (equation (4.29)), using the analytical model (model A1) and the YE form drag model in combination with the Engelund (1966) grain friction model (model A4) for the alluvial bedform data against the ratio of bedform height to mean water depth, $\delta / d$.

Figure 4.4 shows that the relative error is relatively large (i.e., the models underestimate the bed resistance) for small values of the ratio of bedform height to mean water depth. Both models overestimate the bed resistance for values of the ratio of the bedform height to the mean water depth, $\delta / d$, larger than 0.33 . Under these conditions, which are not realistic for the field, it appears that the relative error is smaller for the YE form drag model that is based on expansion of a pipe flow compared to the analytical model that is based on expansion of a free surface flow.

The YE form drag model yields slightly better predictions of the bed resistance than the one of Engelund (1977) for the alluvial bedform data (models A4 and A5). Optimization of the calibration coefficient, $c_{E}$, in the Engelund (1977) model by the authors based on a more extensive alluvial flume data set than the one of Engelund (1977) (i.e., the alluvial data set presented in Section 4.4.1) has not led to an improvement.

The bed resistance model of Karim (1999) (model A6) yields the worst results of the (semi-)analytical models both for the uniform and the alluvial bedform data (Figures 4.3f, 1 ). This is probably due to the fact that momentum is not conserved over the region of flow expansion in this model.

The Yalin (1964a) - Engelund (1966) form drag model in combination with the grain friction model of Engelund (1966) yields better results than the grain friction model of Yalin (1964a) (models A3 and A4) both for the uniform and the alluvial bedform data. The Yalin (1964a) model predicts smaller values of the bed resistance, which may be due to the fact that the grain friction model of Yalin (1964a) only accounts for energy loss due to grain friction along the stoss face of the bedform.

\subsubsection{Results of the Empirical Models}

Figure 4.5 shows predicted bed resistance against measured bed resistance for the empirical bed resistance models E1 through E5 (see Section 4.4.3 and Table 4.1). 


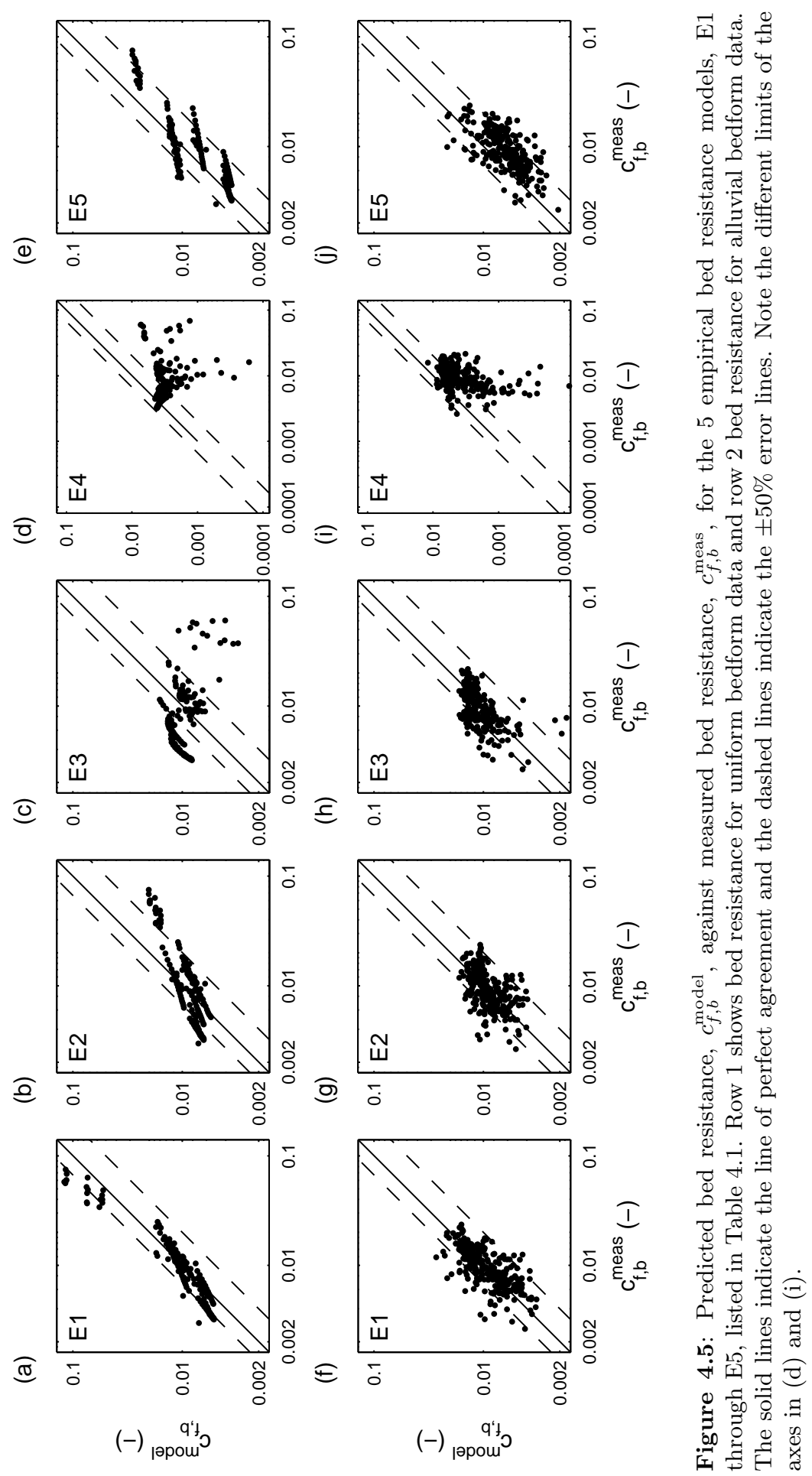


In this section we discuss the results presented in Figure 4.5 and Table 4.1.

The empirical bed resistance models have more problems predicting the bed resistance for the uniform bedform data than the (semi-)analytical models. This may be because the coefficients in the empirical models are calibrated purely on alluvial bedform data.

The bed resistance models of Vanoni and Hwang (1967) and Haque and Mahmood (1983) (models E1 and E5) yield the best results of the empirical models considered. For the uniform bedform data the models of Haque and Mahmood (1983) and Karim (1999) show roughly the same behavior (Figures $4.3 \mathrm{f}$ and $4.5 \mathrm{e})$. A mathematical explanation lies in the fact that in both form drag models the powers corresponding to bedform length and bedform height are of the same order of magnitude, whereas in, for instance, the YE form drag model the power corresponding to bedform height is twice as large as the one corresponding to bedform length.

The empirical model of Van Rijn (1984) (model E2) tends to underestimate the bed resistance for large values of the bed resistance and to overestimate for small values, especially for the uniform bedform data.

It appears that the empirical bed resistance models that need bedform geometry as input yield better results than the implicit models, i.e., the empirical models of Engelund and Hansen (1967) and Wright and Parker (2004).

The empirical model of Wright and Parker (2004) (model E4) is based purely on field data, and is a function of the Froude number. Froude numbers under a dune regime in the flume can be up to 0.6, whereas Froude numbers under a dune regime in rivers are usually smaller than 0.3 (e.g. Simons and Richardson, 1961). The reason for the relatively bad performance of this model (Figures $4.5 \mathrm{~d}$, i) may be the application of the model outside its range of calibration, i.e., to flume data with relatively large Froude numbers.

\subsection{Application to Lee Face Angles Representative for the Field}

There is evidence that lee face angles in the field may be much smaller than in a flume (e.g. Best, 2005; Van der Mark et al., 2008b). Alluvial bedforms in a laboratory flume typically have lee face angles in the order of about $25^{\circ}$, whereas lee face angles of bedforms in the field may be much smaller than $20^{\circ}$ (e.g. Best and Kostaschuk, 2002). In this section we will study the quality of the predictions of the YE form drag model and the semi-analytical model for such small lee face angles. Figure 4.6 shows that the semi-analytical model yields significantly better predictions of bed resistance than the YE form drag model in the case of small lee face angles. Figure 4.6a illustrates this for three numerical simulations using the computational fluid dynamics (CFD) software package Ansys CFX (release 11.0), and Figure 4.6b for laboratory experiment T4-1 of Ogink (1989). See Chapter 3 for a validation of simulations of free surface flow over a series of bedforms set up in Ansys CFX using measured data. In the three numerical simulations we simulate the flow over a series of 

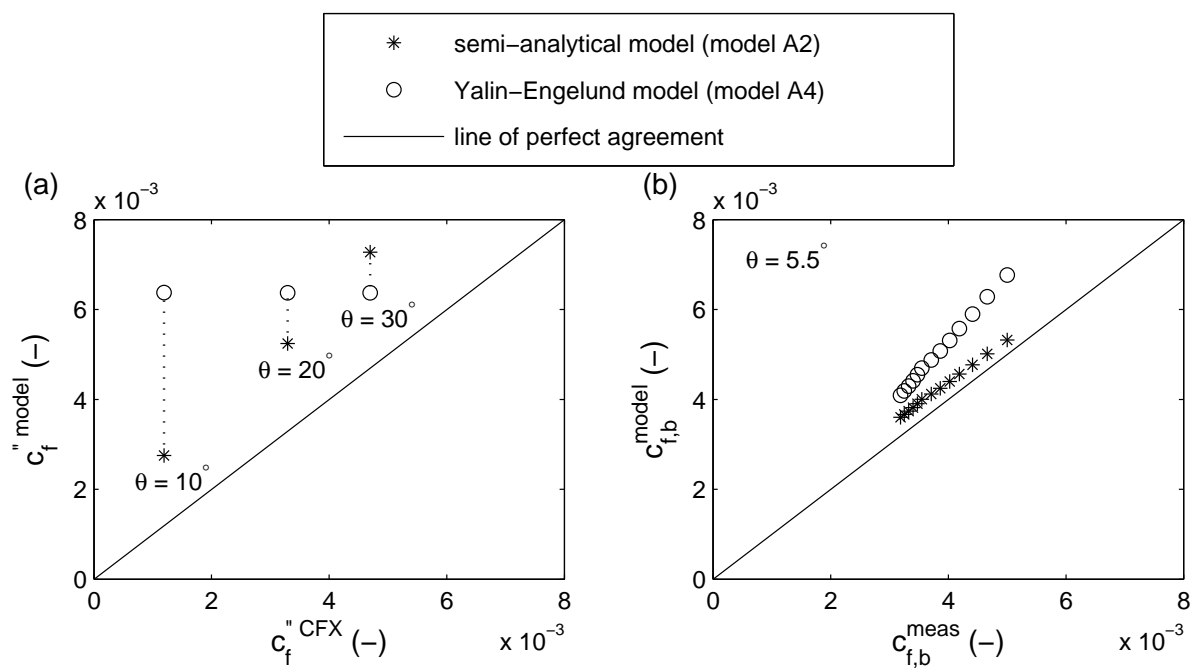

Figure 4.6: (a) Predicted form drag, $c_{f}^{\prime \prime \text { model }}$, using the semi-analytical model and Yalin (1964a) - Engelund (1966) form drag model against simulated form drag using Ansys CFX, $c_{f}^{\prime \prime C F X}$. Lee face angle, $\theta$, varies between the numerical simulations, and flow conditions are kept constant. (b) Predicted bed resistance, $c_{f, b}^{\text {model }}$, using the semi-analytical model and Yalin (1964a) - Engelund (1966) form drag model against measured bed resistance, $c_{f, b}^{\text {meas }}$. Data are from experiment T4-1 of Ogink (1989). Lee face angle, $\theta$, was kept constant $\left(\theta=5.5^{\circ}\right)$, and flow conditions were varied.

uniform fixed bedforms. The bedform length, height, and flow conditions do not vary between the simulations, while the lee face angle does vary $\left(\theta=10^{\circ}\right.$, $\left.\theta=20^{\circ}, \theta=30^{\circ}\right)$. The YE form drag model yields equal results for the three simulations, as the model does not account for differences in the lee face angle. Ogink (1989) performed measurements of flow over a series of uniform fixed bedforms for which the lee face angle was $\theta=5.5^{\circ}$. The water depth and discharge were varied in the experiments. Based on the results presented in Figure 4.6, we expect that in field situations the semi-analytical model yields better predictions of form drag than the YE form drag model.

\subsection{Application to Compound Bedforms}

\subsubsection{Compound Form Drag Model}

The stoss face of river bedforms may be covered with smaller-scale bedforms (e.g. Best, 2005). The semi-analytical form drag model developed by Van der Mark et al. (2009) is based on the concept of summation of the individual energy losses due to the expansion of flow over bedforms. In this section we apply this concept of summation to the case of compound bedforms.

According to the authors, Yalin and Lai (1985), Ogink (1989), and Julien et al. (2002) were the first to apply a summation of form drag coefficients of 
the small- and large-scale bedforms to determine the form drag coefficient for compound bedforms. Ogink (1989) introduces a coverage degree of small-scale bedforms, $D_{c}$, which indicates which percentage of the large-scale bedform is covered with small-scale bedforms:

$$
D_{c}=\frac{N \lambda_{s}}{\lambda_{l}}
$$

in which $N$ denotes the number of small-scale bedforms per large-scale bedform, $\lambda_{s}$ denotes the length of the small-scale bedform, and $\lambda_{l}$ the length of the largescale bedform.

For predicting bed resistance in case of compound bedforms, Van Rijn (2007) suggests to quadratically sum the Nikuradse roughness height values corresponding to ripples, $k_{s, r}$, to dunes, $k_{s, d}$, and to megaripples, $k_{s, m}$ :

$$
k_{s, c}=\sqrt{\left(k_{s, r}\right)^{2}+\left(k_{s, m}\right)^{2}+\left(k_{s, d}\right)^{2}}
$$

Van Rijn (2007) determines the bed resistance using the compound roughness height value, $k_{s, c}$ :

$$
c_{f, b}=g\left[18 \log \left(\frac{12 d}{k_{s, c}}\right)\right]^{-2}
$$

As mentioned earlier (Section 4.4.3), from a physical point of view it is incorrect to sum roughness height values.

We now propose the following form drag model in case of a series of largescale bedforms with small-scale superimposed bedforms:

$$
c_{f, c}^{\prime \prime}=b_{l} c_{f, l}^{\prime \prime}+D_{c} b_{s} c_{f, s}^{\prime \prime}
$$

in which the subscripts $c, l$, and $s$ refer to compound bedforms, large-scale and small-scale bedforms, respectively, and $D_{c}$ denotes the coverage degree of smallscale bedforms. The calibration coefficient, $b_{l}$, accounts for the effect that the energy loss of a large-scale bedform on which small-scale bedforms are superimposed may deviate from the energy loss of such a large-scale bedform under the same flow conditions without small-scale bedforms. Likewise, calibration coefficient, $b_{s}$, accounts for the effect that the energy loss of a small-scale bedform superimposed on a large-scale bedform may deviate from the energy loss of such a small-scale bedform without large-scale bedforms. Please note that $c_{f, l}^{\prime \prime}$ in equation (4.33) describes the form drag of the large-scale bedforms in case small-scale bedforms are not present. $c_{f, s}^{\prime \prime}$ for small-scale bedforms is defined likewise.

In equation (4.33) we now simply assume that the mean water depth, and thus energy loss, is equal for each of the $N$ small-scale bedforms superimposed on a large-scale bedform. This assumption does not agree with reality, but is made to keep the model, i.e., equation (4.33), simple. We will come back to this in Section 4.6.2. By assuming so, the total analytical energy loss due to the small-scale bedforms equals $N$ times the analytical energy loss due to a 


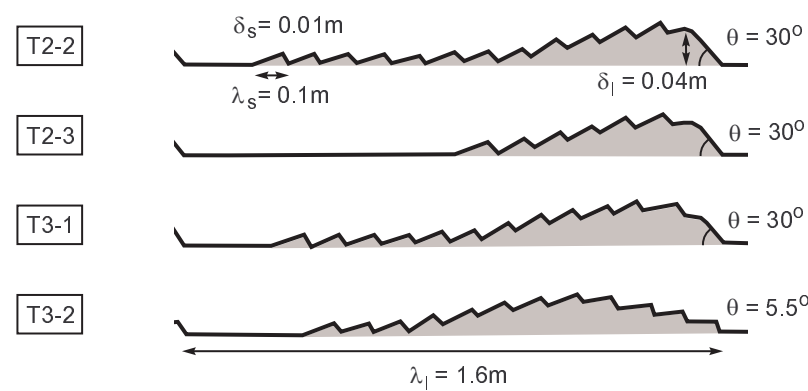

Figure 4.7: Bedform geometry in the laboratory experiments of Ogink (1989). Flow is from left to right.

single small-scale bedform: $\Delta H_{\mathrm{a}, T, s}^{\prime \prime}=N \Delta H_{\mathrm{a}, s}^{\prime \prime}$. Equation (4.33) becomes, by combining equations (4.1), (4.3), (4.30), and (4.33):

$$
c_{f, c}^{\prime \prime}=\frac{c_{1} g d^{3}}{q^{2} \lambda_{l}}\left[\gamma_{T, l} b_{l} \Delta H_{a, l}^{\prime \prime}+\gamma_{T, s} b_{s} N \Delta H_{a, s}^{\prime \prime}\right]
$$

\subsubsection{Calibration of Compound Form Drag Model}

We analyze the calibration coefficients $b_{l}$ and $b_{s}$ in equation (4.33) using the laboratory experiments of Ogink (1989). Ogink (1989) performed measurements of the flow over both single and compound uniform bedforms of concrete (Figure 4.7). For each of the four configurations, Ogink (1989) performed eight measurements in which mean water depth and discharge varied. Below we will study the values of the calibration coefficients in equation (4.33), as the remaining parameters in equation (4.33) are available from the measured data. We define the total relative error, $E_{c}$, as

$$
E_{c}=\sqrt{\frac{1}{n} \sum_{i=1}^{n}\left(\frac{c_{f, c}^{\prime \prime \text { model }}-c_{f, c}^{\prime \prime \text { meas }}}{c_{f, c}^{\prime \prime \text { meas }}}\right)^{2}}
$$

in which $n$ denotes the number of measurements $(n=32)$. We determine the optimal values for the calibration coefficients, $b_{l}$ and $b_{s}$, by searching for the minimum value of the total relative error, $E_{c}$. We find that the values $b_{l}=0.9$ and $b_{s}=1.2$ yield the minimum total relative error, $E_{c}$.

A value of $b_{l}=0.9$, i.e., a value smaller than unity, indicates that the contribution of the energy loss of the large-scale bedform to the total energy loss is smaller than without small-scale bedforms. In order to further analyze the difference in energy loss between the case with and without small-scale bedforms, we have performed (a) a numerical simulation of flow over a series of bedforms without small-scale bedforms and (b) a simulation of flow over a series of bedforms with superimposed small-scale bedforms using Ansys CFX. The two simulations, with bedform shapes similar to experiments T4-2 and T3-1 
(a)

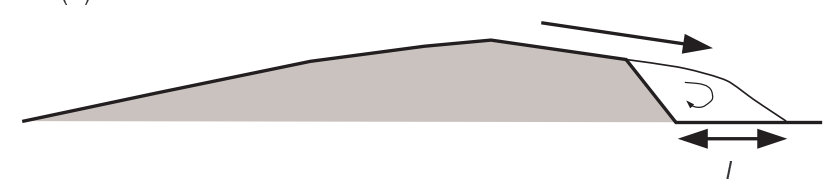

(b)

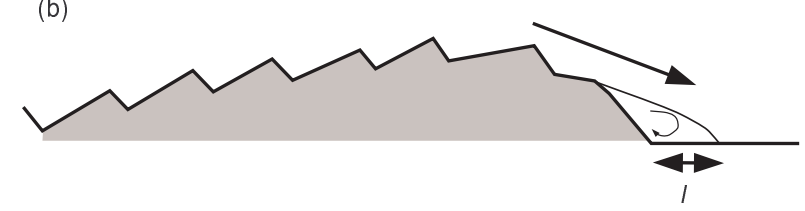

Figure 4.8: Schematization of numerical results using Ansys CFX. In case (b) the length of the flow separation zone becomes smaller than in case (a) as the stream lines at the crest of the large-scale bedform have a larger vertical component in downward direction due to the presence of small-scale bedforms. $l$ denotes the length of the flow separation zone.

of Ogink (1989), show that the length of the flow separation zone downstream of the large-scale bedform with superimposed small-scale bedforms is smaller than the one of the bedform without small-scale bedforms. This is because the streamlines at the crest of the large-scale bedform with small-scale superimposed bedforms (case b) have a larger vertical component in downward direction than without small-scale bedforms (case a) (Figure 4.8). This may explain a value smaller than unity for $b_{l}$. Please note that this experimental (flume) and numerical result may depend on the chosen configuration, and that the result may not be generally valid. The position of the most downstream small-scale bedform on the stoss face of the large-scale bedform affects the flow pattern (see e.g. Fernandez et al., 2006).

The optimal value of calibration coefficient $b_{s}$ appears to be equal to 1.2. A value larger than unity indicates that the contribution of the energy loss of the small-scale bedforms to the total energy loss is larger than without the large-scale bedforms. This may be due to our assumption that all small-scale bedforms are exposed to the same (mean) water depth and so yield equal energy loss. In fact, the small-scale bedforms are located on the sloping stoss face of the large-scale bedform and therefore experience a decreasing water depth from the trough to the crest of the large-scale bedform. Due to the nonlinear dependency of the energy loss on water depth and flow velocity, the total energy loss is larger for small-scale bedforms superimposed on large-scale bedforms than for small-scale bedforms on a flat bed under flow conditions with equal mean water depth.

Figure 4.9 shows the measured bed resistance for the experiments with compound bedforms, as well as the bed resistance predicted using equation (4.33) in combination with Engelund (1966)'s grain friction model. The results are 

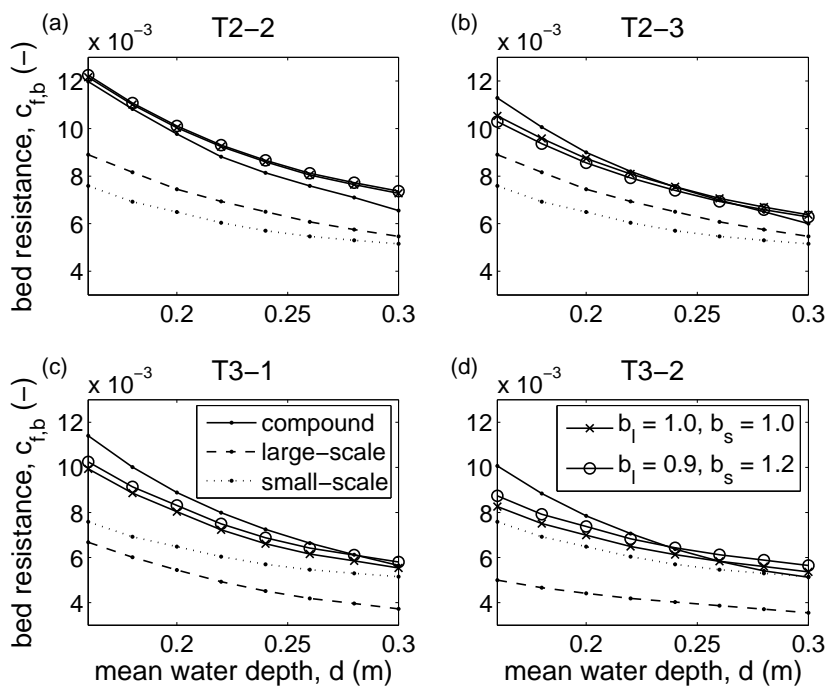

Figure 4.9: Bed resistance, $c_{f, b}$, against mean water depth, $d$, for the laboratory experiments of Ogink (1989): (a) T2-2, (b) T2-3, (c) T3-1, (d) T3-2. The legend in figure (c) applies to all subfigures and indicates the various types of measured bed resistance. The legend in figure (d) applies to all subfigures and indicates the various types of predicted bed resistance using the compound form drag model in equation (4.33).

given as function of the mean water depth, $d$, rather than the dimensionless bedform height, $\delta / d$, as in a compound situation the bedform height is not unambiguous. Summation of the components due to small-scale and large-scale bedforms appears to yield a reasonably good prediction of the bed resistance in case of compound bedforms, both in the case that the contribution of large-scale bedforms is larger than the one of small-scale bedforms (T2-2 and T2-3) and in the case that the contribution of small-scale bedforms is larger than the one of large-scale bedforms (T3-1 and T3-2). The improvement of the predictions is small when using $b_{l}=0.9$ and $b_{s}=1.2$ rather than $b_{l}=1$ and $b_{s}=1$. We therefore suggest to simply apply $b_{l}=1$ and $b_{s}=1$.

Figure 4.9 shows that for decreasing water depth the increase in measured bed resistance is larger than the increase in predicted bed resistance. Yalin and Lai (1985) also find an underestimation for relatively small mean water depths in their flume experiments. We expect that this is due to the assumption that all small-scale bedforms on a large-scale bedform experience the same water depth, and thus yield the same energy loss. This assumption is less valid for decreasing mean water depth. Predicted bed resistance may improve if one applies a varying water depth over the stoss face rather than a constant water depth for the contributions of the small-scale bedforms. 


\subsection{Discussion}

\subsubsection{Alluvial Bedforms}

For the alluvial laboratory data, it appears that the inclusion of additional physical effects, i.e., the effect of nonuniformity of the flow velocity profile via the calibration coefficient, $c_{1}$, the effects of lee face steepness, bedform interaction, deviation of flow separation zone height, and variability in bedform geometry on form drag via the total correction factor, $\gamma_{T}$, does not improve the model results (compare models A1 and A2). This may be due to the fact that (a) the assumption that the correction factors are independent of each other is not valid, (b) the submodels for the physical effects, i.e., the derived expressions for the correction factors, do not capture all relevant processes, for instance, because of insufficient data, (c) the form drag model does not capture all relevant processes, or (d) multiplication of correction factors may not be optimal. Further research is recommended on these topics in order to improve the semi-analytical form drag model.

Processes that are not incorporated in the present model, but may be relevant (also see Chapter 3), are the effects on form drag of (1) suspended load, (2) bedform migration, (3) three-dimensionality, and (4) bedform sequence. The latter two processes will be explained in the next two paragraphs.

Bedforms in the field are often three-dimensional (e.g. Nordin, 1971). Threedimensional bedforms must be defined in three dimensions, whereas two-dimensional bedforms can be adequately described by one transect parallel to the flow (Ashley, 1990). Maddux et al. (2003a,b) show that bed resistance coefficients for three-dimensional bedforms are about $50 \%$ larger than for two-dimensional bedforms. Venditti (2007) concludes that bed resistance for three-dimensional bedforms may be smaller or larger than for two-dimensional bedforms depending on the shape of the three-dimensional bedforms. A feature of three-dimensional bedforms may be that they exhibit variability in height in lateral direction (Allen, 1984). Using laboratory and field data, Van der Mark et al. (2008b) determined variability in bedform geometry in streamwise direction, which was characterized as the coefficient of variation of, for instance, bedform height. If variability in lateral and variability in streamwise direction appear to be positively correlated, this coefficient of variation of bedform height may be a proxy for the variability in bedform geometry in lateral direction. If this is true, the correction factor for variability in bedform geometry, $\gamma_{v}$, may incorporate the effect of variability in bedform geometry in lateral direction via the coefficient of variation of bedform height. It is recommended to continue research on the effect on form drag of variability in bedform geometry in lateral direction, and on the correlation between variability in bedform geometry in lateral and streamwise direction, as at the moment these effects are not well understood. Another feature of three-dimensional bedforms may be that crestlines are curved or discontinuous (e.g. Venditti et al., 2005). The effect of crest curvature or sinuosity on form drag also needs to be further investigated.

A relatively large bedform in a series of irregular bedforms may be followed, for instance, by a smaller bedform downstream or by another relatively large 
bedform downstream. In the derivation of the correction factor for variability in bedform geometry, we do not account for possible effects on form drag of the specific sequence of irregular bedforms.

The expression for the correction factor for variability in bedform geometry derived from analytical computations, accounts for the fact that form drag increases if the variability in bedform height increases. Unfortunately, it is difficult to validate this expression based on measured data, as the variability in bedform height has a more or less constant value (Van der Mark et al., 2008b). In order to analyze the effect of variability in bedform height on form drag from data, numerical or laboratory experiments of the flow over fixed bedforms should be performed. However, problematic in such numerical or laboratory experiments is that the number of bedforms in a series has to be so large that the histogram of bedform heights is representative for a probability density function with imposed coefficient of variation of bedform height.

Based on the comparison of the analytical and empirical bed resistance models applied to uniform and alluvial data in Chapter 3 and this chapter, we advise to apply the semi-analytical form drag model for two reasons: (1) a (semi-)analytical model is preferred above an empirical model, as it is plausible that an analytically-based model in which the dominant processes are included is more widely applicable than an empirical model, and (2) we expect that in field situations, for which lee face angles are often smaller than in the flume, the semi-analytical model yields the best results of the models considered. We recommend to apply the YE form drag model in case a simpler model than the semi-analytical model is preferred, as (1) it yields the best results for the alluvial flume data, and (2) it is easier to apply than the semi-analytical model.

Users of the YE form drag model or analytical form drag model should be aware of the fact that relevant physical effects, i.e., the effect of nonuniformity of the flow velocity profile (calibration coefficient, $c_{1}$ ) and the effects of lee face steepness, bedform interaction, deviation of flow separation zone height, and variability in bedform geometry on form drag (total correction factor, $\gamma_{T}$ ) are not incorporated. It appears that the neglected effect of nonuniformity of the flow velocity profile ( $c_{1}$ is of the order of 2 ) is more or less canceled out by the neglected effects described by the total correction factor $\left(\gamma_{T}\right.$ is of the order of 0.5 for the alluvial flume data). It is important to realize that in the YE form drag model and analytical form drag model, coincidentally, the neglected effects cancel out. Both models yield results comparable to the semi-analytical form drag model, in which more physical effects are included.

The YE form drag model is easier to apply than the (semi-)analytical model, as for the latter a cubic equation needs to be solved. As it is useful to apply a model that is as simple as possible, we recommend to investigate whether the YE form drag model in combination with correction factors yields better results than (1) the YE form drag model and (2) the semi-analytical form drag model.

A form drag model that consists of empirical calibration coefficients should always be applied in combination with the grain friction model that was used to determine these calibration coefficients. The semi-analytical model consists of one calibration coefficient for which a grain friction model was needed, i.e., 
the calibration coefficient, $c_{1}$, in equation (4.3).

The YE form drag model does not contain empirical calibration coefficients, so that the user is free to apply the grain friction model that he/she prefers. Although for most experiments the form drag is dominant over grain friction, the choice of the grain friction model does affect the bed resistance (compare for instance models A3 and A4, which only differ in the grain friction model).

\subsubsection{Water Depth Prediction}

In engineering practice an accurate prediction of bed resistance is important in order to correctly predict the water depth in rivers. Figure 4.3 shows that the predicted bed resistance may well be $50 \%$ smaller or larger than the measured bed resistance. In this section we analyze the effect of an error in predicted bed resistance on the water depth prediction.

For measured energy slope, $S_{\text {meas }}$, water depth, $d_{\text {meas }}$, and specific discharge, $q_{\text {meas }}$, the measured bed resistance equals

$$
c_{f, b}^{\text {meas }}=\frac{g d_{\text {meas }}^{3} S_{\text {meas }}}{q_{\text {meas }}^{2}}
$$

Using a bed resistance model and measured bedform geometry, sediment properties, and flow conditions, the bed resistance can be predicted (i.e., $c_{f, b}^{\text {model }}$ ). Using the following relations, we find the effect of an incorrectly predicted bed resistance on the predicted water depth compared to the measured water depth:

$$
d_{\text {model }}=\sqrt[3]{\frac{c_{f, b}^{\text {model }} q_{\text {meas }}^{2}}{g S_{\text {meas }}}}
$$

We express the relative error in the predicted bed resistance, $e$, as $e=\left(c_{f, b}^{\text {model }}-\right.$ $\left.c_{f, b}^{\text {meas }}\right) / c_{f, b}^{\text {meas }}$ (compare with equation (4.29)). The relative error in predicted water depth, $e_{d}$, equals $e_{d}=\left(d_{\text {model }}-d_{\text {meas }}\right) / d_{\text {meas }}$. Equation (4.37) now becomes

$$
\left(1+e_{d}\right) d_{\text {meas }}=\sqrt[3]{\frac{(1+e) c_{f, b}^{\text {meas }} q_{\text {meas }}^{2}}{g S_{\text {meas }}}}
$$

Combining equations (4.36) and (4.38) yields

$$
e_{d}=\sqrt[3]{(1+e)}-1
$$

Equation (4.39) expresses that if the predicted bed resistance is $50 \%$ smaller than the measured bed resistance $(e=-0.5)$, the water depth is underestimated by $20 \%\left(e_{d}=-0.2\right)$. Likewise, if the prediction of bed resistance is $50 \%$ larger, the water depth is overestimated by $15 \%$. This means that, for the alluvial data in Figures 4.3 and 4.5 located between the $-50 \%$ and $+50 \%$ error lines, the error in the predicted water depth would be between $-20 \%$ and $+15 \%$. It is important that the river manager is aware of this error. 


\subsection{Conclusions}

In this chapter we present an expression for the effect of variability in bedform geometry on form drag to be applied to the semi-analytical form drag model proposed by Van der Mark et al. (2009). The expression accounts for the effect that form drag increases for increasing variability in bedform height and length, and makes the model of Van der Mark et al. (2009) applicable to alluvial bedforms.

We have applied the semi-analytical model to alluvial laboratory data, and have compared the results of the model to those of existing bed resistance models to analyze the performance of the semi-analytical model. The Yalin (1964a) Engelund (1966) form drag model yields the best results for the alluvial flume data, but is expected to overestimate the bed resistance for field data. It may be expected that, for field situations in which lee face angles are often smaller than in the flume, the semi-analytical form drag model yields the best results of the considered models, as the model accounts for a decrease in form drag as the lee face angle decreases.

All considered bed resistance models yield poor results for the alluvial bedform data compared to the uniform fixed laboratory data, which is expressed by the scatter around the lines of perfect agreement. The relative error in the predicted bed resistance may well be $\pm 50 \%$, which results in an error in predicted water depth between $-20 \%$ and $+15 \%$.

In contrast to the uniform fixed data, we find that, for the alluvial data, the semi-analytical model, in which effects of lee face steepness, bedform interaction, flow separation zone height, and variability in bedform geometry, and the effect of nonuniformity of the flow velocity profile on form drag are included, does not yield better predictions of bed resistance than the analytical model and the model of Yalin (1964a) and Engelund (1966), in which these effects are not included. In the analytical model and the model of Yalin (1964a) and Engelund (1966) the neglected effects appear to cancel out.

The assumption in the Yalin (1964a) - Engelund (1966) bed resistance model that flow expansion downstream of the bedform crest can be represented by expansion of a pipe flow rather than a free surface flow appears to be justified.

Based on the analysis we suggest to apply the semi-analytical form drag model, as (a) the model is expected to yield the best results for field situations, and (b) an analytically-based model in which the dominant processes are incorporated is expected to be more widely applicable than an empirical model. The analytical Yalin (1964a) - Engelund (1966) form drag model in combination with the Engelund (1966) grain friction model is recommended if a model is preferred that is easier to apply than the semi-analytical model.

If a form drag model consists of empirical calibration coefficients, it is important to apply the grain friction model that was used when determining these coefficients together with the form drag model. Although the semi-analytical consists of one calibration coefficient (i.e., $c_{1}$ ) that depends on the applied grain friction model, the correction factors for lee face steepness, bedform interaction, flow separation zone height, and variability in bedform geometry in the semi-analytical model do not depend on a grain friction model. 
For the case of compound bedforms, we have shown that a summation of the energy loss due to individual small-scale and large-scale bedforms yields a reasonably good prediction of form drag.

In order to improve the semi-analytical form drag model we recommend further research on the reasons why inclusion of additional physical effects does not improve the model results. Furthermore, we recommend to investigate whether the YE form drag model in combination with correction factors yields better results than both the YE form drag model and the semi-analytical form drag model. The effects of three-dimensionality of bedforms on form drag also needs further analysis.

\section{A Bed Resistance Models}

This appendix describes the applied bed resistance models. Except for the bed resistance models of Van Rijn (1984), Engelund and Hansen (1967), and Wright and Parker (2004), bed resistance, $c_{f, b}$, is determined by summation of grain friction, $c_{f}^{\prime}$, and form drag, $c_{f}^{\prime \prime}$ :

$$
c_{f, b}=c_{f}^{\prime}+c_{f}^{\prime \prime}
$$

\section{Yalin (1964a) Bed Resistance Model (Model A3)}

The grain friction model of Yalin (1964a) is

$$
c_{f}^{\prime}=\frac{\lambda_{s t}}{\lambda}\left[\frac{1}{\kappa} \ln \frac{11 d}{\left.k_{s}\right|_{Y}}\right]^{-2}
$$

in which $\lambda_{s t}$ denotes the length of the bedform stoss face, $\lambda$ the mean bedform length, $d$ the mean water depth, $\kappa=0.4$ the Von Kármán constant, and $\left.k_{s}\right|_{Y}=$ $D_{50}$ the Nikuradse grain roughness height as applied by Yalin (1964a). $D_{50}$ denotes the median grain diameter. The ratio of bedform stoss face length to mean bedform length in equation (4.41) is determined using

$$
\frac{\lambda_{s t}}{\lambda}=1-\frac{\delta}{\lambda} \cot \theta
$$

in which $\delta$ denotes the mean bedform height and $\theta$ the angle of the bedform lee face.

The form drag model of Yalin (1964a) and Engelund (1966) is

$$
c_{f}^{\prime \prime}=\frac{\delta^{2}}{2 d \lambda}
$$

\section{Engelund (1966) Bed Resistance Model (Model A4)}

In the grain friction model of Engelund (1966) first the grain shear velocity, $u_{f}^{\prime}$, is found by solving the following equation (Engelund, 1966):

$$
\frac{U}{u_{f}^{\prime}}=6+\frac{1}{\kappa} \ln \left(\frac{u_{f}^{\prime 2}}{\left.g S k_{s}\right|_{E}}\right)
$$


in which $U$ denotes mean flow velocity, $g$ the gravitational acceleration, and $S$ the energy slope. The Nikuradse grain roughness height equals $\left.k_{s}\right|_{E}=2 D_{65}$, where $D_{65}$ denotes the grain diameter for which $65 \%$ of the sediment is finer (we use $D_{50}$ if $D_{65}$ is unknown from measured data). Grain friction, $c_{f}^{\prime}$, then equals

$$
c_{f}^{\prime}=\left(\frac{u_{f}^{\prime}}{U}\right)^{2}
$$

Like Yalin (1964a), Engelund (1966) uses equation (4.43) to determine the form drag.

\section{Engelund (1977) Bed Resistance Model (Model A5)}

Engelund (1977) applies the same grain friction model as Engelund (1966) (equations (4.44) and (4.45)).

Engelund (1977) extends the form drag model of Yalin (1964a) and Engelund (1966) with a calibration coefficient, $c_{E}$ :

$$
c_{f}^{\prime \prime}=c_{E} \frac{\delta^{2}}{2 d \lambda}
$$

in which $c_{E}=2.5 \exp (-2.5 \delta / d)$.

\section{Karim (1999) Bed Resistance Model (Model A6)}

The grain friction model of Karim (1999) is

$$
c_{f}^{\prime}=0.016875\left(\frac{D_{50}}{d}\right)^{0.33}
$$

and his form drag model is

$$
c_{f}^{\prime \prime}=K_{1} C_{1} \frac{\delta}{\lambda}
$$

in which $K_{1}=0.55\left(\frac{\delta}{d}\right)^{0.375}\left(\frac{\lambda}{d}\right)^{-0.2}$ for the dune, ripple, and transitional regime, and $C_{1}=0.85$.

\section{Vanoni and Hwang (1967) Bed Resistance Model (Model E1)}

Vanoni and Hwang (1967) determine the value of the grain friction, $c_{f}^{\prime}$, from a graph of the friction factor against Reynolds number for several values of the relative roughness (i.e., the Moody diagram). We apply the following expression for the grain friction (Colebrook, 1939), which yields the same values of the grain friction for their data as Vanoni and Hwang (1967) determined from the Moody diagram:

$$
c_{f}^{\prime}=\frac{1}{8}\left[1.8 \log \left(\frac{\left.R e\right|_{V H}}{7}\right)\right]^{-2}
$$


in which $\left.R e\right|_{V H}=4 U R_{b} / \nu$ denotes the Reynolds number, $R_{b}$ the hydraulic radius related to the bed, and $\nu$ the kinematic viscosity. The hydraulic radius related to the bed equals (Vanoni and Brooks, 1957)

$$
R_{b}=R \frac{c_{f, b}}{c_{f, T}}
$$

in which $c_{f, T}$ denotes the total resistance coefficient.

The form drag model of Vanoni and Hwang (1967) is

$$
c_{f}^{\prime \prime}=\frac{1}{8}\left[3.3 \log \left(\frac{R_{b} \lambda}{\delta^{2}}\right)-2.3\right]^{-2}
$$

\section{Van Rijn (1984) Bed Resistance Model (Model E2)}

The empirical model of Van Rijn (1984) is based on a physically incorrect summation of Nikuradse grain roughness height and bedform roughness height:

$$
\left.k_{s}\right|_{R}=3 D_{90}+1.1 \delta\left[1-\exp \left(\frac{-25 \delta}{\lambda}\right)\right]
$$

in which $D_{90}$ denotes the grain diameter for which $90 \%$ of the sediment is finer.

Bed resistance is then determined using

$$
c_{f, b}=g\left[18 \log \left(\frac{12 R_{b}}{\left.k_{s}\right|_{R}}\right)\right]^{-2}
$$

\section{Engelund and Hansen (1967) Bed Resistance Model (Model E3)}

In the Engelund and Hansen (1967) bed resistance model first the water depth due to grain friction, $d^{\prime}$, is found by solving the following equation:

$$
\frac{U}{\sqrt{g d^{\prime} S}}=9.45\left(\frac{d^{\prime}}{\left.k_{s}\right|_{E H}}\right)^{1 / 8}
$$

in which $\left.k_{s}\right|_{E H}=2.5 D_{50}$. This equation is an approximation of equation (4.44) (Engelund and Hansen, 1967). Dimensionless grain shear stress, $\tau_{*}^{\prime}$, is then determined using

$$
\tau_{*}^{\prime}=\frac{d^{\prime} S}{\left(\rho_{s} / \rho-1\right) D_{50}}
$$

in which $\rho$ denotes the water density and $\rho_{s}$ the sediment density. Dimensionless bed shear stress, $\tau_{*}$, now follows from

$$
\tau_{*}=\sqrt{\frac{\tau_{*}^{\prime}-0.06}{0.4}}
$$

Please note that the dimensionless bed shear stress becomes complex-valued if the dimensionless grain shear stress is smaller than 0.06. The grain friction, $c_{f}^{\prime}$, and bed resistance coefficient, $c_{f, b}$, equal, respectively

$$
c_{f}^{\prime}=\frac{\tau_{*}^{\prime} g\left(\rho_{s} / \rho-1\right) D_{50}}{U^{2}}
$$


and

$$
c_{f, b}=\frac{\tau_{*} g\left(\rho_{s} / \rho-1\right) D_{50}}{U^{2}}
$$

\section{Wright and Parker (2004) Bed Resistance Model (Model E4)}

The bed resistance model of Wright and Parker (2004) is an extension of the Engelund and Hansen (1967) model. The water depth due to grain friction, $d^{\prime}$, is first found by solving the following equation:

$$
\frac{U}{\sqrt{g d^{\prime} S}}=\frac{8.32}{\alpha_{s}}\left(\frac{d^{\prime}}{\left.k_{s}\right|_{W P}}\right)^{1 / 6}
$$

in which $\left.k_{s}\right|_{W P}=3 D_{90}$ and $\alpha_{s}$ denotes a stratification coefficient for which we apply $\alpha_{s}=1$, as information on sediment concentration is not available. A value of $\alpha_{s}=1$ corresponds to the situation that the total sediment concentration at $5 \%$ of the water depth above the bed equals zero. The dimensionless grain shear stress, $\tau_{*}^{\prime}$, is then determined using equation (4.55). The dimensionless bed shear stress, $\tau_{*}$, follows from

$$
\tau_{*}=\frac{\left(\frac{\tau_{*}^{\prime}-0.05}{0.7}\right)^{5 / 4}}{F r^{0.7}}
$$

in which $F r$ denotes the Froude number. The grain friction, $c_{f}^{\prime}$, and bed resistance coefficient, $c_{f, b}$, are determined using equations (4.57) and (4.58), respectively.

\section{Haque and Mahmood (1983) Bed Resistance Model (Model E5)}

Haque and Mahmood (1983) apply the following grain friction model (K. Mahmood, pers. comm., 2009):

$$
c_{f}^{\prime}=\left[5.75 \log \left(\frac{12.27 R}{D_{65}}\right)\right]^{-2}
$$

and the form drag model of Haque and Mahmood (1983) is

$$
c_{f}^{\prime \prime}=0.6125\left(\frac{0.8 \delta}{\lambda}\right)^{1.477}\left(\frac{0.8 \delta}{d-\frac{1}{2} \delta}\right)^{0.176}
$$

\section{B Notation}

$b_{l} \quad$ calibration coefficient accounting for the effect of deviating energy loss of a large-scale bedform due to presence of small-scale bedforms, dimensionless.

$b_{s} \quad$ calibration coefficient accounting for the effect of deviating energy loss of a small-scale bedform due to presence of large-scale bedforms, dimensionless. 
$c_{E} \quad$ calibration coefficient in form drag model of Engelund (1977), dimensionless.

$c_{f}^{\prime} \quad$ grain friction coefficient, dimensionless.

$c_{f}^{\prime \prime} \quad$ form drag coefficient, dimensionless. sidewall friction coefficient, dimensionless.

$c_{f, b} \quad$ bed resistance coefficient, dimensionless.

$c_{f, \text { ref }}^{\prime \prime} \quad$ reference form drag coefficient, i.e., form drag for the reference situation, dimensionless.

$c_{f, T} \quad$ total resistance coefficient, dimensionless.

$C_{1} \quad$ parameter in form drag model of Karim (1999), dimensionless.

$c_{1} \quad$ calibration coefficient relating the reference energy loss to the analytical energy loss, dimensionless.

$C_{\delta} \quad$ coefficient of variation of bedform height, dimensionless.

$d \quad$ mean water depth, m.

$d^{\prime} \quad$ water depth due to grain friction, $\mathrm{m}$.

$D_{c} \quad$ coverage degree of small-scale bedforms, dimensionless.

$d_{t} \quad$ water depth at the bedform crest, $\mathrm{m}$.

$D_{x} \quad$ grain diameter for which $x \%$ of the sediment is finer, $\mathrm{m}$.

$d_{2} \quad$ water depth at cross-section 2, i.e., downstream of the influence zone of the bedform, $\mathrm{m}$.

$D_{50} \quad$ median grain diameter, $\mathrm{m}$.

$E$ total relative error between measured and predicted bed resistance, dimensionless.

$e \quad$ relative error between measured and predicted bed resistance, dimensionless.

$E_{c} \quad$ total relative error between measured and predicted bed resistance for the compound bedform data, dimensionless.

$e_{d} \quad$ relative error between measured and predicted water depth, dimensionless.

$\mathrm{Fr} \quad$ Froude number, dimensionless.

$G \quad$ parameter in expression for $\gamma_{v}$, dimensionless.

$g \quad$ gravitational acceleration, $\mathrm{m} / \mathrm{s}^{2}$.

$H \quad$ energy head averaged over a cross-section, $\mathrm{m}$.

$i \quad$ subscript referring to the bedform number in a series, dimensionless.

$J \quad$ parameter in expression for $\gamma_{v}$, dimensionless.

$K_{1} \quad$ parameter in form drag model of Karim (1999), dimensionless.

$K \quad$ parameter in expression for $\gamma_{v}$, dimensionless.

$k_{s} \quad$ Nikuradse grain roughness height, $\mathrm{m}$.

$L \quad$ flume length or length of channel section, $\mathrm{m}$.

$l \quad$ length of the flow separation zone, $\mathrm{m}$.

$N \quad$ number of bedforms, dimensionless.

$n \quad$ sample size, dimensionless.

$p\left(X_{i}\right) \quad$ probability mass function for discrete random variable $X$, dimensionless.

$q \quad$ specific discharge, $\mathrm{m}^{2} / \mathrm{s}$.

$R \quad$ hydraulic radius, $\mathrm{m}$. 
$R_{b} \quad$ hydraulic radius related to the bed, $\mathrm{m}$.

Re Reynolds number, dimensionless.

$S \quad$ energy slope, equal to bed slope under uniform conditions, dimensionless.

$U \quad$ mean flow velocity, i.e., averaged over cross-sectional area, $\mathrm{m} / \mathrm{s}$.

$u_{f}^{\prime} \quad$ shear velocity due to grain friction, $\mathrm{m} / \mathrm{s}$.

$W \quad$ channel width, m.

$\alpha_{s} \quad$ stratification coefficient in form drag model of Wright and Parker (2004), dimensionless.

$\gamma_{f} \quad$ correction factor for flow separation zone (FSZ) height, dimensionless.

$\gamma_{i} \quad$ correction factor for bedform interaction, dimensionless.

$\gamma_{s} \quad$ correction factor for lee face steepness, dimensionless.

$\gamma_{T} \quad$ total correction factor taking into account effects due to deviations from the reference situation, dimensionless.

$\gamma_{v} \quad$ correction factor for variability in bedform geometry, dimensionless.

$\Delta H_{a}^{\prime \prime} \quad$ analytical energy loss, i.e., energy loss due to expansion based on the analytical one-dimensional approach, $\mathrm{m}$.

$\Delta H_{a, T}^{\prime \prime} \quad$ total analytical energy loss of a series of bedforms, $\mathrm{m}$.

$\delta \quad$ mean bedform height, $\mathrm{m}$.

$\delta_{f} \quad$ height of the flow separation zone, $\mathrm{m}$.

$\delta_{l} \quad$ height of large-scale bedform, $\mathrm{m}$.

$\delta_{s} \quad$ height of small-scale bedform, $\mathrm{m}$.

$\theta \quad$ mean angle of bedform lee face, ${ }^{\circ}$.

$\kappa \quad$ Von Kármán constant, dimensionless.

$\lambda$ mean bedform length, i.e., the distance between two subsequent bedform crests, $\mathrm{m}$.

$\lambda_{l} \quad$ length of large-scale bedform, $\mathrm{m}$.

$\lambda_{s} \quad$ length of small-scale bedform, $\mathrm{m}$.

$\lambda_{\text {st }} \quad$ length of the bedform stoss face, $\mathrm{m}$.

$\nu \quad$ kinematic viscosity, $\mathrm{m}^{2} / \mathrm{s}$.

$\rho \quad$ water density, $\mathrm{kg} / \mathrm{m}^{3}$.

$\rho_{s} \quad$ sediment density, $\mathrm{kg} / \mathrm{m}^{3}$.

$\tau_{*} \quad$ dimensionless bed shear stress, dimensionless.

$\tau_{*}^{\prime} \quad$ dimensionless grain shear stress, dimensionless.

Acknowledgments The authors acknowledge Yasuyuki Shimizu and RobertJan Labeur for their contribution to the numerical analysis. KNAW-DJA is acknowledged for supporting a visit to Japan by the first author. We acknowledge Chris Boeije and Jim Kok for answering questions on the numerical model system Ansys CFX. This research project, which is part of the VICI project Rough Water, is supported by the Technology Foundation STW, applied science division of the Netherlands Organization for Scientific Research (NWO) and the technology programme of the Ministry of Economic Affairs. 


\section{Chapter 5}

\section{Discussion}

In this chapter we discuss (as far as not already discussed in the previous chapters) the assumptions made in the derivation of the form drag model and aspects that are not taken into account in the form drag model (Section 5.1). Section 5.2 describes the possible fields of application of the form drag model. In Section 5.3 we describe how the semi-analytical form drag model can be incorporated in a large-scale morphodynamic model system.

\subsection{Assumptions and neglected aspects}

\subsubsection{Independency of correction factors}

In the derivation of the form drag model we have assumed that the four correction factors are independent. Although not analyzed in the present study, the following aspects may give rise to a dependency of the correction factors:

1. Let us consider case A in which a series of bedforms is present with a certain lee face angle. Case B is equal to case A except for its significantly larger bedform length. The horizontal length of the stoss face in case A is smaller, and thus steeper, than the one in case B, as bedform height and lee face angle are equal for both cases. In case A the flow separation zone may be restricted in its size, as the stoss face is steeper. This may imply that the correction factors for lee face steepness and flow separation zone height are related to the correction factor for bedform interaction.

2. Let us consider a series of closely spaced bedforms that vary in size. A bedform just downstream of a relatively large bedform causes less energy loss than the same bedform just downstream of a relatively small bedform. Our expression for the correction factor for bedform interaction does not account for this potential relation with the correction factor for variability in bedform geometry.

In this study we have neglected the above aspects. We expect, however, that the effects on form drag of the (independent) correction factors are more significant than the effects of the dependency between the correction factors. It is recommended to further investigate if the effects of potential relations between the correction factors are significant and, if so, how they can be incorporated in the model. 


\subsubsection{Hydrostatic pressure distribution}

The equation for the analytical energy loss due to a sudden expansion of a free surface flow downstream of a bedform, $\Delta H_{a}^{\prime \prime}$, which is applied to determine the reference form drag, is the equation for energy loss due to a sudden expansion downstream of a broad-crested weir. A broad-crested weir is a structure of which the flat crest extends in downstream direction for such a length that the streamlines at the crest are parallel to the crest. As such, in the equation for energy loss the pressure at the weir crest may be assumed to be distributed hydrostatically (e.g. Henderson, 1966). Likewise, in the derivation of the form drag model, we assume that the bedform crest extends over such a reach that streamlines above the crest are parallel to the bed, so that the pressure at the crest of the bedform is distributed hydrostatically.

Results of the numerical simulations which are described in Sections 3.4.2 and 3. C have shown that the pressure is approximately distributed hydrostatically at the bedform crest. Also Blom (1993) concludes from his numerical simulations of flow over a sill with varying crest length and stoss and lee faces that the pressure distribution may be approximated by a hydrostatic pressure distribution, even for steep stoss and lee faces and for high Froude numbers. We therefore expect that the assumption of hydrostatic pressure at the crest of a bedform is justified.

In the reference form drag model, a hydrostatic pressure distribution is also imposed downstream of the influence zone of the bedform, i.e., at cross-section 2 (Section 3.3.2). This is indeed allowed for a solitary bedform for which the flow pattern is not affected by surrounding bedforms. The correction factor for bedform interaction, $\gamma_{i}$, accounts for the effect that the flow pattern around a bedform is affected by its surrounding bedforms.

\subsubsection{Grain size distribution}

The grain size distribution of the sediment affects the form drag in two ways:

1. The grain size distribution of the bed surface and flow conditions together affect the rate and grain size distribution of the transported sediment and so the bedform geometry. Models for bedform length and height are a function of a transport parameter and the median diameter of the sediment (e.g. Van Rijn, 1984). Bedform geometry affects the form drag, so that, indirectly, the grain size distribution affects the form drag. Please note that in this thesis the focus is not on the derivation of a model for bedform geometry, but on the derivation of a form drag model provided that the bedform geometry is known. As such, it is not needed to incorporate the indirect effect of the sediment properties on form drag in the form drag model since this effect is already expected to be included in the bedform geometry known from predictions or measurements.

2. Form drag is affected by suspended sediment, since suspended sediment load tends to dampen turbulence (Vanoni and Nomicos, 1960), and thereby reduces the resistance to flow (e.g. Richards, 1982; Khullar et al., 2007). We have not incorporated this effect in the form drag model. Also the 
potential effect on form drag of bedform migration is neglected in the derivation of the form drag model, as we expect that the effect is not significant. Further research is needed to analyze the effect of suspended load and potential effect of bedform migration on form drag, as these effects are not yet well understood.

\subsubsection{Boundary shear stress}

In the derivation of the semi-analytical form drag model in Chapters 3 and 4, we apply the assumption that the total boundary shear stress, $\tau_{T}$, is related to the squared mean flow velocity, $U^{2}$ (see equation (3.2)) as follows:

$$
\tau_{T}=c_{f, T} \rho U^{2}
$$

Please note that, for instance in the research field of engineering fluid dynamics, usually $\tau_{T}=\frac{1}{2} \widetilde{c}_{f, T} \rho U^{2}$ is applied $\left(c_{f, T}=\frac{1}{2} \widetilde{c}_{f, T}\right)$ rather than equation (5.1). Equation (5.1) is a generally applied assumption in the shallow water equations which originates from the analogy with equilibrium turbulent boundary layers (e.g. Vreugdenhil, 1994). All considered form drag models apply this assumption. In shallow water flows such as river flows, the boundary layer thickness is usually of the order of the water depth, so that shallow water flows are classified as boundary-layer type flows, for which the above assumption is justified (Vreugdenhil, 1994).

\subsubsection{Water temperature, viscosity, and Reynolds number}

Water temperature and viscosity, which is a function of the water temperature, affect the bedform geometry (e.g. Haushild et al., 1961; Hubbell and AlShaikh Ali, 1961; Franco, 1968; Southard and Boguchwal, 1990). As the bedform geometry affects the form drag, the water temperature, indirectly, affects the form drag. This indirect effect is not incorporated in the form drag model, as the focus is not on the derivation of a model for bedform geometry.

The Reynolds number, which is a function of viscosity, may not only affect form drag via the indirect effect of temperature and viscosity on bed configuration, but may also affect form drag directly. From laboratory data it is known that the drag coefficient, $C_{d}$, which is a dimensionless quantity often used to quantify the resistance of an object in a fluid, is a function of the Reynolds number related to the characteristic length of the object, $R e_{L}$ (e.g. Hoerner, 1965; Fox and McDonald, 1994). Experimental data of flow around obstacles (e.g. cylinders or spheres) show that for increasing Reynolds numbers the drag coefficient becomes nearly constant (e.g. Hoerner, 1965; Fox and McDonald, 1994). The effect of the Reynolds number on form drag is not accounted for in the semi-analytical form drag model, as we expect that the effect is not significant.

\subsubsection{Summary of neglected effects}

In Chapters 3, 4 and the present chapter, we have discussed a number of effects that the present semi-analytical model does not account for. Recapitulating, 
the following aspects need further investigation with respect to their effects on form drag:

- the effect on form drag of assuming that correction factors are independent

$\circ$ the effect of suspended load on form drag

○ the effect of three-dimensionality (e.g., variability in bedform geometry in lateral direction, crest sinuosity) on form drag

o the potential effect of bedform migration on form drag

○ the potential effect of bedform sequence on form drag

\subsection{Fields of application of the form drag model}

\subsubsection{Bedforms under unidirectional flow}

The following bedform regimes may occur in case of a subcritical unidirectional flow $(\mathrm{Fr}<1)$ depending on flow and sediment properties: ripple regime, regime of dunes with ripples superimposed, dune regime, washed-out dunes or transition regime (Simons and Richardson, 1961). Standing waves and antidunes may occur under a supercritical unidirectional flow $(F r>1)$ (Simons and Richardson, 1961). In the case of standing waves or antidunes, the bed undulations are in phase with the free surface undulations (Figure 5.1), so that streamlines are more or less parallel to the bed. Under this condition the flow separation zone and form drag are much smaller compared to the situation of equal bedform height and a Froude number smaller than unity (Simons and Richardson, 1961). The semi-analytical form drag model as presented in Chapters 3 and 4 describes the energy loss in situations in which the Froude number is smaller than unity, and also the formulations for the correction factors are derived for situations in which the Froude number is smaller than unity. As such, the present semianalytical form drag model is not applicable to situations in which the Froude number is larger than unity. It is not clear whether the model can be easily extended to situations with Froude numbers larger than unity. First, it needs to be analyzed whether a form drag model based on flow expansion is a suitable basis for supercritical flow, as flow expansion may not be the relevant mechanism for form drag in this situation. However, such an analysis is beyond the scope of this thesis.

It may be expected that the semi-analytical form drag model is applicable to unidirectional flow over desert sand dunes originated by wind, as these dunes may have the same asymmetric shape as the bedforms considered in this thesis, and may cause flow separation (e.g. Bristow et al., 2000).

\subsubsection{Bedforms under bi- or multidirectional flow}

The semi-analytical form drag model is developed and validated for situations of unidirectional flow over bedforms. Bedforms under bidirectional flow (e.g. wave-dominated ripples, megaripples, sand waves, sand banks in a marine or 
(a)

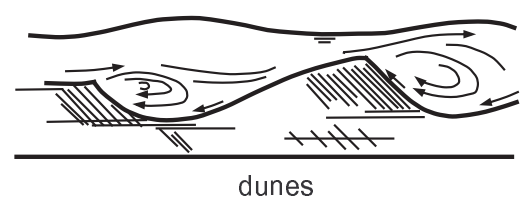

(b)

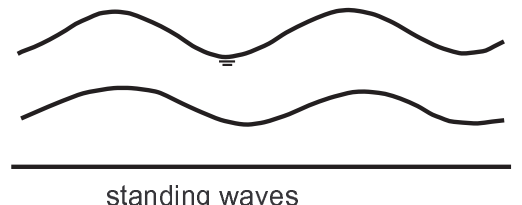

Figure 5.1: Schematic representation of (a) dunes and (b) standing waves (from Richardson et al., 1962).

estuarine environment) may cause energy loss due to flow expansion in the lee side of the bedform, of which the location alternates with the direction of the flow. Provided that flow conditions and (models for) bedform geometry are available, we expect that the semi-analytical form drag model may be capable of predicting the energy loss in the lee side of the bedform under bidirectional flow conditions. The following two aspects are, however, important:

1. The time that is needed for a bedform to adapt after a flow reversal with respect to the period between two successive flow reversals is an important parameter for assessing whether the semi-analytical form drag model can be applied.

A relatively small value of the ratio of adaptation time to flow reversal period means that an equilibrium bedform shape may quickly be reached, and that the bedform shape does not change during some time. It may then be possible to apply the form drag model using the equilibrium bedform geometry.

A relatively large value of the ratio of adaptation time to flow reversal period means that an equilibrium bedform shape may never be reached, and that the bedform shape is constantly evolving. The semi-analytical form drag model can be applied for each time step if the bedform shape is known for each time step.

Please note that, also for situations of unidirectional unsteady flow, bedforms need to adapt to changed flow conditions. In rivers, flow conditions usually change slowly, so that it may be allowed to assume that bedforms are in equilibrium shape each time step. If flow conditions change more rapidly, it may be required to apply a bedform evolution model.

2. In developing the semi-analytical form drag model we have assumed that energy loss only occurs downstream of the bedform crest, as bedforms under unidirectional flow usually have a gentle stoss and steeper lee face. If a bedform has such an asymmetric shape, and the flow reverses, the new stoss face may be so steep that energy loss also occurs at the stoss face. Furthermore, because of the relatively steep stoss face, the flow separation zone downstream of the bedform becomes larger, as the stream lines at the 
stoss have a larger vertical component in upward direction (see Chapter 3). The correction factor for flow separation zone height accounts for this effect. A model for the ratio of flow separation zone height to bedform height is then needed, which is based on, for instance, the stoss face angle.

\subsubsection{Groynes}

Flood plains of rivers can contain a variety of obstacles, e.g. levees, spillways or spur dikes, which affect the flow and its conveyance capacity. Training works such as groynes or spur dikes are constructed to prevent erosion of the banks and to keep the main channel navigable. Under flood conditions obstacles as groynes may be submerged which may have an effect on the conveyance capacity of the river. The resistance to flow of obstacles such as groynes can be determined using (Yossef, 2005) (a) a drag force formulation (e.g. Aya et al., 1997; Yossef, 2005) or (b) by representing the groyne as a submerged weir (e.g. Mosselman and Struiksma, 1992). Both approaches contain an empirical coefficient, the drag coefficient and the discharge coefficient, respectively, accounting for sitespecific aspects such as the length of the groynes with respect to the river width, the stoss and lee face angles of the obstacle, the orientation with respect to the mean flow direction, or the material of the obstacle.

We expect that the approach followed in the derivation of the semi-analytical form drag model, i.e., a reference form drag times correction factors accounting for deviations from the reference situation, may be useful for determining the resistance to flow of groynes or other obstacles. The reference form drag may be determined from the analytical expression for abrupt expansion, comparable to the approach of Mosselman and Struiksma (1992), and the site-specific aspects may be represented by correction factors. Comparing energy loss of a series of groynes to energy loss of bedforms, the groynes have the advantage that they are fixed, the geometry is relatively clearly defined, and they usually do not vary in geometry. We recommend further research on the potential applicability of the semi-analytical model to (series of) groynes.

\subsection{How to apply the form drag model in a morphody- namic model system}

Morphodynamic model systems are important tools in the prediction of water depths and flow velocities, for instance during a flood event, for given (specific) discharge, bed slope, river width, and grain size distribution. Here we define a morphodynamic model system as a system that couples modules for calculating the flow, sediment transport, and morphodynamic changes.

To analyze the large-scale and long-term hydrodynamic and morphodynamic behavior of a river reach, the micro-scale morphodynamic behavior of individual river bedforms is not explicitly solved in the morphodynamic model system because of the required large computational effort. The effect of bedform geometry on the bed resistance is incorporated in such a model system by calculating for each spatial and temporal step the bedform geometry, bed resistance, and flow 
conditions based on the known conditions of the previous temporal and spatial step. Calculation of bedform geometry and bed resistance is done iteratively, as (a) bedform geometry depends on the flow conditions, (b) flow conditions depend on the bed resistance, and (c) bed resistance depends on the bedform geometry.

The semi-analytical form drag model can be incorporated in a morphodynamic model system. In the calculation it is assumed that the resistance relation for steady flow is also applicable to unsteady flow (e.g. Stelling and Verwey, 2005), for instance a flood. Upstream and downstream boundary conditions, for instance, the upstream discharge as a function of time and the downstream water depth, need to be known, just as the initial flow conditions for each spatial step. The following steps need to be followed for each spatial and temporal step in case the semi-analytical form drag model is applied in a morphodynamic model system:

1. Provide a first estimate of the water depth based on the conditions in previous spatial and temporal steps.

2. Determine the type of bedform regime using an existing bedform classification diagram.

3. Determine bedform geometry, i.e., equilibrium bedform height and equilibrium bedform length using existing bedform predictors.

4. Determine the actual bedform height and bedform length using an existing bedform evolution model. Such a model may be needed, as there may exist a time-lag between changing flow conditions and changing bedform geometry, so that bedform geometry is not always in equilibrium state. A bedform evolution model is not needed if it is assumed that for each time step the bedform geometry is in equilibrium.

5. Estimate the bedform lee face angle based on, for instance, the information in Section 2.5.1 and Figure 2.7e. Estimate the ratio of flow separation zone height to bedform height based on, for instance, information in Section 3.4.4. Estimate variability in bedform geometry using equation (4.24).

6. Determine the form drag coefficient using equations (4.1)-(4.7), and equations (4.18), (4.8), (4.9), and (4.10). Equations (4.5) and (4.6) are needed to solve the water depths at the bedform crest and downstream of the influence zone of the bedform. The two equations can be rewritten into a cubic equation that can be solved analytically using Cardano's method (Section 3.B).

7. Determine the grain friction using an existing grain friction model.

8. Determine the bed resistance by summation of grain friction and form drag.

9. Determine the flow velocity, $U$, from the momentum conservation relation and the mass conservation equation. 
10. Determine the water depth from the discharge and mean flow velocity $(d=q / U)$. This water depth is the new estimate of water depth.

11. Repeat the steps $2-10$ until the water depth of step 10 does not evolve anymore.

The steps may differ from the steps above if another bed resistance model is applied. For instance, if the bed resistance model of Engelund and Hansen (1967) is applied, bedform geometry and form drag (steps 3-6) do not need to be determined as this model predicts form drag indirectly based on a relation between grain friction and bed resistance.

The list of steps illustrates which additional submodels are needed in case the semi-analytical form drag model is applied for prediction of water levels, for instance during a flood. The following additional models are needed: (1) a grain friction model, (2) a model that predicts what type of bed configuration occurs (e.g. plane bed, dunes), (3) models that predict equilibrium bedform geometry if bedforms are present, i.e., bedform height, bedform length, lee face steepness, variability in bedform height, brink point height, and (4) if chosen, a model for evolution of bedform geometry.

If the equations are solved numerically, and if a suitable numerical scheme, mesh and time step are applied, iteration may not be needed (K. Sloff, pers. comm., 2009). Please note that we do not include details on numerical aspects such as the numerical scheme, the possibility to distinguish between a hydraulic and morphological time scale in the computation, or the discretization of the equations, as our purpose here is to provide a conceptual description of what aspects needs to be considered when implementing the form drag model in a morphodynamic model system.

As discussed in Section 5.1, the bed resistance relates the bed shear stress to the mean velocity. A depth-averaged velocity is needed to be able to apply the form drag model in the morphodynamic model system. 


\section{Chapter 6}

\section{Conclusions and recommendations}

In Section 6.1 answers will be given to the research questions. In Section 6.2 the author will recommend on topics that require further investigation.

\subsection{Conclusions}

Q1. How can variability in bedform geometry be quantified?

Using laboratory flume and field data of bedforms, it is found that bedform height, bedform length, crest elevation, trough elevation, and lee face slope are best described by a positively skewed distribution such as the Weibull distribution.

Linear relations exist between standard deviation and mean value for bedform height, bedform length, crest elevation, and trough elevation, if the ratio of width to hydraulic radius is larger than about ten. As such, a constant coefficient of variation can be applied to quantify variability in bedform geometry.

The extreme values of the geometric variables (the $95 \%$ and $98 \%$ values are considered in this study) scale with the specific standard deviation of the geometric variable, so that, if the mean values for the geometric variables are known, we are able to predict the extremes using the proposed scaling relations.

\section{Q2. Which physical mechanisms are relevant to form drag?}

Form drag equals resistance to flow due to the pressure gradient along a bedform. Downstream of the bedform crest the flow expands, and thus decelerates. This leads to an increase in pressure downstream of the bedform. The physical mechanism relevant to form drag is the flow expansion, or the deceleration of the flow, downstream of the bedform.

The deceleration of the flow downstream of a bedform and increase in pressure may give rise to flow separation and a recirculation of the flow downstream of the bedform. Energy loss occurs in the flow separation zone. The size of the flow separation zone therefore is a measure for the rate of form drag. Please note that form drag may, however, also be present if the flow does not separate, for instance due to water surface fluctuations. This is also found in numerical simulations in which the flow does not separate due to the very gentle lee face angle of $10^{\circ}$ (Chapter 3 ). 


\section{Q3. Which physical quantities are relevant to form drag?}

Quantities affecting form drag are those quantities that affect the rate of flow expansion downstream of bedforms:

1. mean bedform height,

2. bedform steepness,

3. water depth,

4. Froude number,

5. angle of the bedform lee face,

6. bedform shape parameters that affect the height of the flow separation zone with respect to the bedform height,

7. bedform spacing,

8. variability in bedform geometry in streamwise direction,

9. three-dimensionality of bedforms,

10. suspended sediment load.

All (semi-)analytical and explicit empirical form drag models as considered in Chapter 4 are a function of only the first three quantities. The implicit empirical form drag models of Engelund and Hansen (1967) and Wright and Parker (2004) relate grain friction to bed resistance, and therefore are not a function of bedform geometry.

\section{Q4. How do the relevant quantities affect form drag?}

The above-mentioned quantities affect form drag, as they determine the rate of flow expansion, and (if present) the size of the flow separation zone downstream of a bedform.

The larger the bedform height, the more the flow is disturbed, and the more energy loss occurs (quantity 1). An increasing ratio of mean bedform height to mean water depth (quantities 1 and 3) or an increasing Froude number (quantity 4) yields an increase in form drag. The larger the bedform steepness (quantity 2 ), which is defined as the ratio of bedform height to bedform length, generally the less streamlined is the bedform, and the larger is the form drag.

It has been shown that, for lee face angles smaller than about $50^{\circ}$, a decrease in lee face angle yields a decrease in form drag, and, for lee face angles between about $50^{\circ}$ and $90^{\circ}$, the form drag is roughly independent of the lee face angle (quantity 5).

The shape of the bedform may be such that the height of the flow separation zone differs from the bedform height. A brink point, in this thesis defined as the point where the flow separates from the bed surface and which is located between the bedform crest and trough, may be present. The flow separation zone height is smaller than the bedform height if a brink point is present (quantity 6). 
For a very large bedform spacing, the flow pattern over a bedform is not or hardly affected by the flow patterns over surrounding bedforms. If the bedform spacing decreases, flow patterns over subsequent bedforms influence each other, and the form drag decreases (quantity 7 ).

The equation for energy loss due to an abrupt flow expansion based on the momentum and energy conservation equations is a nonlinear function of the expansion height, such that, under the condition that the mean bedform height is the same, the total energy loss is larger for a series of irregular bedforms than for regular bedforms. As such, for increasing variability in bedform geometry in streamwise direction the form drag increases (quantity 8).

In developing a new form drag model, the effects on form drag of suspended load (quantity 9) and three-dimensionality of bedforms (quantity 10) are not incorporated. Also potential other effects on form drag due to bedform migration and bedform sequence are not incorporated in the form drag model. The mentioned effects on form drag are not incorporated, as they are not yet well understood.

\section{Q5. How can the relevant quantities be incorporated in a form drag model?}

A new semi-analytical form drag model has been developed, which is based on the analytical form drag models of Yalin (1964a) and Engelund (1966), and Karim (1999). An analytically-based form drag model is preferable above an empirical model as an analytically-based model in which the dominant processes are incorporated is likely to be wider applicable than an empirical model.

The semi-analytical form drag model consists of two components:

1. an analytically-based reference form drag model, accounting for the energy loss associated with a deceleration of the flow downstream of the bedform due to a sudden expansion of a free surface flow. The analytically-based reference form drag model is a function of the ratio of mean bedform height to mean water depth, the bedform steepness, and the Froude number. The effect of nonuniformity of the flow velocity profile is accounted for through the calibration coefficient, $c_{1}$.

2. an empirical coefficient, i.e., the total correction factor, taking into account effects on form drag of (a) the angle of the lee face, (b) the deviation of the flow separation zone height from the bedform height, (c) the bedform spacing, and (d) variability in bedform geometry. The total correction factor is a function of four correction factors, each accounting for one of the four effects. The effects of the four correction factors on form drag are assumed to be independent of each other.

The numerical software package Ansys CFX has been used to analyze the effect of lee face steepness and bedform spacing on form drag. A validation of the numerical model to laboratory data of the flow over uniform fixed bedforms shows that Ansys CFX is well capable of simulating flow velocities, form drag, and the free surface elevation. The correction factor for lee face steepness 
incorporates the effect that the flow downstream of a bedform crest expands gradually rather than abruptly. It increases with increasing lee face angle and equals more or less unity for lee face angles larger than about $50^{\circ}$.

The correction factor for bedform interaction, accounting for the effect that the flow pattern over a bedform is influenced by the flow patterns over surrounding bedforms, is found to be a function of the ratio of bedform length to bedform height.

The correction factor for flow separation zone height, describing the effect that for increasing flow separation zone height, the form drag increases, is found to be a function of the ratio of flow separation zone height to bedform height.

The correction factor for variability in bedform geometry accounts for the effect that form drag increases for increasing variability in bedform geometry in streamwise direction.

The semi-analytical form drag model consists of the quantities 1 through 8 .

Q6. How does the new form drag model perform compared to (a) laboratory data and (b) existing form drag models?

For the uniform fixed bedform data, the semi-analytical model yields better results than the Yalin (1964a) - Engelund (1966) model. The considered empirical bed resistance models do not well predict bed resistance for the uniform fixed bedform data.

The Yalin (1964a) - Engelund (1966) form drag model appears to yield the best results of the models under consideration for the alluvial flume data. For the alluvial flume data, the semi-analytical model, in which the four mentioned effects and the effect of nonuniformity of the flow velocity profile are included, does not yield better predictions of bed resistance than the analytical model and the model of Yalin (1964a) and Engelund (1966), in which these effects are not included. In the analytical model and the model of Yalin (1964a) and Engelund (1966) the neglected effects appear to cancel out.

The assumption in the Yalin (1964a) - Engelund (1966) bed resistance model that flow expansion downstream of the bedform crest can be represented by expansion of a pipe flow rather than a free surface flow is justified.

For uniform fixed laboratory data of bedforms with small lee face angles the semi-analytical model yields better predictions of bed resistance than the other considered models. Also numerical simulations in which the lee face angle was varied show that the semi-analytical form drag model yields better predictions of form drag than the Yalin (1964a) - Engelund (1966) form drag model for small lee face angles. Therefore, for bedforms in the field, which are usually gentler than in the laboratory, the semi-analytical model is expected to yield better predictions of bed resistance than the other considered models.

Based on the analysis the author advises to apply the semi-analytical form drag model, as (a) the model is expected to yield the best results in field situations, and (b) an analytically-based model is preferred over an empirical model. The author advises to apply the analytical Yalin (1964a) - Engelund (1966) form drag model if a model is preferred that is more easy to apply than the semi- 
analytical model. Users of the Yalin (1964a) - Engelund (1966) model should be aware of the fact that relevant physical effects are not incorporated in the model.

All bed resistance models show large scatter around the line of perfect agreement when measured and predicted bed resistance are compared. The error between measured and predicted bed resistance may be as large as $\pm 50 \%$. As a result, the error in water depth prediction is between $-20 \%$ and $+15 \%$.

If a form drag model consists of empirical calibration coefficients, this model should always be applied in combination with the grain friction model that was used to determine the calibration coefficients.

For the case of compound bedforms, a summation of the energy loss due to individual small-scale and large-scale bedforms yields a reasonably good prediction of form drag.

\subsection{Recommendations}

The author recommends future research on the following topics:

- In this study, laboratory data are used to analyze the performance of the bed resistance models under consideration. The study on the performance of the semi-analytical model and other bed resistance models needs to be extended with an analysis of field data, for which generally lee face angles are smaller than for the laboratory data.

- It is assumed that the four correction factors are independent. It should be further investigated if the potential effects due to dependency between the correction factors are significant and, if so, how they can be incorporated in the semi-analytical model.

- Compound bedforms generally occur during floods (e.g. Julien et al., 2002). The prediction of form drag in the case of compound bedforms needs to be further analyzed.

- It has been discussed that the approach followed in the development of the semi-analytical form drag model, i.e., a reference form drag times correction factors, may also be useful for determining the resistance to flow of marine or estuarine bedforms (ripples, megaripples, sand waves), bedforms caused by wind, groynes or other obstacles in the flow. Future research on the potential applicability of the form drag model to these fields is advised.

- The proposed expressions for the correction factors for lee face steepness, bedform interaction, flow separation zone height, and variability in bedform geometry are first onsets, as at this point only few data for their derivation are available. More laboratory and numerical data are needed in order to derive more accurate expressions. 
- In the momentum and energy conservation equations it is assumed that the flow velocity distributions are uniform over the cross-section at the cross-sections 1 and 2 (i.e., the kinetic energy coefficients and momentum coefficients are chosen equal to unity). As a result, the calibration coefficient relating the analytical energy loss to the measured energy loss, $c_{1}$, accounts for the nonuniformity of the flow velocity profiles. It is recommended to further analyze the relation between the value of the calibration coefficient and the values of the kinetic energy coefficients and momentum coefficients at both the cross-sections 1 and 2 .

- It is recommended to study the effect on form drag of variability in bedform geometry in lateral direction, and on the correlation between variability in bedform geometry in lateral and streamwise direction, as at the moment these effects are not yet well understood. The effect on form drag of other features of three-dimensionality of bedforms, such as crestline sinuosity, also needs to be further analyzed.

- It is suggested to analyze the performance of the Yalin (1964a) - Engelund (1966) model in combination with (possibly adapted) correction factors and calibration coefficient, $c_{1}$, as it is advisable to apply a model that is as simple as possible.

- In the numerical model system Delft3D, empirical bed resistance models are implemented (Deltares, 2008). The author recommends to implement an analytically-based model.

- The effect on form drag of suspended load, and potentially bedform migration and bedform sequence are neglected. It is recommended to analyze if (and how) these effects need to be incorporated in the semi-analytical form drag model.

- The correction factor for flow separation zone height accounts for a deviation in flow separation zone height with respect to the bedform height. If a brink point is present, not only the height of the flow separation zone height is smaller compared to the situation that no brink point is present, also the length of the flow separation zone may be smaller. As such, the correction factor for flow separation zone height may also be a function of the length of the flow separation zone. It is recommended to analyze whether the correction factor can be improved by incorporating (a model for) the length of the flow separation zone.

- The semi-analytical form drag model is applicable to situations of subcritical flow. It is recommended to analyze whether the form drag model, which is based on flow expansion, is suitable to apply to situations of supercritical flow. 


\section{References}

Aalberts, M. L. (2007), Bed friction and form drag. Effects of large scale bed forms on flow resistance, Tech. rep., Delft University of Technology, Delft, Netherlands.

Alam, A. M. Z., and J. F. Kennedy (1969), Friction factors for flow in sand-bed channels, J. Hydr. Div., 95(HY6), 1973-1992.

Allen, J. R. L. (1978), Computational models for dune time-lag: Calculations using Stein's rule for dune height, Sediment. Geol., 20(3), 165-216.

Allen, J. R. L. (1983), River bedforms: Progress and problems, in Modern and ancient fluvial systems, vol. 6, edited by J. D. Collinson and J. Lewin, pp. 19-33, Int. Assoc. Sedimentol. Spec. Publ., Blackwell, Boston.

Allen, J. R. L. (1984), Sedimentary structures: Their character and physical basis, Elsevier, Amsterdam, Netherlands.

Amsler, M. L., and M. H. García (1997), Discussion: Sand dune geometry of large rivers during floods, J. Hydraul. Eng., 123, 582-585.

Annambhotla, V. S. S., W. W. Sayre, and R. H. Livesey (1972), Statistical properties of Missouri River bedforms, J. Waterw., Harbors Coastal Eng. Div., 98(WW4), 489-510.

Ansys CFX (2006), Ansys CFX Release 11.0 User Manual.

Ashida, K., and Y. Tanaka (1967), A statistical study of sand waves, in Proc. 12 $2^{\text {th }}$ IAHR Congress, pp. 103-110, Fort Collins, Colorado.

Ashley, G. M. (1990), Classification of large-scale subaqueous bedforms: a new look at an old problem, J. Sediment. Petrol., 60(1), 160-172.

Aya, S., I. Fujita, and N. Miyawaki (1997), 2-d models for flows in the river with submerged groins, in Proc. $2^{\text {th }}$ IAHR Congress, pp. 829-834, San Francisco, USA.

Barabási, A.-L., and H. E. Stanley (1995), Fractal Concepts in Surface Growth, 366 pp., Cambridge Univ. Press, New York, USA.

Bardina, J. E., P. G. Huang, and T. J. Coakley (1997), Turbulence modeling validation, testing, and development, NASA Technical Memorandum 110446. 
Batchelor, G. K. (1967), An Introduction to Fluid Dynamics, Cambridge Univ. Press.

Best (2005), The fluid dynamics of river dunes: A review and some future research directions, J. Geophys. Res., 110, F04S02, doi:10.1029/2004JF000218.

Best, J., and R. Kostaschuk (2002), An experimental study of turbulent flow over a low-angle dune, J. Geophys. Res., 107(C9), 1118-1129, 3135, doi:10.1029/2000JC000294.

Bloemberg, G. (2001), Streamlining of summer dikes (in dutch), Master's thesis, Delft University of Technology, Delft, Netherlands.

Blom, A., and G. Parker (2004), Vertical sorting and the morphodynamics of bed form-dominated rivers: A modeling framework, J. Geophys. Res., 109, 1-15, F02007, doi:10.1029/2003JF000069.

Blom, A., J. S. Ribberink, and H. J. De Vriend (2003), Vertical sorting in bed forms: Flume experiments with a natural and a trimodal sediment mixture, Water Resour. Res., 39(2), 1025, doi:10.1029/2001WR001088.

Blom, A., J. S. Ribberink, and G. Parker (2008), Vertical sorting and the morphodynamics of bed form-dominated rivers: A sorting evolution model, $J$. Geophys. Res., 113, F01019, doi:10.1029/2006JF000618.

Blom, P. (1993), Turbulent free surface flow over a sill, Ph.D. thesis, Delft University of Technology, Delft, Netherlands.

Borda, J. C. (1766), Mémoire sur l'écoulement des fluides par les orifices des vases, Histoire de l'Académie Royale des Sciences, pp. 579-607, (publ. 1769).

Bristow, C. S., S. D. Bailey, and N. Lancaster (2000), The sedimentary structure of linear sand dunes, NATURE, 406(6791), 56-59.

Cardano, H. (1545), Artis Magnae, Sive de Regulis Algebraicis Liber Unus.

Carling, P. A., E. Gölz, H. G. Orr, and A. Radecki-Pawlick (2000), The morphodynamics of fluvial sand dunes in the River Rhine, near Mainz, Germany. I. Sedimentology and morphology, Sedimentology, 47, 227-252.

Casas, A., G. Benito, V. R. Thorndycraft, and M. Rico (2006), The topographic data source of digital terrain models as a key element in the accuracy of hydraulic flood modelling, Earth Surf. Proc. Land., 31, 444-456, doi:10.1002/esp.1278.

Chanson, H. (2004), The hydraulics of open channel flow: An introduction, $2^{\text {nd }}$ ed., Elsevier.

Chaudhry, M. H. (2008), Open-channel flow, $2^{\text {nd }}$ ed., Springer, New York, USA. 
Cheng, N. S., and L. H. C. Chua (2005), Comparisons of sidewall correction of bed shear stress in open-channel flows, J. Hydraul. Eng., 131(7), doi:10.1061/(ASCE)0733-9429(2005)131:7(605).

Chow, V. T. (1959), Open-channel hydraulics, McGraw-Hill, New York, USA.

Colebrook, C. F. (1939), Turbulent flow in pipes, with particular reference to the transition region between the smooth and rough pipe laws, J. Inst. Civ. Eng. Lond., 11, 133-156.

Coleman, S. E., V. I. Nikora, S. R. McLean, and E. Schlicke (2005), Spatiallyaveraged turbulent flow over square-rib roughness, in Proc. $4^{\text {th }}$ IAHR symposium on River, Coastal and Estuarine Morphodynamics, edited by G. Parker and M. H. García.

Coleman, S. E., V. I. Nikora, S. R. McLean, T. M. Clunie, and B. W. Melville (2007), Subelement form-drag parameterization in rough-bed flows, J. Hydraul. Eng., 133(2), doi:10.1061/(ASCE)0733-9429(2007)133:2(121).

Crickmore, M. J. (1970), Effect of flume width on bedform characteristics, J. Hydr. Eng. Div., 96(HY2), 473-496.

Daugherty, R. L., and J. B. Franzini (1965), Fluid mechanics with engineering applications, $6^{\text {th }}$ ed., McGraw-Hill, New York, USA.

Davies, T. R. H. (1980), Bedform spacing and flow resistance, J. Hydr. Div., $106(3), 423-433$.

De Jong, C. D., G. Lachapelle, S. Skone, and I. A. Elema (2002), Hydrography, Delft Univ. Press, Delft, Netherlands.

De Koning, M. F. (2007), The stochastic characteristics of geometric properties of sand waves in the North Sea, CEESM Research Report 2007R-004/WEM003 ISSN 1568-4652, University of Twente, Enschede, Netherlands.

De Vriend, H. J. (2006), Flood management research needs, in Floods, from defence to management, edited by J. V. Alphen, E. V. Beek, and M. Taal, $3^{\text {rd }}$ International Symposium on Flood Defence, pp. 49-61.

Deltares (2008), Delft3D-FLOW. Simulation of multi-dimensional hydrodynamic flows and transport phenomena, including sediments. User Manual, Deltares, Delft, Netherlands.

Diplas, P., and A. J. Sutherland (1988), Sampling techniques for gravel sized sediments, J. Hydraul. Eng., 114 (5), 484-501.

Dodds, P. S., and D. H. Rothman (2000), Scaling, universality and geomorphology, Annu. Rev. Earth Planet. Sci., 28, 571-610.

Dong, Z., G. Qian, W. Luo, and H. Wang (2007), A wind tunnel simulation of the effects of stoss slope on the lee airflow pattern over a two-dimensional transverse dune, J. Geophys. Res., 112, F03019, doi:10.1029/2006JF000686. 
Driegen, J. (1986), Flume experiments on dunes under steady flow conditions (uniform sand, $\mathrm{Dm}=0.77 \mathrm{~mm}$ ). Description of bed forms, TOW Report $R$ 657 - XXVII / M 1314 part XV, WL | Delft Hydraulics, Delft, Netherlands.

Einstein, H. A. (1950), The bed-load function for sediment transportation in open channel flows, Technical Bulletin No. 1026, U.S. Department of Agriculture, Soil Conservation Service, Washington, DC.

Einstein, H. A., and N. L. Barbarossa (1952), River channel roughness, Trans. $A S C E, 117,1121-1146$.

Engelund, F. (1966), Hydraulic resistance of alluvial streams, J. Hydr. Eng. Div., 92(HY2).

Engelund, F. (1977), Hydraulic resistance for flow over dunes, Progress report 44 , Institute for Hydrodynamic and Hydraulic Engineering, Tech. Univ. Denmark.

Engelund, F., and E. Hansen (1967), A monograph on sediment transport in alluvial streams, Tech. rep., Copenhagen, Denmark.

Fernandez, R., J. Best, and F. López (2006), Mean flow, turbulence structure, and bed form superimposition across the ripple-dune transition, Water Resour. Res., 42, W05406, doi:10.1029/2005WR004330.

Fox, R. W., and A. T. McDonald (1994), Introduction to fluid mechanics, $4^{\text {th }}$ ed., John Wiley \& Sons.

Franco, J. J. (1968), Effects of water temperature on bed-load movement, $J$. Waterw. Harbors Div., 94(WW3), 343-352.

Fredsøe, J. (1982), Shape and dimensions of stationary dunes in rivers, J. Hydr. Eng. Div., 108(HY8), 932-947.

Gabel, S. L. (1993), Geometry and kinematics of dunes during steady and unsteady flows in the Calamus River, Nebraska, USA, Sedimentology, 40, 237269.

Gibson, A. H. (1911), On the resistance to flow of water through pipes or passages having divergent boundaries, Trans. Roy. Soc. Edinburgh, 48.

Gibson, A. H. (1912), The conversion of kinetic to pressure energy in the flow of water through passages having divergent boundaries, Engineering, 93, 205206.

Guy, H. P., D. B. Simons, and E. V. Richardson (1966), Summary of alluvial channel data from flume experiments, 1956-61, U.S. Geological Survey Professional Paper, 462-I. US Government Printing Office, Washington.

Haque, M. I., and K. Mahmood (1983), Analytical determination of form friction factor, J. Hydraul. Eng., $109(4)$, 590-610. 
Haushild, W. L., D. B. Simons, and E. V. Richardson (1961), The significance of the fall velocity and effective fall diameter of bed materials, U.S. Geological Survey Professional Paper, 424-D. US Government Printing Office, Washington.

Henderson, F. M. (1966), Open channel flow, McMillan, New York, USA.

Hirsch, C. (2002), Numerical computation of internal and external flows. Volume 2: Computational methods for inviscid and viscous flows, Wiley-Interscience Publication.

Hoerner, S. F. (1965), Fluid-dynamic drag, Hoerner Fluid Dynamics.

Hubbell, D. W., and K. Al-Shaikh Ali (1961), Qualitative effects of temperature on flow phenomena in alluvial streams, U.S. Geological Survey Professional Paper, 424-D. US Government Printing Office, Washington.

Hulscher, S. J. M. H. (1996), Tidal induced large-scale regular bed form patterns in a three-dimensional shallow water model, J. Geophys. Res., 101(C9), 20,727-20,744.

Jansen, P. P., L. Van Bendegom, J. Van den Berg, M. De Vries, and A. Zanen (1979), Principles of river engineering. The non-tidal alluvial river, Delftse Uitgevers Maatschappij.

Jenkins, G. M., and D. G. Watts (1968), Spectral analysis and its applications, Holden Day, San Francisco, USA.

Jerolmack, D. J., and D. Mohrig (2005a), Interactions between bed forms: Topography, turbulence, and transport, J. Geophys. Res., 110, F02014, doi:10.1029/2004JF000126.

Jerolmack, D. J., and D. Mohrig (2005b), A unified model for subaqueous bed form dynamics, Water Resour. Res., 41, W12421, doi:10.1029/2005WR004329.

Julien, P. Y., and G. J. Klaassen (1995), Sand-dune geometry of large rivers during floods, J. Hydraul. Eng., 121(9), 657-663.

Julien, P. Y., G. J. Klaassen, W. B. M. Ten Brinke, and A. W. E. Wilbers (2002), Case Study: Bed resistance of Rhine River during 1998 flood, J. Hydraul. Eng., 128(12), 1042-1050.

Karim, F. (1995), Bed configuration and hydraulic resistance in alluvial-channel flows, J. Hydraul. Eng., 121(1), 15-25.

Karim, F. (1999), Bed-form geometry in sand-bed flows, J. Hydraul. Eng., 125(12)

Kennedy, J. F., and A. J. Odgaard (1991), Informal monograph on riverine sand dunes, Tech. rep., Iowa Institute of Hydraulic Research, University of Iowa, Iowa City, Iowa. 
Khullar, N. K., U. C. Kothyari, and K. G. Ranga Raju (2007), Effect of wash load on flow resistance, J. Hydraul. Res., 45(4), 497-504.

Klaassen, G. J. (1990), Experiments with graded sediments in a straight flume. Vol. A (Text) and Vol. B (Tables and Figures), Tech. Rep. Q788, WL | Delft Hydraulics, Delft, Netherlands.

Knaapen, M. A. F. (2005), Sandwave migration predictor based on shape information, J. Geophys. Res., 110, F04S11, doi:10.1029/2004JF000195.

Knighton, D. (1998), Fluvial forms and processes, Arnold, London, England.

Korn, G. A., and T. M. Korn (1968), Mathematical Handbook for Scientists and Engineers, $2^{\text {nd }}$ ed., McGraw-Hill, New York, USA.

Kornman, B. A. (1995), The effect of changes in the lee shape of dunes on the flow field, turbulence and hydraulic roughness, Report on measurements $R$ 95-1, University of Utrecht, Utrecht, Netherlands.

Kundu, P. K., and I. M. Cohen (2004), Fluid Mechanics, $3^{\text {rd }}$ ed., Elsevier Academic Press.

Langhorne, D. N. (1978), Offshore engineering and navigational problems - The relevance of sandwave research, Society for Underwater Technology; Institute of Oceanographic Sciences.

Leclair, S. F. (2002), Preservation of cross-strata due to the migration of subaqueous dunes: an experimental investigation, Sedimentology, 49, 1157-1180.

Leclair, S. F., and A. Blom (2005), A qualitative analysis of the distribution of bed-surface elevation and the characteristics of associated deposits for subaqueous dunes, Spec. Publ. Int. Assoc. Sedimentol., 35, 121-134.

Leclair, S. F., J. S. Bridge, and F. Wang (1997), Preservation of cross-strata due to migration of subaqueous dunes over aggrading and non-aggrading beds: Comparison of experimental data with theory, Geosci. Can., 24(1), 55-66.

Lyn, D. A. (1993), Turbulence measurements in open-channel flows over artificial bed forms, J. Hydraul. Eng., 119(3), 306-326.

Maddux, T. B., J. M. Nelson, and S. R. McLean (2003a), Turbulent flow over three-dimensional dunes: 1. Free surface and flow response, J. Geophys. Res., 108(F1), 6009, doi:10.1029/2003JF000017.

Maddux, T. B., S. R. McLean, and J. M. Nelson (2003b), Turbulent flow over three-dimensional dunes: 2. Fluid and bed stresses, J. Geophys. Res., 108(F1), 6010, doi:10.1029/2003JF000018.

Mahmood, K., and H. Ahmadi-Karvigh (1976), Analysis of bed profiles in sand bed canals, in Proc. Rivers 'r6, ASCE Waterways, Harbors and Coastal Engineering Division Specialty Conference. 
McLean, S. R., S. R. Wolfe, and J. M. Nelson (1999), Spatially averaged flow over a wavy boundary revisited, J. Geophys. Res., 104(C7), 15,743-15,753.

Menter, F. R. (1994), Two-equation eddy-viscosity turbulence models for engineering applications, AIAA-Journal, 32(8), 1598-1605.

Meyer-Peter, E., and R. Müller (1948), Formulas for bed-load transport, in Proc. $2^{\text {nd }}$ IAHR congress, vol. 2, pp. 39-64, Stockholm, Sweden.

Mohrig, D. (1994), Spatial evolution of dunes in a sandy river, Ph.D. thesis, University of Washington, Seattle, USA.

Mohrig, D., and J. D. Smith (1996), Predicting the migration rates of subaqueous dunes, Water Resour. Res., 32(10), 3207-3217.

Morvan, H. P., D. K. Knight, N. G. Wright, X. Tang, and A. J. Crossley (2008), The concept of roughness in fluvial hydraulics and its formulation in $1 \mathrm{~d}, 2 \mathrm{~d}$ and 3d numerical simulation models, J. Hydraul. Res., 46(2), 191-208.

Mosselman, E., and N. Struiksma (1992), The effect of lowering the groynes (in dutch), Tech. Rep. Q1462, WL | Delft Hydraulics, Delft, Netherlands.

Nelson, J. M., S. R. McLean, and S. R. Wolfe (1993), Mean flow and turbulence fields over two-dimensional bed forms, Water Resour. Res., 29(12), 39353953.

Németh, A. A., S. J. M. H. Hulscher, and H. J. De Vriend (2003), Offshore sand wave dynamics, engineering problems and future solutions, Pipeline Gas J., 230(4), 67-69.

Nikora, V. I., and D. M. Hicks (1997), Scaling relationships for sand wave development in unidirectional flow, J. Hydraul. Eng., 123(12), 1152-1156.

Nikora, V. I., A. N. Sukhodolov, and P. M. Rowinski (1997), Statistical sand wave dynamics in one-directional water flows, J. Fluid Mech., 351, 17-39.

Nordin, C. F. (1971), Statistical properties of dune profiles. Sediment transport in alluvial channels, U.S. Geological Survey Professional Paper, 562-F. US Government Printing Office, Washington.

Ogink, H. J. M. (1989), Hydraulic roughness of single and compound bed forms. Report on model investigations, Tech. Rep. Part XI, A36, WL | Delft Hydraulics, Delft, Netherlands.

Paola, C., and L. Borgman (1991), Reconstructing random topography from preserved stratification, Sedimentology, 38, 553-565.

Parsons, D. R., I. J. Walker, and G. F. S. Wiggs (2004), Numerical modelling of flow structures over idealized transverse aeolian dunes of varying geometry, Geomorphology, 59, 149-164. 
Parsons, D. R., J. L. Best, O. Orfeo, R. J. Hardy, R. Kostaschuk, and S. N. Lane (2005), Morphology and flow fields of three-dimensional dunes, Rio Paraná, Argentina: Results from simultaneous multibeam echo sounding and acoustic Doppler current profiling, J. Geophys. Res., 110, F04S03, doi:10.1029/2004JF000231.

Parteli, E. J. R., V. Schwämmle, H. J. Herrmann, L. H. U. Monteiro, and L. P. Maia (2006), Profile measurement and simulation of a transverse dune field in the Lençóis Maranhenses, Geomorphology, 81, 29-42, doi:10.1016/j.geomorph.2006.02.015.

Prent, M. T. H. (1998), Seasonal regime of bedform and hydraulic geometry, Lillooet River, Pemberton, BC., Master's thesis, Simon Fraser University.

Prent, M. T. H., and E. J. Hickin (2001), Annual regime of bedforms, roughness and flow resistance, Lillooet River, British Columbia, BC, Geomorphology, 41, 369-390.

Richards, K. S. (1982), Rivers: form and process in alluvial channels, Methuen \& Co. Ltd, London.

Richardson, E. V., D. B. Simons, and W. L. Haushild (1962), Boundary form and resistance to flow in alluvial channels, Bulletin Intern. Assoc. Sc. Hydr, $7,48-52$.

RIKZ (1997), User manual, Digipol V1.0, Tech. rep., National Institute for Coastal and Marine Management (RIKZ), The Hague, Netherlands.

Rouse, H. (1965), Critical analysis of open-channel resistance, J. Hydr. Div., 91 (HY4), 1-25.

Schatz, V., and H. J. Herrmann (2006), Flow separation in the lee of transverse dunes: A numerical investigation, Geomorphology, 81, 207-216, doi:10.1016/j.geomorph.2006.04.009.

Shen, H. W., H. M. Fehlman, and C. Mendoza (1990), Bed form resistances in open channel flows, J. Hydraul. Eng., 116(6), 799-815.

Simons, D. B., and E. V. Richardson (1961), Forms of bed roughness in alluvial channels, J. Hydr. Eng. Div., 87, 87-105.

Simons, D. B., and E. V. Richardson (1966), Resistance to flow in alluvial channels, U.S. Geological Survey Professional Paper, 422-J. US Government Printing Office, Washington.

Sincich, T. (1985), Statistics by example, $2^{\text {nd }}$ ed., Dellen Pub Co, San Francisco.

Southard, J. B., and L. A. Boguchwal (1990), Bed configurations in steady unidirectional water flows. Part 3: Effects of temperature and gravity, $J$. Sediment. Petrol., 60(5), 680-686. 
Stelling, G. S., and A. Verwey (2005), Numerical flood simulation, in Encyclopedia of Hydrological Sciences, vol. 1, pp. 257-270, John Wiley \& Sons Ltd.

Ten Brinke, W. B. M. (1997), Bed composition of the rivers Waal and IJssel in 1966, 1976, 1984 and 1995 (in Dutch), Tech. Rep. 97.009 ISBN 9036950562, Institute for Inland Water Management and Waste Water Treatment, Netherlands.

Van der Mark, C. F., and A. Blom (2007), A new and widely applicable tool for determining the geometric properties of bedforms, CEEM Research Report 2007R-003/WEM-002 ISSN 1568-4652, University of Twente, Enschede, Netherlands.

Van der Mark, C. F., M. F. De Koning, A. Blom, S. J. M. H. Hulscher, and A. Stolk (2008a), Sea bed sand waves studied to help pipeline planners, Pipeline Gas J., 235(4), 78-81.

Van der Mark, C. F., A. Blom, and S. J. M. H. Hulscher (2008b), Quantification of variability in bedform geometry, J. Geophys. Res., 113, F03020, doi:10.1029/2007JF000940.

Van der Mark, C. F., A. Blom, W. S. J. Uijttewaal, S. J. M. H. Hulscher, and H. W. M. Hoeijmakers (2009), A semi-analytical form drag model: Application to uniform bedforms, J. Geophys. Res., submitted.

Van Mierlo, M. C. L. M., and J. C. C. De Ruiter (1988), Turbulence measurements above artificial dunes; Report on measurements, Tech. Rep. Q789, WL | Delft Hydraulics, Delft, Netherlands.

Van Rijn, L. C. (1982), Equivalent roughness of alluvial bed, J. Hydraul. Eng. Div., 108(HY10), 1215-1218.

Van Rijn, L. C. (1984), Sediment Transport, Part III: Alluvial roughness, J. Hydraul. Eng., 110(12), 1733-1754.

Van Rijn, L. C. (2007), A unified view of sediment transport by currents and waves. I: initiation of motion, bed roughness and bed-load transport, J. Hydraul. Eng., 133(6), 649-667, doi:10.1061/(ASCE)0733-9429(2007)133:6(649).

Van Rijn, L. C., and G. J. Klaassen (1981), Experience with straight flumes for movable bed experiments, in Proc. IAHR Workshop on Particle Motion and Sediment Transport, HY10, Rapperswil, Switzerland.

Vanoni, V. A., and N. H. Brooks (1957), Laboratory studies of the roughness and suspended load of alluvial streams, Tech. Rep. E-68, Sediment. Lab., Calif. Inst. of Technol., Pasadena, USA.

Vanoni, V. A., and L. S. Hwang (1967), Relation between bed forms and friction in streams, J. Hydr. Div., 93, 121-144. 
Vanoni, V. A., and G. N. Nomicos (1960), Resistance properties of sedimentladen streams, Trans. ASCE, 125.

Venditti, J. G. (2007), Turbulent flow and drag over fixed two- and threedimensional dunes, J. Geophys. Res., 112, F04008, doi:10.1029/2006JF000650.

Venditti, J. G., and S. J. Bennett (2000), Spectral analysis of turbulent flow and suspended sediment transport over fixed dunes, J. Geophys. Res., 105(C9), $22,035-22,047$

Venditti, J. G., M. Church, and S. J. Bennett (2005), On the transition between 2D and 3D dunes, Sedimentology, 52, 1343-1359, doi:10.1111/j.13653091.2005.00748.x.

Vreugdenhil, C. B. (1994), Numerical methods for shallow water flow, Kluwer Academic Publishers, Netherlands.

Wang, W. C., and H. W. Shen (1980), Statistical properties of alluvial bed forms, in Proc. $3^{\text {rd }}$ Int. Symposium on Stochastic Hydraulics, pp. 371-389, Tokyo, Japan.

Wilbers, A. (2004), The development and hydraulic roughness of river dunes, Ph.D. thesis, University of Utrecht, Utrecht, Netherlands.

Wilcock, P. R., and J. B. Southard (1989), Bed load transport of mixed size sediment: Fractional transport rates, bed forms, and the development of a coarse bed surface layer, Water Resour. Res., 25(7), 1629-1641.

Williams, G. P. (1970), Flume width and water depth effects in sediment transport experiments, U.S. Geological Survey Professional Paper, 562-H. US Government Printing Office, Washington.

Wright, S., and G. Parker (2004), Flow resistance and suspended load in sand-bed rivers: Simplified stratification model, J. Hydraul. Eng., 130(8), doi:10.1061/(ASCE)0733-9429(2004)130:8(796).

Yalin, M. S. (1964a), On the average velocity of flow over a mobile bed, $L a$ Houille Blanche, 1, 45-53.

Yalin, M. S. (1964b), Geometrical properties of sand waves, J. Hydr. Eng. Div., 90, 105-109.

Yalin, M. S., and A. M. F. Da Silva (2001), Fluvial processes. IAHR Monograph, IAHR, Delft, Netherlands.

Yalin, M. S., and G. Lai (1985), On the form drag caused by sand waves, in Proc. of JSCE, No. 363/II-4 (Hydraulic and Sanitary Eng.), pp. 245-248.

Yan, Z., S. Bate, R. E. Chandler, V. Isham, and H. Wheater (2002), An analysis of daily maximum wind speed in northwestern Europe using generalized linear models, J. Clim, 15(15), 2073-2088. 
Yang, S.-Q., and S.-K. Tan (2008), Flow resistance over mobile bed in an openchannel flow, J. Hydraul. Eng., 134(7), 937-947, doi:10.1061/(ASCE)07339429(2008)134:7(937).

Yen, B. C. (2002), Open channel flow resistance, J. Hydraul. Eng., 128(1), 20 39, doi:10.1061/(ASCE)0733-9429(2002)128:1(20).

Yoon, J. Y., and V. C. Patel (1996), Numerical model of turbulent flow over sand dune, J. Hydraul. Eng., 122(1), 10-18.

Yossef, M. F. M. (2005), Morphodynamics of rivers with groynes, Ph.D. thesis, Delft University of Technology, Delft, Netherlands. 


\section{Appendix A}

\section{The effect of postprocessing multibeam echosounding data on bedform geometry}

\section{A.1 Multibeam echosounding measurements}

Multibeam echosounding (MBES) is a survey technique that provides a rapid means of determining the bathymetry of a sea or river bed. An echosounder placed underneath a sailing vessel determines depths, i.e., distances between the echosounder and the bed, from observation of travel time of acoustic waves (De Jong et al., 2002). The vessel usually sails tracks in streamwise direction of the river. As such, the sailing direction is roughly perpendicular to the bedform crest lines. If the vessel sails in lateral direction, (a) the vessel would need to turn more often, and (b) no measurements would be obtained close to the banks due to the vessel's turning circle.

In a swath multibeam system multiple acoustic beams are produced from a single echosounder (De Jong et al., 2002). Rijkswaterstaat, i.e., the directorate for public works and water management in the Netherlands, uses a swath multibeam system. A swath system transmits an acoustic pulse in a wide fan in one direction (Figures A.1a and A.1b). This results in a wide footprint in that direction. A lane of soundings rather than a single line of soundings is obtained from a single vessel's track. Each individual beam is projected as a circle at the bed. The circle of a beam at a large swath angle has a larger diameter as the distance to the bed is larger (Figure A.1c). Therefore accuracy decreases for increasing swath angle (De Jong et al., 2002). The survey line spacing $d x$ (Figure A.1a) and the vessel speed are chosen such that neighboring swaths are overlapping in order to avoid gaps and to enhance reliability (De Jong et al., 2002).

The following aspects are relevant for interpreting data that are obtained from multibeam measurements:

- The echosounder records the earliest return from its transmission, i.e., the echo having traveled the shortest distance (Figure A.2). The earliest return is set to be the depth corresponding to beam width, $\beta$. The larger the beam width, the larger the error may become, as the diameter of the circle is larger. For multibeam measurements the beam width, $\beta$, nowadays is so small that this effect does not occur in practice (L. Dorst, pers. comm., 2008). As the echosounder records the earliest return, depth measurement errors may occur when an echo returns from a target other than the bed 
(a)
cross-section
lateral direction

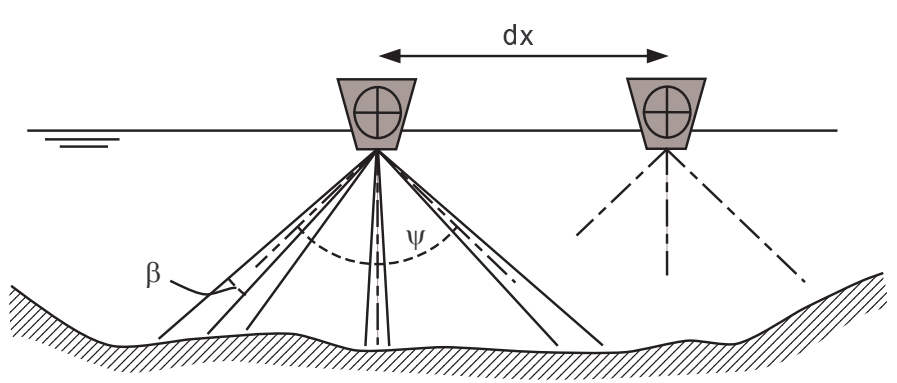

(b)

plan view
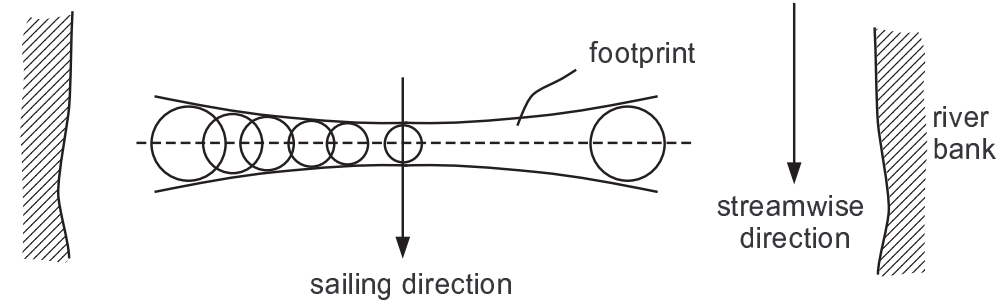

(c)

3D view individual beams

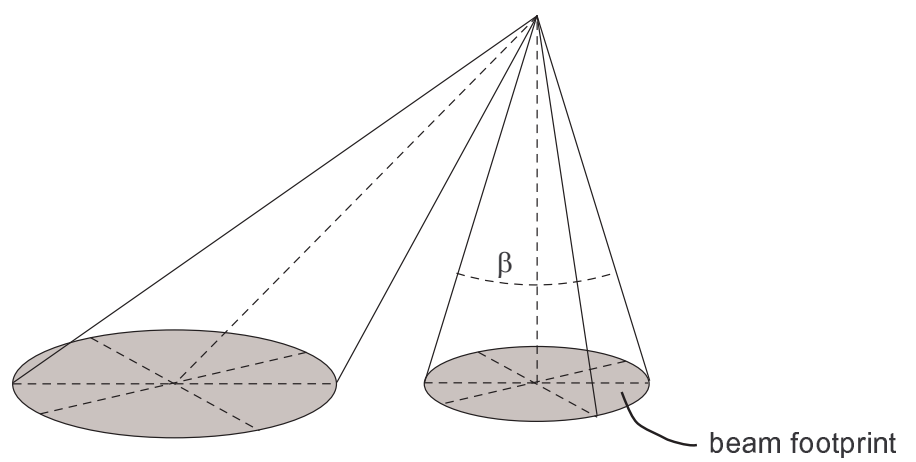

Figure A.1: Definition sketch of multibeam echosounding: (a) swath in river crosssection, (b) footprint in plan view, (c) three-dimensional view of two individual beams. 
cross-section

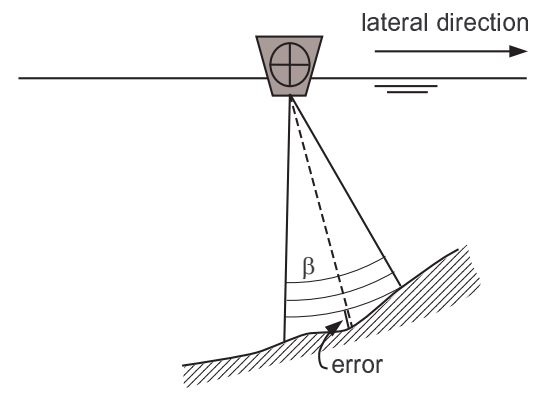

Figure A.2: Depth measurement error due to beam width.

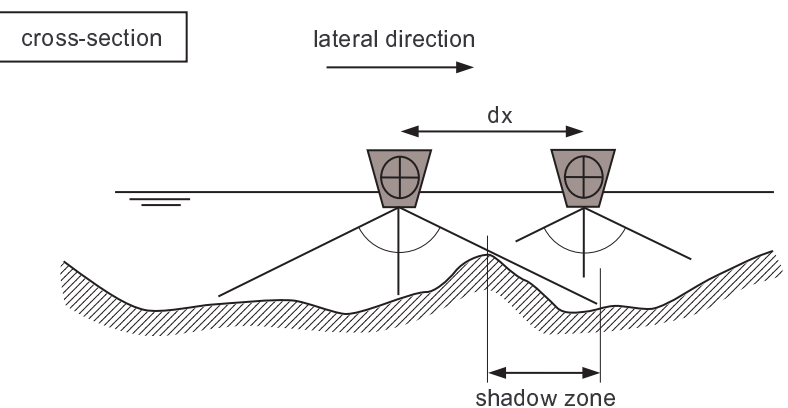

Figure A.3: Sufficient overlap between neighboring swaths prevents that no measurements are taken in the shadow zone.

(e.g. a fish or sediment in suspension).

- For steep bed gradients in lateral direction of the river and for large swath angles a shadow zone may occur, i.e., a zone where beams cannot reach the bed (Figure A.3). If there is sufficient overlap between neighboring swaths (i.e., survey line spacing, $d x$, is sufficiently small), measurements will also be obtained in the shadow zone. Note that bed gradients due to bedforms (the bedform stoss and lee faces) are gradients in streamwise direction rather than in lateral direction, which means that shadow zones behind lee and stoss faces of bedforms will generally not occur.

- The measurements are corrected for the motions of the vessel, i.e., roll, pitch, heave, and yaw (De Jong et al., 2002). 

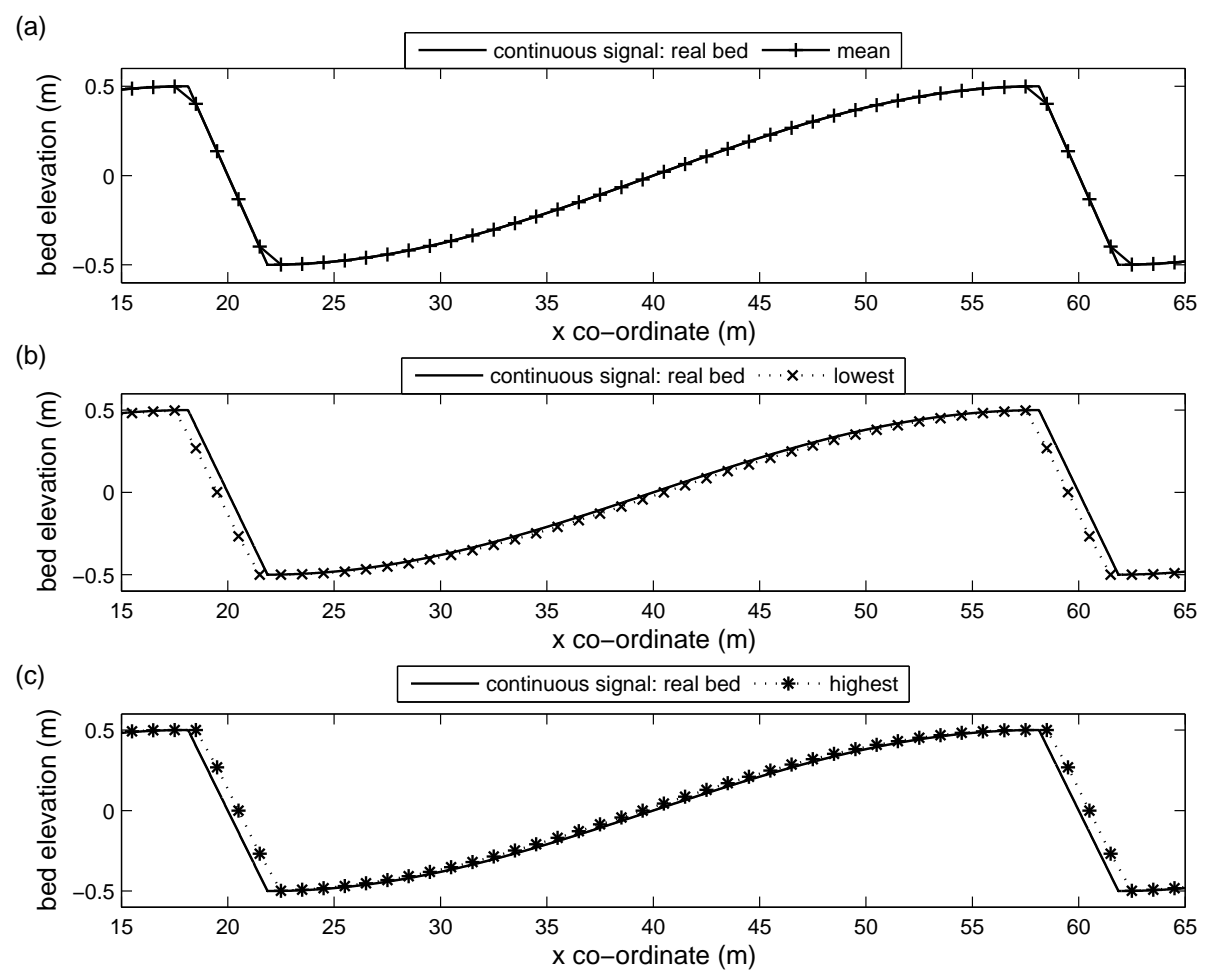

Figure A.4: A continuous signal representing a bed elevation profile is projected on a regular grid by assigning (a) the mean elevation, (b) the lowest elevation, (c) the highest elevation within each grid cell to this cell.

\section{A.2 Postprocessing of MBES data}

\section{A.2.1 Projection of bed elevations on a regular grid}

The measured bed elevations are postprocessed as the set of elevation data may contain erroneous measurements, and the elevation data are not regularly spaced. The bed elevation data of the Rhine River measured in December 2006 are projected on a regular grid of $1 \times 1 \mathrm{~m}^{2}$ by averaging the available bed elevation measurements (at least 10) within each grid cell (A. Wagener, pers. comm., 2007). It is also possible to assign the highest or lowest elevation within each grid cell to this cell rather than the mean elevation. The highest bed elevation is usually applied for navigational charts (L. Dorst, pers. comm., 2008). Figure A.4 illustrates the effect of applying the mean, lowest, or highest bed elevation when projecting bed elevation data on a regular grid. Projecting a continuous signal, which represents a streamwise bed elevation profile, on a regular grid by using the mean, lowest, or highest bed elevation within each grid cell, results in a projected bed elevation profile that is smoothed, shifted upstream or shifted downstream, respectively (Figure A.4). 


\section{A.2.2 Effect of grid projection on bedform geometry}

Figure A.4a shows that assigning the mean bed elevation to a grid cell smooths the resulting bed elevation profile. This may affect bedform geometry derived from the projected bed elevation profile. The ratio of grid size to bedform size, or in other words the number of bed elevation data per bedform, determines to what extent the geometry is affected. For a series of identical bedforms we vary the ratio of grid size to bedform length, assign the mean, lowest, and highest value within each grid cell to this cell, and determine bedform height, bedform length, crest elevation, trough elevation, and lee face slope using the bedform tracking tool (Appendix B). Figure A.5 shows that if (a) the ratio of grid size to bedform length is equal to or smaller than 0.1 (i.e., the number of bed elevation data per bedform length is equal to or larger than 10) and if (b) mean bed elevations are assigned to the grid cells, bedform geometry is only slightly affected (see Table A.1). The ratio of grid size to bedform length in the multibeam measurements of the Rhine River taken in December 2006 is equal to or smaller than 0.1. This means that we may conclude that the effect of the averaging procedure as applied for the Rhine River on bedform geometry is not significant as the grid size is sufficiently small with respect to bedform length.

Table A.1: Underestimation of bedform geometry (in \%) for ratios of grid size to bedform length smaller than 0.1 in case the mean elevation within a grid cell is assigned to this cell.

\begin{tabular}{lc}
\hline bedform parameter & $\%$ \\
\hline bedform height & $0-5$ \\
bedform length & 0 \\
crest elevation & $0-3$ \\
trough elevation & $0-3$ \\
lee face slope & 0 \\
\hline
\end{tabular}

Figure A.5e shows that no lee face slopes are determined for ratios of grid size to bedform length larger than 0.025 . This is because the bedform tracking tool only determines lee face slopes if the number of bed elevation data within the considered lee face reach is equal to or larger than 3.

It is possible to correct for the underestimation of bedform height, crest and trough elevation. In this research project we have not corrected for the underestimation presented in Table A.1, as we expect that the effect on the results is small. 
(a)

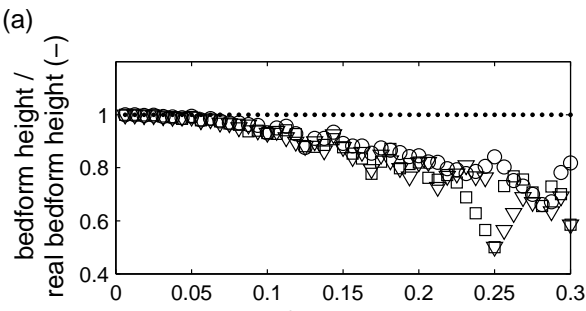

(c)

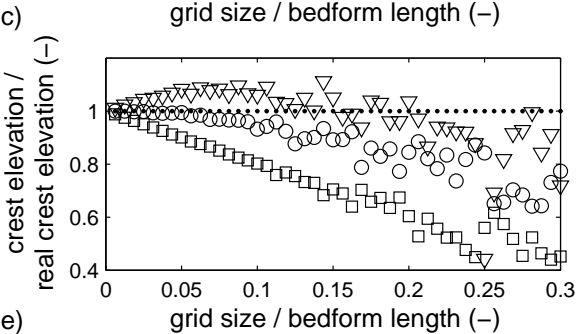

(e)

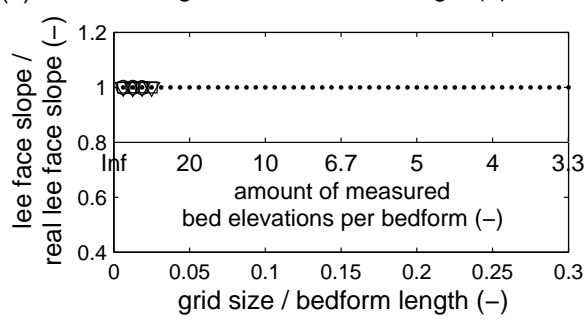

(b)

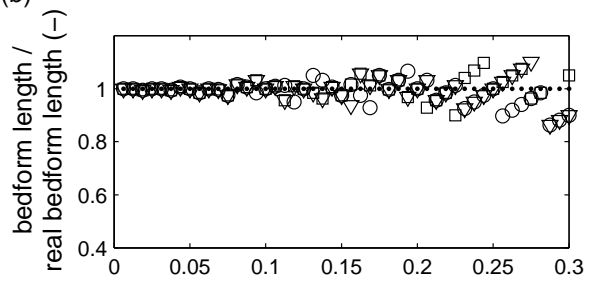

(d) grid size / bedform length (-)

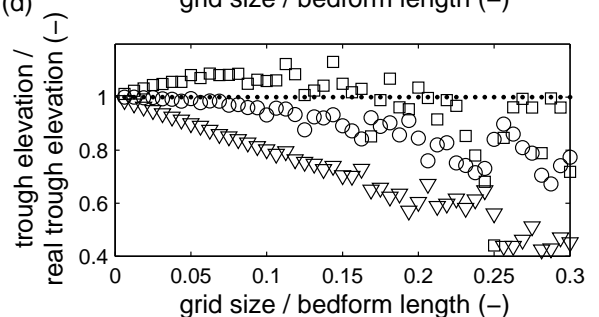

Figure A.5: Bedform parameter as determined by the bedform tracking tool divided by the imposed bedform parameter plotted against the ratio of grid size to bedform length: (a) bedform height, (b) bedform length, (c) crest elevation, (d) trough elevation, (e) lee face slope. 


\section{Appendix B}

\section{A new and widely applicable tool for determining bedform geometry ${ }^{\star}$}

\section{B.1 Introduction}

In order to study the variability in geometry of measured bedforms, we need a method that determines the locations of crests and troughs in a measured bed elevation profile and then determines the geometric properties of individual bedforms. This report presents a method (a bedform tracking tool) to locate bedforms and determine their geometry.

In this research project all data sets have to be processed using the same method or code in order to compare bedform geometry determined from various data sets. There exists a considerable number of methods or numerical codes (e.g. Wilbers, 2004; Blom et al., 2003; Leclair, 2002; Knaapen, 2005) that determine bedform geometry from laboratory or field data. An objective method that is applicable to both flume and field data (river and marine data), however, is not available.

The aim of this report is to present a method that determines the bedform geometry from measured bed elevation profiles as objectively as possible.

\section{B.2 Method for determining bedform geometry}

We have developed a bedform tracking tool by writing a numerical code in Matlab (version 7 R14) that enables us to study the variability in bedform geometry. The tool automatically selects crest and trough locations in measured bed elevation profiles (BEPs) and determines bedform geometry. The bedform tracking tool (BTT) is developed such that (1) as few as possible subjective choices have to be made and (2) the tool is applicable to field and flume measurements.

\section{B.2.1 Procedure of the bedform tracking tool}

The procedure of the bedform tracking tool consists of eight steps. Below, each of the steps is explained in closer detail.

${ }^{\star}$ This appendix is a shortened version of: Van der Mark, C.F. and A. Blom (2007), A new and widely applicable tool for determining the geometric properties of bedforms, CE\&M Research Report 2007R-003/WEM-002 ISSN 1568-4652, 57 pp., University of Twente, Enschede, Netherlands. 


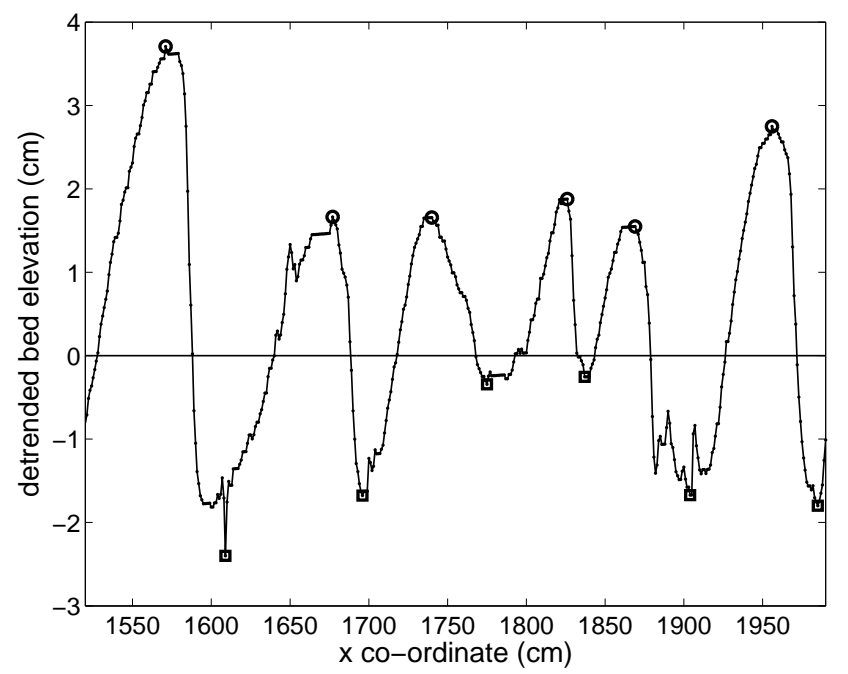

Figure B.1: A minimum (outlier) is incorrectly specified as a trough.

\section{Step 1. Removing outliers}

In step 1 we find outliers in each BEP and replace them. When a BEP consists of outliers (e.g. measuring errors), it may happen that maxima or minima are incorrectly specified as crests or troughs, respectively (Figure B.1). Therefore, we need to remove outliers before we start determining crests and troughs.

The procedure is as follows. The BTT loads the raw data. The absolute vertical distances, $d z$, between all consecutive measured points in the BEP under consideration are computed. The mean value of all vertical distances, $d z_{m}$, is then used to find outliers in the BEP. An outlier is defined as a point that differs more than $+5 d z_{m}$ with its previous point and $-5 d z_{m}$ with its next point or that differs more than $-5 d z_{m}$ with its previous point and $+5 d z_{m}$ with its next point (as in Figure B.1). The user is asked whether he/she wants to replace the point(s) with point(s) determined by linear interpolation or wants to keep the point(s).

\section{Step 2. Determining equilibrium trend line}

In step 2 we determine a trend line. We ask the user whether he/she prefers (a) a linear trend line or (b) a weighted moving average trend line.

(a) In a laboratory flume, an experiment is often run until the flow and transport reach an equilibrium stage. Several BEPs may be measured during equilibrium conditions. We consider these BEPs as statistically homogeneous. The trend lines of these individual BEPs can deviate from each other, because a BEP can consist of incomplete bedforms or only a few bedforms. Especially in short flumes the trend lines of individual BEPs can 
fluctuate considerably. Therefore the equilibrium trend line is determined by taking the average trend line of the individual BEPs.

(b) For field measurements, a linear trend line may not be suitable as the mean elevation of the river bed is usually rather represented by a fluctuating line than a linear line. In such situations the user can choose to apply a weighted moving average filter for determining the trend line. A weighted moving average filter smooths data by replacing each data point with the weighted average of the neighboring data points defined within a given span. The span defines the number of neighboring points that are used to take the weighted average. The span must be an odd number in order to prevent a phase shift.

We determine the trend line span, $P_{0}$, in case (b) as follows:

- For each trend line span value, $P_{0}$, varying from 3 data points through $N$ data points, we determine a weighted moving average trend line of the BEP under consideration. Here $N$ denotes the total number of data points the BEP consists of.

- We subtract the moving average trend line from the original BEP which yields a detrended BEP.

- We use a spectral density function to find the peak bedform length in the detrended BEP.

- We plot the peak bedform length against the trend line span, $P_{0}$.

The graph of the peak bedform length against the trend line span shows which bedform lengths are present in the original BEP. The user can specify which bedform lengths he/she is interested in. The trend line span corresponding to these bedform lengths is used for determining the trend line.

\section{Step 3. Detrending the bed elevation profile}

In step 3 we detrend the BEP by subtracting the trend line from the original BEP. The detrended BEP now fluctuates around the zero line.

\section{Step 4. Weighted moving average filter}

In step 4 we determine a filtered BEP using a weighted moving average technique in order to determine zero crossings. In this way not every small disturbance that crosses the zero line is specified as a zero crossing (also see Figure B.2). An important choice is the filter span value, $P$, that is used in creating the filtered BEP. A small filter span results in a signal that is almost equal to the original BEP. In that case crossings with the zero line will wrongly be interpreted as up- or downcrossings of a bedform. On the other hand, a large filter span will smooth out the bedforms. The filter span depends both on the length of the bedforms of interest in the BEP and on the distance between two consecutive 


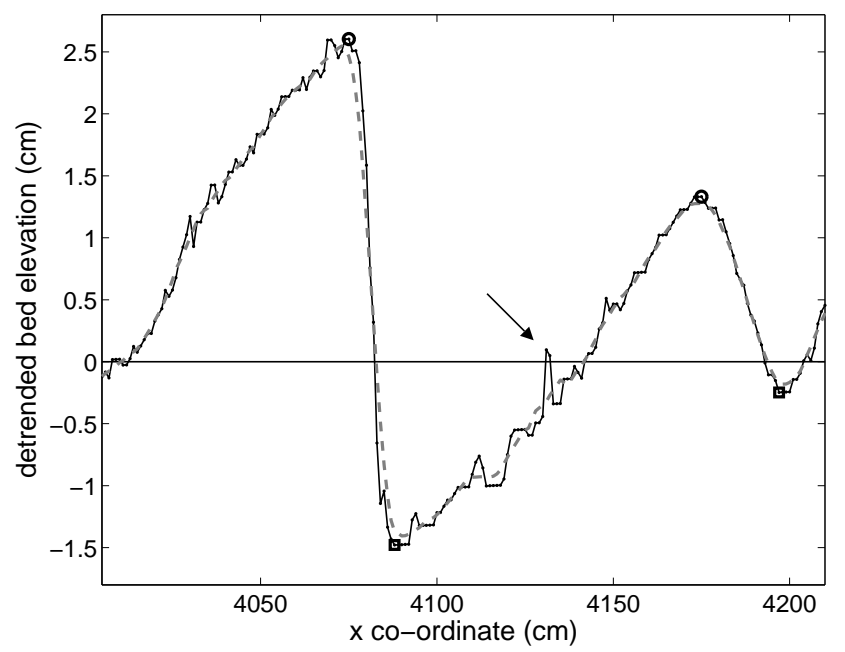

Figure B.2: A filter is needed to prevent that a small disturbance that crosses the zero line is considered to be a bedform. The dashed line indicates the filter. Crests and troughs are indicated with circles and squares, respectively.

data points. We apply a weighted moving average filter with a filter span, $P$, equal to $P=\frac{1}{6}\left(\lambda_{\mathrm{av}} / s+1\right)$, in which $\lambda_{\mathrm{av}}$ denotes the mean bedform length of the BEP under consideration determined by its zeroth and first spectral moments $\left(\lambda_{\mathrm{av}}=m_{0} / m_{1}\right)$, and $s$ denotes the horizontal distance between two consecutive data points. Please note that the filter is used only to determine up- and downcrossings of the BEP.

\section{Step 5. Determining zero crossings}

In step 5 we determine zero upcrossings and zero downcrossings in the filtered BEP. A zero upcrossing is located where the filtered BEP crosses the zero line in upward direction. Likewise, a zero downcrossing is located where the filtered $\mathrm{BEP}$ crosses the zero line in downward direction.

\section{Step 6. Determining crests and troughs}

In step 6 we determine the locations of crests and troughs. A crest is located between a zero upcrossing and zero downcrossing. A trough is located between a zero downcrossing and a zero upcrossing. We determine the crest and trough locations from the original detrended BEP, but we first use the filtered BEP to find the rough locations of the crests and troughs. A local disturbance could wrongly be selected as crest or trough if we would just take the highest or lowest data point between two zero crossings in the original detrended BEP as the crest or trough location, respectively (as illustrated in Figure B.3). Therefore, for determining the crest location, we first determine the location of the maximum value of the filtered BEP between a zero up- and zero downcrossing. Then, 


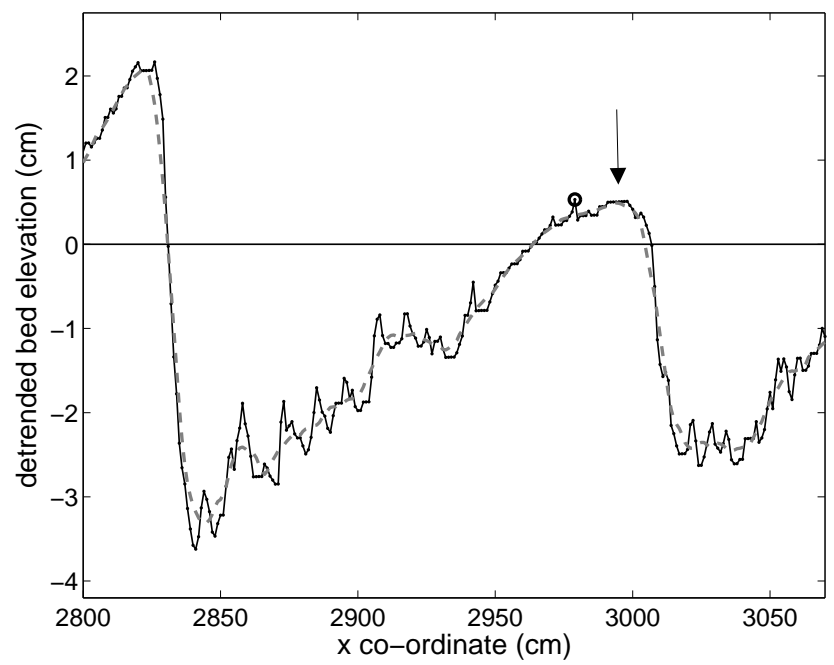

Figure B.3: If we would define the highest value of the original detrended BEP as the crest location, a small disturbance could be selected as the crest, indicated with the circle. Therefore, a crest is defined as the highest point of the original detrended BEP within the filter span of the maximum value of the filtered BEP (indicated with the arrow) between a zero upcrossing and a consecutive zero downcrossing. The dashed line indicates the filter.

the crest is located at the maximum value of the original BEP within the filter span, $P$, of the maximum value of the filtered BEP. Likewise, for determining the trough location, we determine the location of the minimum value of the filtered BEP between a zero down- and zero upcrossing. The trough is located at the minimum value of the original BEP within the filter span of the minimum value of the filtered BEP.

\section{Step 7. Crests and troughs at the boundaries of the bed elevation profile}

In step 7 we determine crests and troughs at the boundaries of the BEP. At the start and end of a BEP a crest or trough may be present that is not characterized as such in case the BEP does not cross the zero line. Especially in short BEPs it is desirable to take into account as many crests and troughs as possible. Figure B.4 shows that close to $X \approx 4300 \mathrm{~cm}$ a trough is located, but it is not characterized as such as it is not located between two zero crossings. In step 7 we look for additional crests and/or troughs at the boundaries of the BEP. There are four possibilities (Figure B.5):

a) a crest is located before the first zero downcrossing;

b) a crest is located after the last zero upcrossing;

c) a trough is located before the first zero upcrossing; 


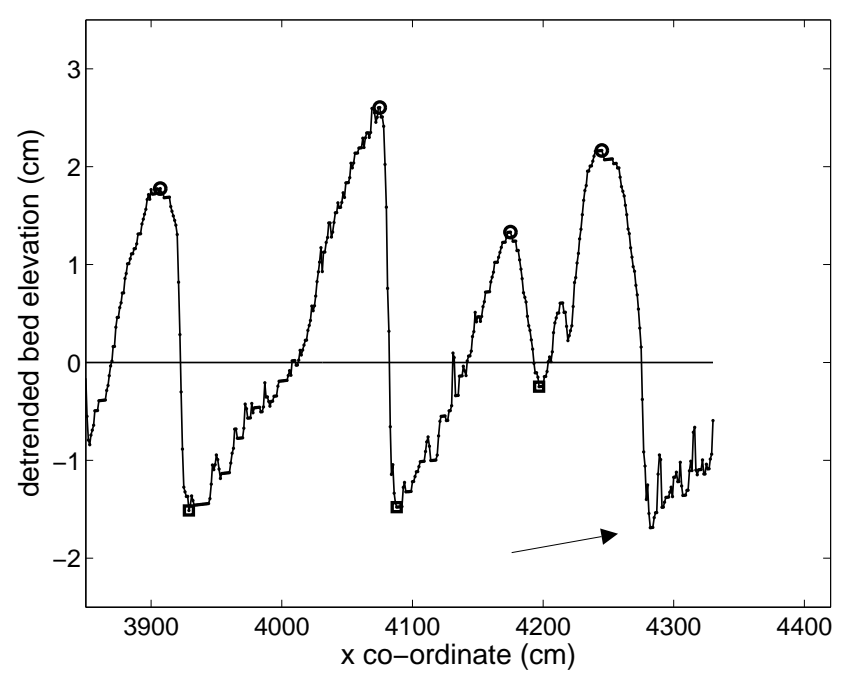

Figure B.4: A trough is located at the boundary of the BEP, indicated with the arrow. This trough is not recognized as such, as it is not surrounded by two zero crossings.

d) a trough is located after the last zero downcrossing.

We are only able to characterize a maximum as a crest or a minimum as a trough if there are enough data points before (a and c) or after (b and d) the extreme values. As such, we specify an extreme value as a crest or a trough if the number of data points before or after the extreme value is larger than or equal to half the filter span, 0.5P (see shaded areas in Figure B.5).

\section{Step 8. Determining bedform geometry}

In this study we are specifically interested in the stochastic properties of bedform geometry. The BTT saves all individual crest and trough locations, bedform heights and lengths in order to analyze the stochastics of the bedform geometry in more detail. Furthermore, mean values and standard deviations of bedform geometry and the equilibrium trend line are saved. The following bedform geometry is determined in the detrended BEP and saved (Figure B.6):

\section{symbol name}

$\eta_{c} \quad$ crest elevation

$\eta_{t} \quad$ trough elevation

$\delta_{s} \quad$ height of stoss face

\section{description}

vertical distance from crest to equilibrium trend line

vertical distance from trough to equilibrium trend line

vertical distance between crest and upstream trough 
$\delta_{l} \quad$ height of lee face

$\lambda_{s} \quad$ length of stoss face

$\lambda_{l} \quad$ length of lee face

$\lambda_{c} \quad$ bedform length between crests

$\lambda_{t} \quad$ bedform length between troughs

$\lambda_{\text {upcr }}$ bedform length between zero upcrossings

$\lambda_{\text {downcr }}$ bedform length between zero downcrossings

$S_{l} \quad$ slope of lee face of bedform vertical distance between crest and downstream trough

horizontal distance between crest and upstream trough

horizontal distance between crest and downstream trough

horizontal distance between two consecutive crests

horizontal distance between two consecutive troughs

horizontal distance between two consecutive zero upcrossings

horizontal distance between two consecutive zero downcrossings

vertical distance divided by horizontal distance of a part of the lee face

For determination of the slope of the lee face of a bedform, we do not consider the whole lee face region between crest and its subsequent trough. We exclude a distance of one sixth of the bedform height below the crest and a distance of one sixth of the bedform height above the trough as in these regions the slope is flatter due to the crest and trough. We fit a linear line through the data points for determining the slope. We exclude lee face slopes consisting of a region where the slope is subsequently negative, positive and negative (see the dashed line in Figure B.7).

\section{Built-in checks}

We have built in some checks to check whether the output of our code is correct. We check if both the zero upcrossings and zero downcrossings and the troughs and crests are found alternately. As a result of the chosen method for crest and trough tracking, crests are located above the zero line and troughs below the zero line. This is checked for all crests and troughs. Finally, each BEP, together with the selected crests and troughs, is plotted and screened visually.

\section{B.2.2 Evaluation of the procedure}

\section{Consequences of the zero crossing method}

We have chosen to apply a zero crossing method for the determination of crests and troughs. This choice has some consequences.

- Bedform A in Figure B.8 is not characterized as a bedform since the crest is not located above the zero line. This has consequences for the bedform 
(a)

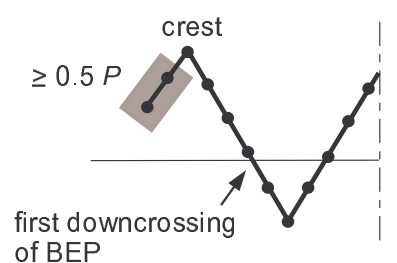

(c)

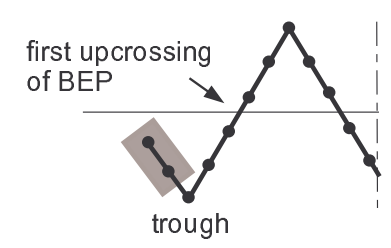

(b)

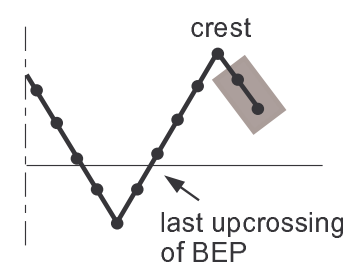

(d)

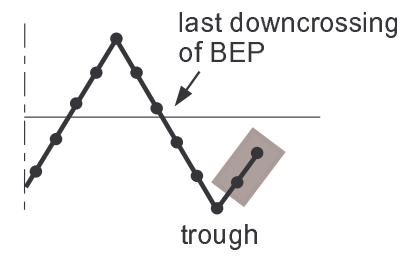

Figure B.5: Sketches of the four possibilities for extreme values at the boundaries of a BEP. If the number of data points in the shaded areas is larger than or equal to half the filter span, the maximum or minimum is considered as a crest or a trough, respectively.

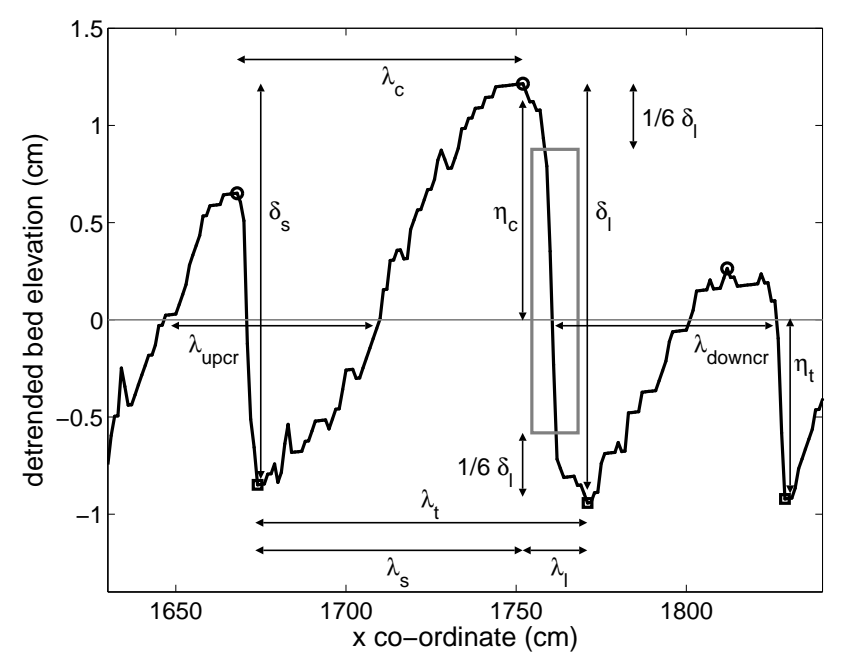

Figure B.6: Definitions of the determined bedform geometry in a detrended BEP. See the text for an explanation of the symbols. The rectangle illustrates which part of the lee face is used for determining the slope of the lee face of the bedform. Flow is from left to right. 


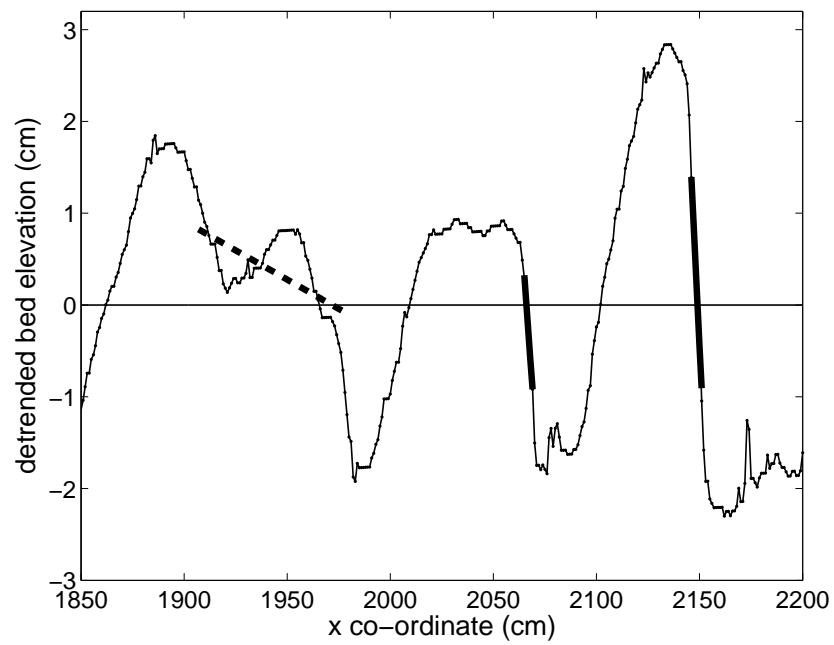

Figure B.7: Determination of the slope of the lee face. The bold lines indicate the slopes. The dashed line is excluded from the analysis. 


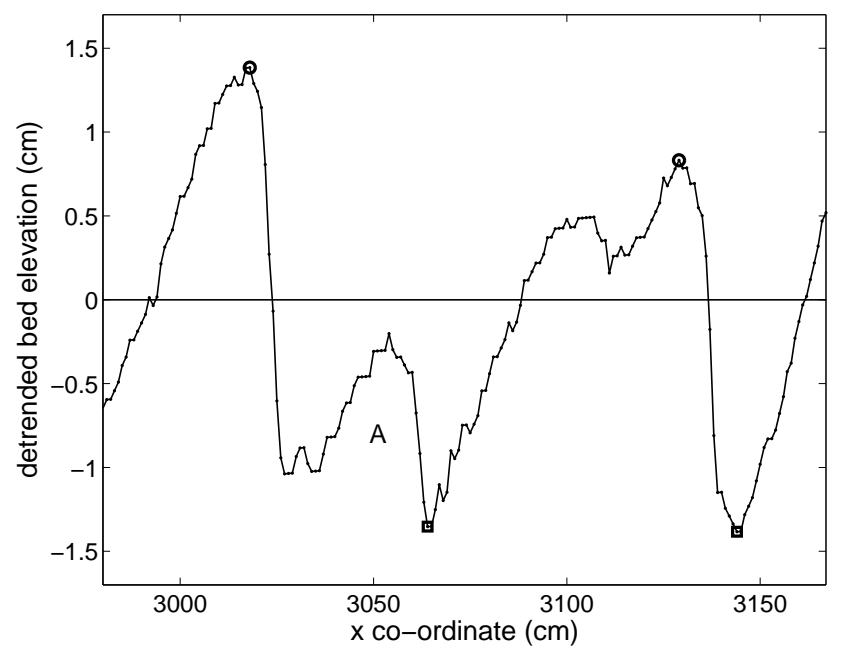

Figure B.8: Bedform A is not characterized as a bedform since it does not cross the zero line.

geometry, mainly for the bedform length. Mean bedform length would be smaller if bedforms such as A would be characterized as bedforms.

- In the neighborhood of the zero line sometimes a small bedform is characterized as a bedform (Figure B.9).

- A characteristic of a moving average filter is that, due to averaging, the amplitude of the filtered signal is slightly smaller than the amplitude of the original signal. As a result, the original detrended BEP may cross the zero line, whereas the filtered BEP does not. As a result, this bedform is not characterized as such (Figure B.10).

\section{Use of the weighted moving average trend line}

The trend line span, $P_{0}$, which is needed for determining the moving average trend line in step 2 is determined by first plotting a graph of the peak bedform length against the trend line span. With the help of this graph, the user can select the bedform length of his/her interest. The corresponding trend line span is then used for determining the trend line and detrending the data. Creating the graph of peak bedform length against trend line span takes some computational time. It takes roughly 3 minutes to plot such a graph for a BEP of 3000 data points (on a Pentium 4 computer).

\section{Applicability of the bedform tracking tool}

The BTT is a one-dimensional tool, which means that the input of the tool are longitudinal BEPs. The original data have to be converted into longitudinal 


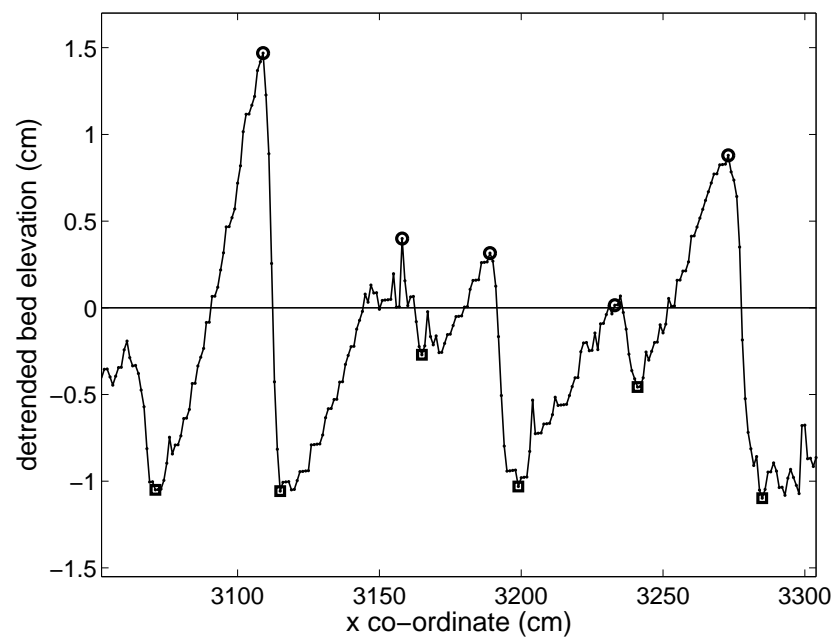

Figure B.9: Small bedforms fluctuating around the zero line are characterized as bedforms.

BEPs perpendicular to the bedform crest lines before the user can apply the BTT. This conversion is not included in the BTT. Two aspects are important in determining the longitudinal BEPs.

- In flumes or straight rivers, the longitudinal direction is parallel to the direction of the flume or river axis; the crest lines of the bedforms are roughly perpendicular to the flume or river axis. However, in river bends, the bedform crest lines may not be perpendicular to the river axis. To find the direction perpendicular to the crest lines, we suggest to use a part of the 'Digipol' interpolation procedure. The Dutch Ministry of Transport, Public Works and Water Management (Rijkswaterstaat) uses this procedure for interpolating depth measurements. A part of the procedure determines the direction of the crest lines. De Koning (2007) applied this method to find the direction of sand wave crest lines in the North Sea.

- Measurements may consist of several BEPs taken at different times but at the same location and/or BEPs taken at different locations at the same time. If several longitudinal BEPs are grouped together in order to study the bedform geometry, these BEPs need to be statistically homogeneous in both space and time. A spatial scaling technique (Barabási and Stanley, 1995; Jerolmack and Mohrig, 2005b) can be used to verify whether the BEPs are statistically homogeneous.

In the development of the BTT, we have tried to avoid subjective decisions, such as values for threshold values, as much as possible. Nevertheless, the proposed method consists of four quantitative choices:

1. the criterion of five times the mean value of all absolute vertical distances 


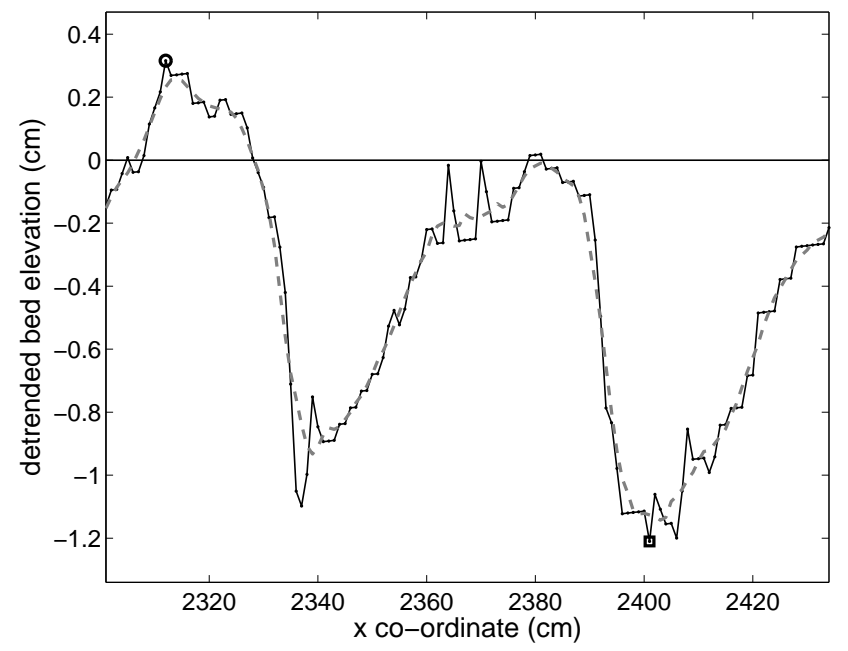

Figure B.10: A bedform is not characterized as such, as the filtered BEP (dashed line) does not cross the zero line.

between consecutive data points within a BEP for the outlier selection $\left( \pm 5 d z_{m}\right)$,

2. the trend line span, $P_{0}$, corresponding to a dominant bedform length to detrend the BEP in case a weighted moving average trend line is used,

3. the filter span constant $C=1 / 6$ for determining the filter span, $P$, for the filtered BEP,

4. half the filter span value $(0.5 P)$ for the selection of crests and troughs at the boundaries of the BEP.

We wrote the numerical code such that it can be applied to each data set, without the necessity to tune the code to each data set. At the moment, we applied the code successfully to river data, marine sand wave data (De Koning, 2007) and flume data. It has appeared that there was no need to change the quantitative choices. We expect that the BTT can be applied to all kinds of BEPs.

\section{Limitations of the bedform tracking tool}

It is important to mention that the BTT can only be applied to data sets in which bed elevations are measured on a uniformly spaced grid ( $s=$ const).

In the case of Barchan dunes or solitary bedforms (Figure B.11) bedform length is sometimes defined as the horizontal distance between the stoss toe and lee toe, as Carling et al. (2000) sketched in their definition diagram (their Figure 5). The bedform length between stoss toe and lee toe is smaller than the horizontal distance between two crests. This bedform length between two toes 


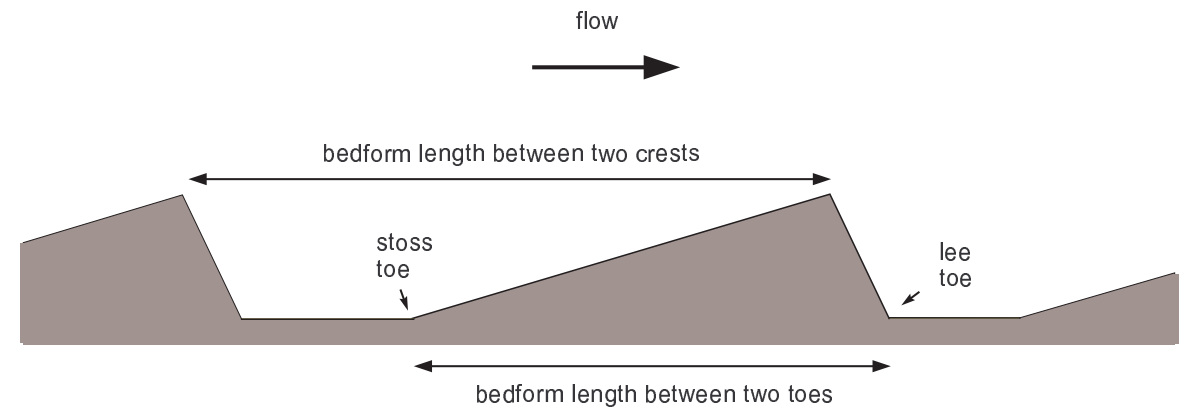

Figure B.11: Bedform length defined as the distance between the stoss toe and lee toe in case of solitary bedforms is smaller than the bedform length defined as the distance between two crests.

is not determined, as we do not estimate the locations of the stoss and lee toe in the BTT.

\section{B.3 Conclusions}

We have developed a numerical code, called the bedform tracking tool (BTT), which selects crests and troughs in a measured bed elevation profile and determines the bedform geometry of individual bedforms, as well as mean values and standard deviations. The BTT has been used successfully in determining bedform geometry of various sets of flume experiments, field measurements in river and marine environments.

The BTT determines whether there is more than one dominant bedform length present in the bed elevation profile. Subsequently, it determines the bedform geometry of more than one bedform length of interest.

The BTT is developed such that as few as possible subjective choices have to be made in determining bedform geometry. There are four quantitative subjectivities in the code for which values are proposed. For the data sets we analyzed so far, these four values have been used satisfactorily.

We have used the output of the BTT for analyzing bedform geometry of laboratory flume data. We recommend to use the vertical distance between a crest and its downstream trough as a definition of bedform height. It is recommended to use the horizontal distance between two crests as a definition of bedform length. 


\section{Appendix C}

\section{Variability in bedform geometry of sand waves in the North Sea*}

\section{C.1 Introduction}

For pipeline laying and operations on the bed of the North Sea, the industry needs information on the average geometric properties of sand waves and their variability. Németh et al. (2003) outlined how important it is to have more insight into sand wave behavior. Illustrated here is the importance of sand wave variability using two of their examples.

1. Pipelines sometimes have to cross a sand wave field. Migrating sand waves can form a threat if they expose a pipeline. Free spans may develop, causing stresses in the pipeline due to gravity and water flow. The pipeline may start vibrating due to turbulence generated under the free span. This may cause the pipeline to bend or break. Once exposed, a pipeline can be damaged by a ship anchor or fishing gear. Knowledge on the deepest troughs that may occur in a sand wave field helps us in determining how deep a pipeline should be buried.

2. Navigational channels often need to be dredged so as to be wide and deep enough for ships to pass safely. Nautical charts provide, among other things, information on the areas with the shallowest water depths. Information on the highest sand waves or highest crest elevations which can occur in a sand wave field may result in a more efficient monitoring and dredging strategy.

The objective of the study was to get more insight into the variability of sand wave characteristics in the North Sea. We performed a data analysis to investigate probability density functions, coefficients of variation and extreme values of the following geometric properties: sand wave length, sand wave height, crest elevation, trough elevation, and sand wave asymmetry.

${ }^{\star}$ This chapter has been published as: Van der Mark, C.F., M.F. de Koning, A. Blom, S.J.M.H. Hulscher, and A. Stolk (2008), Sea bed sand waves studied to help pipeline planners, Pipeline Gas J., 235(4), pp. 78-81. 


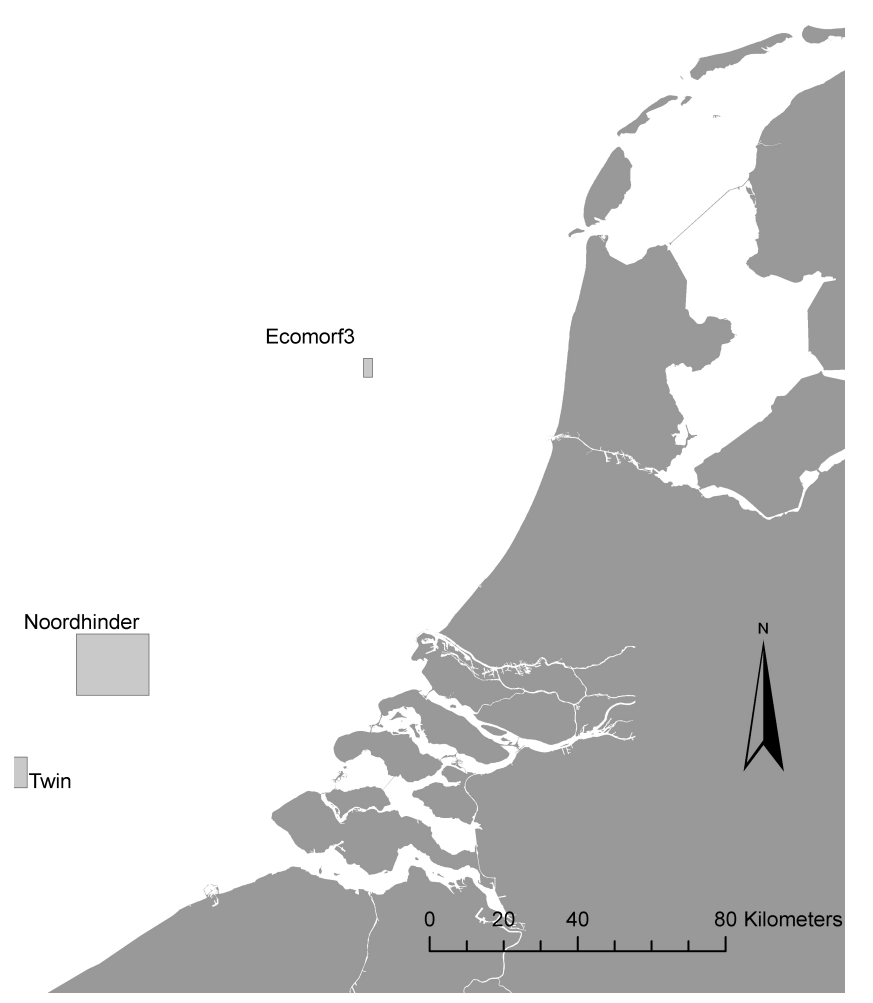

Figure C.1: Locations of bathymetric data sets in the North Sea.

\section{C.2 Data processing}

We used multi-beam measurements of three fields in the North Sea in which sand waves occur (Figure C.1). We considered six areas in the Noordhinder sand wave field (Figure C.2), two areas in the Twin field, and the area Ecomorf3 (Figure C.3). Figure C.2 shows a three-dimensional sand wave pattern, whereas Figure C.3 shows a two-dimensional sand wave pattern in which the crest lines are more or less parallel. We classified the sand waves of the Noordhinder area and also the Twin area as short-crested sand waves and the ones in the Ecomorf3 area as long-crested sand waves.

In order to draw longitudinal bed elevation profiles from these measurements, we first determined the orientation of the sand wave field using a part of the digipol method (RIKZ, 1997, chapter 4). For each orientation (from 0 - 180 degrees) we determined the gradient in bed elevation. The angle at which the highest gradient is found is assumed to correspond best with the direction perpendicular to the crest lines and is assumed to be the orientation of the sand wave field.

Given the orientation of the sand wave field, longitudinal bed elevation profiles are processed using the bedform tracking tool (BTT) of Van der Mark and 


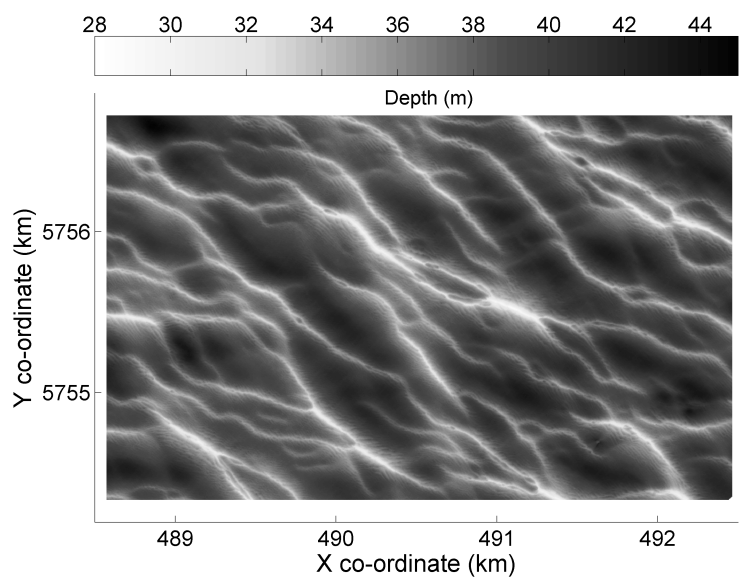

Figure C.2: Bathymetric map of the sand wave area Noordhinder 5B. Data from North Sea Directorate of the Ministry of Transport, Public Works, and Water Management.

Blom (2007). The BTT determines geometric properties of sand waves from the measured bed elevation profiles as objectively as possible. We analyzed sand wave length, $\lambda$, sand wave height, $\delta$, crest elevation, $\eta_{c}$, trough elevation, $\eta_{t}$, and sand wave asymmetry, $A$, in the detrended bed elevation profiles (Figure C.4). Sand wave asymmetry is computed as $A=\left(\lambda_{1}-\lambda_{2}\right) / \lambda$.

\section{C.3 Probability density functions}

We determined the probability density function (PDF) of measured trough elevations in one area. We imposed Normal, Gamma, Rayleigh, Weibull, Exponential, Log-normal, and Gumbel distributions for each area using the mean and standard deviation of the trough elevations in each area. Figure C.5 shows an example of imposed distributions for trough elevations occurring in one of the Noordhinder areas. The appropriateness of the imposed distributions was determined for the probability density function of trough elevations. We plotted probability density functions for all nine sand wave fields, and for each geometric property. For sand wave height, crest elevation, and trough elevation we found that the Weibull distribution provides the best approximation. For sand wave length the Log-normal or Weibull distributions yield the best approximation. For sand wave asymmetry the Normal distribution provides the best approximation. 


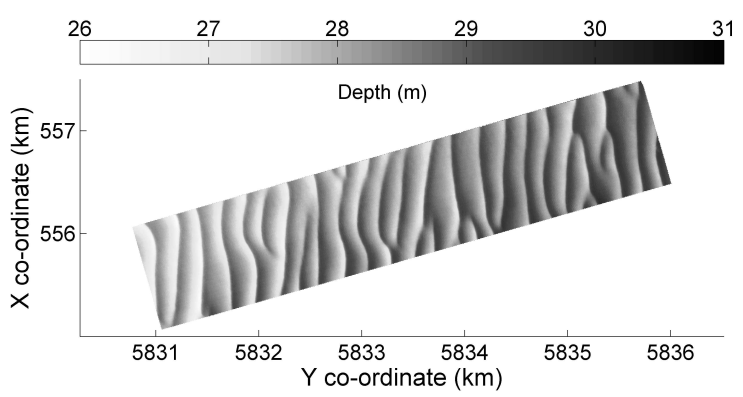

Figure C.3: Bathymetric map of the sand wave area Ecomorf3. Data from North Sea Directorate of the Ministry of Transport, Public Works, and Water Management.

\section{C.4 Coefficients of variation}

For each geometric sand wave property the coefficient of variation was determined. The coefficient of variation $C$ is defined as $C=\sigma / \mu$, in which $\sigma$ denotes the standard deviation, and $\mu$ the mean value of the geometric sand wave property. Figure C.6 shows the relationship between standard deviation of sand wave length and the mean sand wave length. It appears that the long-crested sand waves of Ecomorf3 have more regular sand wave lengths than the short-crested sand waves of the other areas. This is also the case for sand wave height, crest elevation, trough elevation, and sand wave asymmetry. Furthermore, if we only consider the short-crested areas, we find that the coefficients of variation of sand wave length, sand wave height, crest elevation, and trough elevation are more or less constant values, while the coefficient of variation of sand wave asymmetry is not. The coefficient of variation of sand wave length $C_{\lambda}$ equals more or less 0.55 (Figure C.6). The coefficients of variation of sand wave height, crest elevation, and trough elevation are $C_{\delta}=0.49, C_{\eta_{c}}=0.59$, and $C_{\eta_{t}}=0.64$, respectively. The standard deviation of sand wave asymmetry appears to be more or less constant $\left(\sigma_{A} \approx 0.35\right)$, independent of the mean sand wave asymmetry.

A constant coefficient of variation of sand wave length means that the standard deviation in sand wave length can be estimated if the mean sand wave length and the coefficient of variation for sand wave length, $C_{\lambda}$, are known. The same holds for sand wave height, crest elevation, and trough elevation.

\section{C.5 Extreme values}

We analyzed the $5 \%$ highest and $5 \%$ longest sand waves, the $5 \%$ deepest troughs and $5 \%$ highest crests. For short-crested sand waves we found that, for sand wave 


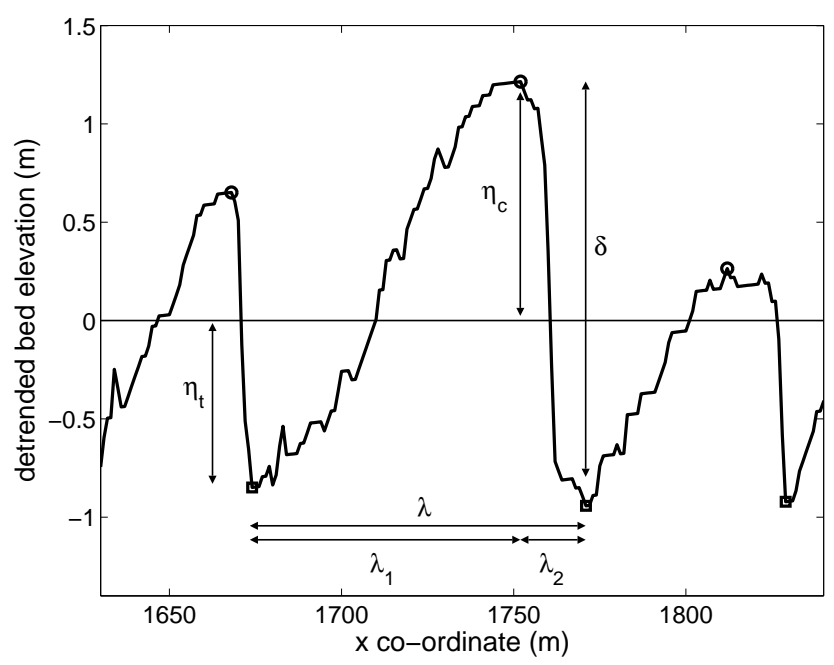

Figure C.4: Definitions of the sand wave properties in a detrended bed elevation profile: $\lambda$ denotes sand wave length, $\delta$ denotes sand wave height, $\eta c$ and $\eta t$ denote crest elevation and trough elevation, respectively. $\lambda_{1}$ and $\lambda_{2}$ are used to determine sand wave asymmetry. Crests and troughs are indicated with circles and squares, respectively. Note that the vertical axis is exaggerated with respect to the horizontal axis.

length, sand wave height, crest elevation, and trough elevation, the $95 \%$ values are linearly related to the mean value. For instance, for sand wave length we found that the $95 \%$ coefficient for sand wave length $C_{\lambda, 95}=\left(\lambda_{95}-\mu_{\lambda}\right) / \mu_{\lambda}=1.1$ (Figure C.7). Likewise, we found that the $95 \%$ coefficients for sand wave height, crest elevation, and trough elevation are $C_{\delta, 95}=0.9, C_{\eta_{c}, 95}=1.0$, and $C_{\eta_{t}, 95}=$ 1.2 , respectively. This means that we can estimate the extreme geometric sand wave properties, given the $95 \%$ coefficient and the mean value. Note that the given coefficients of variations and $95 \%$ coefficients are only valid for shortcrested sand waves.

\section{C.6 Planning pipelines}

Knowledge on the variability of sand waves may help us, for instance, in determining the optimal depth of a pipeline trench. The optimal depth depends on factors such as dredging costs, pipeline construction costs, monitoring costs, and risk (Németh et al., 2003). Consider, for instance, a sand wave field through which a pipeline has to be constructed. Assume that it is known from previous monitoring surveys that the sand waves are short-crested, and that the sand waves migrate, but do not grow or decay, as there are no dredging activities and net currents are more or less constant. We also know from a previous survey that the mean sand wave height is more or less four meters. Our data analysis shows that mean crest elevation is smaller than the correspond- 


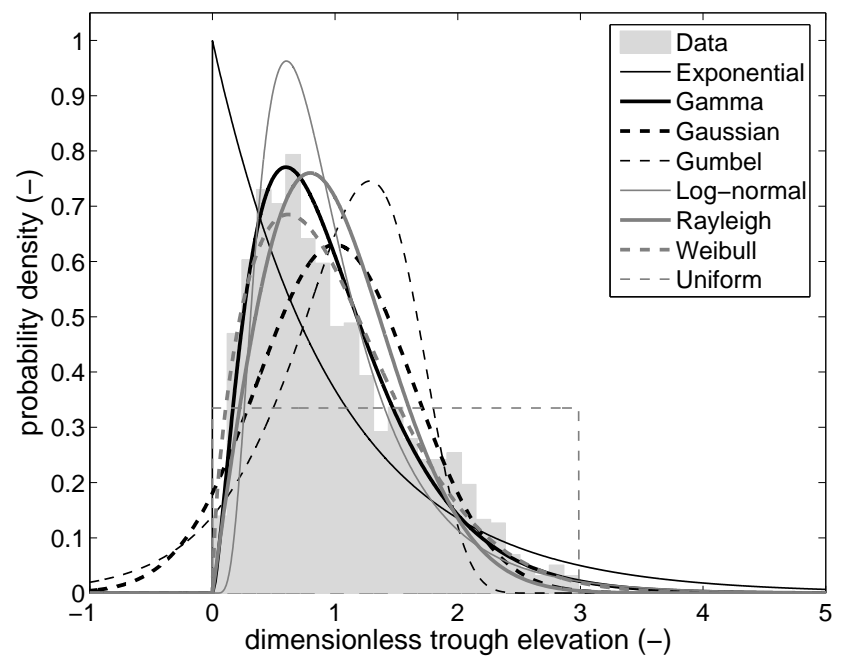

Figure C.5: Probability density function of dimensionless trough elevation (trough elevation divided by mean trough elevation) for one of the sand wave fields under consideration. The lines indicate the imposed probability distributions.

ing mean trough elevation such that a sand wave height of four meters corresponds to a mean trough elevation of 2.5 meters and a mean crest elevation of 1.5 meter. From our analysis we may conclude that the standard deviation in trough elevations is: $\sigma_{\eta_{t}}=C_{\eta_{t}} \mu_{\eta_{t}}=1.6 \mathrm{~m}$. The $95 \%$ trough elevation is: $\eta_{t, 95}=\left(C_{\eta_{t}, 95}+1\right) \mu_{\eta_{t}}=5.5 \mathrm{~m}$. This means that in an area of more or less 100 sand waves, five of these sand waves will have a trough elevation that is equal to or larger than 5.5 meters. Taking into account the risk one is willing to accept (which may depend on the type of liquid that is transported), one may decide to place the pipeline at a depth of more or less 5.5 meters below the mean bed elevation. If the pipeline is exposed by one of these five deep migrating troughs, this trough will probably not be much deeper than 5.5 meters, and the free span length will be small. As this example illustrates, our simple relationships may help in getting a first estimate for the optimal depth of a pipeline.

Acknowledgements This research project is part of VICI project Rough Water (STW TCB.6231) and is supported by the Technology Foundation STW, the applied science division of NWO and the technology program of the Ministry of Economic Affairs. The work by the second author served the partial fulfillment of the requirements for the M.S. degree in civil engineering at University of Twente, the Netherlands. We acknowledge the North Sea Directorate of the Ministry of Transport, Public Works, and Water Management for providing us with the bathymetric data. 


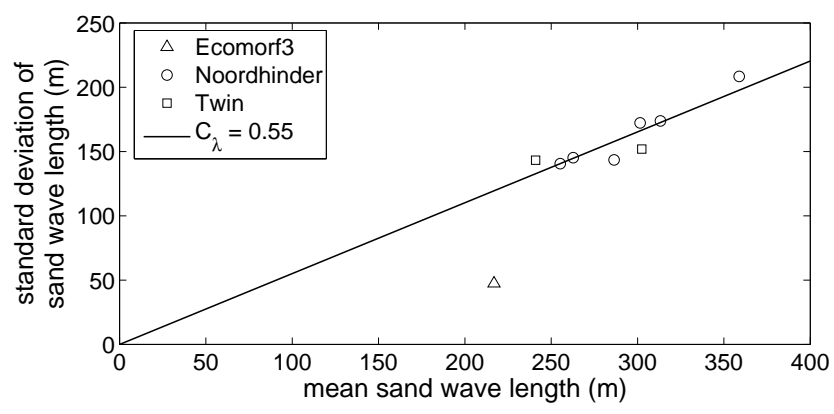

Figure C.6: Standard deviation of sand wave length versus mean sand wave length. $C_{\lambda}$ denotes the coefficient of variation of sand wave length fitted through the shortcrested data points.

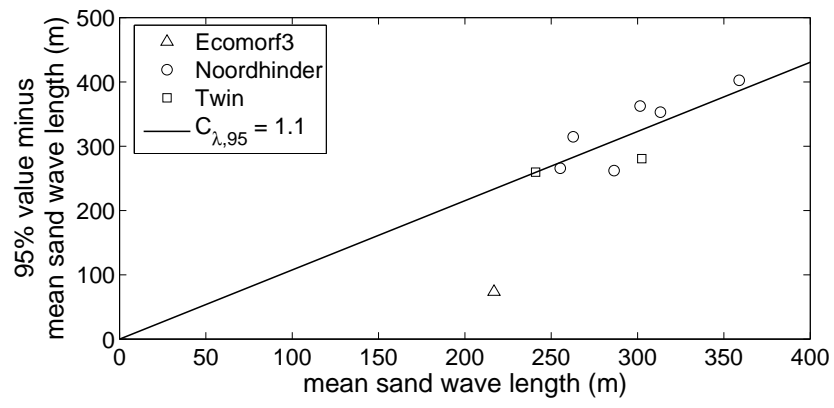

Figure C.7: The $95 \%$ sand wave length minus mean sand wave length versus mean sand wave length. $C_{\lambda, 95}$ denotes the $95 \%$ coefficient of sand wave length fitted through the short-crested data points. 


\section{Appendix D}

\section{Derivation of mass, momentum, and energy conservation equations from integral formulations}

In Chapter 3 the reference form drag model is derived using the momentum and energy conservation equations applied to the reference situation. In this appendix the applied conservation equations are derived from the integral formulations of the mass, momentum, and energy conservation equations.

\section{D.1 Continuity equation or the law of conservation of mass}

The integral form of the conservation of mass reads (e.g. Kundu and Cohen, 2004)

$$
\frac{\partial}{\partial t} \iiint_{V} \rho d V+\iint_{\partial V} \rho\left[\left(\vec{u}-\vec{u}_{\partial V}\right) \cdot \vec{n}\right] d A=0
$$

The first term represents the time rate of change of mass within the control volume, and the second term the flux of mass out of the control volume. For an incompressible fluid and a fixed control volume, equation (D.1) reduces to (e.g. Kundu and Cohen, 2004)

$$
\iint_{\partial V} \rho(\vec{u} \cdot \vec{n}) d A=0
$$

The differential form can be obtained by transforming the surface integral in equation (D.2) to a volume integral by means of the divergence theorem, which yields for equation (D.2) (e.g. Kundu and Cohen, 2004)

$$
\iiint_{V} \vec{\nabla} \cdot(\rho \vec{u}) d V=0
$$

Equation (D.3) holds for any volume, which can be possible only if the integrand vanishes at each point (Kundu and Cohen, 2004). This requires

$$
\vec{\nabla} \cdot(\rho \vec{u})=0
$$

which is called the differential form of the continuity equation. 


\section{D.2 Newton's second law of motion or law of conservation of momentum}

Newton's second law of motion describes that the total rate of change of momentum within a control volume is equal to the sum of acting forces. The general form of the equation of momentum in integral form reads (e.g. Hirsch, 2002)

$$
\begin{array}{r}
\frac{\partial}{\partial t} \iiint_{V} \rho \vec{u} d V+\iint_{\partial V} \rho \vec{u}\left[\left(\vec{u}-\vec{u}_{\partial V}\right) \cdot \vec{n}\right] d A= \\
\iiint_{V} \rho \vec{f} d V-\iint_{\partial V} p \vec{n} d A+\iint_{\partial V} \overline{\bar{\tau}} \vec{n} d A
\end{array}
$$

in which $V$ denotes an arbitrary control volume, $A=\partial V$ the surface bounding the control volume, $\vec{n}(\vec{x}, t)$ the outward pointing unit normal vector, $\vec{u}(\vec{x}, t)$ the velocity of the fluid, $\vec{u}_{\partial V}(\vec{x}, t)$ the velocity of boundary $\partial V, \rho(\vec{x}, t)$ the density of the fluid, $\vec{f}$ the external densimetric volume force (i.e., force per unit mass), $p$ the pressure, and $\overline{\bar{\tau}}$ the Cauchy stress tensor. The position vector $\vec{x}$ equals $\left[\begin{array}{lll}x & y & z\end{array}\right]^{T}$, the velocity vector $\vec{u}$ equals $\left[\begin{array}{ll}u & w\end{array}\right]^{T}$, and the unit normal vector equals $\vec{n}$ equals $\left[\begin{array}{lll}n_{x} & n_{y} & n_{z}\end{array}\right]^{T}$. The stress tensor is symmetric and equals (e.g. Batchelor, 1967)

$$
\overline{\bar{\tau}}=\left[\begin{array}{ccc}
\tau_{x x} & \tau_{y x} & \tau_{z x} \\
\tau_{x y} & \tau_{y y} & \tau_{z y} \\
\tau_{x z} & \tau_{y z} & \tau_{z z}
\end{array}\right]
$$

The first term on the left-hand side of equation (D.5) represents the time rate of change of momentum within the control volume, the second term the net outgoing momentum flux at the boundaries of the control volume. The terms on the right-hand side represent the acting forces. The first term represents the external volume forces or body forces acting on the control volume, the second and third represent the surface forces acting on the control surface, i.e., pressure and viscous forces, respectively.

It is allowed to subtract the atmospheric pressure, $p_{a}$, from the pressure, $p$, in equation (D.5), as for any closed surface the following holds:

$$
\iint_{\partial V} \vec{n} d A=0
$$

As such, equation (D.5) becomes

$$
\begin{aligned}
& \frac{\partial}{\partial t} \iiint_{V} \rho \vec{u} d V+\iint_{\partial V} \rho \vec{u}\left[\left(\vec{u}-\vec{u}_{\partial V}\right) \cdot \vec{n}\right] d A= \\
& \iiint_{V} \rho \vec{f} d V-\iint_{\partial V}\left(p-p_{a}\right) \vec{n} d A+\iint_{\partial V} \overline{\bar{\tau}} \vec{n} d A
\end{aligned}
$$

If the component of the momentum in $x$-direction is considered, equation (D.5) becomes

$$
\frac{\partial}{\partial t} \iiint_{V} \rho u d V+\iint_{\partial V} \rho u\left[\left(\vec{u}-\vec{u}_{\partial V}\right) \cdot \vec{n}\right] d A=
$$




$$
\left[\iiint_{V} \rho \vec{f} d V\right] \cdot \vec{e}_{x}-\left[\iint_{\partial V}\left(p-p_{a}\right) \vec{n} d A\right] \cdot \vec{e}_{x}+\left[\iint_{\partial V} \overline{\bar{\tau}} \vec{n} d A\right] \cdot \vec{e}_{x}
$$

The body force, here equal to the gravitational force, i.e., $\vec{f}=\vec{g}$ (Batchelor, 1967), equals zero in $x$-direction, since the channel is chosen to be horizontal in the reference situation. We assume flow conditions to be steady, so that the first term on the left-hand side of equation (D.9) equals zero. The control volume is fixed, so that $\vec{u}_{\partial V}=0$. Equation (D.9) now reduces to

$$
\iint_{\partial V} \rho u \vec{u} \cdot \vec{n} d A=\left[-\iint_{\partial V}\left(p-p_{a}\right) \vec{n} d A\right] \cdot \vec{e}_{x}+\left[\iint_{\partial V} \overline{\bar{\tau}} \vec{n} d A\right] \cdot \vec{e}_{x}
$$

We assume that in the control volume, i.e., in the expansion region, the viscous force term is negligible, so that equation (D.10) reduces to

$$
\iint_{\partial V} \rho u \vec{u} \cdot \vec{n} d A=\left[-\iint_{\partial V}\left(p-p_{a}\right) \vec{n} d A\right] \cdot \vec{e}_{x}
$$

Please note that neglecting the viscous stress in the development of the form drag model does not mean that we neglect grain friction. We use an existing grain friction model to predict the bed resistance (i.e., predicted bed resistance equals the sum of predicted form drag and predicted grain friction).

At the inlet (cross-section 1) and outlet (cross-section 2) pressure forces act. As streamlines are parallel at cross-sections 1 and 2 and the velocity in the flow separation zone is small, we are allowed to assume that the pressure has a hydrostatic distribution both at cross-sections 1 and 2:

$$
\frac{d p}{d z}=-\rho g
$$

in which $z$ denotes the upward normal coordinate from the bed. By integrating and evaluating the constant of integration under the condition of atmospheric pressure at the water surface, it follows from equation (D.12) that

$$
p(x, z)=p_{a}+\rho g[d(x)-z]
$$

in which $d(x)$ denotes the local water depth. By integrating the pressure over the water depth and channel width, $W$, the pressure force at cross-section 1 becomes

$$
\begin{gathered}
F_{p, 1}=\left[-\iint_{A_{1}}\left(p-p_{a}\right) \vec{n} d A\right] \cdot \vec{e}_{x}=\iint_{A_{1}}\left[\rho g\left(d_{1}-z\right)\right] d A= \\
W \int_{0}^{d_{1}}\left[\rho g\left(d_{1}-z\right)\right] d z=\frac{1}{2} \rho g d_{1}^{2} W
\end{gathered}
$$

Likewise, the pressure force at cross-section 2 becomes

$$
F_{p, 2}=-\frac{1}{2} \rho g d_{2}^{2} W
$$


Subscripts 1 and 2 refer to cross-sections 1 and 2, respectively. Equation (D.11) now reduces to

$$
\iint_{\partial V} \rho u \vec{u} \cdot \vec{n} d A=\frac{1}{2} \rho g W\left[d_{1}^{2}-d_{2}^{2}\right]
$$

In Section 3.3.2 it is shown that equation (D.16) reduces to

$$
\frac{1}{2} \rho g\left(d_{f}+\delta_{f}\right)^{2}+\beta_{1} \rho \frac{q^{2}}{d_{f}}=\frac{1}{2} \rho g d_{2}^{2}+\beta_{2} \rho \frac{q^{2}}{d_{2}}
$$

in which $q$ denotes the specific discharge, $d_{f}$ the water depth at the location where the flow separates, $\delta_{f}$ the height of the flow separation zone, and $\beta$ the momentum coefficient which corrects for the fact that the velocity distribution is not uniform over the cross-section (e.g. Chow, 1959). Equation (D.17) is the one-dimensional momentum conservation equation for the reference situation (e.g. Chanson, 2004).

\section{D.3 First law of thermodynamics or the law of conserva- tion of energy}

The first law of thermodynamics describes that the total rate of change of the total energy in the control volume is equal to the rate of work done on the fluid by the acting forces plus the rate at which heat is added to the control volume. The general form of the equation of energy in integral form reads (e.g. Hirsch, 2002; Kundu and Cohen, 2004)

$$
\begin{gathered}
\frac{\partial}{\partial t} \iiint_{V} \rho E d V+\iint_{\partial V} \rho E\left[\left(\vec{u}-\vec{u}_{\partial V}\right) \cdot \vec{n}\right] d A= \\
\iiint_{V} \rho[\vec{f} \cdot \vec{u}] d V+\iiint_{V} \dot{Q}_{h} d V- \\
\iint_{\partial V} p[\vec{u} \cdot \vec{n}] d A+\iint_{\partial V}[(\overline{\bar{\tau}} \vec{n}) \cdot \vec{u}] d A-\iint_{\partial V}\left[\vec{q}_{h} \cdot \vec{n}\right] d A
\end{gathered}
$$

in which

$$
E=e+\frac{1}{2}|\vec{u}|^{2}
$$

Here, $E$ denotes the total energy per unit volume, which equals the internal energy, $e$, plus the kinetic energy, $\dot{Q}_{h}$ denotes the rate of volumetric heating, and $\vec{q}_{h}$ the rate of heat conduction through boundary $\partial V$. The first term on the left-hand side represents the time rate of change of the total energy within the control volume, the second term the total energy flux over the control surface out of the control volume. The first term on the right-hand side represents the rate of work done by the external force field, the second the rate of volumetric heating, the third and fourth terms represent the rate of work done by surface forces (i.e., pressure and viscous forces), and the fifth term represents the rate of heat conduction through the control surface into the control volume. 
The flow is steady, so that the first term on the left-hand side of equation (D.18) equals zero. The control volume is fixed, so that $\vec{u}_{\partial V}=0$. We assume an adiabatic process, i.e., no heat is transferred to or from the working fluid, so that the second term on the right-hand side equals zero. Also the fifth term on the right-hand side equals zero, as the effect of heat conduction is ignored. Equation (D.18) now becomes

$$
\begin{gathered}
\iint_{\partial V} \rho E(\vec{u} \cdot \vec{n}) d A= \\
\iiint_{V} \rho \vec{f} \cdot \vec{u} d V-\iint_{\partial V} p[\vec{u} \cdot \vec{n}] d A+\iint_{\partial V}[(\overline{\bar{\tau}} \vec{n}) \cdot \vec{u}] d A
\end{gathered}
$$

The integrand in the first term on the right-hand side of equation (D.20) is rewritten using $\vec{f}=-\vec{\nabla}(g z)$ (e.g. Kundu and Cohen, 2004) as follows:

$$
\rho \vec{f} \cdot \vec{u}=-\rho \vec{u} \cdot \vec{\nabla}(g z)=-\vec{\nabla} \cdot(\rho \vec{u} g z)+g z \vec{\nabla} \cdot(\hat{\vec{u})}=0
$$

The last term equals zero as this term equals the continuity equation (equation (D.4)). Using the divergence theorem, the first term on the right-hand side of equation (D.20) becomes

$$
\iiint_{V} \rho \vec{f} \cdot \vec{u} d V=-\iiint_{V} \vec{\nabla} \cdot(\rho \vec{u} g z) d V=-\iint_{\partial V}(\rho \vec{u} g z) \cdot \vec{n} d A
$$

Equation (D.20) now becomes by using equation (D.22)

$$
\iint_{\partial V} \rho E(\vec{u} \cdot \vec{n}) d A=\iint_{\partial V}[(\overline{\bar{\tau}} \vec{u}) \cdot \vec{n}] d A-\iint_{\partial V}(p+\rho g z)(\vec{u} \cdot \vec{n}) d A
$$

placing the second term on the right-hand side on the left-hand side yields

$$
\iint_{\partial V}(\rho E+p+\rho g z)(\vec{u} \cdot \vec{n}) d A=\iint_{\partial V}[(\overline{\bar{\tau}} \vec{u}) \cdot \vec{n}] d A
$$

In a fluid flow with constant temperature, the internal energy, $e$, will be constant as well (e.g. Kundu and Cohen, 2004), and equation (D.24) becomes

$$
\iint_{\partial V} \rho g\left(\frac{|\vec{u}|^{2}}{2 g}+\frac{p}{\rho g}+z\right)(\vec{u} \cdot \vec{n}) d A=\iint_{\partial V}[(\overline{\bar{\tau}} \vec{u}) \cdot \vec{n}] d A
$$

If the component of the energy flux in $x$-direction is considered, each of the terms are elaborated for the cross-sections 1 and 2 , and the atmospheric pressure is subtracted from the pressure just as done in the momentum conservation equation, equation (D.25) becomes

$-\rho g \iint_{A_{1}} u_{1}\left(\frac{u_{1}^{2}}{2 g}+\frac{p-p_{a}}{\rho g}+z\right) d A+\rho g \iint_{A_{2}} u_{2}\left(\frac{u_{2}^{2}}{2 g}+\frac{p-p_{a}}{\rho g}+z\right) d A=$ 


$$
-\iint_{A_{1}} \tau_{x x} u_{1} d A+\iint_{A_{2}} \tau_{x x} u_{2} d A
$$

The terms on the left-hand side represent the energy fluxes, $P$, at the crosssections 1 and 2, respectively (e.g. Fox and McDonald, 1994; Chaudhry, 2008). We indicate the difference in energy flux between cross-sections 1 and 2 as $\Delta P=$ $P_{1}-P_{2}$. The pressure has a hydrostatic distribution both at cross-sections 1 and 2 (equation (D.13)), so that equation (D.26) becomes

$$
\rho g \iint_{A_{1}} u_{1}\left(\frac{u_{1}^{2}}{2 g}+d_{1}\right) d A-\rho g \iint_{A_{2}} u_{2}\left(\frac{u_{2}^{2}}{2 g}+d_{2}\right) d A=\Delta P
$$

We express the velocity in terms of the section-averaged velocity $U=\frac{1}{A} \iint_{A} u d A$ (i.e., averaged over the cross-sectional area). We introduce the kinetic energy coefficient, $\alpha$, which is equal to

$$
\alpha=\frac{\iint \frac{1}{2} \rho u^{3} d A}{\frac{1}{2} \rho U^{3} A}=\frac{\overline{u^{3}}}{U^{3}}
$$

where the overbar indicates averaging over the cross-sectional area. Equation (D.27) becomes after integrating and combining with equation (D.28)

$$
\left[\frac{\rho}{2} \alpha_{1} U_{1}^{3} A_{1}+\rho g d_{1} U_{1} A_{1}\right]-\left[\frac{\rho}{2} \alpha_{2} U_{2}^{3} A_{2}+\rho g d_{2} U_{2} A_{2}\right]=\Delta P
$$

By applying that the water discharge, $Q$, equals $Q=U_{1} A_{1}=U_{2} A_{2}$, equation (D.29) becomes

$$
\rho g Q\left[\frac{\alpha_{1} U_{1}^{2}}{2 g}+d_{1}\right]-\rho g Q\left[\frac{\alpha_{2} U_{2}^{2}}{2 g}+d_{2}\right]=\Delta P
$$

or

$$
\left[\frac{\alpha_{1} U_{1}^{2}}{2 g}+d_{1}\right]-\left[\frac{\alpha_{2} U_{2}^{2}}{2 g}+d_{2}\right]=\frac{\Delta P}{\rho g Q}
$$

or in terms of the energy head, $H$ (e.g. Chanson, 2004)

$$
H_{1}-H_{2}=\Delta H
$$

where $H$ denotes the energy head averaged over a cross-section, and $\Delta H$ denotes the energy head loss expressed in units of length. For a free surface flow with a hydrostatic pressure distribution and a horizontal bed, energy head, $H$, is defined as (e.g. Henderson, 1966; Fox and McDonald, 1994; Chaudhry, 2008)

$$
H=z_{b}+d+\alpha \frac{U^{2}}{2 g}
$$

Equations (D.32) and (D.33) have been applied in Section 3.3.3 to derive the reference form drag model. 


\section{Dankwoord}

Voorliggend proefschrift is het resultaat van ruim vier jaar onderzoek aan de afdeling Water Engineering and Management (WEM) van de Universiteit Twente. Graag wil ik de mensen bedanken die aan dit onderzoek hebben bijgedragen.

Allereerst wil ik mijn promotoren Suzanne Hulscher en Harry Hoeijmakers bedanken. Suzanne: dank je wel dat je me de mogelijkheid hebt gegeven om dit promotieonderzoek uit te voeren. Ik heb het erg gewaardeerd dat je gedurende het hele traject je vertrouwen uitte. Daarnaast hield je altijd scherp voor ogen wat de eindproducten moesten worden; ik vond dit prettig, omdat aan stukken tekst altijd wel geschaafd kan blijven worden. Harry: ik heb onze overleggen als erg plezierig ervaren. Bedankt voor je motiverende woorden en anekdotes. Maar vooral wil ik je bedanken voor je hulp bij wiskundige analyses en CFX.

Astrid Blom heeft me van begin tot eind met veel enthousiasme begeleid. Astrid: jouw kritische blik, inhoudelijke nieuwsgierigheid, betrokkenheid, rode pen, flexibiliteit en kennis hebben een zeer belangrijke rol gespeeld bij de totstandkoming van dit proefschrift. Ik raadpleegde je met grote regelmaat, zelfs bij je thuis met de kids erbij. Ik ben je ontzettend dankbaar voor alles, ook voor alle koppen koffie!

Tijdens mijn promotieonderzoek bezocht ik regelmatig de afdeling vloeistofmechanica aan de TU Delft. Ik wil Wim Uijttewaal hartelijk bedanken voor het enthousiast meedenken en meelezen. Dankzij Wim kon ik aanvullende laboratoriummetingen verrichten en kwamen zaagtand-metingen beschikbaar. RobertJan Labeur ben ik dankbaar, omdat ik zijn numerieke stromingsmodel Finlab mocht gebruiken om stroming over bodemvormen te simuleren. Guus Stelling wil ik bedanken voor de discussies die we samen hadden, en voor zijn exercities met zijn 1D Fortran code tijdens mijn verblijf aan de TU Delft.

I am very grateful to Yasuyuki Shimizu of the Hokkaido University in Japan for the opportunity to apply his numerical flow model. I greatly enjoyed my stay in Japan, mainly because of the warm welcome, the events and outings Yasuyuki arranged for me. I also want to thank Yasuyuki's MSc and PhD students; they made me feel comfortable. Thanks for taking me to the Sushi bar and for translating the Japanese language. I would like to thank Sanjay Giri for answering my questions about the numerical model when I was back home in the Netherlands. 
De leden van de STW gebruikerscommissie Janrik van den Berg, Hanneke van der Klis, Erik Mosselman, Arjan Sieben, Ad Stolk en Paul Termes ben ik erkentelijk voor hun kritische en constructieve bijdrage. Kees Sloff en Willem Ottevanger wil ik bedanken voor hun bijdrage aan Sectie 5.3. In korte tijd CFX onder de knie te krijgen was me niet gelukt zonder de hulp van Chris Boeije, Wouter den Breeijen, Jim Kok en de Ansys helpdesk.

Michiel de Koning heeft met zijn afstudeerwerk een grote bijdrage geleverd aan Appendix C. Michiel: ik vond het leuk en leerzaam om je te begeleiden. Marjolein Dohmen-Janssen wil ik bedanken voor het presenteren van Michiel's werk op het ICCE congres.

I acknowledge Brandon McElroy for the useful conversations we had during his stay in the Netherlands.

De WEM afdeling heb ik als een erg aangename werkomgeving ervaren. Allereerst wil ik mijn kamergenoten Jebbe van der Werf en Wouter Kranenburg bedanken voor alle koffiepauzes, tips (Matlab, $\mathrm{L}_{\mathrm{T}} \mathrm{T} \mathrm{X}$, enz.) en interessante gesprekken. Verder wil ik de volgende (ex-)collega's dankzeggen voor inhoudelijke discussies en/of gezelligheid tijdens borrels, damesdaghappen of zaalvoetbal: Andries, Bas, Blanca, Daniëlle, Denie, Ella, Erik, Fenneke, Freek, Jan, Joerg, Jolanthe, Jord, Henriët, Kathelijne, Leendert, Lisette, Matthieu, Mehmet, Pieter, Pieter, René, Rianne, Saskia, Tanya, en uiteraard de WEM secretaresses Anke, Brigitte en Joke. Ik ben blij dat Arjan Tuijnder en Judith Janssen mijn paranimfen zijn. Bedankt voor het delen van ups en downs tot en met de dag van de verdediging!

Het is inmiddels 2 uur 's nachts; de nachtelijke uren zijn geschikt gebleken om bergen werk te verzetten. Joost: in de eerste plaats bedankt voor al je opofferingen. Het moet niet eenvoudig geweest zijn om met zo'n nachtdier samen te wonen. Ik beloof dat ik me gauw zal aanpassen aan jouw ritme. Daarnaast wil ik je bedanken voor het aanhoren van mijn klaagliederen en voor je immer positieve kijk op de momenten dat ik dit nodig had. Joost, bedankt voor alles! 


\section{About the author}

Rolien van der Mark was born in Sassenheim, the Netherlands, on 20 March 1978. She grew up in Sassenheim and Oegstgeest, the Netherlands. She received primary education at 'De Hofdijckschool' and secondary education at the 'Stedelijk Gymnasium Leiden' in Leiden. Rolien started studying Civil Engineering at the Delft University of Technology in 1997.

Rolien chose for the Hydraulic Engineering track, and later specialized in River Engineering.

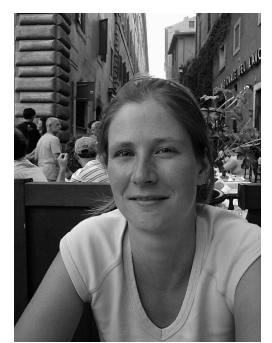
During her study, she conducted an internship of three months at the Ministry of Transport, Public Works \& Water Management, Directorate North-Holland, Division 'Vaarwegen en Waterkeringen'. Here she worked on instability of the IJmuiden breakwaters and effects of man-made structures on the tidal difference along the Dutch coast. Her internship was awarded with the prize for best internship of the year.

In October 2002 Rolien joined in a field work trip to Bulgaria, where measurements were conducted on hydraulic processes. In June 2004 Rolien finished her M.Sc. thesis on sediment distribution at river bifurcations. She conducted this research at WL $\mid$ Delft Hydraulics.

From September until December 2004 Rolien worked as a research employee at the Water Engineering \& Management Department of the University of Twente, the Netherlands. In December 2004 she started her Ph.D. research at the same department. During her Ph.D. research, Rolien visited Delft University of Technology for three months, and the Hokkaido University, Sapporo, Japan, for one month, to work with the numerical models of ir. R.J. Labeur and prof. dr. Y. Shimizu, respectively. In July 2008, Rolien conducted flume experiments at the Environmental Fluid Mechanics Section, Delft University of Technology, to study the interaction of flow patterns over subsequent bedforms.

At the moment, Rolien works as a researcher/advisor at the River Engineering and Morphology department of Deltares. 


\section{List of publications}

\section{International journals}

Van der Mark, C.F., A. Blom, S.J.M.H. Hulscher, and H.W.M. Hoeijmakers, A semi-analytical form drag model: Application to alluvial and compound bedforms, J. Geophys. Res., to be submitted.

Van der Mark, C.F., A. Blom, W.S.J. Uijttewaal, S.J.M.H. Hulscher, and H.W.M. Hoeijmakers, A semi-analytical form drag model: Application to uniform bedforms, J. Geophys. Res., submitted.

Van der Mark, C.F., A. Blom, and S.J.M.H. Hulscher (2008), Quantification of variability in bedform geometry, J. Geophys. Res., 113, F03020, doi:10.1029/2007JF000940.

Van der Mark, C.F., M.F. De Koning, A. Blom, S.J.M.H. Hulscher, and A. Stolk (2008), Sea bed sand waves studied to help pipeline planners, Pipeline Gas J., $235(4), 78-81$.

\section{Conference proceedings}

Van der Mark, C.F., A. Blom, W.S.J. Uijttewaal, S.J.M.H. Hulscher, and H.W.M. Hoeijmakers (2009), An analytically-based form drag model for river dunes, in Proc. $6^{\text {th }}$ IAHR symposium on River, Coastal and Estuarine Morphodynamics, Santa Fe, Argentina, in press.

Van der Mark, C.F., A. Blom, W.S.J. Uijttewaal, and S.J.M.H. Hulscher (2008), Predicting form drag due to dunes using a Nikuradse roughness height model and an expansion loss model, in River Flow 2008, Proc. International Conference on Fluvial Hydraulics, vol. 2, edited by M.S. Altinakar, M.A. Kokpinar, M. Gogus, G. Tayfur, S.Y. Kumcu, and N. Yildirim, pp. 1345-1352, Çeşme, Izmir, Turkey.

Van der Mark, C.F., A. Blom, and S.J.M.H. Hulscher (2007), Variability in bedform characteristics using flume and river data, in Proc. $5^{\text {th }}$ IAHR symposium on River, Coastal and Estuarine Morphodynamics, edited by C.M. Dohmen-Janssen and S.J.M.H. Hulscher, Taylor \& Francis, Leiden/London, Enschede, Netherlands.

Van der Mark, C.F., A. Blom, and S.J.M.H. Hulscher (2007), Irregularity of bedform dimensions, in Proc. NCR days 2006, edited by D.C.M. Augustijn and A.G. van Os, pp. 82-83, Netherlands, NCR-publication 31-2007. 
Van der Mark, C.F., A. Blom, S.J.M.H. Hulscher, S.F. Leclair, and D. Mohrig (2006), Stochastics of bedform dimensions, in Proc. NCR days 2005, Research on river dynamics from geological to operational time scales, edited by H.J.T. Weerts, I.L. Ritsema, and A.G. van Os, pp. 23-24, Netherlands.

Van der Mark, C.F., A. Blom, S.J.M.H. Hulscher, S.F. Leclair, and D. Mohrig (2005), On modeling the variability of bedform dimensions, in Proc. $4^{\text {th }}$ IAHR symposium on River, Coastal and Estuarine Morphodynamics, edited by G. Parker and M.H. García, Urbana, Illinois, USA.

\section{Abstracts}

Van der Mark, C.F., M.F. De Koning, A. Blom, S.J.M.H. Hulscher, A. Stolk, and C.M. Dohmen-Janssen (2008), Sand waves in the North Sea: the stochastics of their geometry, in $31^{\text {st }}$ International Conference on Coastal Engineering, Book of Abstracts, pp. 407, Hamburg, Germany.

Van der Mark, C.F., A. Blom, S.F. Leclair, D. Mohrig, and S.J.M.H. Hulscher (2005), Stochastic modelling of bedform dimensions, in $8^{\text {th }}$ International Conference on Fluvial Sedimentology, Book of Abstracts, pp. 297, Delft, Netherlands.

\section{Reports}

Van der Mark, C.F., and A. Blom (2007), A new and widely applicable tool for determining the geometric properties of bedforms, CEEM Research Report 2007R-003/WEM-002 ISSN 1568-4652, University of Twente, Enschede, Netherlands. 